\title{
DISEASES OF TRUCK CROPS \\ AND THEIR CONTROL
}

I.J. TAUBFNHAUS, PH.D. 


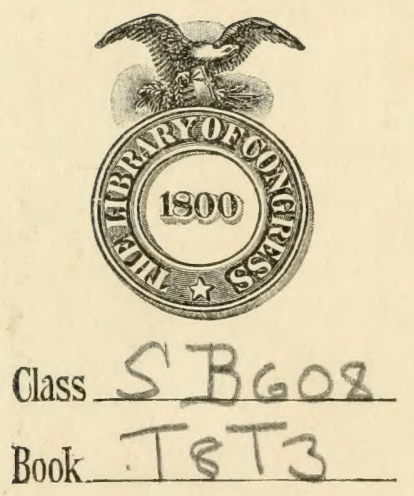

Copyight $\mathrm{N}^{0}$.

COPYRIGHT DEPOSE. 




\section{DISEASES OF TRUGK CROPS AND THEIR CONTROL}




\section{OTHER WORKS \\ BY THE SAME AUTHOR}

The Culture and Diseases of the Sweet Pea - \$2.00 net.

Profusely Illustrated

Diseases of Greenhouse Plants

(In Preparation)

Diseases of the Sweet Potato (In Preparation)

E. P. DUTTON \& COMPANY

NEW YORK 


\title{
DISEASESOF TRUCK CROPS
}

\section{AND THEIR CONTROL}

\author{
BY \\ J. J. Taubenhaus, Рн.D. \\ Plant Pathologist and Physiologist to the Agricultural and Mechanical \\ College of Texas \\ Author of "Culture and Diseases of the Sweet Pea"
}

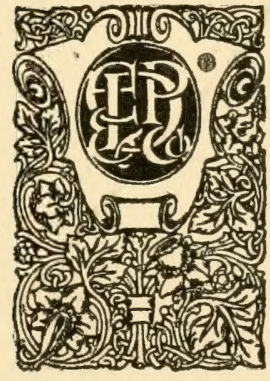

NEW YORK

E. P. DUTTON \& COMPANY 681 FIFTH AVENUE 


\section{8 \\ T8 $T_{3}$}

Copyright, 1918

By E. P. DUTTON \& COMPANY

JUN 261918

PRINTED IN THE UNITED STATES OF AMERICA

(C) $\operatorname{cin} 497934$ 
TO MY FRIEND

B. $\mathrm{K} A \mathrm{~A} Z \mathrm{E} R$ 



\section{PREFACE}

THE world never has faced a greater shortage of food than to-day. War's destructive agencies have added themselves to our old invisible foes, namely parasitic and disease-producing bacteria and fungi.

More than half of our diet is made up of vegetables. They furnish the necessary food bulk which the body requires, supply important nutritive elements, and act as stimulants to a better blood circulation. According to the Thirteenth Census of the United States the area devoted to truck crops in the United States in 1909 was estimated at $7,436,551$ acres. The total money value of the truck crops grown on this acreage was estimated at \$3OI, IO4, I44. The crops thus estimated included asparagus, beans (green), beans (dry), beets, cabbage, cauliflower, corn (pop and sweet), cantaloups, carrots, celery, chicory, cucumbers, egg plant, horse-radish, kale, lettuce, mint, okra, onions, parsley, parsnip, peas (green), peas (dry), peppers, pumpkin, radish, rhubarb, rutabagas, spinach, sprouts, squash, sunflower, sweet potato and yam, tomatoes, turnips, and watermelon.

We scarcely realize the large sums of money which the trucker loses annually from specific plant diseases, because there are few available data as to vii 
the money losses. But as an example, the following figures, kindly given to the writer by Professor R. P. Haskell, Pathological Inspector of the United States Department of Agriculture, will be of compelling interest.

"Potato Diseases.-It is estimated that the State of New York losi in 1915, principally from late blight, about $\$ 20,000,000$. This outbreak was widespread in the northern States and reduced the yields as shown below, in comparison with 1914. Other conditions than disease were relatively equal:

$\begin{array}{lr}\text { Maine } & \text { I0,000,000 bu. } \\ \text { New Hampshire } & 1,200,000 \text { “ } \\ \text { Vermont } & 1,600,000 \text { “ } \\ \text { New York } & 30,000,000 \text { “ } \\ \text { Pennsylvania } & 8,000,000 \text { “ } \\ \text { Michigan } & 23,000,000 \text { “ } \\ \text { Wisconsin } & \text { I I,700,000 “ }\end{array}$

"It is estimated that the market value of the potato crop in Aroostock County, Maine, in I9I5 was reduced about $10 \%$, or $\$ I, 078,000$, on account of the occurrence of the powdery scab disease. In some sections the reduction amounted to as much as $50 \%$.

"It is estimated that $50 \%$ of the potato crop in Idaho was injured by diseases last year and from $10 \%$ to $20 \%$ rendered wholly unsalable. The total annual loss in this State is estimated at $\$ 196,000$.

"Sweet-Potato Diseases. - It is estimated that the annual loss due to sweet-potato diseases in the 
United States is approximately $\$ 10,000,000$. About $\$ 750,000$ of this loss may be attributed to stem rot, the other important diseases being black rot, foot rot, and storage rots.

"Asparagus Rust.--Asparagus rust has practically destroyed all of the original plantings of asparagus and driven the old varieties out of cultivation. These have now been replaced by partially resistant kinds and the new strain bred by this Department is almost wholly resistant, so that in the near future these losses will be eliminated. Tests of some of the new rust-resisting strains in I9I 5 showed gains over the standard varieties amounting to more than $\$ 200$ per acre.

"Cowpea Diseases.-It is estimated that the annual saving as a result of the introduction of wilt and root-knot resistant cow-peas is $\$ 3,000,000$."

A conservative estimate of the money loss from diseases would be about $20 \%$ of the total value of the truck crops grown in the United States. According to the estimate given on page vii, the total value of the truck crop in the United States in 1909 amounted to the sum of $\$ 301,104,144$. If $20 \%$ of this was lost through damage from diseases, it will be seen that in 1909 the American truckers lost $\$ 60,220,828$. This does not include the large losses from insect pests, nor losses incurred in storing, or in shipping truck produce.

It is no exaggeration to state that if our present knowledge of Plant Pathology were made use of by truck farmers, nearly $80 \%$ of this loss could be 
prevented. Can any one say that such a saving would be insignificant, untimely, or unpatriotic?

The present work has been prepared with the aim of stimulating more research in truck-crop diseases, and also of assisting the trucker to make use of our present knowledge, in order to prevent avoidable losses, increase the trucker's profits, and assure a greater food supply. The writer seriously solicits suggestions or criticisms on his work.

Acknowledgments are due to Dr. and Mrs. D. de Sola Pool, of New York City, for the inspiration, the encouragement, and the valuable assistance rendered in the preparation of the manuscript, and later in reading and criticizing it. To Dr. E. A. Bessey of the Michigan Agricultural College, and to Dr. Mel. T. Cook of Rutgers College, the author owes hearty thanks for the careful reading and the valuable suggestions and criticisms which they have given this work. Acknowledgments are also due to Dr. G. $\mathrm{H}$. Coons of the Michigan Agricultural College, to Prof. F. B. Paddock and to Mr. W. T. Brink of the Texas Agricultural Experimental Station for reading the manuscript and proof. Grateful appreciation is likewise due to Dr. I. Adlerblum of the Metropolitan Life Insurance Co. of New York City for criticizing the manuscript and proofs.

For the use of illustrations the author is indebted: to Dr. G. P. Clinton; to Dr. Mel T. Cook; to Drs. G. H. Coons and E. Levin; to Dr. H. A. Edson; to Dr. B. B. Higgins; to Prof. H. S. Jackson; to Dr. L. R. Jones; to Dr. T. F. Manns; to Prof. A. V. Osmun; 


\section{Preface}

to Prof. F. B. Paddock; to Prof. W. G. Sackett; to Prof. A. D. Selby; to Prof. R. E. Smith; to Prof. H. E. Stevens; to Prof. J. A. Stevenson; to Prof. D. B. Swingle; to Prof. DeVault and to Dr. F. A. Wolf.

Last, but not least, grateful acknowledgments are due my wife Esther Michla Taubenhaus, whose devotion to art and science, and whose inspiration made this work possible.

\section{J. J. Taubenhaus}

College Station, Texas

January 22, 1918 . 



\section{PREFATORY NOTE}

WITH the greater specialization along all lines of industry the problems that confront such a specialist as the author of this book are felt more keenly and the necessary remedies are more fully appreciated. So there has grown up in the last few decades in this country a body of agricultural experts, the truck growers, who have found, as they have concentrated their attention more and more intensively upon a limited number of crops, that they are paying a great tax in the shape of losses due to diseases. Probably, in fact we know that very often it certainly is the case, similar losses are suffered by general farmers, but with their large plantings and less intensive culture these losses are not appreciated as they are by the truck grower. Other factors, too, enter in. In general the truck crops occupy land near cities or which from its adaptability to special crops or from its accessibility to markets is accordingly more valuable than ordinary farm lands. Furthermore, the crops themselves have a greater monetary worth than the staple crops. Both these factors make the losses by plant diseases much more keenly felt. With this recognition of the losses incurred has arisen a demand for 
help in the prevention of the diseases responsible for the damage. So plant pathologists have had to direct their attention to diseases of truck crops. The present book is an attempt by such a pathologist who has specialized along this line to meet the demand for help in the way of giving information as to the diseases occurring on truck crops and, so far as it is possible, telling how these losses may be prevented or at least reduced.

The last quarter century has seen a marvelous development of that division of the science of Botany that is devoted to the study of plant diseases, Plant Pathology. As each crop has been given greater attention the number of diseases found to occur upon it has been amazing. Plants nearly related to each other may have some of their diseases in common, but even with very closely related species some of the troubles affecting them will be different. When we now consider the large number of crop plants that are the subject of intensive culture as truck crops, and note, furthermore, that they represent the most diverse families of plants, it is not to be wondered at that the number of organisms causing diseases of truck crops is a large one. The author by grouping the crop plants together by their botanical affinities has taken full advantage of the fact that nearly related plants may suffer from some of the same diseases and thus has made it possible in some cases to consider such diseases only once for several different, but closely related, crops.

Considerable attention is directed to the symptoms 


\section{Prefatory Note}

by which the various diseases may be distinguished. These descriptions are made in non-technical language so that the practical grower can understand them and recognize the diseases in question. Besides this the methods of control are also described in popular terms. The author's long study of the subject has made it possible for him to approach this part of the work from the standpoint of the grower, so that as far as possible the remedies or preventive measures recommended are those with which he has practical experience. Occasionally it is impossible to recommend a remedy since sometimes a disease is of such a nature that by the time it becomes apparent the damage is done. But even in such cases directions are given which will reduce the loss or at least permit its avoidance another season. The discussions as to the cause of the disease are unavoidably given in somewhat more technical form from the very nature of the case, especially where it is the question of diseases caused by fungi or bacteria for which brief scientific characterizations are necessary. These technical discussions are essential for pathologists and other students of the subject so that the book will be appreciated by Experiment Station workers, Extension Specialists, college students, and others, as well as by the truck growers themselves for whom the book is primarily intended.

ERnst A. Bessey, Professor of Botany, Michigan Agricultural College. 



\section{CONTENTS}

\section{PART I}

CHAPTER I

The Normal SoIl Aivd its Requirements

CHAPTER II

Sick Soils not Influenced by Parasites

CHAPTER III

Soll Sickness Due to the Presence of Parasites Harmful to Plants • • • 4 I

CHAPTER IV

Methods of Treating Sick Solls . . . 53

\section{PART II}

\section{CHAPTER V}

The Healthy Host and its Requirements a 63

CHAPTER VI

Causes of Diseases in Crops ․ . 7 I
A. Diseases of a Mechanical Nature
B. Diseases Due to Physiological Causes
C. Diseases of Unknown Origin 
D. Diseases Due to Parasitic Bacteria or Fungi

E. Diseases Induced by Parasitic Flowering Plants

CHAPTER VII

POOR SEFD

$$
\begin{gathered}
\text { PART III } \\
\text { SPECIFIC DISEASES OF TRUCK CROPS } \\
\text { CHAPTER VIII }
\end{gathered}
$$

Family Agaricace

Diseases of the Mushroom

CHAPTER IX

Family Araliace⿸te

Diseases of the Ginseng

CHAPTER $\mathrm{X}$

Family Chenopodiace⿸ .

Diseases of the Beet

Diseases of the Spinach

CHAPTER XI

Family Composite.

Diseases of the Artichoke (Jerusalem)

Diseases of the Artichoke (Globe)

Diseases of the Lettuce

Diseases of the Salsify

Diseases of the Sunflower 


\section{Contents}

xix

CHAPTER XII

PACB

Family Convolvulace

Diseases of the Sweet Potato

CHAPTER XIII

Family Crucifere .

Diseases of the Cabbage

Diseases of the Cauliflower

Diseases of the Horse Radish

Diseases of the Kale

Diseases of the Mustard

Diseases of the Radish

Diseases of the Turnip

CHAPTER XIV

Family Cucurbitace

Diseases of the Cantaloupe

Diseases of the Cucumber

Diseases of the Citron

Diseases of the Squash

Diseases of the Watermelon

CHAPTER XV

Family Graminee

Diseases of the Sweet Corn

CHAPTER XVI

Family Labiate

Diseases of the Balm

Diseases of the Catnip

Diseases of the Horehound 
PAGE

Diseases of the Mint

Diseases of the Peppermint

CHAPTER XVII

Family Leguminos

Diseases of the Bean

Diseases of the Lima Bean

Diseases of the Cow Pea

Diseases of the Garden Pea

CHAPTER XVIII

FAmily Liliace

Diseases of the Asparagus

Diseases of the Chive

Diseases of the Onion

CHAPTER XIX

Family Malvaceat .

Diseases of the Okra

CHAPTER XX

Family Portulacace

Diseases of the Purslane

CHAPTER XXI

FAMILy SOlANACEAE .

Diseases of the Egg Plant

Diseases of the Pepper

Diseases of the Potato

Diseases of the Tomato 
Contents $\quad$ xxi

CHAPTER XXII

PAGE

FAMILy UMBELLIFERE $\quad$ - . • . 354

Diseases of the Carrot

Diseases of the Celery

Diseases of the Parsley

Diseases of the Parsnip

Weeds

\section{PART IV}

CHAPTER XXIII

Methods OF Control . . . . . 36I

CHAPTER XXIV

Control of Ixsect Pests by Naturai, Factors 375

CHAPTER XXV

Treatment of Fence Posts . . . . 378

Glossary * . . . . . 381

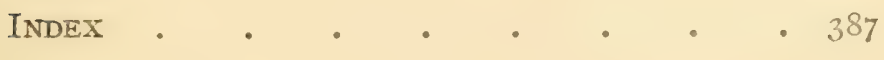





\section{ILLUSTRATIONS}

FIG.

PAOB

I. BACTERIA . . . . . . 4

2. StRUCture OF Fungi . . . . II

3. Nitre-Sick Beet Field, Showing Barren SPOTS • . . . . . . 25

4. Effect of Lime . . . . . 27

5. Pythium deBaryanum . . . . 43

6. RHizoctonia . • . . . . 45

7. Fusarium Wilt . . . . . . 47

8. Nematode Root KNot . . . . 49

9. Inverted PAN for Stean Sterilization 55

io. Surface Watering, Showing Portable Spray Equipment Used in Gardens about Cold Frames and Hotbeds • $\quad 55$

II. Watermelon Si.ICE Showing HaIl Injury 74

I2. Lightning InjuRy in Potato Field. Drought Injury of Sweet Corn . 78

13. Malnutrition, Showing a Cabbage Leaf AFFECTED BY THE Disease • . . 8I

14. BlossOM DROP . . . . 83 
F1G.

I5. MosAIC \& . . . . 84

16. Bean Seeds Affected with Anthracnose, Colletotrichum lindemuthianum . $\quad$. 84

I7. DODDER . . . . . . 90

I8. Mycogone Disease of Mushrooms . - io5

19. Ginseng Diseases . . . . . IO9

20. BeEt Diseases . . . . . II9

21. Spinach Diseases . . . . . I3I

22. LeTTUCE DROP . . . . . I43

23. LetTuce Diseases . . . . . I44

24. Southern Blight of the Salsify •

25. Sweet Potato Diseases . . . . I52

26. Sweet Potato Diseases . . . . I59

27. Sweet Potato Diseases . . . . I67

28. Sweet Potato Diseases . . . . I7o

29. Sweet Potato Storage Houses • • 183

30. Cabbage Diseases . . . . . 187

31. Cabbage Diseases . . . . . . I96

32. Cabbage Diseases . . . . . 198

33. Diseases of the Cauliflower and Radish 202

34. Cercospora leaf Spot of Horse-Radish . 207

35. Radish Diseases . . . . . 210 


\section{Illustrations}

FIG.

PAGE

36. Turnip Diseases

37. Turnip Diseases

217

38. Cantaloup Diseases . . . . 221

39. Resistant Cantaloup Strain • • . 228

40. Cucumber Diseases. . . . . 230

41. Squash Diseases . . . . . 235

42. Watermelon Diseases . . . . 239

43. WATERMelon ANthrachose . . . $24 \mathrm{I}$

44. Watermelon Diseases . . . . 244

45. Sweet Corn Diseases . . . . $25 \mathrm{I}$

46. Bean Diseases . . . . . 260

47. Bean Diseases . . • . . 262

48. Diseases of Lima Bean . . . . 267

49. Bean Diseases . . . . . 269

50. Diseases of the Cow Pea . . . 272

51. Diseases of the Garden Pea and Bean. 274

52. Asparagus Diseases . . . . 280

53. Onion Diseases . . . . . 285

54. Onion Diseases . . • . . 286

55. Diseases of the OkRA • • • . 296

56. Eggrlant Diseases • . . . 302

57. Diseases of the Pepper . . . 305 
FIG.

58. Potato Diseases . . . . . 308

59. Diseases of the Potato . . . 314

6o. Pox or Pit of the White Potato, Showing Different Stages of Infection . . 3 I 5

61. Potato Diseases . . . . . 322

62. Potato Diseases . . . . . 325

63. Potato Diseases . . . . . 33 I

64. Tomato Diseases . . . . 340

65. Tomato Diseases . . . . 346

66. Tomato Diseases . . . . . 347

67. Tomato Diseases . . . . . 35 I

68. Sleeping Sickness of Tomato • . 352

69. Celery Diseases . . • • • 356

70. Celery Diseases . . . . 357

71. Spray Machinery . . . . 372

72. Parasitized Insects. Treatment of Fence Posts . . . . . . 376 


\section{INTRODUCTION}

THE present world crisis has suddenly transposed the farmer from his former modest and humble position into the ranks of our foremost national figures. To-day the services of the tiller of the land are at a premium. The heroes of the day are not only those who can shoulder a gun at the front, but also those who can produce the food necessary to feed the great civil and military armies in the field and at home. It is to the credit of the American people that they have realized that intelligent farming requires as much skill, thought, and energy as is required to build up industries or to formulate laws of government.

Of the many phases of agriculture, trucking belongs to the highest forms of intensified farming. Whether it is conducted on a large or on a small scale, it requires a thorough knowledge of plant life. An intelligent understanding of crop rotation is essential for success. Someone has well said that the farmer may be judged intellectually by the system of rotation which he practices. Great skill is also required to keep the land in a state of production during the greater part of the year. This is especially true for our Southern States. As a whole, 
therefore, successful truckers must be a highly intelligent class of agriculturists.

In trucking, as in all intensive farming, the aim is to produce superior crops, embodying both high yield and good quality. This can be made possible only through intensive breeding and culture. Unfortunately, however, improvement in quality and yield is often accompanied by a loss of natural vigor and of power of resistance to disease. The great problem of the trucker is twofold-that of striving for quantity and quality, while protecting his crops from disease. This latter phase has generally been overlooked. We all realize to-day that it is necessary not only to produce two blades of grass where one grew before, as Dean Swift declared, but also to conserve it during growth and prevent it from being carried off by various diseases. The great famine in Ireland in I844 resulted from an epidemic of late blight which destroyed the potato crop. Such a condition could hardly occur to-day, because we now have a better knowledge of plant life, the causes which induce disease, and the methods of coping with it.

Considerable research has been carried out on the diseases of truck crops. The work of Professors Stewart, Selby, Jones, Orton, Clinton, Lutman, Melhus, Manns, Harter, Sackett, Whetzel, and of others has already yielded valuable information on the diseases and their control in the case of some of our staple food crops. Still, in the case of many diseases, little is known as yet as to methods of treatment. But much is to be looked for from research in the future. 


\section{Introduction}

It was the writer's intention to avoid technical terms as far as possible. However, it was found extremely difficult to omit every trace of a technical vocabulary, inasmuch as the popular terms are not always adequate in identifying a disease or in describing its causal organism. As far as was consistent all popular names were accepted and retained in this work. However, there are many diseases which have as yet no popular names. As an illustration may be mentioned certain spot diseases of particular hosts. These spots may be caused by different fungi and yet resemble each other. In such a case how are we to name these diseases? The surest way to avoid confusion is to call the diseases by the name of the causal organism, such as Phyllosticta leaf spot, Cercospora leaf spot, etc. Professor Stevens has suggested that we name all diseases by the name of their causal organism and add to it the term "ose," such as Phyllostictose, Cercosporose, Sclerotinose, etc. The writer has not adopted Stevens terminology. In many cases the popular name of a disease describes it far better than a technical term can do. To drop altogether such valuable popular terminology would only confuse the practical man. For instance, the popular term for lettuce "drop" is far more suggestive than "Sclerotinose."

From a practical consideration, the healthy plant is of greater importance than the disease. If we were to bend all our energy and skill to safeguarding the health of our crops, we would not be pestered with diseases. This is the point of view of this work. 
For this reason, too, much space has been given to a consideration of the healthy hosts and of the soil, the mother of all vegetation.

For the sake of convenience, the crops here considered have been taken up in the natural order of families to which they belong. The families have then been arranged in alphabetical order, and the crops in each family taken up alphabetically by their popular names. On the other hand, the diseases have been arranged according to their causes, classified according to the system generally accepted by students in mycology.

The present work is intended as a guide to the trucker and gardener, and to the student in Plant Pathology. It is the result of several years of research in truck crop diseases. Where information has been drawn from other sources full references have been given, so far as possible from the latest investigations. The writer has aimed at making this work as broad and as generally useful as possible rather than confining it to local interest.

Because of the great economic importance of the subject of truck crop diseases, it is felt that the present work fills a timely want and needs no apology. We cannot expect a general text-book on Plant Pathology to go into lengthy treatment of all plant diseases, and even less so with those of the trucking crops. The subject in itself is too important and too broad to be dealt with adequately in a few pages. The time will undoubtedly come when the diseases of every important crop will be treated separately in 


\section{Introduction}

book form. The Culture and Diseases of the Sweet $P e a$, by the writer, was an attempt in that direction. Meanwhile, until we have available the results of more extended researches on particular crops, the present work, it is hoped, will fill the gap. 

PART I 



\section{CHAPTER I}

\section{THE NORMAL SOIL AND ITS REQUIREMENTS}

THE aim of this chapter is to study the conditions under which a healthy plant lives and grows. Such knowledge will prepare us to consider the causes or factors which are responsible for abnormalities and diseases. Plants are endowed with life, and to live they must have food. Part of the food is derived from the air, but they cannot subsist on air alone. The sustenance of plants is also derived from the soil.

It is to be regretted that laymen often regard the soil as merely a conglomeration of inert particles of dead rock. If this were true, plant life would be an impossibility. It is because soils are teeming with various forms of organisms beneficial to them that plant life is made possible therein. The science of Soil Bacteriology, though still in its infancy, has already taught us much to help make the trucking business much more profitable and successful than it has been hitherto.

Indeed we may judge a soil by the kind of flora which predominates there, and call it fertile and healthy when this germ life helps to make it a favor- 


\section{Diseases of Truck Crops}

able medium for the plants. On the contrary, we call it sick or poor when it teems with bacteria and fungi which act as parasites on plants, or when the beneficial ones are absent or perform their duties imperfectly.

\section{Structure AND Life History of Bacteria}

The term bacteria (singular bacterium), or microbe, or germ, refers to the smallest microscopical form of plant life. As we shall see later, bacteria are but one of the many forms of life in the soil. The first man to recognize bacteria was Anton van Leeuwenhoek, a native of Holland, and a lens maker by trade. He made use of the microscope in testing materials for lens making. In 1675 he happened to mount in a drop of water some tartar which he scraped off from his teeth. To his great surprise he discovered minute little "animals" which moved about in curious fashions. In I882, Robert Koch succeeded in growing bacteria artificially and outside their natural environment. Thus was laid the foundation of the modern science of Bacteriology.

Bacteria are very simple in form. We recognize the rod-shaped known as Bacillus (fig. I a), the spherical form as Coccus (fig. I b), and the corkscrew or comma form as Spirillum (fig. I c). Bacteria are very minute. It would take about fifteen to twenty thousand individual bacteria placed end to end to make one inch in length. Thcy occur, however, in tremendous numbers and this enables them to per- 

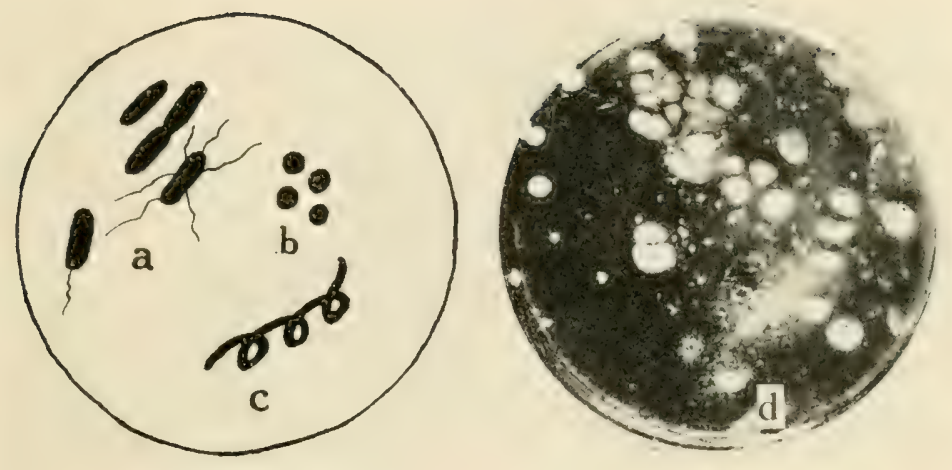

Fig. I. Bacteria.

a. Rod shaped, b. coccus, c. spirillum, d. plate culture, showing bacterial colonies isolated from soil. 



\section{Normal Soil and Its Requirements}

form wonderful tasks, as we shall soon see. Bacteria multiply in the simplest ways. A single individual upon reaching maturity becomes constricted in the center, then divides in two, each part now becoming a separate individual capable of nutrition, growth, and multiplication. It has been estimated by scientists that division of a single individual takes place about every twenty minutes. Granting that this rate of division is uninterrupted for twenty-four hours, the descendants of one germ would be in round numbers I,800,999 trillions. These when placed end to end would make a string two trillion miles long, or a thread long enough to go around the earth at the equator seventy million times. It would take a ray of light four months, traveling as it does, to pass from one end of it to another.

Individual bacteria can be detected only with a compound microscope. When grown on artificial media and under aseptic conditions, all the descendants of a single parent cell live together and constitute a colony, which becomes visible to the naked eye as a creamy jellylike drop (fig. I d).

\section{Relationship of Bacteria to the Function of A SoIL}

The health of a soil as shown in its fertility is intimately connected with the kind of bacteria present in it. We are as yet in the dark as to the possible function of numerous groups of the soil organisms. Bacteriologists are seeking to discover their proper 
functions. A recent exhaustive study ${ }^{\mathrm{x}}$ of Actinomyces, or thread bacteria, in the soil seems to show that they serve to decompose grass roots, being more numerous in sod than in cultivated land. Other groups of bacteria undoubtedly must perform other important functions.

The mere presence of friendly bacteria in the soil, however, would be insufficient to assure the welfare of our cultivated lands. What concerns us most is the work that they perform. Most of the plant's food as it is found in the soil is in a crude and unavailable form. The bits of mineral matter, the manure or fertilizer, in the truck patches all contain plant foods but in a form which plants cannot readily use; they must be softened and predigested and this work is done by the friendly organisms. Plant food is therefore directly dependent on the work of these minute scavengers. An intimate relation exists between the higher and the lower forms of plant life, the one depending on the other.

\section{Distribution OF SOIL BACTERIA}

For a practical purpose we ought to know in what soil and at what depth the beneficial bacteria are most likely to abound. Since the presence of bacteria is necessary to maintain the fertility of a normal healthy soil, it is essential to study the main factors that determine their increase or decrease. We cannot expect to find them equally distributed in differ-

${ }^{x}$ Conn, Joel H., New York (Geneva) Agr. Expt. Sta. Bul. 52 : $3^{-I}$ I, 1916. 


\section{Normal Soil and Its Requirements 7}

ent depths of the same soil. Brown ${ }^{\mathrm{I}}$ has shown that bacteria are generally more abundant in the upper eight inches. Table I, adapted from Brown throws much light on this phase of the problem.

\section{TABLE I}

Bacteria as Found in Various Depths of Soil and Under Different Cropping Systems

\begin{tabular}{|c|c|c|c|c|c|c|c|}
\hline \multirow{2}{*}{$\begin{array}{l}\text { Plot } \\
N o .^{2}\end{array}$} & \multirow{2}{*}{$\begin{array}{l}\text { Lab. } \\
\text { No. }\end{array}$} & \multirow{2}{*}{$\begin{array}{l}\text { Depth of } \\
\text { Sampling }\end{array}$} & \multicolumn{5}{|c|}{ Bacteria per Gram of Air-Dry Soil } \\
\hline & & & I & II & III & IV & Average \\
\hline \multirow[t]{8}{*}{601} & A & 4 in. & 2033000 & 1627000 & I 793000 & I 555000 & 1752000 \\
\hline & B & 8 in. & I 437000 & I 2 I I000 & 1241000 & 1104000 & I 248250 \\
\hline & C & 12 in. & 541000 & 567000 & 559000 & 525000 & 546000 \\
\hline & D & 16 in. & 287000 & 292000 & 312000 & 302000 & 298250 \\
\hline & $\mathrm{E}$ & $20 \mathrm{ill.}$ & 147000 & I 54000 & I 59000 & I 54000 & I 53500 \\
\hline & $\mathrm{F}$ & 24 in. & 92300 & 96500 & 95100 & $9 \mathrm{I} 500$ & 93850 \\
\hline & G & $30 \mathrm{in.}$ & 49900 & 46300 & 50900 & 46900 & 48500 \\
\hline & $\mathrm{H}$ & 36 in. & 32900 & 30000 & 33100 & 30400 & 31600 \\
\hline \multirow[t]{8}{*}{602} & A & 4 in. & 3102000 & 2870000 & 2917000 & 2947000 & 2959000 \\
\hline & B & 8 in. & 2238000 & 2177000 & 2105000 & 2258000 & 2194500 \\
\hline & C & 12 in. & 498000 & 531000 & 531000 & 528000 & 522000 \\
\hline & D & 16 in. & 255000 & 328000 & 316000 & 314000 & 304250 \\
\hline & $\mathrm{E}$ & 20 in. & 182000 & I92000 & I88000 & 177000 & 184750 \\
\hline & F & 24 in. & 89200 & 93300 & 91600 & 88300 & 90600 \\
\hline & G & $30 \mathrm{in.}$ & 53300 & 54900 & 53100 & 51800 & 54275 \\
\hline & $\mathrm{H}$ & 36 in. & 31700 & 35700 & 34200 & 31300 & 33225 \\
\hline \multirow[t]{8}{*}{604} & A & 4 in. & 4606000 & 3908000 & 4210000 & 3932000 & 4164000 \\
\hline & B & 8 in. & 3132000 & 2834000 & 2976000 & 2793000 & 2943750 \\
\hline & C & 12 in. & IOI 6000 & 882000 & 901000 & 831000 & 907500 \\
\hline & D & 16 in. & 320000 & 309000 & 311000 & $3^{20000}$ & 315000 \\
\hline & $\mathrm{E}$ & 20 in. & I 55000 & I63000 & I 56000 & I 49000 & I $5575^{\circ}$ \\
\hline & F & 24 in. & 89400 & 96100 & 92900 & 88900 & 91825 \\
\hline & $\mathrm{G}$ & 30 in. & 51900 & 55800 & 55000 & 52400 & 53775 \\
\hline & $\mathrm{H}$ & 36 in. & 35100 & 36600 & 34900 & 32600 & 34800 \\
\hline
\end{tabular}

× Brown, P. E., Iowa Agr. Expt. Sta. Research Bul.8:283-32 I, 19 I 2.

${ }^{2}$ Plot No. 601.-Continuous corn. 602.-2-year rotation, corn and oats. 604.-3-year rotation, corn, oats, and clover. 
In studying Table I we find that in every case there is a marked decrease in soil organisms with each increase in the depth of the soil tested. It was further found by Brown that the moisture content was higher for four inches than for a greater depth. It seems evident that the decrease of soil bacteria below twelve inches is dependent not so much on moisture but rather on a decrease of air in the lower substratum. It must not be expected that the data given in Table I are applicable to every locality. Differences in the mechanical and chemical composition of the soil and subsoil, differences in topography, climate, and weather conditions, will all no doubt tend to influence more or less the increase or decrease of bacteria.

\section{Influence of Depth of Cultivation on the Number of SoIL BACTERIA}

The work of King and Doryland ${ }^{\mathrm{x}}$ has shown that the depth of cultivation is a potent factor in influencing the number of bacteria in the soil. This is briefly summarized by them in Table 2 .

\section{TABLE 2}

\section{Influence of Depth of Cultivation on Soil Bacteria} Silt-

plowed 4 inches deep increases the number of bacteria. . $15.46 \%$ plowed 6 inches deep increases the number of bacteria. . 10.94\% plowed 8 inches deep increases the number of bacteria. . $24.20 \%$ plowed Io inches deep increases the number of bacteria . . $26.89 \%$

× King, W. E., and Doryland, Ch., Kansas Agr. Expt. Sta. Bul. I6I : 2 I I-242, 1909. 


\section{Normal Soil and Its Requirements}

Sand-

plowed 4 inches deep increases the number of bacteria . $35.06 \%$ plowed 6 inches deep increases the number of bacteria . . $13.53 \%$ plowed 8 inches deep increases the number of bacteria. . $22.90 \%$ plowed Io inches deep increases the number of bacteria. . 5.11\%

The Influence of Manure on the Number of SOIL BACTERIA

Besides cultivation, there are other treatments which may lead to an increased bacterial flora in the soil. As shown by Temple ${ }^{\mathrm{x}}$ such a result is obtained through the application of manure. In working with a nervly clearcd sandy loam, and applying fresh cow manure (this included solid excreta and no bedding), at the rate of ten tons per acre, Temple obtained the following results as shown in Table 3 .

TABLE 3

Showing Number of Bacteria per Gram of Dry Soil

\begin{tabular}{|c|c|c|}
\hline & Soil No. 326 & Soil No.326a \\
\hline Date & No Manure & With Manure \\
\hline March 26, 1909.. & $\mathbf{I}, 220,000$ & $1,220,000$ \\
\hline April $x$, I909.... & $1,633,000$ & $4,300,000$ \\
\hline April 9, 1909 & $6,120,000$ & I $4,000,000$ \\
\hline April I5, 1909.. & $3,780,000$ & $10,610,000$ \\
\hline April 22, 1909. & $2,730,000$ & $5,860,000$ \\
\hline April $29,1909$. & $2,770,000$ & $3,340,000$ \\
\hline May 6, 1909... & $5,5 \mathrm{I} 0,000$ & $5,190,000$ \\
\hline
\end{tabular}

As further evidence that manure increases the soil flora, Temple used a clay loam, dividing it in the following manner; and treated as follows:

x Temple, J. C., Georgia Agr. Expt. Sta. Bul. 95 : 6-35, I9Ir. 
Plat No. I-Stable manure.

Plat No. 4-Sodium nitrate.

Plat No. 5-A complete fertilizer, PKN.

Plat No. 6-Nothing, check.

The effect of these treatments is briefly summarized in Table 4 .

TABLE 4

Colonies per Gram of Dry Soil

\begin{tabular}{c|r|r|r|r}
\hline Date & Plat No. I & Plat No. 4 & Plat No. 5 & Plat No.6 \\
\hline Dec. 9, 1910....... & $28,230,000$ & I I,430,000 & $19,850,000$ & $8,250,000$ \\
March 30, 191 I .... & $18,500,000$ & $9,150,000$ & $8,040,000$ & $6,240,000$ \\
May 26, 191 . ..... & $20,200,000$ & $4,850,000$ & $6,720,000$ & $5,010,000$ \\
\hline
\end{tabular}

The above Table shows that although sodium nitrate or a complete fertilizer increases the soil flora, neither one can be compared to manure in efficiency.

\section{Structure And Life History of FungI}

Besides bacteria of all sorts, our cultivated soils are also teeming with fungi. The true function of the latter remains to be studied. There seems no doubt, however, that certain fungi like certain bacteria in the soil work on the organic and the mineral matter to make it available as plant food. Parasitic fungi depend for their food on living plants altogether. Examples of these are the Uredinales, the 



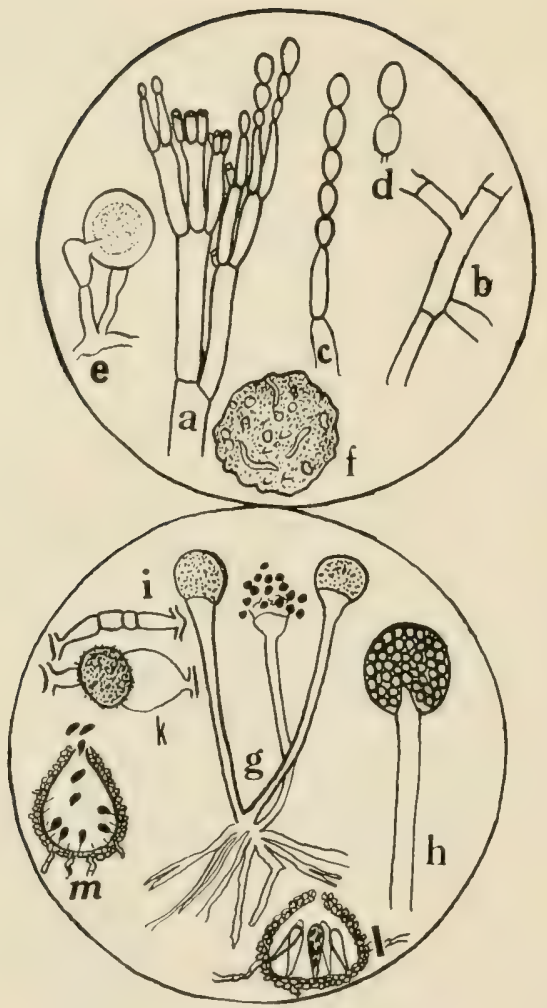

Fig. 2. Structure of Fungi.

a. Fruiting branch of Penicillium, showing conidiophores and conidia, $b$. mycelium of Penicillium, c. an individual conidiophore and chain of conidia of Penicillium, d. two conidia of Penicillium, showing attachment of spores in the chain, e. fertilization of female oogonium by male antheridium, $f$. mature oospore, g. fruiting stalks of Rhizopus, $h$. individual fruiting head of Rhizopus showing spores, $i$. sexual fertilization and $k$. zygospore of Rhizopus showing spores, $l$. perithecium, showing asci and ascospores, or winter spores, $m$. Pycnidium or sac in which the summer spores are borne. 


\section{Normal Soil and Its Requirements I}

cause of the true rust diseases. Saprophytic fungi are those which depend for their food on the dead and decaying organic matter in the soil. Between these two extremes there are intermediaries. As an illustration of a soil fungus may be taken the ordinary blue mold, Penicillium expansum Lk. This organism is made up of colorless feeding threads technically known as hyphæ or mycelium (fig. 2 b). The spores, which correspond to the seed of higher plants, are borne on short stalks which bear broomlike tufts composed of chains of small bluish, round bodies, the spores (fig. 2 a-c).

Fungi differ from the higher plants in their nutrition and mode of reproduction. Fungi have no green coloring matter, chlorophyll, and are thus unable to manufacture their own carbon by the decomposition of carbon dioxide as do green plants. This is why fungi must depend for their supply of carbon on dead organic matter or on the higher plants. Unlike the green plants, fungi have no flowers and reproduce by means of spores (fig. $2 \mathrm{~g}-\mathrm{h}$ ). It has been estimated that over 61,000 species of fungi have been found and described on the higher plants. The Soil Bacteriologist however has scarcely touched on the soil fungi.

Fungi are classified according to the mode of spore formation. In some the spores are formed by a regular sexual union of a female egg known as oogonium and of a male element, the antheridium (fig. 2 e, $\mathrm{i}, \mathrm{k})$. The resultant fertilized spore egg is known as oospore (fig. $2 \mathrm{f}$ ). The latter germinates by serding 
out a germ tube, or as is more generally the case, by the outer wall dissolving and the inner mass breaking up into small bits of naked protoplasm known as zoospores. Most fungi have two spore stages, the summer form intended for rapid dissemination and spread, the winter form intended to carry it over through cold or any other unfavorable weather conditions. The term conidia is applied to all spore forms borne free on special fruiting stalks known as conidiophores (fig. 2 a). A pycnidium is a saclike body (fig. $2 \mathrm{~m}$ ) in which are borne the summer spores. A perithecium is a sac-like body (fig. 2 1) which bears the winter spores of certain fungi. Other terms here used in describing parts of fungi will be found in the glossary.

\section{Nature and Function of a Healthy Soll Flora}

The function of a normal soil is to provide available plant food. About 95 per cent. of the combustible weight of a growing plant is made up of carbon, hydrogen, and oxygen and nitrogen. The remaining 5 per cent. constitutes the mineral or the ash of the plant. Carbon, hydrogen, and oxygen are taken in the form of carbonic acid and water; nitrogen from nitrates produced by bacteria out of organic matter of the soil. The ash or the mineral elements of the plant are taken directly from the soil. Neither the organic nor the mincral elements are in a form which plants can make use of until they have been acted on by certain definite organisms in the soil. 


\section{Normal Soil and Its Requirements}

\section{A. The Transformation of Carbon}

Cellulose, which is but a form of carbon, constitutes a large per cent. of the woody tissue of plants. Soils contain large amounts of cellulose and this undoubtedly helps to maintain their proper physical condition. Straw manure, or green vegetable matter all contain large amounts of cellulose. When it is incorporated in the soil, living plants cannot make use of it, because of its complex form. It therefore must first undergo a certain decomposition. This is accomplished by a group of soil bacteria known as Amylobacter. These feed on the dead vegetable cellulose, breaking it up and reducing it back to carbon dioxide, hydrogen, and fatty acids. The carbon dioxide either returns to the air to replenish the atmospheric supply, or unites with water to form carbonic acid and soil carbonates. The carbon dioxide is taken in by the plants cither directly from the air through the leaves, or from the soil in some carbonate form. Thus we see that it is not the cellulose nor the product of its decomposition that furnishes plant food, but certain inorganic elements which are set free in its decomposition.

\section{B. Elaboration of Available Nitrogen}

From the viewpoint of plant nutrition, nitrogen is unquestionably the most important of all elements. The nitrogen of the air, although totalling about 79 per cent. of it, is not in an available form. In the transformation of proteids into available nitrogen 
in the soil two definite processes take place, all thanks to the work of certain soil bacteria.

I. Ammonification. In this process, the soil bacteria attack the complex proteids and convert them into ammonia. The odor of ammonia from decomposed 'urea, manure, or any other organic matter is always an indication that ammonification takes place. According to Sackett ${ }^{ \pm}$and others the ability to bring about this change is attributed to the following soil bacteria: Bacillus mycoides, Bacillus proteus vulgaris, Bacillus mesentericus vulgatus, Bacillus subtilis, Bacillus janthinus, Bacillus coli-communis, Bacillus megatherium, Bacillus fuorescens liquefaciens, Bacillus fluorescens putridus, and Sarcina lutea.

2. Nitrification. Both ammonia and ammonia compounds are forms of nitrogen that are not yet readily available to plants. They must be changed further into simpler compounds or, as the process is known, must undergo nitrification. The ammonia is first oxidized into nitrous acid and nitrates. This is accomplished by two species of soil bacteria, Nitrosomonas and Nitrosococcus. The nitrates are then oxidized into nitric acid and nitrates, through the work of the bacterium Nitrobacter. The nitrates are the only forms of nitrogen which plants can use.

\section{Action of Soil Flora on Mineral Substances}

We have already pointed out that the inert mineral substances in the soil are not in a form in which

I. Sackett, W. G., Colorado Agr. Expt. Sta. Bul. 196:3-39, 1916. 
plants can readily assimilate them. These too must first be acted upon by certain soil bacteria.

I. Changes of Phosphates. Phosphates as they commonly occur in nature are but little soluble in water. This is why they cannot be used in their first form, although they are required by most plants. Soils deficient in this element may be improved by such fertilizers as superphosphate of lime, ground bone, phosphate rock, or Thomas slag. In the process of decomposition that organic matter must undergo as it becomes available for plant food, large quantities of carbon dioxide are liberated which unite with the water in the soil to form carbonic acid. This acid attacks the insoluble phosphates, transforms them into superphosphates,- the only form soluble in water,-and renders them available to plant life.

2. Changes in Potassium, Sulphur, and Iron. Like phosphorus, potassium, sulphur, and iron are made available for plants through the indirect action of soil bacteria. The carbon dioxide and other organic acids produced during the fermentation of organic matter, attack the potash feldspar which occurs in the soil. The product is potassium carbonate which is soluble in water and hence readily taken up by plants. The nitric acid which is formed during nitrification may also combine with the raw potash in the soil forming potassium nitrate which is a form available for plants.

As a result of the activity of soil bacteria, hydrogen sulphide is evolved from the decomposition of pro- 
teids. The sulphur may be further changed into sulphur dioxide, and, when combining with water and oxygen, into free sulphuric acid. The latter readily combines with calcium or magnesium, forming calcium or magnesium sulphate. The plant obtains sulphur for the construction of its proteids from some of the soluble sulphates.

\section{How to Maintain the Fertility of Solls}

We have already seen that the fertility of a soil is directly dependent upon the activity of certain beneficial bacteria. The latter constitute the life of a soil. It is therefore evident that for a soil to produce its maximum, its germ flora must receive careful consideration at the hands of truckers and gardeners. We must at any cost encourage these organisms to do their full duty at all times. Should they cease activity the soil would become barren.

There is no doubt that plants remove large quantities of plant food from the soil. Headen ${ }^{\mathrm{I}}$ has calculated that for 80,000 tons of sugar beet, there are consumed as fertilizers, 33I tons of potash, worth $\$ 3$ I,IOO; 7 I tors of phosphoric acid worth $\$ 5,680$; I60 tons of nitrogen worth $\$ 54,400$, making a total of $\$ 9 \mathrm{I}, \mathrm{I} 8 \mathrm{o}$, or a trifle over one dollar per ton. What is true for the sugar beet is true for every other trucking crop. In other words, soil fertility is capable of being exhausted. Most of it may be returned in the form of manure and chemical fertilizers, but

× Headen, W. P., Colorado Agr. Expt. Sta. Bul. 99: 3-16, 1905. 


\section{Normal Soil and Its Requirements}

these are very expensive and reduce the net profit from the crops. The object of every intelligent trucker should therefore be to reduce his manure and fertilizer bills by encouraging his soil bacteria to manufacture the greatest amount of the available food which his crops require. Like any other living form these bacteria require certain conditions of life if they are to thrive.

\section{Maintaining the Nitrogen Supply}

The nitrifying bacteria are air-loving organisms. Hence the more aeration we give them, the more pronounced their activity. Schlosing ${ }^{\mathrm{I}}$ determined that when a soil was entirely void of oxygen the nitrates were reduced, and brought about an actual evolution of free nitrogen which is useless to the plant. With I.5 per cent. of oxygen nitrification was marked. When 6 per cent. oxygen was added to the soil nitrification was more than doubled. It is therefore evident that cultivation which aims at soil aeration also accelerates nitrification. The effect of soil aeration cannot be too strongly emphasized. According to Chester, ${ }^{2}$ every cultivation of the soil with its attendant aeration is equivalent to a dressing of nitrate of soda in its cheapest form. If we realized this, and that nitrate fertilizers are usually the most costly, the alert trucker would learn the economy of more cultivating.

I Schlosing, Compt. Rend. Acad. Sci. Paris, 1xxvii, 203-253.

${ }^{2}$ Chester, F. D., Pa. State Dept. of Agr. Bul. 98: 9-88, 1912. 
Besides oxygen, the nitrifying organisms demand, as an indispensable condition for work, a sufficient moisture in the soil. In dry soils and during dry weather, nitrification is almost suspended within the upper layers of soil. A third important factor is the chemical reaction of the soil. The nitrifying organisms work best when the soil gives a slight alkaline reaction. Too much alkalinity, however, like too much acidity, is detrimental as we shall see further on. Nitrification is further dependent on soil temperature. At 99 degrees Fahrenheit it is at its highest. A degree less than $54 \mathrm{~F}$. retards it considerably. At 122 degrees $\mathrm{F}$. very little nitrate is produced, and at I $\mathbf{I}$ degrees F. nitrification ceases entirely. The physical condition of the soil is another important element to be considered. The highest rate of nitrification is found in truck lands, that is, in the sandy loams.

\section{Nitrogen Fixation from the Air}

It has been the common knowledge of farmers and truckers that legume plants, such as peas and beans, cause the soil on which they are grown to become more productive. It is not necessary here to enter into an abstract discussion of this phenomenon. Suffice it to say, that science has definitely shown that there is a bacterial soil organism, Pseudomonas radicicola, which is capable of fixing the free nitrogen from the air. This organism attacks the young rootlets of the legume crops as other parasitic forms also do. Its presence in the root results in a nodule 
or swelling. Soon, however, it loses its parasitic character and becomes an agent for fixing the free nitrogen of the air, which is then stored up in the root nodule. In this form the nitrogen is consumed by the plant itself. As far as is known, P. radicicola can thrive on the roots of legume plants only. The Rhode Island Experiment Station ${ }^{\mathrm{I}}$ has found that an acre of soy beans for instance may fix about IO0O pounds of nitrogen from the air during a period of five years, or 200 pounds per year. One hundred and forty pounds of the 200 were removed with the crop, and 60 pounds remained in the field. Since one pound of nitrogen was worth at least $16 c ., 200$ pounds would cost $\$ 32$. We must not, of course, suppose that every acre of soy beans would produce 200 pounds of nitrogen every year. This would depend somewhat on the nature of the soil, the degree of moisture, the amount of oxygen, and other conditions congenial or unfavorable. What is certain, however, is that every alert gardener and trucker should learn to use legumes more extensively in his system of cropping.

Soils which have grown leguminous crops for a period of years are well supplied with $P$. radicicola. Other soils are deficient in it and must be artificially inoculated. The numerous types of pure cultures of the organism sold in liquid form have as a rule proven a failure. The organism dies out or loses its effectiveness in the artificial liquid media. The best forms of pure cultures now used are those grown on

s Rhode Island Agr. Expt. Sta. Bul. I47. 
sterilized soil. This method has been developed at Cornell University. The soil is after all the natural and best medium where soil bacteria can grow. On it $P$. radicicola lives longer, and hence when it is used for inoculation, better success may be expected. The Alphano Humus Co. of New York City have on the market cans with sterilized soils, in which the legume bacteria have been introduced. Each can is sufficient to inoculate one acre of soil. The ability of the organism of one legume crop to inoculate another crop has long been a subject of discussion and has not as yet been satisfactorily answered. Garman and Didlake $^{\mathrm{I}}$ have shown that there exist six different species of legume organisms. For example they found that the organism of alfalfa is the same as or similar to the one which works on the sweet clover (Melilotus alba), trefoil or black medick (Melilotus lupulina), and bur clover (Melilotus denticulata). This same organism, however, cannot produce nodules on the roots of any species of Trifolium, of Vicia, Pisum, Vigna, Glycine, or Phaseolus. The organisms of all the species of Trifolium (clover) are one and the same. The organisms of all the species of the vetch and garden pea are one and the same. They cannot work, however, on red or crimson clover, or on alfalfa. The cowpea organism seems to be adapted to the cowpea only. The same thing appears to be true for the soy bean organism and for that of the garden bean. Therefore when a land is to be inoculated s Garman, H. and Didlake, Mary, Kentucky Agr. Expt. Sta. Bul. 184: 343-363, 1914. 


\section{Normal Soil and Its Requirements 2I}

with the garden bean organism, for instance, none must be used but those taken from the bean. Under ordinary conditions, where a soil is known to produce healthy crops of one (legume) variety, some of that soil may be used to inoculate other soils intended for the same crop.

\section{Economical Use of Commercial Fertilizer}

A knowledge of the functions of soil bacteria and a proper management of the soil means a saving of commercial fertilizer and the proper maintenance of soil fertility. In trucking more than in any other phase of farming, the soil is being made to produce the whole year around. This is especially true for our Southern States where the summer and fall seasons are longest, or where the winters are very mild. It, therefore, often becomes necessary to use chemical fertilizers to supplement the work of the soil bacteria. This is especially true for some particular crops which draw heavily on certain mineral constituents. In order to obtain the greatest results from the use of chemical fertilizers, the following items should be carefully considered.

I. The Location of the Field. Uplands or hillsides will require heavier application of fertilizer since some of it is likely to be carried off by washing. Lowlands, especially those near uplands which wash badly, generally require less.

2. The Character of the Soll. The chemical composition of the soil has a marked influence on the 
effect of fertilizers. A chemical analysis of the soil will enable the trucker to make a more economical use of his fertilizer. If a land, for instance, contains too much iron and aluminium, applied phosphate fertilizers may be modified into ferric and aluminium phosphate, which become slowly available to plants. On the other hand when phosphate fertilizers are changed in the soil into tricalcium phosphate it becomes available more readily. Sandy soils are generally quick to respond to fertilization; they can therefore stand heavier application than the cold clay scils which respond more slowly. In the latter, the fertilizers are likely to be converted into forms unavailable to plants. The trucker should therefore avoid depending altogether on the use of chemical fertilizers. The best results are always obtained and the fertility of the scil best preserved when the use of chemical fertilizer is supplemented with animal or green manures. 


\section{CHAPTER II}

SICK SOILS NOT INFLUENCED BY PARASITES

WE have seen that a normal and healthy soil is one in which the beneficial soil flora is at its maximum of normal activity, making the food of the plant assimilable. We have to discuss the abnormal or sick soils now. In this class we include those which are either physically or chemically so constituted as to have a detrimental effect on the activity of the soil flora; and those which are overrun with organisms directly parasitic on the plants grown in that soil. There are five classes to be considered in the first division.

\section{Denitrified SoILs}

This detrimental condition in the soil is brought about by a group of undesirable organisms, some of which are Bacillus ramosus, $B$. pestifer, $B$. mycoides, $B$. subtilis, $B$. mesentericus vulgatus. In Chapter I we have seen that the nitrifying bacteria oxidize the nitrogen and make it available for plants. In denitrification, the harmful bacteria tend to reconvert the available nitrogen into a non-available form, or else to liberate it into the air, where it may be considered as lost so 
far as the crops are concerned. Most trucking lands contain the nitrifying and denitrifying organisms in about equal proportions. To encourage the activity of the one over the other is the aim of intelligent trucking. The denitrifying bacteria thrive best in an abundance of carbohydrate foods. Fresh coarse manure with a high percentage of straw, when applied to the soil, will favor denitrification. It should therefore be avoided as far as is possible. There are, however, market gardeners who often use as much as fifty tons of such manure per acre in addition to a nitrate fertilizer. Such action is very likely to encourage denitrification because of the large amount of carbohydrates incorporated in the soil.

Indirectly denitrification will finally cause various physiological plant troubles, most of which are little understood. Poor growth and the shedding of blossoms will characterize plants deprived of available nitrogen food. Denitrification may largely be prevented. A judicious use of manure, especially on the heavy soils, drainage, and proper tillage are all factors which induce nitrification, thereby also preventing denitrification.

\section{NitRE-Sick SOILS}

This form of sickness, peculiar to certain Colorado soils, was carefully studied by Headen ${ }^{\mathrm{I}}$ and Sackett. ${ }^{2}$ Nitre-sick soils are those which contain such large quantities of nitrates that they inhibit plant growth.

s Headen, W. P., Colorado Agr. Expt. Sta. Bul. I55.

2 Sackett, W. G., Colorado Agr. Expt. Sta. Bul. 196:3-39, 1914. 



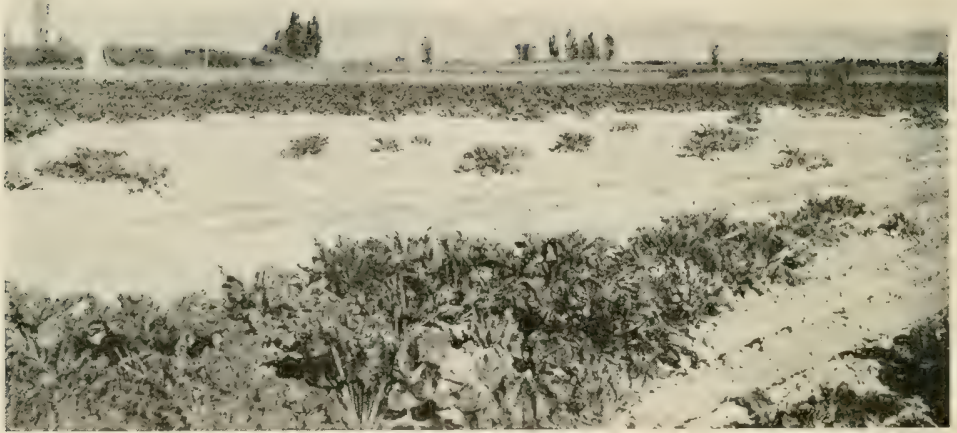

Fig. 3. Nitre-Sich Beet Field, Showing Barren Spots. 


\section{Sick Soils not Influenced by Parasites 25}

Truck crops (fig. 3), grains, and fruit trees rapidly deteriorate on such lands. This condition occurs in a variety of soils in Colorado. It is met with in the light sandy loams as well as in the heavy clay loams, on lowlands as well as on hilltops. It is to be distinguished from true alkali troubles.

The distinguishing characteristic of a nitre-sick soil is its brownish-black wet appearance. From afar the soil looks as if it had been wetted with crude oil; however the soil is usually dry. Sometimes the soil may be moist and slippery, due no doubt to the presence of large quantities of deliquescent salts. Walking through such a field produces a sensation similar to that which one would get from walking on cornmeal or ashes.

The accumulation of excessive amounts of nitrates in the soil is due to the activity of a bacterial soil organism, Azotobacter chroococcum. This organism has the power of fixing free nitrogen from the air and depositing it in the form of nitrates in the soil. The conditions which favor this activity still await study. Normally, soils contain from I40 to I50 pounds of nitrates per acre foot. In a nitre-sick soil, each acre foot contains II 3,480 pounds, or 56.74 tons. With such a high concentration of nitrate, it is impossible for plants to grow. So far, we know of no methods to reclaim nitre-sick soils.

\section{ACID-SICK SoILS}

Soils which contain an excess of acid in which crops refuse to grow, may be termed acid-sick. Acids 
in soils have a directly poisonous effect on plants. Soil acidity may be brought about by the loss of lime and other bases; and by the decomposition of organic and inorganic matter.

Crops are known to draw heavily on the lime of the soil, and thus increase the proportion of acidity. This then is one direct way of depleting the soil lime. A ton of alfalfa, for instance, is known to take up 50 pounds of lime. With a yield of 6 tons per acre, the annual loss of lime per acre would be 2100 pounds.

Lime and other bases are further lost from the soil by leaching. The soluble carbonates are but slowly soluble in pure water. However, carbon dioxide, nearly always present in soils, changes the calcium carbonate into calcium bicarbonate, which is rather soluble, and readily leaches out with the drainage water.

Soils which are heavily manured are apt to become more acid. The decomposition of the organic matter yields large quantities of carbon dioxide which act on the carbonate in the manner above indicated. The annual leaching of lime from soils varies from Ioo to 1000 pounds per acre.

In addition to these causes, poor drainage has a tendency to increase the soil acidity. The application of ammonium sulphate as a fertilizer leads to a development of acidity by the production of sulphuric acid. The same is true when muriate of potash is added. In the process of nitrification in which nitrogen is made more available for plants, acids are produced.

Acidity in a soil is usually characterized by a lan- 


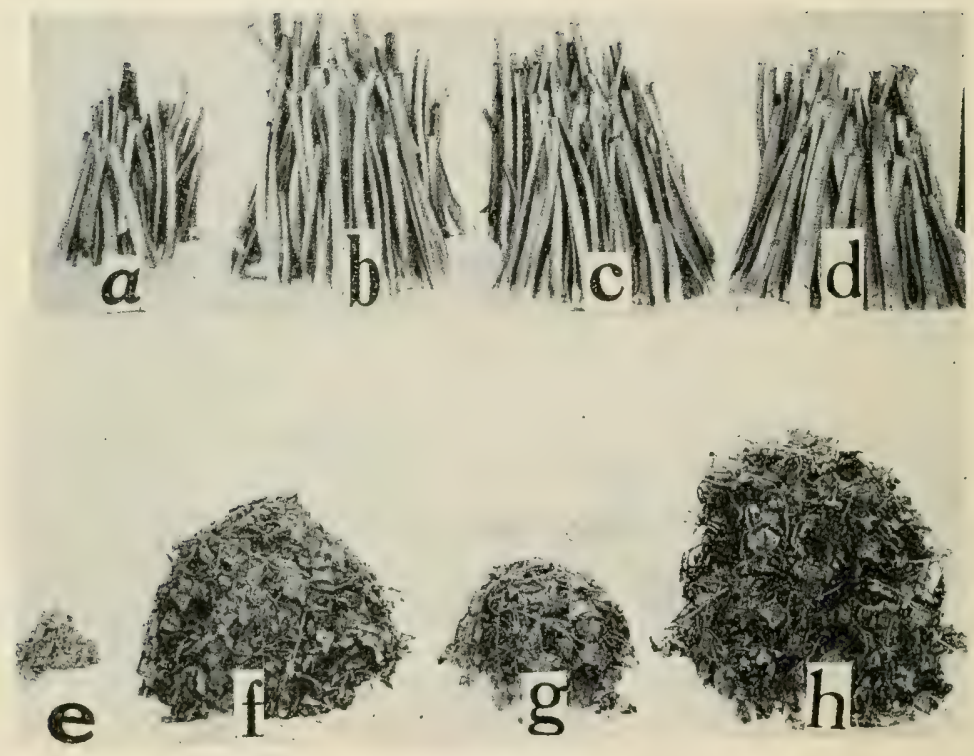

Fig. 4. EFFEct of LIME.

$a$. to $d$. R hubarb, $e$, to $h$. New Zealand Spinach. $a$. and $b$., $e$. and $f$. both receiving sulphate of ammonia, $a$. and $e$. unlimed, $b$, and $f$. limed, $c$, and $d ., g$. and $h$. both received nitrate of soda, $c$, and $g$. unlimed, $d$, and $h$. limed (after Hartwell and Damon). 


\section{Sick Soils not Influenced by Parasites 27}

guid condition of the growing crop. Sorrels, poverty grass, broomsedge, cinquefoil, and redtop thrive best, and are generally indicative of acid soils. Not all truck crops are equally sensitive to soil acidity. Hartwell and Damon ${ }^{\mathrm{I}}$ have determined the degree in which truck crops are benefited by the application of lime to an acid soil. As a guide to the effect of lime on crops, those which seem to benefit most are indicated by the number (3), lesser degrees of improvement are indicated by the numbers (2) and (I). Crops which tolerate a moderate amount of acidity are followed by the figure (0), and those which thrive best without lime by $(-I)$ : Asparagus (3), beans (0), beets (3), cabbage (2), carrots (I), cauliflower (2), celery (3), chard (2), chicory (0), cowpea (0), cress (o), cucumber (1), eggplant (2), endive (3), okra (3), horseradish (2), kale (I), kohlrabi (I), leek (3), lettuce (3), mustard (2), muskmelon (0), onion (3), parsley (o), parsnip (3), pea, garden (I), pepper (3), potato (o), radish (I), rape (2), rhubarb (3), sorrel ( $-\mathrm{I}$ ), spinach (3) (fig. 4a to h), turnip (o), watermelon (-I).

Treatment of Acid Soils. The best remedy known is lime. Its effect is to neutralize the acidity, restoring the normal equilibrium for the activity of the soil flora, and thus enabling the plant to flourish. The amount of lime to be used depends largely on the kind of soil and the degree of its acidity. According to Blair ${ }^{2}$ a loamy to a clay loam will require

s Hartwell, B. L., and Damon, S. C., Rhode Island Agr. Expt. Sta. Bul., I60: 408-446, I9I4.

- Blair, A. W., New Jersey Agr. Expt. Sta. Cir., 54: 3-II, 1916. 
from 1500 to 2000 pounds of burned lime per acre. This is generally considered a moderate application. For sands and sandy loams it would be safe to apply 1000 to 500 pounds. If the soil is known to be very acid or to contain large amounts of organic matter, heavier application of lime may be given. Lime is sold as ground limestone or as burned lime. A ton of burned limestone will yield II20 pounds. If enough water is added, it will weigh 1480 pounds. If II2O pounds of burned lime or the I480 pounds of hydrated lime are allowed to air slack, the weight of both will be 2000 pounds. Air-slacked lime has the same composition as ground limestune. In buying hydrated lime we do not get ar: better quality, but merely pay an excess in fright for the amount of water it contains. The cost of delivery should determine the kind of lime to buy.

Wood ashes may often be used instead of lime to correct soil acidity. Hardwood ashes contain about 30 per cent. lime and 60 per cent. potash. Two and a half tons of good wood ashes are equivalent to one ton of burned lime to overcome soil acidity. Leached ashes have lost their potash and its lime is in the form of a hydrate or carbonate.

Magnesium lime which contains high percentages of magnesia is not ubjectionable for use. In fact, a ton of limestone which contains magnesium carbonate is more effective on acid soils than a ton of limestone without magnesium carbonate. Lime should be applied only when the acidity of the soil 


\section{Sick Soils not Influenced by Parasites 29}

requires it. After that an additional application of IOOO pounds of burned lime or 2000 pounds of limestone every five years will be desirable. Should lime be used at more frequent intervals, the organic matter of the soil will fast deplete. "The saying that "lime makes the father rich and the son poor" is only true where the use of lime is overdone, and not otherwise.

\section{Muck or Peat Solls}

Muck or peat soil is sick because most plants refuse to grow there unless it is properly treated. However, muck may be transformed into the best trucking land. There are States in the Union which possess muck lands by the thousands of acres. Yet these are the last to be reclaimed. In Europe, scientists have long concerned themselves with the reclaiming and utilization of muck lands. Norway, Sweden, and Denmark have dealt to a large extent and with fair success with the problem, though much of it still remains to be solved. As the term implies, peaty soils are those in which peat is the dominating constituent. Peat is always formed under water, in swamps or marshes, undrained flat land, indeed, any place where waterloving plants grow in abundance. Most peat is made up mainly of sphagnum and moss. Grass peat is composed of swamp grasses, sedges, rushes, or flags. In swamps where rushes, sedges, or other grasses occur, peat formation is more rapid than where moss or sphagnum grows. Peat itself is nothing more than rotten vegetable matter. Com- 
plete decomposition is impossible, because of the absence of air and the accumulation of plant acids which contain antiseptic properties.

The chemical composition of peaty soils, as given by Conner and Abbot, ${ }^{\mathrm{x}}$ may be seen in Table 5 .

\section{TABLE 5}

Chemical Analyses of Different Types of Unproductive Black Soils.

\begin{tabular}{|c|c|c|c|c|}
\hline \multirow[b]{2}{*}{ Substance determined } & \multicolumn{4}{|c|}{ Kind of Soil } \\
\hline & $\begin{array}{l}\text { Acid } \\
\text { peat }\end{array}$ & $\underset{\text { Deat }}{\text { Neut }}$ & $\begin{array}{l}\text { Acid } \\
\text { peaty } \\
\text { sand }\end{array}$ & \begin{tabular}{|l} 
Neutral \\
Deaty \\
sand
\end{tabular} \\
\hline 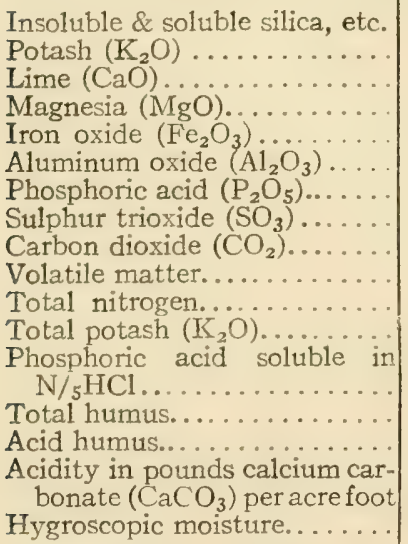 & $\begin{array}{r}10.40 \\
.23 \\
1.86 \\
.26 \\
\\
2.87 \\
.36 \\
.49 \\
.20 \\
83.16 \\
3.82 \\
.34 \\
\\
.032 \\
30.68 \\
27.74\end{array}$ & $\begin{array}{r}9.00 \\
.12 \\
3.89 \\
.52 \\
\\
4.27 \\
.40 \\
.28 \\
.63 \\
81.16 \\
3.51 \\
.26\end{array}$ & $\begin{array}{c}88.63 \\
.14 \\
.08 \\
.11 \\
\\
3.25 \\
.08 \\
.04 \\
.10 \\
8.16 \\
.28 \\
1.62 \\
\\
.0058 \\
4.86 \\
4.64\end{array}$ & $\begin{array}{r}71.47 \\
.28 \\
5.91 \\
1.31 \\
\\
5.03 \\
.21 \\
4.42 \\
.22 \\
12.16 \\
.57 \\
1.25 \\
.037 \\
4.72 \\
\text { none }\end{array}$ \\
\hline
\end{tabular}

From the table it is evident that the chemical composition is not the same for all peaty soils. This is naturally to be expected, since no two soils are

${ }^{3}$ Conner, S. D., and Abbot, J. B., Purdue Agr. Expt. Sta. Bul. 157 : vol. I6, 1912. 


\section{Sick Soils not Influenced by Parasites 3I}

chemically identical. In treating peaty soils it should be remembered that what applies to one does not generally apply to another.

Depth of Peat Soils. Hopkins, Readhimer, and Fisher ${ }^{I}$ classify peaty soils according to the depth as follows:

I. Soils in which the very peaty material extends three or four feet at least, and often to much greater depths.

2. Soils with one to three feet of peaty material resting on deep sand.

3. Soils with one to three feet of peaty material resting on rock, usually with some inches of sandy material between the two.

4. Soils with six inches to three feet of peaty material resting on a clayey subsoil.

5. Soils with only a few inches resting on the sand.

When the peat is about three feet in depth over a deep sand subsoil, the land may be lacking in potash. This must then be supplied in the form of potassium salts, or of manure.

Of the many types of peaty soils, the best for trucking are those black deposits which have reached an advanced state of decomposition, are of a fine texture, and have a high ash content. Brown peat of a fibrous nature is not very desirable. Its physical condition is such that the water cannot be properly controlled.

Treatment of Peat Soil: Burning. The mistake is

${ }^{x}$ Hopkins, C. G., Readhimer, J. E., and Fisher, O. S., Illinois Agr. Expt. Sta. Bul. I57 : 95-I3I, 1912. 
often made of burning over peaty soils with a view to improving them. This practice cannot be too strongly condemned. It is difficult to see where any permanent benefit can result from such treatment. Moreover, burning destroys the nitrogen and the organic matter, which are two valuable and expensive assets of such a soil. Should peat ever catch fire accidentally, pouring water or throwing soil on the flames will not smother them. In this case it is best to dig an open trench around the fire to a depth of moist earth and let it burn itself out within that limit.

Drainage. The best method of reclaiming peat soils is drainage. This process is not so easily done as on ordinary land because peat holds water better than ordinary soils. Peat soils may be drained if sufficiently large tiles are used and a proper outlet is at hand. The best results are obtained when the tiles are laid in the underlying muck or clay, but not too deeply in the subsoil.

Plowing. The second best method of improving peat soils is a proper working of them. Fall plowing is to be highly recommended. The peat in this case is exposed to the action of the frost, rain, and snow, all of which helps in the more rapid decay of the organic matter. In shallow peaty layers, deep plowing is of great value. This helps to mix the clay with the peat and makes it more readily available by bringing up the potassium and the phosphorus of the subsoil. In deep peaty layers, deep plowing exposes a larger part of the organic matter to the air and sunlight. Rolling should never be 


\section{Sick Soils not Influenced by Parasites 33}

practiced in very shallow layers. It is recommended only where the layer is over sixteen inches deep. Frequent cultivation is also very beneficial and provides aeration which favors a more rapid decay of the organic matter. It helps to heep down weeds.

The Choice of a Crop. On newly reclaimed peat soils, the best crops to plant are timothy, sudan grass, or alsike clover, which may be pastured to advantage. Peat soils cannot be surpassed for trucking purposes. They seem especially adapted for onions, celery, tomatoes, and potatoes.

Use of Fertilizers. The application of certain chemical fertilizers to peaty soils is decidedly beneficial. The kind of fertilizers will depend largely on the nature of the crop grown. Conner and Abbot present interesting data on the effect of fertilizer on onions. This is summarized in Table 6.

TABLE 6

Results of Field Fertilizer Tests with Onions on Various Peat Soils

\begin{tabular}{|c|c|c|c|c|c|c|}
\hline \multirow{2}{*}{$\begin{array}{c}\text { Experi- } \\
\text { ment } \\
\text { No. }\end{array}$} & \multirow{2}{*}{$\begin{array}{c}\text { Pounds } \\
\text { fertil- } \\
\text { izer } \\
\text { per acre }\end{array} \mid$} & \multirow{2}{*}{$\begin{array}{c}\text { Average } \\
\text { unfer- } \\
\text { tilized } \\
\text { yield }\end{array}$} & \multicolumn{4}{|c|}{ Increase in bushels per acre } \\
\hline & & & $4-8-10^{x}$ & $0-8-10$ & $4-0-10$ & $4-8-0$ \\
\hline $4-3 I$ & 1000 & 606.9 & I I 3.0 & 124.2 & 76.3 & 75.5 \\
\hline $43^{-1}$ I & 1000 & 79.1 & I 33.1 & 58.0 & 49.6 & $57 . \mathrm{I}$ \\
\hline $92-21$ & 1000 & 307.0 & 130.0 & 240.0 & 145.0 & 20.0 \\
\hline $37-14$ & 1000 & 234.0 & 332.0 & 285.0 & 120.0 & 89.0 \\
\hline
\end{tabular}

${ }^{3}$ 4-8-10 formula indicates 4 per cent. nitrogen, 8 per cent. phosphoric acid, and ro per cent. potash made from dried blood, acid phosphate, and sulphate of potash. Minus sign (-) indicates decrease. 
TABLE 6-(Continued)

\begin{tabular}{|c|c|c|c|c|c|c|}
\hline \multirow{2}{*}{$\begin{array}{c}\text { Experi- } \\
\text { ment } \\
\text { No. }\end{array}$} & \multirow{2}{*}{$\left|\begin{array}{c}\text { Pounds } \\
\text { fertil } \\
\text { izer } \\
\text { per acre }\end{array}\right|$} & \multirow{2}{*}{$\begin{array}{c}\text { Average } \\
\text { unfer- } \\
\text { tilized } \\
\text { yield }\end{array}$} & \multicolumn{4}{|c|}{ Increase in bushels per acre } \\
\hline & & & $4^{-8-10}$ & $0-8-10$ & $4-0-10$ & $4-8-0$ \\
\hline $\begin{array}{c}37-\text { I } 5 \\
43^{-2} \text { I } \\
57-\text { I I } \\
57-\text { I Ia } \\
\text { Average }\end{array}$ & $\begin{array}{r}1000 \\
1000 \\
1000 \\
500 \\
\ldots\end{array}$ & $\begin{array}{l}613.0 \\
628.0 \\
394.2 \\
372.8 \\
404.4\end{array}$ & $\begin{array}{r}73.7 \\
0.0 \\
89.0 \\
171.7 \\
130.3\end{array}$ & $\begin{array}{r}-27.1 \\
75.0 \\
49.1 \\
178.6 \\
122.8\end{array}$ & $\begin{array}{r}\text { I27.I } \\
-30.0 \\
55.2 \\
\text { I } 28.6 \\
84.0\end{array}$ & $\begin{array}{r}-64.6 \\
25.0 \\
47.6 \\
145.5 \\
49.0\end{array}$ \\
\hline \multicolumn{4}{|c|}{$\begin{array}{l}\text { Cost of fertilizer. . . . . . . . } \$ \text { Ar } 7.34 \\
\text { Average profit per acre.... } 47.81\end{array}$} & $\begin{array}{r}\$ 9.56 \\
51.84\end{array}$ & $\begin{array}{r}\$ 12.84 \\
29.16\end{array}$ & $\begin{array}{r}\$ 12.28 \\
12.22\end{array}$ \\
\hline
\end{tabular}

We have as yet no definite data on the effect of lime on peaty soils. Those in charge of the development of peaty soils caution against using it too freely. Of the forms to use, ground limestone or marl are perhaps the best kinds to apply. The amount to use will vary from one to four tons, depending largely on the acidity of the soil. Too much lime tends to destroy the nitrogenous compounds, and encourages serious plant diseases.

\section{AlKALI-Sick SOILS}

The alkali problem is even of more widespread concern, as it affects nearly all irrigated districts of the arid and semi-arid regions of the United States. An alkali-sick soil is one which contains an excess of accumulated soluble salts which are injurious to plant growth. For convenience, alkali soils are divided into black and white. The black alkali lands are known to contain sodium carbonate or washing soda as the essential salt. The 


\section{Sick Soils not Influenced by Parasites 35}

latter does not act so much on the soil as on the organic matter, turning it black. This black material is always found on the surface with the salts. The blackening of the soil, however, is not always an indication of black alkali. Many dark spots are found to contain the white alkali. Moreover, soils which contain little or no organic matter may contain large quantities of sodium carbonate and never turn black. The white alkali in reality is not a true alkali. The salts found in it are sodium chloride or table salt, calcium sulphate or gypsum, sodium sulphate, magnesium sulphate or Epsom salt. In addition to these may be found salts of potassium. Table 7 , taken from Harris, ${ }^{1}$ shows a comparative study of the total soluble salts which are found to be injurious to plants.

\section{TABLE 7}

Summary of Total Soluble Salis, Chlorides, Carbonates, and Sulphates in Alkali Soils. Average to a Depth of Four Feet, Parts per Million of Dry Soil.

Parts of field producing best crop

\begin{tabular}{l|r|r|r|r}
\hline \multicolumn{1}{c|}{ Counties } & $\begin{array}{c}\text { Total } \\
\text { Soluble } \\
\text { Salts }\end{array}$ & Chlorides & Carbonates & Sulphates \\
\hline Boxelder & 4,806 & $\mathbf{1}, 485$ & $\mathbf{1}, 983$ & $71 \mathrm{II}$ \\
Salt Lake & 2,440 & 545 & 858 & 2,334 \\
Millard & 10,852 & 640 & $\mathbf{1}, 418$ & 9,795 \\
Cache & 5,792 & $\mathbf{1 , 5 7 3}$ & $\mathbf{1}, 5 \mathrm{I} 5$ & 2,539 \\
\hline
\end{tabular}

Harris, F. S., Utah Agr. Expt. Sta. Bu1., I45 : 3-21, 1916. 
Diseases of Truck Crops

TABLE 7-(Continued)

Parts of field producing medium crop

\begin{tabular}{l|r|r|r|r}
\hline \multicolumn{1}{c|}{ Counties } & $\begin{array}{r}\text { Total } \\
\text { Soluble } \\
\text { Salts }\end{array}$ & Chlorides & Carbonates & Sulphates \\
\hline Boxelder & 7,075 & $3,02 \mathbf{1}$ & $\mathbf{1}, 727$ & 543 \\
Salt Lake & 4,228 & 875 & 792 & $\mathbf{1}, 8 \mathbf{1 2}$ \\
Millard & 18,325 & 3,077 & $\mathbf{1}, 27 \mathbf{1}$ & $\mathbf{1 3 , 2 3 8}$ \\
Cache & 17,218 & $2,54 \mathbf{1}$ & 888 & $\mathbf{1 3}, \mathbf{1 2 6}$ \\
\hline
\end{tabular}

Parts of field where no crop would grow

Boxeider

Salt Lake

Millard

Cache

\begin{tabular}{r|r|r|r}
10,079 & 6,767 & $\mathrm{I}, 874$ & $\mathbf{1}, \mathbf{1} 54$ \\
6,938 & 2,045 & 689 & 3,636 \\
$2 \mathbf{1}, 488$ & 6,289 & $\mathrm{I}, 875$ & $\mathrm{I3}, 304$ \\
$30, \mathbf{I} 48$ & 3,585 & 795 & 23,027 \\
\hline
\end{tabular}

Origin of Alkali Soils. Soils are formed through the disintegration of rocks due to various agencies such as weather, water, chemicals and organic matter, and the action of the soil flora. In this process, substances are released, some of which are insoluble while others are readily soluble in water.

Although in moist and cold climates the more rapid decomposition of rocks leaves more salt deposits in the soil, the abundant rainfall washes out these salts, which are carried off by the streams and rivers to the ocean. This is not the case in arid regions where the salts are gradually allowed to accumulate. Much of the rain in the arid regions does not find an outlet in streams, but accumulates in the lower regions, where the water finally evapo- 


\section{Sick Soils not Influenced by Parasites 37}

rates, leaving a deposit of salts. This then is one way in which alkali spots are formed. Another source of alkali formation is through the decomposition of volcanic rocks. This condition is found in some parts of New Mexico. Another, and by far the most important, source of alkali formation is through capillarity and evaporation. This occurs when the water accumulated in the soil is insufficient to raise the water table high enough to permit evaporation. The condition which most favors such an accumulation of water is a bed or layer of a clayey character which prevents the percolation of water downwards, below a soil which does not have sufficient lateral drainage. The source of the water may be springs, or the percolation of surface rainwater, and in irrigated regions, leaky canals or over-irrigation. The depth of the water table, where capillarity becomes a source of trouble, is about three feet. As all soil water contains diluted salts, continual evaporation will leave alkali spots or beds. To realize further what the alkali accumulation means, Tinsley ${ }^{1}$ has worked out some interesting figures.

"Suppose an acre of land, with the water table within less than two feet of surface, and that the amount of water evaporated from the surface in a year was enough to cover the acre to a depth of one foot, which the writer considers a low estimate for a bare soil. Suppose further that when it reached the surface, the water carried Ioo parts of soluble matter in 100,000 parts of water, which is about the salt × Tinsley, J. D., New Mexico Agr. Expt. Sta. Bul. 42 : 3-3I, I yoz. 
content of the best irrigating waters in the Roswell district. This would give 43,560 cubic feet of water on the acre, which would weigh about $2,720,000$ pounds, and would leave on evaporation 2720 pounds of salt, about one and one half tons.

"This would amount to an addition of .07 per cent. of salt to the surface foot of that acre per year. If this were continued about seven years, and none of the salts were removed, the amount added would be about .5 per cent. in the first foot of soil, which is more per foot than cultivated plants could usually withstand. Under actual conditions, it is probable that more than one and one half tons of salts per acre per year are carried to the surface in many cases, but the rain washes a portion of them back and they are distributed to a greater depth than one foot."

Effect of Alkali on Plant Growth. Plants can stand the baneful effect of alkali only to a limited degree. The damage is always confined to the stem end. Here the epidermis turns brown for half an inch or more, gradually tearing away in a girdling fashion. This results in the collapse and death of the plant, which assumes a corroded appearance. The physiological effect of alkali is to plasmolize the cell contents of the bark.

Crops Adapted to Alkali Lands. Unlike peaty lands, alkali soils are adapted to very few trucking crops. Sugar beets, carrots, and artichokes seem to thrive fairly well in such soils. Irish potatoes will thrive well in soils which do not contain more than I 8,400 pounds of alkali per acre, of which 4000 


\section{Sick Soils not Influenced by Parasites 39}

pounds may be carbonate of soda, and 6880 pounds common salt. Broccoli, chard, fennel, and sweet corn will thrive fairly well in lands containing up to a total of 3720 pounds of alkali per acre.

How to Reclaim Alkali Soils. We have seen that the accumulation of alkali in a soil is often brought about by the evaporation of water which is charged with mineral salts. To obviate this it is evident that the evaporation must be counteracted. Good surface cultivation will establish a dry surface mulch and prevent the rise of water to the upper level, thereby preventing evaporation. Tillage to be effective must be started early, because then, large quantities of salt would be carried into the subsoil by the spring rains. If the crop is started early, it may be forced to maturity before the effect of alkali can make itself felt on the plants. Tillage, however, will afford only temporary relief, as it will not remove the salts from the soil. Drainage on the other hand affords permanent relief. The land is first flooded, preferably in the winter, and then the water which is now laden with soluble salts is removed by a system of drainage. Tile drainage, while more expensive in its initial cost, is cheapest in the long run. Such a system when laid down permanently will prevent the further accumulation of salts.

The application of manure or straw to alkali land often brings marked relief. Many a barren spot has been reclaimed by this method. The beneficial action of manure or straw is easily accounted for. Both of these tend to loosen the surface soil, thereby 
acting as a surface mulch, and indirectly preventing evaporation. They may also stimulate young plants to more rapid growth, enabling them to withstand the action of alkali. Young plants are much more sensitive to alkali than older ones. The older plants of cantaloupes, for instance, are far more resistant to alkali than the young seedlings. 


\section{CHAPTER III}

SOIL SICKNESS DUE TO THE PRESENCE OF PARASITES HARMFUL TO PLANTS

WHEN a soil is sick because its beneficial bacteria do not perform their functions properly, or because of abnormalities in its chemical properties, careful treatment and proper cultural methods will restore it to health. But when a soil becomes sick and unproductive because parasitic forms gain a foothold there, much greater skill and knowledge are required to cope with the problem. Its solution is of the greatest economic importance to the trucker and gardener.

Parasitic fungi finding their way in a soil do not necessarily interfere with the work of the beneficial bacteria, such as the ammonifiers and nitrifiers, for instance. Neither do they always influence the chemical or physical nature of the soil. They attack directly the crop itself. Of the numerous parasites rendering soils unproductive, we will consider here only two types.

I. Soll Sickness Due to Parasitic Fungi.

Fungi which produce DAMPING OFF in seedlings. 
Fungi which produce damping off as well as wILTs, BLIGHTS, or ROTS in plants.

\section{DAMPing OFF}

\section{Caused by Pythium de Baryanum Hesse.}

This disease is very familiar to every grower of plants. The trouble is peculiar to seedlings or very tender plants. It is prevalent in the greenhouse, the hotbed, the cold frame, and frequently also in the field. The trouble is induced by the presence of definite parasitic fungi in the soil. They thrive best when the land is continually damp, and the atmospheric temperature comparatively high. Damping off is also favored by thick sowing and too much shade in the seed bed.

Symptoms of Damping Off. Every experienced trucker knows the disease when he sees it. Seedlings freshly damped off are soft and water-soaked at the base of the stem. If they are pulled they often break off easily. A more careful examination shows that the root system is entirely decayed by this time, although the upper part of the stem and leaves may still be green, possibly also fresh. The degree of prostration in the seedlings is regulated by the amount of moisture in the soil. If the amount of moisture is slight, the seedlings will be flabby and wilted before they topple over. With a high moisture content, they are more firm, but become prostrate as soon as infection starts in. Damping off 



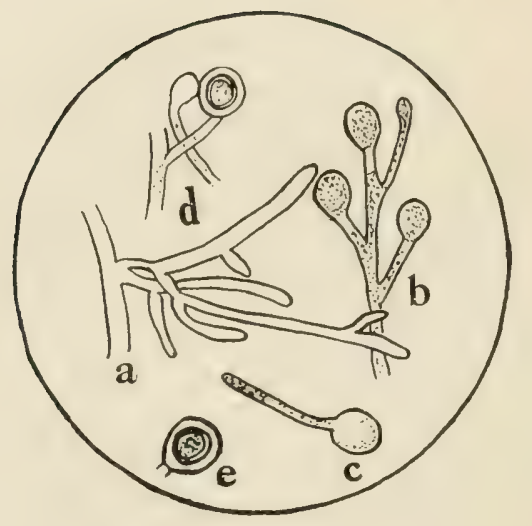

Fig. 5. Pythium debaryanum.

$a$. Mycelium, $b$. conidiophore bearing conidia, $c$. germinating conidium, $d$. fertilantheridium, $e$. oospore. 


\section{Soil Sickness Due to Parasites}

usually begins in spots in the seed bed or in the field and then may spread in every direction.

The Organism. Pythium de Baryanum was first named and described by Hesse in 1874 . Ward ${ }^{\mathrm{x}}$ found it to be a very prevalent parasite in the garden soils of Europe. In America the fungus was first recognized by Atkinson ${ }^{2}$ as of great economic importance. Pythium de Baryamum, when examined under a compound microscope, is seen to be made up of coarse, non-septate, highly granular, irregular branched hyaline vegetative threads or mycelium (fig. 5 a). The younger threads are more finely granular, the oldest ones are coarsely granular or more often empty. These threads penetrate the cells of the host, where they obtain food.

Pythium de Baryanum does not often fruit freely on the dead host. The fruiting is better observed when it is grown in a pure culture. Under normal conditions the fungus produces two forms of spores, conidia (fig. 5 b) and oogonia (fig. $5 \mathrm{~d}$, e). The summer spores, or conidia, are swellings formed at the tip of the hyphæ. These swellings readily break off from the mother threads and germinate by sending out a slender tube (fig. $5 \mathrm{c}$ ). This tube penetrates the seedling tissue, where it grows and develops and after due incubation reproduces the disease. The oospore or sexual spore is the stage which is most commonly found. The female oogonium first devel-

I Ward, M., Quart. Jour. Micros. Soc., New Ser. 22 : 487, I883.

${ }^{2}$ Atkinson, G. F., New York (Comell) Agr. Expt. Sta. Bul. 94 : $233^{-272}, 1895$. 
ops as a terminal enlargement which is cut off by a septum from the mother thread. Next or adjacent to it a siender tube is cut off from the mycelium by a septum. This tube now performs the function of the male sexual organ and is known as antheridium. The latter then comes into close contact and empties all its content into the oogonium (fig. 5 d). Fertilization thus takes place, and a mature egg or oospore or winter resting spore is formed (fig. 5 e).

The latest investigations have not yet disclosed whether or not Pythium de Baryanum is carried over from year to year by its oospores. It is apparently able to propagate itself indefinitely by its vegetative mycelium. The seedlings of the following truck crops are subject to damping off by Pythium: Beans, beets, cabbage, cauliflower, endive, lettuce, pumpkin, tomato, and turnip.

Of the other fungi which are capable of producing a damping off in seedlings may be mentioned; Sclerotinia libertiana Fck1., Phoma solani Halst., Colletotrichum sp., Fusarium sp., Sclerotium Rolfsii Sacc., and Rhizoctonia solani Kühn. The first five will be taken up separately in connection with the study of their respective hosts (see pages 45, 46, I43, 305, 324).

\section{Other SoIl Diseases}

We have seen that Pythium de Baryanum is most active as a disease on young seedlings. Other fungi, however, may attack not only seedlings, but also older plants, in various stages of development. As 


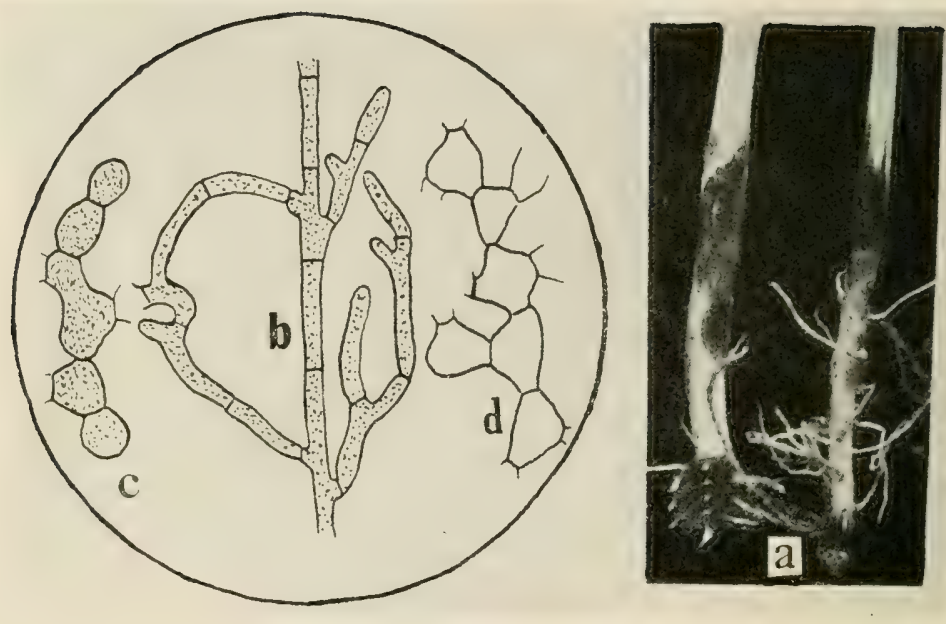

Fig. 6. RHIzoctoniA.

a. Rhizoctonia cankers on stems of young bean plants, $b$, young growing hyphæ of Rhizoctonia, $c$. young barrel shaped cells which compose the sclerotia of Rhizoctonia, $d$. older and empty barrel shaped cells of scierotia ( $a$. to $d$. after Peltier). 
a guide to the trucker and gardener, we shall consider two typical soil diseases, one which produces root rot, the other wilt only.

\section{Root Rot}

Caused by Rhizoctonia solani Kühn.

This fungus is of great economic importance because of its widespread distribution. It is capable of producing a damping off on a variety of seedlings, as well as of attacking older and mature plants.

Symptoms. The symptoms of Rhizoctonia wilt do not differ materially from those produced by Pythium de Baryanum. On older plants however Rhizoctonia produces cankers or deep lesions which are very characteristic (fig. 6 a). These are formed on the roots as well as on the base of the stem. The lesions are reddish brown and extend into the cortical or vital layer as well as into the woody tissue. There is perhaps no other parasitic fungus which is so widespread and capable of attacking such a variety of hosts as Rhizoctonia. The work of Peltier ${ }^{\mathrm{x}}$ shows that the following truck crops are susceptible to Rhizoctonia: Beet, bean, cabbage, cauliflower, celery, cowpea, cucumber, cress, eggplant, horseradish, lettuce, muskmelon, okra, pepper, radish, squash, sweet potato, garden pea, parsnip, potato. and tomato.

The Organism. In 1828 Duhamel described Rhi-

* Peltier, G. L., Illinois Agr. Expt. Sta. Bul. I89: 283-391, 1916. 
zoctonia for the first time. In the United States the first extended account of the fungus was given by Pammel. ${ }^{\text {I }}$ Many other excellent accounts by American workers have appeared from time to time, to which we shall have occasion to refer later.

The genus Rhizoctonia includes several forms of sterile fungi, all of which are distinguished by their manner of growth in pure culture, and by their mycelium form. Young hyphæ of $R$. solani Kühn are at first hyaline, then deepen in color from a yellowish to a deep brown. The young branches are somewhat narrowed at their point of union with the parent hypha and grow in a direction almost parallel to each other (fig. $6 \mathrm{~b}$ ). A septum is also laid down at a short distance from the point of union with the parent mycelium. There is another form of mycelium which is made up of barrel-shaped cells, each of which is capable of germinating like a spore (fig. $6 \mathrm{c}, \mathrm{d}$ ). In pure cultures $R$. solani produces sclerotia, which are at first soft, whitish, and later become hard and dark. The fungus is carried over from year to year as sclerotia which are able to withstand the effect of heat, cold, drought, or moisture.

\section{PARASITIC SOIL FUSARIA}

Next in importance to Rhizoctonia is a group of fungi which belong to the genus Fusarium. Lands infected with these species of fungi become unfit for cabbage, potatoes, tomatoes, etc., causing great finan-

× Pammel, L. H., Iowa Agr. Expt. Sta. Buil. 15: 244-25I, I891. 


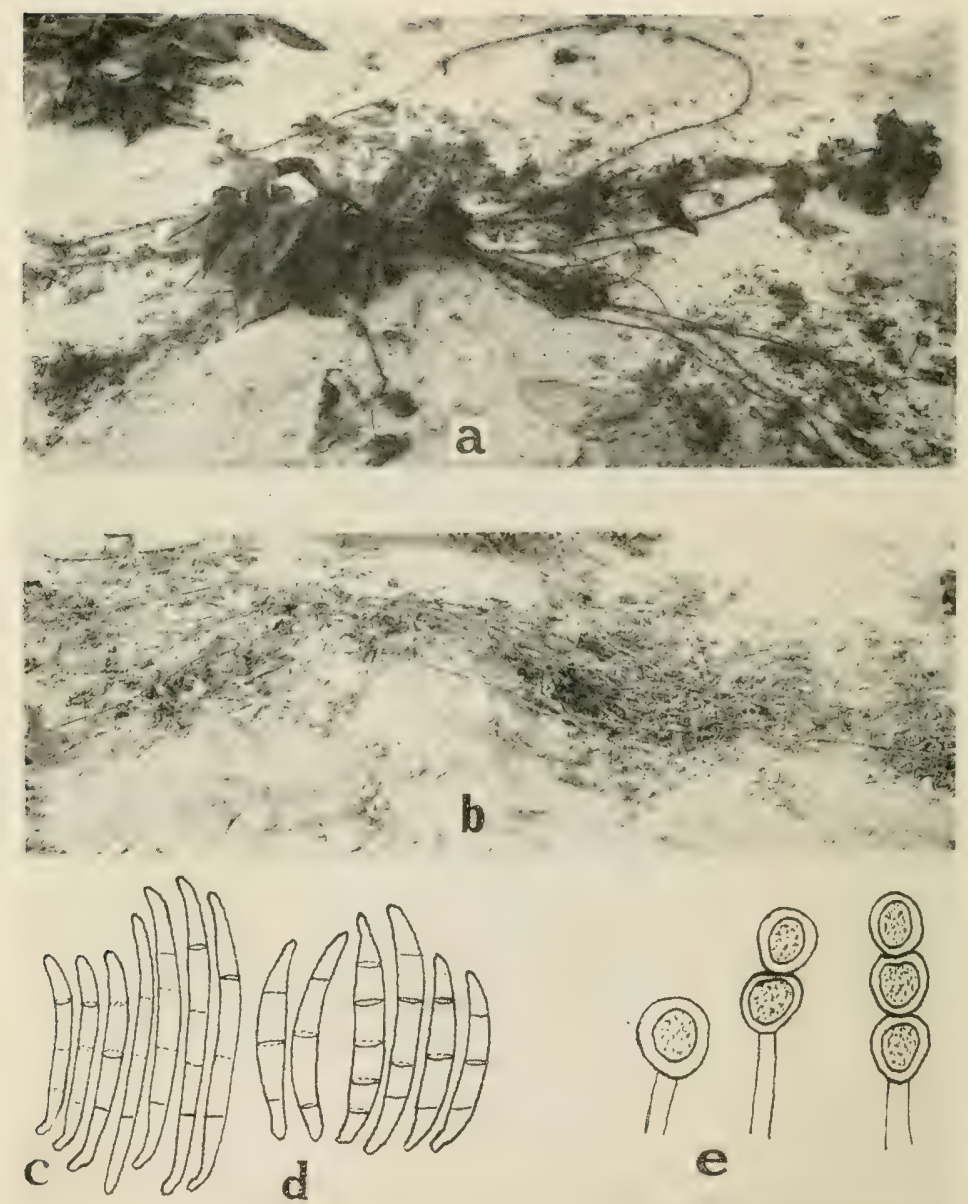

Fig. 7. Fusarium Wilt.

a. Early stage of Fusarium wilt of sweet potato, $b$. sweet potato hill killed by Fusarium wilt, $c$. spores of Fusarium batatatis, $d$. spores of Fusarium hyperoxysporum, $e$. chlamydospores of Fusarium (c. and $d$. after Harter). 
cial losses to the trucker. We will take up the specific troubles in studying each of these crops respectively. As an illustration of a typical Fusarium-sick soil we will consider the wilt of sweet potatoes.

\section{Wilt or Yellows of the Sweet Potato}

Caused by Fusarium batatatis Woll. and $P$. hyperoxysporum Woll.

Symptoms. The first indication of sweet potato wilt is a slight difference in the color of the foliage in the affected plants. The leaves become dull, then yellow between the veins and slightly puckered; this is followed by the wilting of the affected vines (fig. 7 a). If one of these vines be split open at the stem end, the interior of the woody portion will be found blackened. All parasitic soil Fusaria invade the interior of the water or fibro-vascular bundles which are situated in the woody tissue of the stem. Wilting and death of the plant follow (fig. 7 b).

The morphology of Fusarium is identical in many species. They differ only from a pathological point of view, and in peculiarity of certain colors produced on media in pure cultures. Pathologically, many of the species are distinct. The Fusarium of the sweet potato wilt cannot, as far as we know, attack potatoes, tomatoes, or any other host. This is similarly true for the Fusarium which produces a wilt on tomatoes, etc. The mycelium of Fusarium is hyaline, septate, and branched. The spores are sickle-shaped and 
very characteristic (fig. 7 c, d). Some Fusaria also produce chlamydospores or resting spores, by which the fungus is carried over winter (fig. $7 \mathrm{e}$ ). As far as we know the wilt-producing Fusaria do not form a winter or ascus stage. They are carried over as mycelium, or chlamydospores, in dead plants and in the soil.

\section{Solls Rendered Sick by Certain Forms of Animal Life}

The present discussion deals with the root knot, a disease produced by a little worm generally known as nematode, or eel worm.

\section{RoOT KNOT}

\section{Caused by Heterodera radicicola (Greef) Müll.}

Root knot is most prevalent in light soils. This, however, does not exclude it from heavier lands where it may sometimes be found. The trouble is most widespread in the Southern States, where the winter is mild. In unprotected places in the North its numbers are probably greatly reduced each winter. The annual financial losses from this disease are staggering in extent. With proper culture and fertilization, however, a crop may be produced with practically very little loss where neglect would have caused a total failure. This is especially true under greenhouse conditions. 



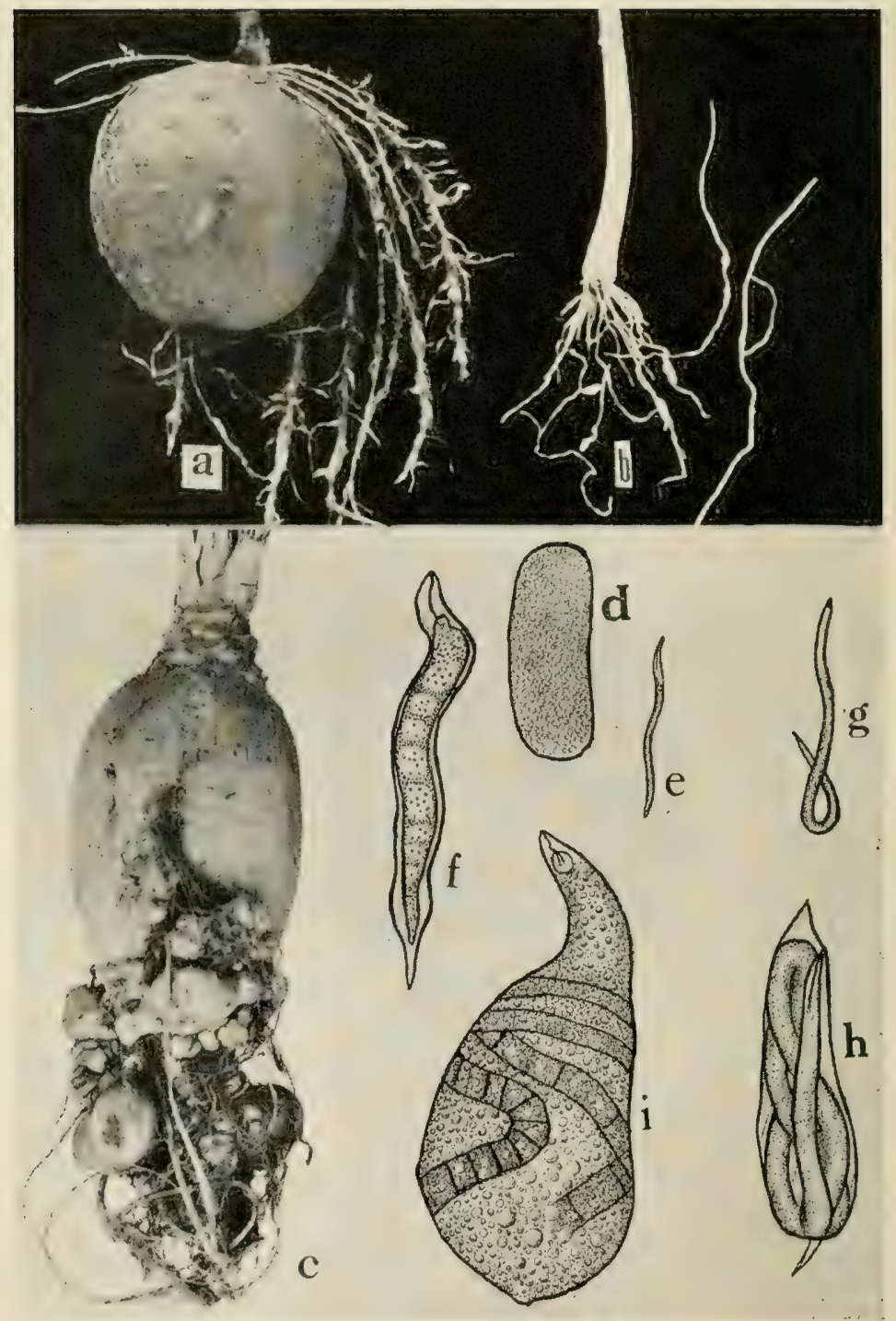

Fig. 8. Nematode Root KNot.

a. Root knot of Irish potato, $b$. rnot knot of onion, $c$. root knot of parsnip, $d$. egg of nematode, Iteterodera radicicola, $e$. young female worm, $f$. half-grown female egg of nem worm ready to emerge from old body covering, $i$. matured female worm (d. to $i$. greatly enlarged, after Stone and Smith). 
Symptoms. The disease is characterized by a swelling on the roots, showing itself in small knots formed either singly or in pairs, or in strings, giving the affected root a beaded appearance (fig. 8 a, b). Sometimes, however, the swellings are so large that they may be mistaken for the root nodules (fig. $8 \mathrm{c}$ ) of legume plants, which occur normally in great abundance. Infested plants usually linger for a long time, but they can be distinguished by a thin growth and yellow sickly looking leaves and stems.

Distribution. The eelworm seems to be of worldwide distribution, being found in Europe, Asia, Australia, and both North and South America. And yet, there are many localities in which this pest has never been known.

Life History. The eelworm is a very minute worm, seldom exceeding one twenty-fifth of an inch in length. It is semitransparent, so that it cannot be easily detected by the naked eye. In searching for the eelworm, break a fresh knot. Close examination will reveal two types of worms: a spindle-shaped worm, the male (fig. $8 \mathrm{~g}, \mathrm{~h}$ ), and a pearly white pear-shaped organism, the female (fig. 8 e, f), firmly embedded in the gall tissue. The female is very prolific, depositing no less than 400 to 500 eggs during her lifetime. The eggs are whitish (fig. 8 d), semitransparent bean-shaped bodies, and too small to be noticed without the aid of a magnifying glass. The time which elapses until the eggs hatch depends largely upon weather conditions. In warm days the eggs hatch sooner than in cold days. Upon hatching, the 
young larvæ either remain in the tissue of the host plant in which they have emerged, or, as is more often the case, leave the host and enter the soil. This is the only period during which the worms move about to any great extent in the soil, where they either remain for some length of time or immediately penetrate another root of the host. The nematodes in most cases become completely buried in the root tissue, establishing themselves in the soft cellular structure which is rich in food. The head of the worm is provided with a boring apparatus consisting of a sharply pointed spear, located in the mouth. This structure not only aids it in getting food but is also valuable in helping the young worms to batter through the cell walls before becoming definitely located. The two sexes during the development are undistinguishable up to fifteen or twenty days, both being spindle-shaped. In the molting or shedding of the skin, there is a marked change in the case of the female, especially in the posterior region of the body, which no longer possesses a tail-like appendage. Fertilization occurs soon after this molt, and many radical changes occur in the shape and structure of the organization of the worm. The fertilized female increases rapidly in breadth and becomes a pearly white flask- or pear-shaped individual (fig. 8 i). At this stage it is far from being wormlike and may, therefore, be overlooked by one unfamiliar with the life-history of the eelworm. The adult male is much like that of the young female larvæ, being spindleshaped in outline. The male does not cause as much 
damage to the root tissue as the female, and its purpose in life seems to be only that of fertilizing the female, for after this function has been performed, it is quite probable that the male worm takes no more food.

Omnivorous Nature of the Eelworm. There are almost five hundred species of plants known to suffer from the eelworm. This number includes all the important families of the flowering plants. According to Bessey ${ }^{\mathrm{I}}$ the following are among the plants subject to root knot:

a. Truck Crops. Asparagus, bean, beet, cabbage, carrot, cauliflower, celery, chicory, cucumber, dill, eggplant, endive, gourd, Jerusalem artichoke, leek, lettuce, muskmelon, mustard, okra, onion, parsley, parsnip, pea, pepper, potato, pumpkin, radish, rutabaga, salsify, shallot, spanish oyster plant, spinach, squash, sweet potato, tomato, turnip, watermelon, yam.

b. Garden Weeds. Birdsfoot trefoil, burdock, carpetweed, dandelion, dead nettle, Florida beggarweed, horse nettle, lamb's-quarters, mayweed, milkweed, nightshade, pigweed, plantain, pokeweed, ribgrass, shepherd's-purse, sheep sorrel, snow thistle, wild morning-glory.

From the above large list of susceptible hosts, it is evident that the trucker cannot afford to permit infestation of his land. Once a soil becomes sick because of the presence of eelworm there is very little range left in the choice of a crop.

× Bessey, E. A., U. S. Dept. Agr. Bureau PI. Ind. Bul. 217 : 7-89, I9II. 


\section{SOIL-INFESTING InsECtS}

Soils infested with insect pests are as sick as when infested with eelworm or parasitic fungi. The trucker, in sowing his seed, has often great difficulty in obtaining a good and even stand. The frequent resowings invariably result in late crops, and this means heavy money losses. Frequently the stand is reduced by fifty per cent. in spite of the many resowings. The cause of this may be traced to the presence in the soil of certain insect pests. Among those dreaded most by the trucker and gardener are: Cutworms (Agrotis sp.), (Lycophotia sp.), (Peridroma $\mathrm{sp}$. ), wireworms (Melanotus sp.), and white grubs (Phyllophaga sp.). 


\section{CHAPTER IV}

\section{METHODS OF TREATING SICK SOILS}

DAmpIng OFF, whether induced by Pythium, Rhizoctonia, or any ther parasitic organism, is usually confined to seedlings in the seed bed, under cover or in the open. The loss of seedlings not only means a waste of seeds, but it also results in late crops. Growers are usually in the habit of using the same soil in the seed bed, year in and year out. This practice cannot be encouraged, since contamination of the seed-bed soil is bound to take place. The disease-producing organisms are usually brought in with the manure. A number of truckers make it a practice to empty their beds and fill them with fresh soil. This, unfortunately, is not always a safe method, for the reason that the new soil too may be contaminated, or that it may become infected as soon as it is placed in the bed previously contaminated. Sick seed-bed soils may be freed from damping off in various ways.

Formaldehyde. When steam sterilization is not feasible because of the absence of a steam boiler, the formaldehyde treatment is the next best. With this treatment we may control Fusarium, Rhizoctonia, 


\section{$54 \quad$ Diseases of Truck Crops}

and Pythium in infected beds. It is doubtful, however, if this treatment will entirely eradicate eelworms from infested soils. The method is as follows: the beds are thoroughly prepared in the usual way, and then drenched with a gallon per square foot of formaldehyde solution composed of one pint of commercial formaldehyde ( $40 \%$ pure) to thirty gallons of water. The solution should be put on with a watering can and distributed as evenly as possible over the bed, so as to wet the soil thoroughly to a depth of a foot. It will, in most cases, be necessary to apply the solution two or three times, as the soil may not absorb the full quantity of the liquid at one time. After the treatment the beds should be covered with a heavy burlap to keep in the formaldehyde fumes for a day or two, and then aired for a week before planting. Stirring the soil at once would help the escape of the fumes. Formaldehyde may be bought in any drug store $40 \%$ pure.

Steaming. This method of treatment is far superior to any other yet evolved. For seed beds on a large scale the inverted pan method is the best. This was first devised by A. D. Shamel of the U. S. Department of Agriculture. The boiler must be able to generate a pressure of not less than eighty pounds, which should be maintained for at least one and a half hours. In setting a pan the rim is sunk into the soil of the seed bed, to a depth of two to three inches, to make the inclosed chamber steam tight. In heavy soil, trenching may be necessary. It is also advisable to put a heavy weight on the pan when the 



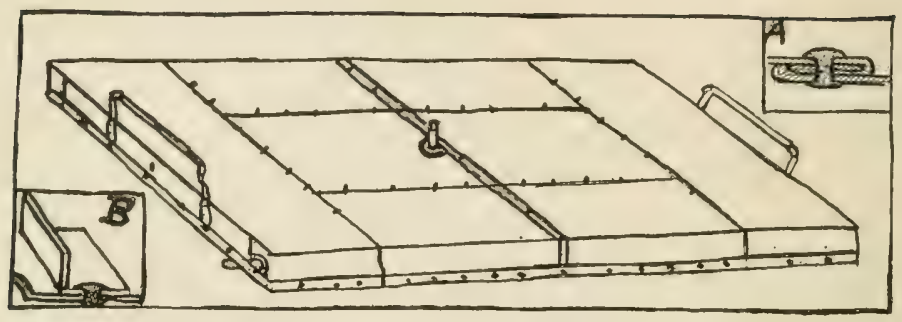

Fig. 9. Inverted Pan for Steam Sterilization. (After Selby.)

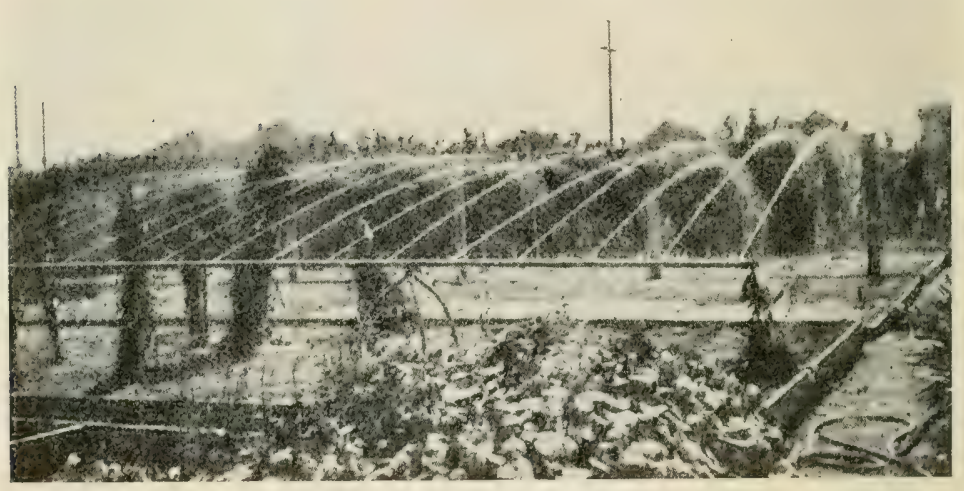

Fig. io. Surface Watering. Showing Portable Spray Equipment Used in Gardens about Cold Frames and Hot Beds. (AFTER WILLIAMS.) 


\section{Methods of Treating Sick Soils}

steam operates. When one pan is used, a traction engine or a portable boiler of ten to twelve H. P. will suffice. While the standard size of the pan is six by eight feet, the dimensions may be modified to suit the size of the seed beds.

Selby and Humbert ${ }^{1}$ describe the method of constructing an inverted (fig. 9) pan as follows:

"Material used for construction of a pan is galvanized sheet iron; the most useful weight is No. 20 gauge, which weighs 26.5 ounces per square foot. The heavier material requires little in the way of frame supports. The galvanized iron sheets come in sizes varying from two to three feet in width by eight to ten feet in length. Figure 9 shows a pan $6 \mathrm{x}$ Io feet in size, 6 inches deep, constructed from five such strips $21 / 2 \times 8$ feet in size. These sheets are joined by double-fold seam and riveted at intervals of 6 to ro inches to make the pan steam tight. This pan is further strengthened by a band of strap iron $2 \mathrm{x} I$ inch riveted to the bottom edge, and stiffened by a brace of $I / 4$ inch angle iron across the top and extending down the sides. This is bolted at the sides to the supporting strap iron stiffener. The corner illustrations show at 'A' the joint used for the galvanized iron sheets, and ' $\mathrm{B}$ ' a section of the angle iron supporting the top.

"The entrance pipe for the steam may be placed at the side or end of the pan (see dotted construction lines of fig. 9) or may enter from the top as per illus-

s Selby, A. D., and Humbert, J. G., Ohio Agr. Expt. Sta. Circ. I5I : 65-74, 1915 . 
tration. The latter form has the advantage in that it will not interfere with the box boards when used on frames. The pipe, after entrance, should be a $\mathrm{T}$ form, so that steam in being forced into the pan when in place does not blow holes in the soil."

Surface Firing. This method of soil sterilization is used only in the absence of steam facilities or where formaldehyde cannot be obtained, which, however, is seldom the case. It consists simply in producing a hot fire for an hour or more over the bed to be sterilized. A combustible material such as brush, straw, or wood may be used for that purpose. The objection to it is that the fire may destroy the organic matter in the soil.

Roasting or Pan Firing. In this method the soil to be sterilized is removed from the bed and placed in a pan, underneath which fire is present. After roasting the soil is returned to the bed and more of it sterilized. This method is too slow and is open to the same objection as the surface burning. The advantage of steam sterilization and of the "fire" methods consists in the destruction of all weed seed, together with the fungi which cause damping off.

Other Methods of Control. Damping off may be largely controlled by careful cultural conditions. Unless the soil of the seed bed is to be sterilized, it is never wise to sow the seeds in beds where damping off was known to have occurred previously. Thick sowing especially should not be permitted. In 
Table 8 , Johnson ${ }^{x}$ presents some interesting data on the effect of thick sowing on damping off.

\section{TABLE 8}

Effect of Thick Sowing on Percentage of Diseased Plants.

\begin{tabular}{|c|c|c|c|}
\hline \multirow{2}{*}{ Flat No. } & \multicolumn{2}{|c|}{ Weight of seed sown } & \multirow{2}{*}{ Plants Diseased } \\
\hline & per flat & per I00 sq. $f t$. & \\
\hline 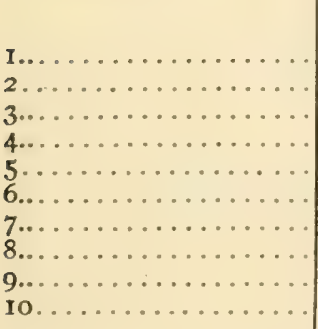 & $\begin{array}{c}\text { Grams } \\
0.1 \\
0.2 \\
0.3 \\
0.4 \\
0.5 \\
0.6 \\
0.7 \\
0.8 \\
0.9 \\
1.0\end{array}$ & $\begin{array}{l}\text { Ounces } \\
0.16 \\
0.33 \\
0.49 \\
0.66 \\
0.83 \\
0.99 \\
1.16 \\
1.33 \\
1.49 \\
1.60\end{array}$ & $\begin{array}{c}\text { Per cent. } \\
\text { o } \\
0 \\
8 \\
\text { 15 } \\
35 \\
75 \\
80 \\
80 \\
92 \\
96\end{array}$ \\
\hline
\end{tabular}

Certain soils are especially favorable to damping off. Soils which contain a high percentage of unrotted vegetable matter and those which are hard to drain need especial attention. Great care should be taken that the seed bed is kept at the right temperature. The latter cannot be guessed at by personal sensation. It should be accurately determined by -hormnmeters placed in the bed at suitable distances. It should also be remembered that any covering cloth or sash will exclude light and air. Every precaution

'Johnson, James, Wisconsin Agr. Expt. Sta. Research Bul. 3I: 3I-6I, I9I4. 
should be taken to prevent the seedlings from becoming "drawn," for at that stage they are most susceptible to damping off. The safest plan is to keep the temperature a trifle lower than is generally required, and allow as much ventilation as possible. Very often damping off starts in one corner of the bed. To check the rapid spread of the disease, the infected area may be removed. Spraying the seedlings with various fungicides in a bed where damping off has become well established will be of little help.

\section{Control of Fusarium- ANd Nematode-Sick SoIls}

The formaldehyde or the steam sterilization methods which are so effective in the treatment of sick seed beds cannot be used on a large scale for sick soils on account of the extensive cost involved. The trucker, therefore, must resort to other methods of control. Soils which are made sick by the presence of parasitic fungi or nematodes may be reclaimed by crop rotation as well as by the development of wiltresistant varieties. Both of these methods will be discussed at length in pages 372,373 .

\section{Control of Insect-Infested SoIL}

Spraying the soil will be of little value in the control of underground insect pests. Fortunately, however, we have more effective means for dealing with them. To destroy wireworms, sow corn which has been 


\section{Methods of Treating Sick Soils}

soaked for ten days in water containing arsenic or strychnine sulphate before planting the regular crop. The larvæ will feed on the poisonous corn kernels and die. Another way is to treat the seed with gas (coal) tar.

White grubs may be controlled by the use of bisulphide of carbon. Fall plowing is a valuable remedy, since many of the grubs are thus exposed to the cold winter weather and killed.

Cutworms may be controlled by the use of a poisoned bran made as follows: to three ounces of molasses add one gallon of water and sufficient bran to make a fairly stiffened mixture. To this add Paris green or arsenic and stir well into a paste. A heaping teaspoonful of the mixture is scattered here and there over the infested land. 

PART II 



\section{CHAPTER V}

\section{THE HEALTHY HOST AND ITS REQUIREMENTS}

WE have seen that soil is the medium in which plant life is made possible. We have also seen that to produce good yields in crops it is essential to have a healthy soil-a condition directly dependent upon the work of friendly organisms. When these perform their work imperfectly, or when the soil is overrun by parasitic fungi or by pestiferous animal life, the soil is considered sick.

Let us now consider the plant itself, since practically and economically it is the crop that concerns us most. We are interested in the soil only in so far as it is capable of maintaining economic crops. The general needs of plant life are the same to a striking extent for higher plants and for the lower microörganisms of the soil.

\section{NEED OF AIR}

Plants must breathe, since air is indispensable 
for all life. Plants breathe through their leaves, and, according to Whitney, ${ }^{\mathbf{I}}$ through the roots also. Hence, cultivation is necessary not only to supply air to the microörganisms in the soil, but also to the roots of the crop. In the opinion of Whitney, cultivation accomplishes a step further; by stirring the soil we permit the escape of foul gases given off by the plant roots as well as by the soil organisms.

\section{NEED OF WATER}

Plants to live must drink. This is one of the most important considerations from the trucker's point of view. It is generally supposed that roots are fixed things in the soil, receiving water and food material by capillary action. This occurs only in very moist and saturated soils. However, in dry seasons and in dry soils the roots have to move downward towards the water. This may be proved by a simple ingenious experiment described by Whitney. "If you take some soil from the field with what we call an optimum amount of moisture, or the best amount for plant growth, put it in a tumbler, filling the tumbler about half full, and put some dry soil on the surface,

Whitney, Milton, U. S. Depart. of Agr. Farmers Bul. 257: 5-35, 1909. 


\section{Healthy Host and Its Requirements 65}

you can see the difference in moisture contents by the difference in color, the moist soil being darker than the dry. Then, if you cover the tumbler to prevent evaporation you can leave the dry soil in contact with the moist soil and there will be no appreciable interchange of moisture between the moist and the dry layers. This simple experiment demonstrates that if cultivation is also to conserve the soil moisture, we must always strive to form a pulverized dry mulch on top. Capillary action practically ceases when a dry mulch or layer is found on top of the soil."

From the trucker's point of view, the water requirement of crops deserves careful consideration. In intensive gardening the water supplied by natural precipitation of rainfall cannot always be depended upon for crop production, and must be supplemented by irrigation. In fact irrigation is often a fundamental requirement, if we are to meet in a timely way the demands of the market. Irrigation when properly carried out may mean success, and the opposite total failure. To be what farmers call a "water hog," using too much water, is detrimental to the crops, for they are very sensitive to an excess of it. Widtsoe and Merrill ${ }^{1}$ have shown that the yields of truck crops directly depend on the proper amount of water supplied. The result of their investigation is shown in Table 9.

s Widtsoe, J. A., and Merrill, L. A., Utah Agr. Expt. Sta. Bul. ı17: 69-1I9, I9I2.

5. 


\section{TABLE 9}

The Yields of Truck Crops as Harvested, with Different Quantities of Water

Yield of crops is expressed in lbs. per acre; quantities of water used are expressed in acre-inches."

CARROTS

I. Irrigation water supplied

2. Rainfall and soil water.

3. Total water for use of crop..............

4. Total yield of carrots (lbs. per acre)

5. Yield per inch of irrigation water...........

6. Yield per inch of total water.

\begin{tabular}{r|r|r|r|r|r}
3.75 & 7.50 & 15.00 & 25.00 & 35.00 & 60.00 \\
10.25 & 10.25 & 10.25 & 10.25 & 10.25 & 10.25 \\
14.00 & 17.75 & 25.25 & 35.25 & 45.25 & 70.25 \\
34577 & 33223 & 49507 & 46755 & 56930 & 68420 \\
9221 & 4430 & 3306 & 1871 & 1627 & 1129 \\
2469 & 1872 & 1963 & 1326 & 1258 & 974
\end{tabular}

\section{CABBAGE}

I. Irrigation water supplicd......

2. Rainfall and soil water.......

3. Total water for use of crop...

4. Total yield of cabbage (lbs. per acre).......................

5. Yield per inch of irrigation

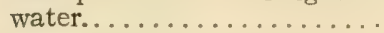

6. Yield per inch of total water...

\begin{tabular}{r|r|r|r|r}
12.50 & 20.00 & 25.00 & 40.00 & 70.00 \\
5.54 & 5.54 & 5.54 & 5.54 & 5.54 \\
18.04 & 25.54 & 30.54 & 45.54 & 75.54 \\
& & & & \\
18490 & 18524 & 16310 & 20432 & 23098 \\
& & & & \\
1479 & 926 & 652 & 511 & 330 \\
1025 & 725 & 534 & 449 & 306 \\
\hline
\end{tabular}

ONIONS

\begin{tabular}{|c|c|c|c|c|}
\hline I. Irrigation water supplied. & 15.00 & 20.00 & 30.00 & 65.00 \\
\hline 2. Rainfall and soil water. & 5.54 & 5.54 & $5 \cdot 54$ & $5 \cdot 5$ \\
\hline 3. Total water for use of crop......... & 20.54 & $25 \cdot 54$ & $35 \cdot 54$ & 70.54 \\
\hline 4. Total yield of onions (lbs. per acre).. & $2147 \mathrm{I}$ & 22038 & 32437 & $3417 \mathrm{I}$ \\
\hline inch of irrigation water... & 1432 & $\mathrm{I} 102$ & 1098 & 526 \\
\hline per inch of total water.. & 1045 & 863 & 913 & 48 \\
\hline
\end{tabular}

- The term acre-inch means the quantity that will cover one acre to the depth of one inch. Likewise in speaking of an acre-foot of water, it means the water necessary to cover one acre to a depth of one foot. 


\section{Healthy Host and Its Requirements 67}

A careful study of Table 9 shows that excessive watering results in a decrease of yield. Widtsoe and Merrill in their work on sugar beets found that when 30 acre-inches of water is spread over one acre 30 inches deep, the yield was 20.82 tons. When this same amount of water was spread over two acres and for a depth of fifteen inches, the yield increased to 38.90 tons per acre. Finally when the 30 acreinches of water were spread over six acres and five inches deep, the yield increased to 82.68 tons per acre. Every trucker should study the water requirements of the crops under his conditions of soil and climate. To obtain the best results from irrigation we must be familiar with the root system of each particular crop and the depth to which it normally penetrates the ground.

Methods of Irrigation. There are two methods of watering recommended. Each trucker can determine for himself which of the two will give him the best results under his particular conditions.

(a) Subirrigation. As this implies, the water is applied underground and through perforated pipes. The conditions necessary for subirrigation are a clay subsoil or a hardpan capable of retaining the irrigation water. The topsoil must be of a sandy loam, neither too loose nor too compact. The land must be of a nature to admit of perfect drainage, having a fall of one inch to each one hundred feet. The land must also be level without raised places. Where these conditions cannot be fulfilled, subirrigation will prove a failure. The crops that are best bene- 
fited by subirrigation are celery, lettuce, and Irish potatoes. Tomatoes, watermelons, cantaloupes, or sweet potatoes are not benefited by it.

The advantages claimed for subirrigation are many: (I) The moisture is better controlled in the soil and the roots will have easy access to it. (2) No crust is formed to shut out the air from the soil, or to favor the development of fungous diseases. (3) The soluble salts and fertilizers are not washed down deeply and are not carried beyond the reach of the roots.

(b) Surface or Spray Irrigation. As this implies, water is applied on the surface overhead, in the form of rain (fig. Io). The many advantages claimed for this system are as follows: (I) For the same volume of water a much larger area may be irrigated, or the same area may be watered with a smaller quantity of water. (2) Very little skilled labor is necessary in this system. (3) Large areas for irrigation can be rapidly covered. (4) The rain effect will control frosts. (5) There are no leaky wasteful channels, and no boggy roads. (6) An economy of land in channels and ditches. (7) Spray irrigation is independent of the topography of the field, and may be extended to lands too rolling or rough for subirrigation. Truckers in the arid sections seem in favor of a combination of spray and surface irrigation on the same field. The spray is used in preparing the seed bed, germinating the seeds, and for newly set out plants. Later, as the crop advances in age, especially during blossoming and fruiting, irrigation is carried out by 


\section{Healthy Host and Its Requirements 69}

surface furrow or check methods. A portable spray equipment meets these conditions well. The disadvantage of this system like that of rain is the baking of the surface soil, thereby necessitating more frequent cultivations. Moreover, when spray irrigation is overdone it is likely to encourage the development of mildews and various leaf spots.

\section{Need of Sanitary Environments}

Science has shown us the reasons for sanitary living for men and animals and equally for plants. Since the soil is the home of the plant, we must keep that soil as clean as we do our houses, or the stalls in stables. The soil organisms give off numerous poisonous excreta, which become harmful to them and to the crops. Through their own activities, the roots of plants, too, throw off certain poisonous excreta. If they are allowed to accumulate in the soil through growing the same crop too long in the same soil, a point is reached where that crop will refuse to grow there any longer, even if there is no evidence of soil exhaustion. The best purifier of soils is organic matter applied as manure or green vegetable matter which is converted into humus.

Clean Culture. There are two other means by which we can keep soils in a sanitary condition. Rotation of crops is discussed on page 372. Clean culture, too, is an essential means of safeguarding the health of our economic plants. Not only do weeds help to carry fungous diseases which are also 
common to crops, but they too excrete certain poisons into the soil which become harmful to the crop in the company of which they grow. Moreover, weeds rob the soil of vast quantities of water which otherwise would be utilized by crops. This is an important consideration where irrigation is not practiced extensively and in the more arid regions. 


\section{CHAPTER VI}

\section{CAUSES OF DISEASES IN CROPS}

IT is, indeed, very difficult to define the term disease. Health and disease are only relative terms, and it is not easy to draw a line where health leaves off and disease begins. Disease, however, may be applied to all deviation from the normal which threatens the life of the plant. Perhaps the nearest conception of health and disease is that of Marshal Ward, who says: "If we agree that a living plant in a state of health is not a fixed and unaltering thing, but is ever varying and undergoing changes as its life works out its labyrinthine course through the vicissitudes of the ever-varying environment, then we cannot escape the conviction that a diseased plant, so long as it lives, is also varying in response to the environment. The principal difference between the cases is, that whereas the normal healthy plant varies more or less regularly and rhythmically about a mean, the diseased one is tending to vary too suddenly or too far in some particular direction from the mean. The healthy plant may, for our present purposes, be roughly likened to a properly balanced top spinning regularly and well, whereas the diseased one is lurch- 
ing here, or wobbling there, to the great danger of its stability. For we must recognize at the outset that disease is but variation in directions dangerous to the life of the plants. That the passage from health to disease is gradual and ill-defined in many cases will be readily seen." Excluding the injury from insect pests, the diseases of truck crops may be considered as follows:

\section{A. Diseases of a Mechanical Nature}

Diseases brought about by mechanical injuries are very numerous and varied. Truck crops such as spinach, lettuce, etc., are cultivated for their edible tender parts. It is not strange that such crops should be susceptible to injuries of a mechanical nature.

\section{WIND STORMS}

Wind storms are often the cause of great losses to the trucker. This is especially the case in soil districts of a sandy nature. Strong winds cause the sand to be thrown about in the field with considerable force and velocity. The small sand particles blown violently on plants cut the foliage and not infrequently the fruit too. Tomatoes, watermelons, eggplants, in fact, all the tender crops, suffer greatly from sand or dust storms. Besides this form of injury, dust or sand storms carry off large quantities of fertilizer. Moreover, sick particles of soils may be carried by the wind from farm to farm, and in this 


\section{Causes of Diseases in Crops}

way soil diseases be spread. Wind storms cannot well be prevented. Perhaps the best safeguard is never to allow bare spaces in the field, and to have the soil thoroughly covered with vegetation. In windy localities, crops should be planted closer than is generally the custom.

\section{RAINSTORMS}

Heavy rains when pounding on tender plants may cause considerable damage in tearing tender foliage. Another indirect injury is the pounding and packing of the soil. This shuts out the free circulation of air and is bound to interfere with the normal metabolism of the plant. Heavy rains by pounding on the soil, splash mud and sand on all parts of the plant. This encourages infection of numerous diseases, and reduces the shipping and market value of the crop.

Besides rainstorms, frequent showers are detrimental to truck crops cultivated for their fruit or seed. They prevent pollination by insects. There is, of course, no feasible method of preventing unfavorable weather conditions. Deep plowing may encourage the absorption of all the rain and prevent baking. Windbreaks too may protect crops from severe storms.

\section{HAILSTORMS}

The injury to truck crops from this source is considerable. It results in deep bruises or cuts in stem, 
foliage, and fruit. The writer knows of cases where large areas of tomatoes, cantaloupes, and waterm ilons were totally ruined by hail. With the sweet potato hail does not always ruin the crop, but it retards it. The foliage and vines dry up as a result of the mechanical cutting and bruising from hail, but new growth soon follows. Even when hail does not ruin a crop, there is danger of infection at the place of each cut or bruise (fig. II). If the affected crop is valuable and shows promise of recovery, it should be sprayed with a good standard fungicide.

\section{LIGHTNING INJURY}

Injuries to trees from lightning are familiar to all. Jones and Gilbert ${ }^{\mathbf{I}}$ record an interesting case of lightning injury to potato plants. The injury is noticed in round spots in the field (fig. I2 a), the spots varying from ten to twenty feet in diameter. The potato tops appear broken and disheveled and upon drying off, within twenty-four hours they wilt and die. In examining the individual plant we find that the stem collapses and the top falls over, the stem browns and shrivels faster above, and less rapidly below this point. The pith at this region browns and collapses, leaving a hollow stem, but without any softening such as usually occurs with blackleg. No evidence of splitting or mechanical rupture of the stem has been observed. Lightning injury may occur when thunderstorms are very

× Jones, L. R., and Gilbert, W. W., Phytopath. 5 : 94-IoI, I9I 5. 


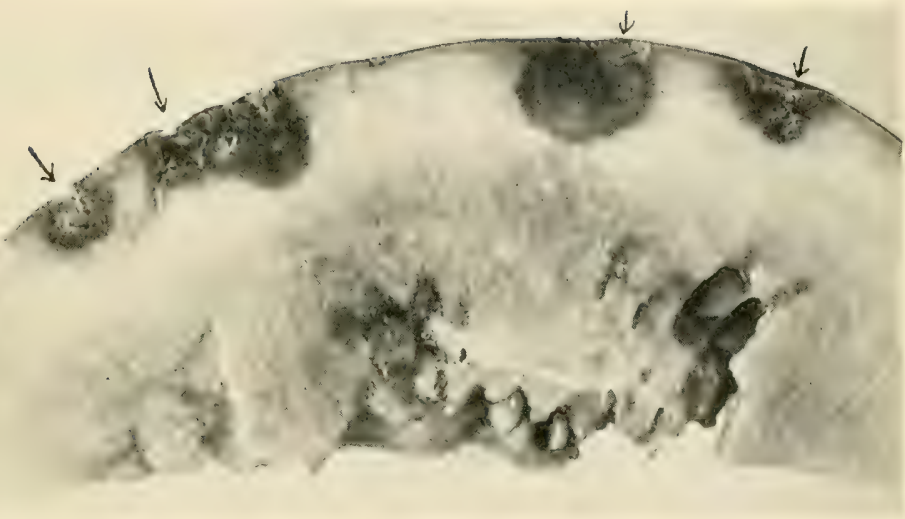

Fig. il. Watermelon Slice Showing Hail Injury. Arrows In. dicate Place of Injury Followed by a Rotting Due to the SECONDARY Invasion OF SEMI-PARASITIC Fungi. 



\section{Causes of Diseases in Crops}

prevalent, usually during July. It may be found in sandy as well as clay loam fields, and the contour of the land seems to have no influencing effect. The following is Jones and Gilbert's explanation of the phenomenon: "When an electric storm breaks suddenly following a period of dry weather and the first rain wets the topsoil, there remains a layer of dry earth between this wet surface and the moist soil underneath, which is a poor conductor of electricity. When the lightning strikes the wet surface spot, it disperses in all directions, horizontally and then downwards into the earth, following lines of least resistance. The plant stems and roots with their abundant water content are better conductors than the layer of dry soil just mentioned, and so the electric current passes through them. The tissues may thus be variously injured or killed, depending upon the amount of current passing through them."

\section{FROST INJURY}

The greatest profits in trucking are generally made when crops are available for the early market. This means that truckers must be prepared to meet losses directly due to spells of frost. Not all truck crops are equally sensitive to frost, but we have as yet no crops which are absolutely frost proof. When the temperature at which condensation of moisture in the air takes place is below freezing, ice may form in the intercellular spaces, and the plant is then destroyed, without any frost 
deposited on the outside. Equal injury results when the exterior of the plant is at or below the freezing point, and frost is deposited on the plant. It is supposed that in this case the cold does not freeze the water in the cells, but draws it out. The more sap a plant has, the faster it is withdrawn. In this case, then, the plant dies not from cold but from drought.

Frost conditions are determined by various factors. Trucking lands situated near large bodies of water generally enjoy immunity from frost not found in inland localities. Tender crops growing on low hills or on greatly sloping hillsides, somewhat above the valley floor, are also well protected from frost. Lowlands, particularly those which have no outlet through which the cold air may drain off, are not suited for early trucking because of the danger from frost. Lands which are properly drained and cultivated will not only produce larger yields, but will also be protected from frost.

How to Predict Frost. There are usually several signs which the trucker may use as a warning of the approach of frost. Frost should be looked for after unusual warm spells in the spring. The state of the sky is also an indication. Frost is not likely to occur when the sky is overcast because the heat given off by the earth at night does not easily penetrate the clouds and is therefore retained in the air below. On the other hand, during clear nights, the earth's heat readily escapes and this is likely to result in a disastrous drop of temperature. Frost is brought 


\section{Causes of Diseases in Crops}

about also by a sudden change from wind to calmness of air. Winds prevent frost formation because they prevent the accumulation of the colder air at the surface. The trend of temperature is also an important consideration. A temperature of forty degrees at about 6 P. M. with a clear sky may indicate the approach of frost. A fall of temperature of two degrees an hour in the afternoon would also indicate the approach of frost. If the air pressure is increasing rapidly, as indicated by a rapid rise in the barometer, frost may be approaching. A change in pressure usually precedes, by a short interval, the change in direction of wind.

How to Prolect Crops from Frost. Crops may be protected from frost in two ways. (I) Artificial covering is an old practice widely used by truckers, and consists in protecting the plants by covering them with newspapers, carpets, sacks, straw, tar paper, or a mulch of soil. This, however, is applicable only to small gardens or to seed beds. On a large scale it is not practical because of the labor involved. (2) Smudging and heating consists in the burning of any combustible material capable of producing heavy smoke, such as moist straw or coal tar. Through smudging we prevent the escape of the earth's heat.

A better method consists in heating the air of the field by means of evenly distributed small fires generally supplied by ovens of various designs. The material used is wood, coal, or oil, the choice being determined by the local price and supply. With 
the warning from an alarm thermometer which rings a bell as the danger point in temperature is reached, the fires may be started. Smudging and heating are extensively used by orchardists. Truckers, however, have generally been slow to adopt this method.

\section{Drought INJURY}

By drought is meant a scarcity of water in the soil, affecting and preventing the normal life process of plants. Drought injury is variously indicated by different crops. With beans, for instance, the leaves lose their chlorophyll, and the entire plant becomes whitish, brittle, dead, and dry. With cabbage, on the other hand, the tips of the lower leaves first bleach, then wilt, eventually drying and falling off. With sweet corn the plants shrivel and bend over (fig. I2 b). The amount of injury from drought is proportional to the scarcity of the water in the soil. The only remedy for drought is, of course, irrigation. This is especially true for arid and semi-arid regions. Trucking is never safe unless provisions are made for proper irrigation.

\section{SMOKE INJURY}

As a rule, trucking centers are situated near large cities, which are usually centers for industrial production and manufacture. Truckers who are situated nearest to manufacturing plants are apt to lose in crops from the effect of smoke and deleterious gases that escape from the furnaces into the air. 

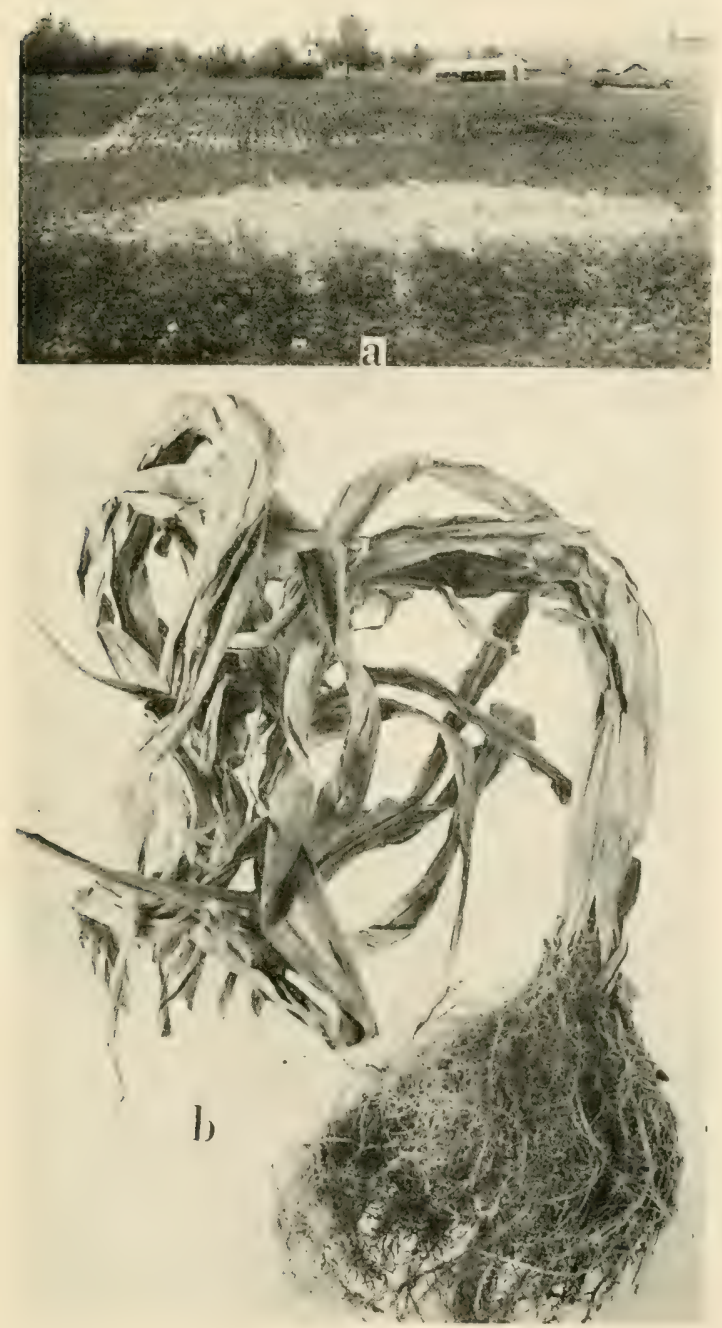

Fig. I2.

a. Lightning injury, showing hilled spot in potato field, $b$ drought injury of sweet corn ( $l$, after Jones and (iibert). 

The sources of smoke may be classified into three divisions: (I) Smoke from large buildings or from manufacturing plants. (2) Smoke from locomotives. (3) Smoke from chimneys of dwellinghouses. Smoke is generally produced because of improper furnace construction, improper draft, overloaded boiler, insufficient air space, insufficient air supply to boiler room, and finally carelessness of operation.

Smoke contains large quantities of carbon dioxide, steam, and sulphur dioxide, besides its characteristic soot. The latter consists of carbon, tar, and mineral matter mixed with small quantities of sulphur, arsenic, and nitrogen compounds which are of an acid nature. Soot adheres to plants, especially to foliage, giving these a burned, contorted appearance. Another effect of soot and smoke is to close up the stomata or respiratory openings of the leaf, which results in asphyxiation. The effect of smoke on plants is loss of leaflets in case of compound leaves, and abnormal vegetation because of curling and distortion. Lesions and spots may be formed on the foliage as a result of the sulphur dioxide which is present in smoke. The spots are at first small, but soon enlarge and finally involve the whole leaf, which dries and becomes gray. Smoke injury, although of a mechanical nature, may also be considered from a physiological point of view. The after effect of smoke on plants resolves itself into a question of insufficient food supply and assimilation. This is indirectly brought about by diminished illumination, 
interference with the normal transpiration, and the reduction of leaf surface.

It seems that not all truck crops are equally subject to smoke injury. Potatoes seem to be very sensitive to its effect, while peas are the most resistant.

Methods of Control. There is as yet no definite method of control known. All that the trucker can do is to avoid the smoke belts. The greatest injury occurs in the line of the general direction of the winds. These areas therefore should be avoided. As far as possible, irrigation should be postponed during windy days. The injury from the smoke is greatest when the soil is wet. Truckers have a right to expect reimbursement in case of loss from smoke injury, when the offending factory is set up subsequent to the trucker's settlement in that place.

\section{B. Diseases Due to Physiological Causes}

In this class are included disturbances which are due to unfavorable conditions of nutrition. There are numerous diseases of plants which are brought about by lack of, or by an excess of, certain food elements in the soil. The effect is an interference with the proper life functions of plants.

\section{MALNUTRITION}

Caused by improper food supply.

Symptoms. The symptoms of malnutrition are not always the same. They differ somewhat with 



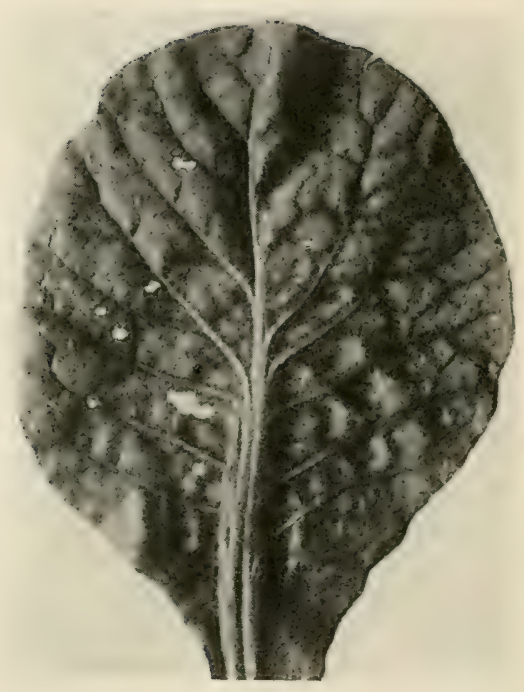

Fig. I3. Malnutrition, Showing a Cabbage Leaf Affected by the Disease. (After Harter.) 


\section{Causes of Diseases in Crops}

the crop, the nature of the soil, and the fertilizer applied. In malnutrition the symptoms to be looked for are retarded growth, change of color in the foliage, and root injury. Affected plants remain dwarfed at a time when maximum growth is expected. The color of the foliage turns lighter green, especially in the spaces between the veins (fig. I3) which become yellowish green to brown. Roots of such plants are poorly developed, and secondary roots or rootlets are often missing.

Causes of Malnutrition. The work of Stone ${ }^{\mathrm{I}}$ and Harter $^{2}$ and others seems to have established the fact that malnutrition cannot be attributed to the work of parasitic organisms. Stone cites instances where constant watering with liquid fertilizers or manure would cause malnutrition in cucumber plants. The same is also induced when pig and cow manure are mixed, or when manure is worked into a soil already well fertilized otherwise. Harter records cases of malnutrition brought about by an excess of acidity in the soil. In cabbage fields suffering from malnutrition, it often required from 3500 to 6000 pounds of lime to neutralize the excess of the soil acidity. This condition is apparently the result of intensive trucking and the heavy applications of chemical fertilizers which leave the soil acid. Sulphate of ammonia, muriate and sulphate of potash,

Stone, G. E., Massachusetts Agr. Expt. Sta., Ann. Rept., 5-13, I910.

${ }^{2}$ Harter, L. L., Virginia Truck Expt. Sta. Bul. I : 4-16, 1909 (Norfolk, Va.). 
and acid phosphate when used continuously will leave the soil in a very acid condition. On the other hand, nitrate of soda, carbonate of potash, and Thomas phosphate tend to make the soil alkaline.

Another important cause of malnutrition is the exhaustion of humus. This is a natural result where commercial fertilizers are used at the expense of any form of organic manure.

Methods of Controlling Malnutrition. From what has already been said, the trucker is the loser if he uses his fertilizer injudiciously. Not only is malnutrition favored by such a course, but the yields, too, are considerably reduced. For instance, with cabbage, larger yields are obtained when Iooo pounds of commercial fertilizers are used than from any higher application. Liming to neutralize the soil acidity will help control malnutrition. To overcome the humus deficiency of a soil the application of stable or green manure is recommended. The amount of manure to use will vary with the crop. The important thing to guard against is the excessive use of organic matter. For green manure, the iron cowpea is recommended. This variety is resistant to wilt, and fairly so to root knot. The best time to plow under green manure is generally in October when the plants approach maturity.

\section{BLOSSOM DROP}

This is another trouble which may be termed physiological, and the cause of which cannot be 


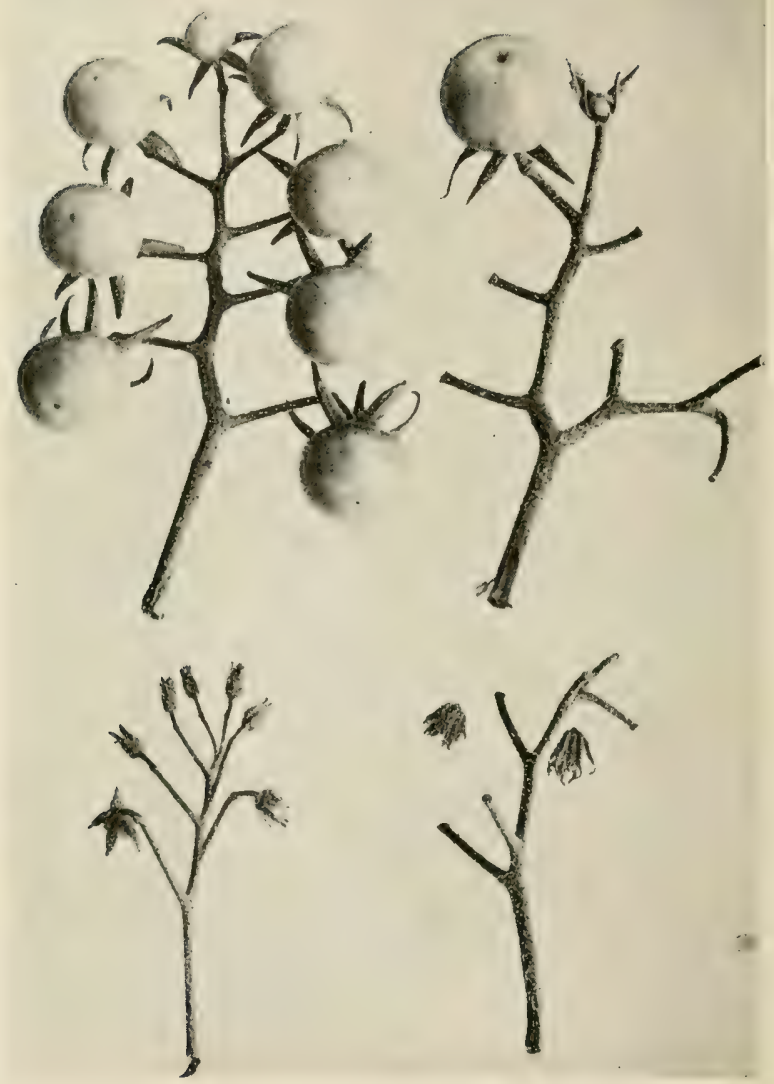

Fig. I4. Blossom Drop, Showing to the Left a Normal Bunch of Tomato Blossoms and Fruit, to the Right most of the Blossoms and Fruit Fallen OFF. 


\section{Causes of Diseases in Crops 83}

attributed to the work of parasitic organisms. It is often noticed on tomatoes (fig. I4) and beans. Various causes may lead to it. A period of warm weather accompanied by cool nights, or by sudden drops of temperature, will induce many truck crops to shed their blossoms. In this case truckers are helpless, for weather conditions are not controllable. Blossom drop may also be brought about when too much nitrogen is applied to the soil in the form of manure, hen manure especially. To overcome this, the fertilizer in the soil must be balanced by the addition of 600 pounds of acid phosphate and 150 pounds of muriate of potash per acre.

\section{Diseases of Unknown Origin}

\section{MOSAIC}

This trouble extends practically to all parts of the host except the roots. To the tomato grower the disease is very important, for it may reduce the yield of his crop by 50 per cent.

Symptoms. Mosaic is readily distinguishable by a yellow dotting or mottling of the leaf, presenting in some instances a beautiful mosaic structure (fig. I5), whence its name. Affected leaves linger for a time, but they eventually lose all of their chlorophyll. Another symptom is a curling of the leaves resembling the curling induced by green aphids, but in this case the insects have no association with it. The disease makes its appearance after the seedlings are 
from two to three weeks old, but more often when the plants have attained full growth. Often the trouble is so serious and the curling so pronounced that the plants thus affected cannot make any headway and remain dwarfed. An attempt is made by the curled plants to produce blossoms, but the latter, too, are distorted and abnormal. Frequently, however, the affected plants outgrow the disease entirely, and thus a distinct line of demarcation is observed between the previously diseased part and the healthy part of the new growth. In rare cases, affected plants seem to thrive in spite of the disease. Such plants should be selected for the purpose of breeding resistant strains.

Cause of Mosaic. The recent works of Allard and Freiberg ${ }^{2}$ have shown that the cause of mosaic is as yet a disputed question. Allard claims that mosaic is caused by an ultra-microscopic pathogen, that is, a parasitic organism which cannot be detected by our present technique in microscopy. Freiberg claims that the cause of mosaic is physiological. The following is a summary of the claims advanced by these two investigators.

\section{Allard}

I. The virus is not inhibited by concentrations of one part of formaldehyde in $100,200,400$, $600,800,1000,1200$, and 1500 parts of virus solution.

\section{Freiberg}

I. The virus is not inhibite 1 by formaldehyde.

x Allard, H. A., "Some properties of the virus of the mosaic disease of tobacco," Jour. Agr. Research, 6 : 649-674, 1916.

"Frciberg, G. W., "Studies in the mosaic diseases of plants," Ann. Missouri Bot. Gard., 4 : 175-232, 1917. 


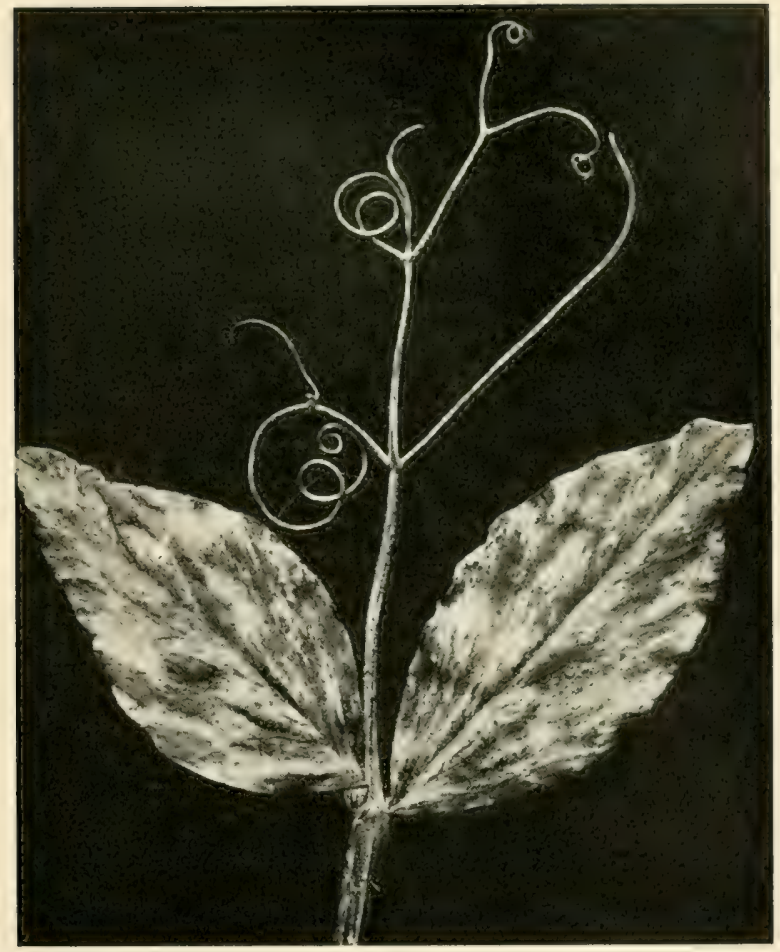

Fig. I5. Mosaic, Showing Affected Pea Leaf.

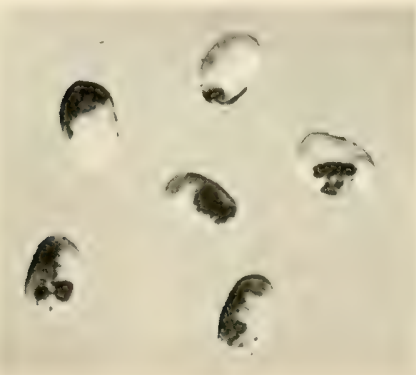

Fig. i6. Bean Seeds AfFected With Anthracnose, Colletotrichum lindemuthianum. 



\section{Causes of Diseases in Crops}

2. The virus is not inhibited by either chloroform, carbon tetrachloride, toluene, or acetone.

3. The virus is quickly killed at temperatures near the boiling point.

4. The virus is highly resistant to low temperatures at minus $180^{\circ} \mathrm{C}$. with liquid air and its infectious properties were not weakened.

5. The cause of mosaic is not an enzyme.

6. The virus is a specific particulate substance which is not found in healthy plants. Since this virus is highly infectious and is capable of increasing indefinitely within susceptible plants, there is every reason to believe that it is an ultra microscopic parasite of some kind.
2. Treatment with either chloroform, carbon tetrachioride, toluene, acetone or glycerine do not destroy the infectious properties.

2a. The infectious properties are destroyed by concentrations of alcohol which are destructive to enzymes.

3. The temperatures which destroy the infectious portions are the same as those which affect enzymes or hydrolyze some organic compounds.

4. Cooling has no more effect on the infectious properties than is exerted on any chemical compound, enzyme included.

5. Properties of the infective principle substantiate the view that the infectious substance is an enzyme and not a virus. This enzyme is not of the nature of the oxidases giving the guaiacum reaction.

6. The reproduction of the mosaic enzyme can be accounted for on purely physiological grounds, but the factors which originally induced its formation are still unknown. The continued production of the mosaic enzyme in inoculated plants is in accord with the fundamental principles of pathology and physiology.

Work of the future will no doubt establish the true cause of mosaic. 
Mode of Infection and Period of Incubation. Mosaic may be readily transmitted from plant to plant. The easiest way to prove this is to rub with the fingers a diseased plant, and then immediately rub a healthy plant. The disease will appear on the inoculated host in about ten days. In the field, insects act as carriers of mosaic. The truclier may prevent much of this trouble by proper spraying against sucking and biting insects.

\section{Diseases Due to Parasitic Bacteria or FUNGI}

We have already seen that certain classes of beneficial bacteria perform an important function in the soil. This, too, must be true for certain soil fungi. Not all microörganisms, however, are beneficial. But, fortunately for the trucker, only a small per cent. of bacteria and fungi are parasitic, and produce disease on plants. On page 4 a description was given of the nature and structure of bacteria. Before proceeding further it becomes necessary to familiarize ourselves with the nature of fungi.

Fungi. As already stated, these are low forms of plant life, some of which are beneficial, while others live as parasites on the higher green plants, the results of which may be considered as follows:

I. Actual death may result from the destruction of vital organs or tissues. 2. A crippling and dwarfing of plants due to the slow destruction of the root 


\section{Causes of Diseases in Crops}

system. 3. Destruction of leaf, flower, and fruit without disturbing the root system.

FACTORS WHICH FAVOR THE SPREAD OF FUNGOUS DISEASES

The amount of soil moisture may either protect or predispose a certain crop to fungous disease. For instance, in dry seasons and with a limited rainfall, truckers lose heavily from asparagus rust (Puccinia asparagi). In this case, the lack of soil moisture weakens the plants, making them therefore more susceptible to rust. An excess of water, such as is found in poorly drained soils, undoubtedly favors the spread of damping off, and the numerous root rots. Weather conditions exert a powerful influence on the prevalence or absence of plant diseases. Wet weather favors the spread of downy mildews (Peronosporaceæ). Late blight of potatoes (Phytophthora infestans), downy mildew of lima beans (Phytophthora phaseoli), and many other similar diseases, are really wet weather troubles.

\section{HOW PARASITIC ORGANISMS ARE DISSEMINATED}

Fungi may be carried from place to place as bits of mycelium, as spores, or as sclerotia. Fungi produce enormous numbers of spores, not all of which find their way to receptive healthy plants. Large numbers are destroyed by exposure to sunlight and air, others fall on crops upon which they are unable to 
thrive, while a relatively small proportion find ideal conditions on the proper hosts.

Wind. If we consider the microscopic minuteness of fungous spores we shall appreciate how easy it is for winds and air currents to become carriers of these spores.

Water. Water is another important agent which helps in carrying and disseminating fungous spores. The latter may beactually carried in streams from one territory to another, or by rain washing and splashing from plant to plant. The spores of Phytophthora infestans, for instance, the cause of late blight of Irish potatoes, are spread about from plant to plant by rain.

Seed-Bome Diseases. A large number of our truck crop diseases are introduced with the seed. This is often brought about unconsciously or through carelessness. Seeds and tubers may carry fungous pests as bits of mycelium in the interior tissue. An example of this is the bean anthracnose (Colletotrichum lindemuthianum) (fig. I6), which is carried as mycelium within the seed. The late blight of the Irish potato is carried in a similar way within the tubers. Seeds and tubers may also carry fungous pests as spores or sclerotia which adhere to the exterior of the seed coat. The smut of onions, for instance, is carried as spores on the onion seed. The Rhizoctonia disease of Irish potatoes is carried as sclerotia on the surface of the tuber. The same is true for numerous other diseases. The methods of prevention of seedborne diseases is taken up on page 99 .

Insects. Little do we realize as yct the importance 


\section{Causes of Discases in Crops}

of insects as carriers and disseminators of plant diseases. We are beconing increasingly aivare of the rôle which insects play in the carrying and disseninating of human and animal diseases. They are equally responsible in distributing plant diseases, acting as carriers of spores of parasitic fungi which may adhere to any part of their body. Insects both by feeding on plants or in searching for the nectar of the blossoms are likely to come in contact with diseased parts of plants. In this way thcir bodies may bccome coated with parasitic bacteria or spores of fungi, which are thus carried from plant to plant and from ficld to field. The striped cucumber beetle, for instance, is known to carry and to spread about the virus of cucumber mosaic, and the germ of cucumber wilt (Bacillus tracheiphilus). Likewise, the Colorado potato beetle is a carrier of the germ of the Southern blight (Bacillus solanacearumi) of tomato and potato. Noxious insects act not only as cirect carriers of spores of parasitic fungi and bacteria, but also induce diseases through the bites and wounds which they inflict on plants when feeding. It is therefore very essential that every effort which aims at controlling fungous pests should also take in consideration the control of noxious insects; see page 367 .

\section{E. Diseases Induced by Parasitic Flowering PlantS}

Fungi and bacteria, as we have seen, are low forms of plant life. These derive their food either from 
living green plants and are termed parasites, or from dead organic matter and are referred to as saprophytes. Some higher flowering plants, too, have lost the power of manufacturing their own food, and have degenerated to the extent of assuming a parasitic life. Of those which concern the trucker may be mentioned the dodder.

\section{DODDER (Cuscuta sp.)}

Dodders or love vines are a group of flowering plants which are closely related to the Convolvulus or Morning glory family. Dodders are peculiar in that they are destitute of the green coloring matter chlorophyll, and for this reason must lead a parasitic life. The plant obtains food by actually sending its own roots into the tissue of the attacked green plant.

The Parasite. When the dodder seed germinates it is at first able to support itself and it then consists mainly of a yellow, threadlike stem. This independent existence is maintained until the food in the seed is used up. By this time the young tendril-like plant attaches itself to its host (fig. $17 \mathrm{a}, \mathrm{b}$ ) and sends in suckers or feeders which penetrate the interior tissue. The attacked plant naturally becomes weakened and may even die as a result of being robbed of its food, which is taken up by the dodder. After reaching maturity, the parasite blossoms and forms seed in the usual way as any other flowering plant.

Methods of Control. Dodder is often introduced as seed mixed in with the seed which we buy. By care- 


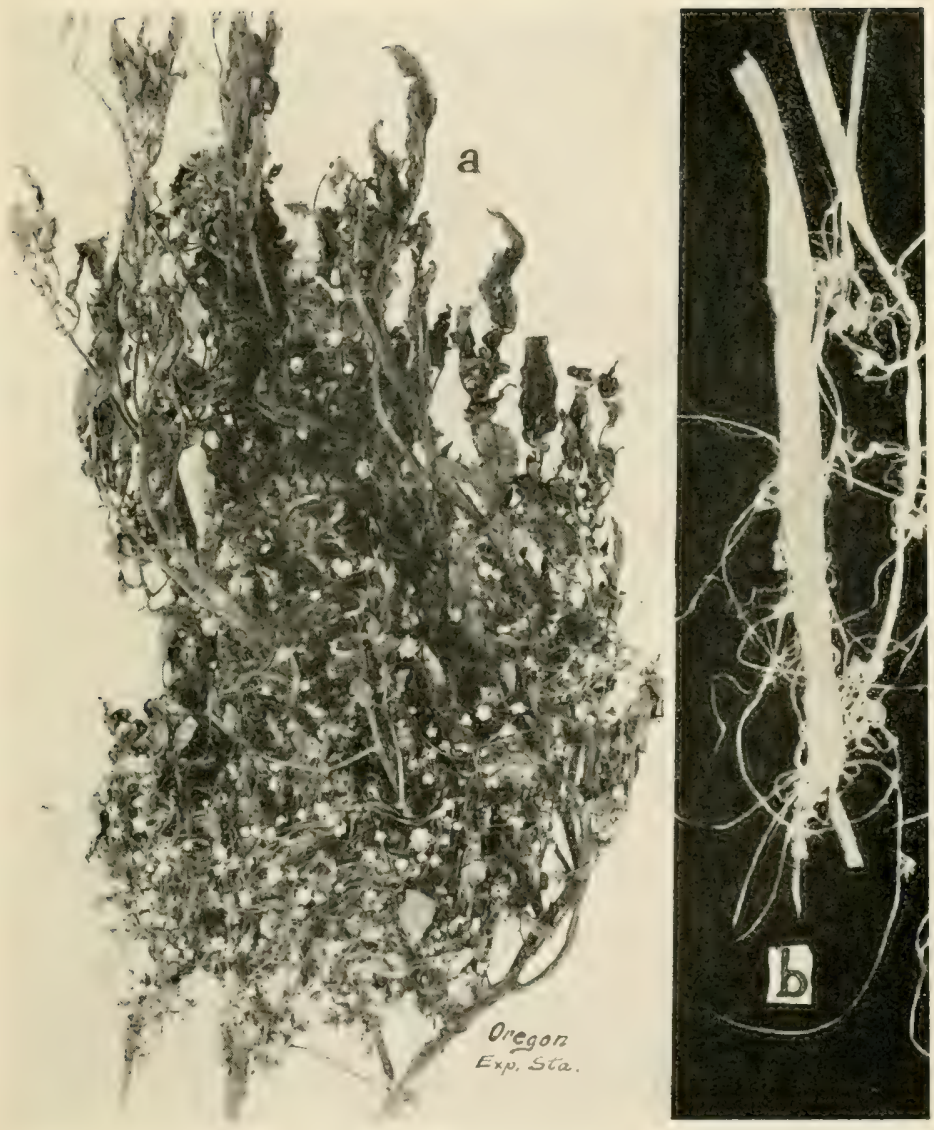

FIG, 17. DODDER.

a. Dodder on Tomato plant, b. dodder on onion leaves (after IIalsted). 



\section{Causes of Diseases in Crops 91}

ful sifting, the dodder seed may be separated out from the others. Infested areas should be burned over so that the dodder would be prevented from spreading and producing seed. In case of large infested spots in the field it may be necessary to use drastic measures. Each trucker, of course, could best decide for himself the cheapest and speediest way of eradicating the pest. 


\title{
CHAPTER VII
}

\author{
POOR SEED
}

IT has been briefly stated, page 88 , that seeds can be carriers of various diseases. The trucker may also experience difficulty in the germination of seeds which may be accounted for in many ways.

Age of Seed. In determining the causes of poor germination the age of the seed is to be considered, for after a certain age limit deterioration sets in. With many species of seeds there are apparently no external symptoms to indicate loss of vitality due to age. Each seed has its own age limit, generally determined by the character of the seed itself, i.e., whether oily or starchy or lacking in both. Thus the vitality of the minute seed of tobacco is perhaps eight times as great as that of the large oily seed of the castor bean.

Cultural Conditions. The viability of seed is also largely determined by the conditions under which the previous crop grew. The more vigorous the mother plant the more vitality will there be imparted to its offspring. The vigor of the previous crop depends on favorable climatic conditions, 


\section{Poor Seed}

care in cultivation and in fertilization. Old seed produced in a favorable scason may be preferred to fresh seed but of an inferior quality, produced in a bad season.

Weight and Color of Secd. As a rule, light weight seed is inferior to heavy seed of the same variety. The weight of the seed is influcnced by culture and by imperfect fertilization which results in minute and weak embryos. The weight of seed may be readily determined by the water method. Flace the seed in a tumbler filled with water. After shaking and letting it stand for a few minutes, the heary ones sink and the light ones float. Using this method, Stone ${ }^{\mathrm{I}}$ has shown that the heavy sinling seed give a higher per cent. of germination than the lighter (see Tables ro and II).

\section{TABLE IO}

Showing the Results of Seed Separation by the Wrater Method

\begin{tabular}{|c|c|c|c|}
\hline \multirow{2}{*}{ Name of Sced } & \multicolumn{2}{|c|}{ No. of Seeds Germinated } & \multirow{2}{*}{$\begin{array}{c}\text { Per Cent. of Increase in } \\
\text { Germination of Light } \\
\text { over Heavy Sced }\end{array}$} \\
\hline & Light & Heavy & \\
\hline $\begin{array}{l}\text { Lettuce } \\
\text { Onion } \\
\text { Onion } \\
\text { Lettuce } \\
\text { Onion } \\
\text { Average }\end{array}$ & $\begin{array}{r}68 \\
100 \\
38 \\
44 \\
50 \\
60\end{array}$ & $\begin{array}{r}90 \\
\mathbf{1 1 7} \\
85 \\
88 \\
58 \\
87\end{array}$ & $\begin{array}{r}32 . \\
17 . \\
142 . \\
100 . \\
17 . \\
61 .\end{array}$ \\
\hline
\end{tabular}

× Stone, G. E., Massachusetts Agr. Expt. Sta. Bul. I2 I : 3-14, 1908. 


\section{TABLE II}

Showing Results of Seed Separation by the Water Method on Germination and Growth of Seeds of Onions. Total of 400 Seeds Used

\begin{tabular}{ll|r|r|r|r}
\hline Per Cent. of Germination & $\begin{array}{r}\text { No. of } \\
\text { Plants }\end{array}$ & $\begin{array}{r}\text { Wi. of Plants } \\
\text { (grams) }\end{array}$ & $\begin{array}{r}\text { Per Cent.of Increase } \\
\text { of Heavy over } \\
\text { Light }\end{array}$ \\
\hline Heavy (sank) & 45.5 & 85 & Total & Average & \\
Light (floated) & 19.5 & $3^{8}$ & 5.9 & .155 & .213 \\
\hline
\end{tabular}

The color of the seed does not seem to have any influence on the germination. Darker colored seed is usually preferred to the lighter of the same variety. Color, however, depends largely on the degree of ripeness.

Storage Conditions. The vitality of seed is greatly influenced by storage conditions. The longest lived seed may be ruined by improper storage. The ideal conditions of storage, however, are not always those which favor germination. Seed should be cured or dried before storing. The drier it is the less likely it is to spoil, and the higher will be the temperature it can stand. When large quantities of seed are to be handled by the trucker, it is advisable to build a seed house. The seeds are best kept in strong paper or cloth bags and placed in tin cans. 
Seed Testing. In buying seed we must never take it for granted that the germination will be perfect. To make sure, a sample of the seed should be tested for germination and for purity. The simplest method is to sow a definite number of seeds in a shallow pan filled with moist sand.

The fact that a seed sprouts does not always mean a full stand in the field. Some weak seeds may germinate and then fail completely to make proper growth. Allowance must be made for this possibility where germination tests are made in the laboratory or at home. In testing for germination, the purity of the seed is also to be considered. As a rule there is no danger of truck seed introducing weeds, due to the fact that vegetable gardens are kept in a clean state of cultivation. The honest seedman may be trusted, too, to screen his seed carefully.

Effect of Fertilizer on Seed. With the hope of hastening germination, truckers apply various fertilizers to the seed bed. This practice cannot be too strongly discouraged, especially when muriate of potash and nitrate of soda are used. These two fertilizers when used in strengths of one per cent. or more inhibit the germination of the seed, whether applied directly or mixed with the soil. Phosphoric acid or lime when not used in excess seem to have no injurious action on germination. However, on no account should commercial fertilizers be brought into direct contact with the seed. The injury in this case is not apparent on the seed coat, but it will appear on the young tender sprouts. Although much remains to be 
investigated as to the effect of fertilizers on seed, the work of Hicks ${ }^{x}$ will serve as a guide to the trucker. Tables 12 and 13 , adapted from Hicks, clearly show the effect of chemical fertilizers on lettuce and radish seeds.

\section{TABLE I2}

Effect of Chemical Fertilizers on the Germination of Curled Simpson Lettuce Seed

\begin{tabular}{|c|c|c|c|c|}
\hline Fertilizer Used & How Applied & $\begin{array}{l}\text { First } \\
\text { Sprouts }\end{array}$ & $\begin{array}{c}\text { Per Cent. } \\
\text { Germinated } \\
\text { Fourth Day }\end{array}$ & $\begin{array}{l}\text { Per Cent. } \\
\text { Germinated } \\
\text { Twelfth Day }\end{array}$ \\
\hline Potash & $\begin{array}{l}\text { In the rows } \\
\text { Mixed with the soil }\end{array}$ & & No sprouts & No sprouts \\
\hline $\begin{array}{l}\text { Phosphoric } \\
\text { acid }\end{array}$ & $\begin{array}{l}\text { In the rows } \\
\text { Mixed with the soil }\end{array}$ & $\operatorname{May}_{62} 26$ & " 2.5 & $\begin{array}{c}2.5 \\
45.25\end{array}$ \\
\hline Nitrogen & $\begin{array}{l}\text { In the rows } \\
\text { Mixed with the soil }\end{array}$ & & No sprouts & $\mathrm{No}_{66}$ sprouts \\
\hline Lime & $\begin{array}{l}\text { In the rows } \\
\text { Mixed with the soil }\end{array}$ & $\begin{array}{l}\operatorname{May}_{66} 23 \\
22\end{array}$ & $\begin{array}{l}0.75 \\
4.00\end{array}$ & $\begin{array}{l}36.0 \\
39.75\end{array}$ \\
\hline $\begin{array}{l}\text { Mixed } \\
\text { fertilizer }\end{array}$ & $\begin{array}{l}\text { In the rows } \\
\text { Mixed with the soil }\end{array}$ & & No sprouts & No sprouts \\
\hline $\begin{array}{l}\text { Check, } \\
\text { no fertilizer }\end{array}$ & & May 2 I & 40.5 & 73.0 \\
\hline
\end{tabular}

\section{TABLE I3}

Effect of Chemical Fertilizers on the Germination of Breakfast Radish Seed

\begin{tabular}{l|l|c|c}
\hline \multicolumn{1}{c|}{ Fertiliser Used } & How Applied & First Sprouts & $\begin{array}{c}\text { Per Cent. of } \\
\text { Germination }\end{array}$ \\
\hline Potash & In the rows & No sprouts & $\mathbf{1 . 5}$ \\
Phosphoric acid & Mixed with the soil & " & I.5 \\
& In the rows & May 26 & I0.0 \\
& Inixed with the soil & "6 & 95.0
\end{tabular}

s Hicks, G. H., U. S. Department of Agr., Div. of Botany., Bul. $24: 5^{-15}, 1900$. 


\section{TABLE I3-(Continued)}

\begin{tabular}{|c|c|c|c|}
\hline Fertilizer Used & How Applied & First Sprouts & $\begin{array}{l}\text { Per Cent. of } \\
\text { Germination }\end{array}$ \\
\hline Nitrogen & $\begin{array}{l}\text { In the rows } \\
\text { Mixed with the soil }\end{array}$ & $\begin{array}{l}\text { May } 25 \\
26\end{array}$ & $\begin{array}{l}2.0 \\
6.5\end{array}$ \\
\hline Lime & $\begin{array}{l}\text { In the rows } \\
\text { Mixed with the soil }\end{array}$ & May 24 & $\begin{array}{l}37.5 \\
93.0\end{array}$ \\
\hline Mixed fertilizer & In the rows & May 25 & $34 \cdot 5$ \\
\hline Check, no fertilizer & Mixed with the soll & $\begin{array}{r}24 \\
\text { May } 24\end{array}$ & $\begin{array}{l}92.0 \\
96.5\end{array}$ \\
\hline
\end{tabular}

Treatment of SeEd against Insect Injury. In storage, the greatest enemies of the seed are weevils. These feed on any part of the seed lobes or embryo, thus impairing the germinating power. Weevils and other seed-feeding insects may be destroyed by fumigating the seed house, the bin, or the seed can, with carbon bisulphide used at the rate of three pounds to each thousand cubic feet of space. The carbon bisulphide is placed in a dish on top of the seed and allowed to evaporate. The fumes, which are heavier than air, fall to the bottom. The seed house or bin should be made air-tight for twenty-four hours during fumigation, and all fires including lighted pipes should be kept away for fear of an explosion.

A new and safer fumigant, para-dichlorobenzene, has recently been placed on the market. This is less poisonous when inhaled than carbon bisulphide. For each hundred cubic feet of space, twelve ounces of the former are dissolved in water. The liquid is soaked in rags which are placed in the air-tight seed house or bins to be fumigated. 
Seed beds are very often attacked by mole crickats. They may be kept out by a wire gauze floor. When the seed bed is made and the earth is dug out to a depth of one foot or more, a sheet of galvanized or copper mosquito netting is placed at the bottom, coming up at the sides, and projecting a couple of inches above ground. Ants, too, are often destructive to seed beds. They feed on the seed and carry it away to their nests. This is especially true with lettuce seed. Ants are best controlled by pouring half a pint of carbon bisulphide in each nest and immediately plugging its entrance.

Other Seed Treatment. Since seed may be a carrier of diseases, it is essential that we have a method of treatment capable of destroying the disease-producing organism in its initial stage. Exposing the seed in hot water at various degrees of temperature is effective in controlling certain smuts of grains. Treating the seed with sulphuric acid accelerates the germination of certain hard seed, destroying at the same time spores of fungi which may adhere to the exterior of the epidermis. Unfortunately there have been no extensive trials made of the effect of hot water and sulphuric acid, in accelerating the germination, and preventing the diseases which are carried on or within the seed of truck crops. However, the treatment of seed (especially tubers) with corrosive sublimate or formaldehyde is now extensively practiced. Where the soil in the bed is sterilized, seed treatment becomes necessary. With the exception of tubers or roots, seeds should preferably 


\section{Poor Seed}

be treated in formaldehyde. Manns ${ }^{x}$ recommends that before planting, all seed should be soaked for twenty minutes in a solution of one part of formaldehyde in 320 parts of water, i.e., I oz. of 40 per cent. formaldehyde in 22 gallons of water. The cost of this treatment is very small.

× Manns, T. F., Ohio Agr. Expt. Sta. Bul. 228 : 255-297, 191 I. 

PART III 



\section{CHAPTER VIII}

\section{SPECIFIC DISEASES OF TRUCK CROPS}

\section{FAMILY AGARICACE $\mathbb{E}$}

IN this important family of fungi we may consider the ordinary cultivated mushroom, Agaricus campestris. Few truckers as yet grow mushrooms on a large scale; but as food is getting scarce and its prices soaring higher, more attention will no doubt be paid to this important crop.

\section{DISEASES OF THE MUSHROOM (Agaricus campestris L.)}

Mushrooms are subject to few diseases. There are but two which need concern the grower.

\section{BACTERIAL Spot}

Caused by Pseudomonas fluorescens (F1.) Mig.

This disease, although serious, seems to be restricted as yet to the mushroom caves in St. Paul, Minnesota. The trouble was first described by Tolaas. Symptoms. It is characterized by an unsightly

r Tolaas, A. S., Phytopath. $5:$ 5I-53, I9I5. 
spotting of the caps, the severity of which differs with the cultivated varieties, especially the large white kinds. The spots, which do not extend deep into the flesh, appear while the mushroom is in the button stage, or when the cap is fully expanded. The spots are pale yellow, becoming a chocolate brown. Though the disease does not seem to reduce the yield, the market value of the spotted mushrooms is considerablv reduced.

The Organism. Pseudomonas fluorescens is a small rod rounded at both ends and motile by means of polar flagella. It is a facultative anærobe; produces no endospores, no gas, but liquifies gelatine. On beef and potato agar it produces a shiny grayish white growth accompanied by a greenish pigmentation, which diffuses in the substratum.

Control. Spraying the mushroom caps with solutions of benetol, sodium carbonate, or copper sulphate seems to have no beneficial effect. On the other hand, fumigating the beds with sulphur before planting the spawn insures the production later of a clean crop of mushrooms. The amount of sulphur to use is about one and a half pounds to each thousand cubic feet of cave space.

\section{The Mycogone Disease}

Caused by Mycogone perniciosa Mag.

The Mycogone is a very destructive mushroom disease. The exact amount of its distribution in the 



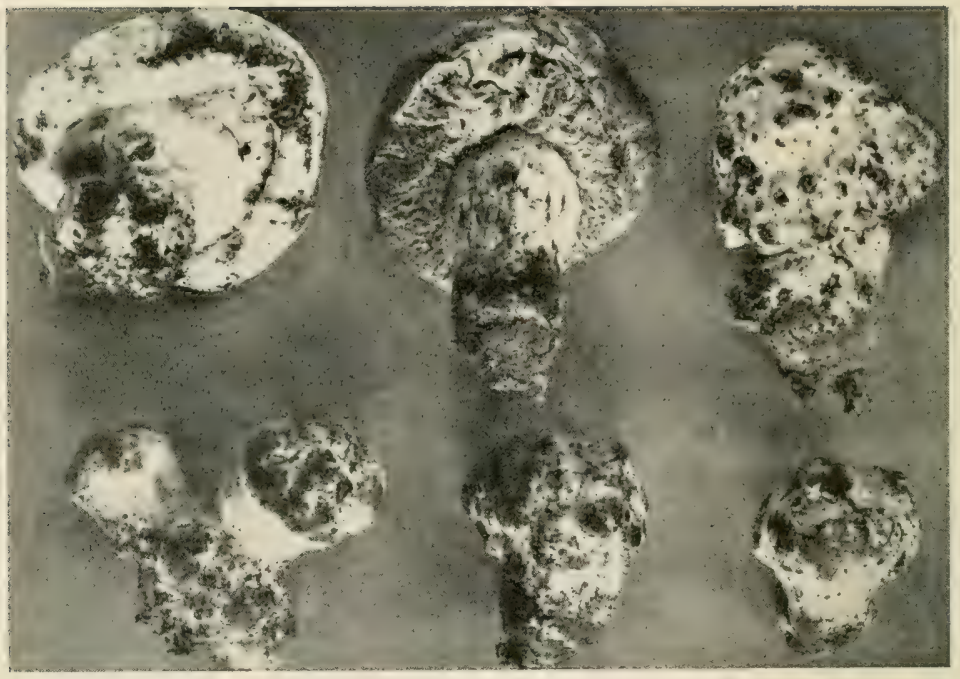

Fig. is. Mycogone Disease of Mushrooms. (After Veihmeyer.) 
United States is as yet unknown. However, if once introduced in a cave, it is likely to ruin the entire crop.

Symptoms. The symptoms of the disease are often various. The presence of the malady may be indicated by small tubercules on the cap and by a form of fluffy white growth on the gills, which interferes with their normal development (fig. I 8). The result is distorted caps and stipes and finally a general darkening and decay of the tissue. In severe cases monstrous soft masses with thick white fungus coatings are observed in houses in which the disease is very prevalent. In this case the affected plants have little resemblance to mushrooms. They decay rapidly, and emit a very disagreeable odor.

The Organism. The spores of Mycorone perniciosa are very characteristic. They consist of two cells, the upper spherical, rough, and covered with warts, the lower hyaline, smooth. Both cells possess a thick wall.

Control. According to Veihmeyer, ${ }^{\mathrm{T}}$ there are no evidences that tend to show that the Mycogone disease is carried with the spawn manufactured by the "tissue culture" method. It is very probable, however, that the disease was introduced into this country from France with imported virgin spawn collected at random from fields. The disease may be introduced into a new place with the manure and then spread quickly in a number of ways. Immediate temporary measures are essential for the control of this trouble. Diseased plants when first noticed

${ }^{x}$ Veihmeyer, F. J., U. S. Dept. of Agr. Buł. 127 : I-24, x914. 
should be pulled out and disposed of by fire. Allowing these infected plants to decay in the beds is a sure means of spreading the fungus broadcast in the cave. The gain from keeping the beds free from diseased specimens will more than compensate for the trouble. At the end of the season the beds should be thoroughly cleaned, the manure should be carried away to a distance where mushrooms will not be grown, although it may be used for garden purposes, since the Mycogone disease is only known to attack mushrooms. After the cave has been thoroughly cleaned out, it should be disinfected with the formaldehyde gas method. This is carried out as follows: For every thousand cubic feet of cave space use three pints of formaldehyde and twenty-three ounces of potassium permanganate. The potassium permanganate is placed in two or three earthen or wooden vessels, each having a capacity of one quart for every ounce of permanganate. When ready for the operation, the mushroom house is sprinkled with water, the potassium permanganate placed in the receptacles, the formaldehyde poured evenly over the permanganate, and the cave doors closed at once. They are kept closed for twenty-four hours and then opened to allow the formaldehyde fumes to escape. All lights must be kept away from the caves while they are being fumigated since formaldehyde gas explodes when coming in contact with fire. Mushroom houses thus treated may be thoroughly rid of the Mycogone disease, but care must be taken to prevent reinfection. 


\section{Family Agaricaceæ}

It is hardly necessary to add that all tools and wagons which were used in connection with the previously infected caves should be disinfected before being used again. All such tools and vehicles should be washed in a solution of one pint of formaldehyde in twenty gallons of water. In all these operations extreme care is necessary for the man who operates not to inhale any of the poisonous formaldehyde fumes. 


\section{CHAPTER IX}

\section{FAMILY ARALIACEAE}

TuE ginseng is the only plant in this family which is of economic importance. Although not exactly a truck crop, it is nevertheless grown by truckers. The distribution of the crop is limited. According to the Thirteenth Census of the United States, the area devoted to ginseng in 1909 was 23 acres, and the total crop valued at \$I5I,888. The 23 acres are distributed in the following States: New York, Wisconsin, Missouri, Ohio, Pennsylvania, and Michigan.

\section{DISEASES OF THE GINSENG (Panax quinquefolium)}

Ginseng is subject to numerous diseases, most of which may be kept in check.

\section{Damping off (Fig. I9 a), see Pythium}

\section{Downy Mildew}

Caused by Phytophthora caciorum (C. and L.) Sch.

Downy mildew is a destructive disease and is fcund wherever ginseng is grown. It attacks all parts of the plant, rendering it useless. 


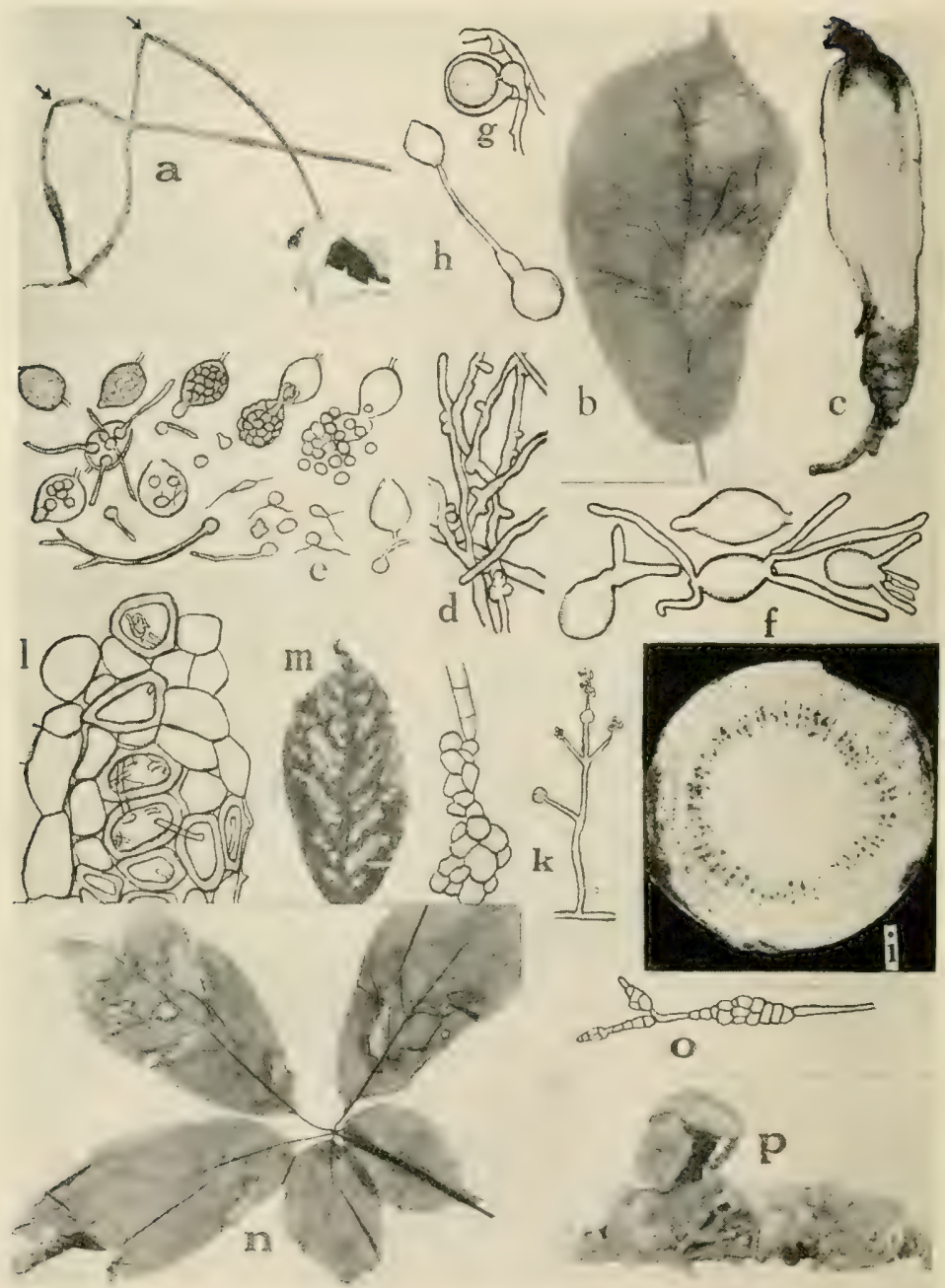

\section{Fig. I9. Ginseng Diseases.}

a. Damping off, $b .-c$. Phytophthora mildew on leaf and root, $d$. Phytophthora mycelium, $c$, germination of conidia by means of zoospores, $f$. germination of conidia by means of germ tubes, $g$. sexual fertilization of the female oogonium by the male anthericlium, $h$. prerminating oospore by means of a germ tube, $i$. cross section of a root infected with Acrostalagmus showing diseased condition of fibro-vascular bundles, $k$. fruiting stalks of Acrostalagmus and sclerotia of same, $l$. cross section of root to show presence of mycelium of Acrostalagmus in vascular bundles, $m$. papery leaf spot, $n$. Alternaria blight on leaf, $o$. Alternaria spore, $p$. black rot shorving fruiting cup of Sclerolinia panicis (. . e. f. $g .$, and $h$. after Rosenbaum, the other figures after Whetzel and Rosenbaum). 


\section{Family Araliaceæ}

Symptoms. The disease first attacks the petioles, resulting in the drooping of the leaflets. In severe cases, the leaf stalks are killed at the base where they join the stem. This causes the leaves to droop over the stem. The diseased areas usually become soft and slimy. On the leaves, the spots are dark green, watersoaked, and bent, soon becoming dry white in the center with a prominent dark green water-soaked margin (fig. I9 b). In wet weather, the disease attacks the stem, and from there works downward to the root causing it to decay (fig. I9 c).

The Organism. The mycelium (fig. I9 d) of Phytophthora cactorum somewhat resembles $P$. infestans, the cause of late blight of the Irish potato, but differs from it in producing an abundance of sexual or oospores (fig. I9 g) within the dead tissue. The oospores pass over the winter unaffected by cold weather. In the spring they germinate, each sending out a germ tube (fig. I9 $\mathrm{h}$ ) which later may bear from one to two conidia. These as claimed by Rosenbaum ${ }^{r}$ may germinate by means of a germ tube or by swarm spores. The conidia germinate in the same way (fig. I9 e and f).

Control. Downy mildew may be controlled by spraying with 3-3-50 Bordeaux. Diseased plants should be pulled out and destroyed by fire. Planting the roots deep in the soil will also protect them from rotting. This seems to prevent the working downward of the disease from the stem to the roots.

${ }^{2}$ Rosenbaum, J., New York (Cornell) Agr. Expt. Sta. Bul. 363: 65-106, 1915. 


\section{WHITE ROT}

Caused by Sclerotinia libertiana Fckl.

White rot, although fairly destructive, attacks only isolated individual plants. It is prevalent in New York, Ohio, Michigan, and Wisconsin. The same disease also attacks cucumbers and numerous other crops later mentioned.

Symptoms. The disease usually appears during continuous damp weather. It attacks the plant at its stem end near the soil line. The infected part becomes soft, watersoaked, bieached, and overrun by a white weft of mycelial growth on the surface of the epidermis. Later sclerotia or dark masses of fungal threads appear irregularly within the pith and on the surface of the diseased crown. Infected plants wilt, topple over, and collapse. For a description of the causal organisms, see lettuce, p. I43.

Control. Spraying will not control this disease. Whetzel and Rosenbaum ${ }^{\mathrm{I}}$ suggest that the soil be well drained, and that plenty of ventilation be given the shacks. The disease may also be eradicated in the same manner as prescribed for lettuce drop, p. $\mathbf{1 4 4}$.

\section{BLACK ROT}

\section{Caused by Sclerotinia panacis Rank.}

Black rot is not as prevalent as white rot above mentioned. The disease was named and described by Rankin. ${ }^{2}$

r Whetzel, H. H., and Rosenbaum, J., U. S. Dept. of Agr., Bur. of P1. Ind., Bul. 250 : 7-44, 1912.

2 Rankin, W. H., Phytopath. 2 : 28-3 I, I9r2. 


\section{Family Araliaceæ}

Symptoms. Black rot is apparently a root disease only. Roots dug from affected areas are coal black, with no rootlets, but with intact bud, which, however, is also blackened like the root. On the surface of the latter are found numerous sclerotia the size of a small pea. On cutting open a diseased root only the outer rind is found to be blackened, while the center remains white, spongy, and watery. The affected root does not soft rot, but becomes very bitter in taste. If left over in the soil for two seasons the root will turn black all through, shriveling and decaying. Black rot works only in cold weather of early spring or late fall. In structure Sclerotinia panacis greatly resembles $S$. libertiana (fig. I9 p).

Control. Remove the diseased plants and the surrounding healthy ones on a strip a foot wide. Drench the soil with a heavy application of one part commercial formaldehyde in 50 parts of water-about I gallon per sq. ft.

\section{Fiber Rot (RUST)}

Caused by Thielavia basicola (B. and Br.) Zopf.

Symptoms. The manifestations of fiber rot depend largely on the age of the root and the part attacked. With seedlings and in dry weather the leaves lose their dark green color, become pale, tinting into shades of red, and finally the leaflets wither and the stems wilt. Often the leaves of infected seedlings take on a purple bronze color. In wet weather the 
wilting is more sudden, and the stems bend into a curve. In this case affected seedlings seem to preserve their natural green color. The disease is confined to the root fibers, which turn rusty brown or black. In severe cases, all that is left is a charred stub. The affected tissue is dry, although several soft rots may follow the primary injury. For a description of the causal organism see garden pea, p. 275.

Control. For seed beds the soil should be treated with steam or formaldehyde as described in pages 53-59. For large beds the application of acid phosphate at the rate of one thousand pounds per acre will be found beneficial. The treatment, to be effective, must be given to soils not too allaline. Where the soil is strongly alkaline, heavier quantities of acid phosphate should be applied, so that the treated soil may become distinctly acid.

\section{Stem Anthracnose}

Caused by Vermicularia dematium (P.) Fr.

Symptoms. Anthracnose is apparently a seedling disease of little importance. It appears as numerous black spots on the stems of the young plants. These enlarge and very frequently end by girdling and killing the entire stem.

Control. The disease may be controlled by spraying with Bordeaux mixture as soon as the plants are about three weeks old. Spraying should be repeated every two to three weeks until about August Ist. 


\section{Leaf Anthracnose}

Caused by Pestalozzia funerea Desm.

Symptoms. This malady attacks the base of the leaves and flower stalks. It results in an early drop of the foliage which also indirectly affects the roots. Spraying with Bordeatux is said to control this trouble.

\section{Acrostalagmus Wilt}

Caused by Acrostalagmus panax Ran.

This wilt seems to be destructive only in the spring of the year. It is prevalent wherever ginseng is growing.

Symptoms. The first evidence of the disease is a slow drying and wilting of isolated plants here and there in the field. At first the leaves droop, suggesting a lack of water in the soil. This, however, is not the case. Outwardly the roots of affected plants appear sound, but on cutting open one of these the fibrovascular bundles will be found to be yellowed, indicating the presence of the fungus within (fig. $19 \mathrm{i}$ and 1). The spores of the fungus are very minute and are formed on slender branched stalks (fig. $19 \mathrm{k}$ ) which appear on the surface of such decayed stems or roots. The fungus also produces sclerotial like bodies (fig. I9 $\mathrm{k}$ ) which apparently serve in tiding it over unfavorable weather conditions. The fungus has been identified by Rankin ${ }^{x}$ as Acrostalagmus panax. So

I Rankin, W. H., Spec. Crops. U. S., 9 : 349, 1910, 
far as is known, no definite method of control can be recommended. The use of healthy roots should be depended upon. Wherever possible soil sterilization with steam or formaldehyde is also recommended.

\section{Alternaria Blight}

Caused by Alternaria panax Whet.

Blight is perhaps the most common of all ginseng diseases. It is found practically wherever this crop is grown.

Symptoms. The disease at first manifests itself as dark brown spots on one side of the stem. Often the spots work in deep and cause the stem to rot and break at the point of the lesion. On the leaves, blight appears as watersoaked spots. These gradually dry out, becoming thin and papery with a distinct rusty brown border (fig. 19 n). The disease may also attack the leaflets at the point of attachment to the leaf stalk. This generally causes a dropping and dying of the leaflets. Later a velvety brown cover appears on the dead tissue which consists of the spores of the fungus. Frequently the seed heads are also infected.

The Organism. The mycelium of Alternaria panax is brown, septate. The conidiophores are erect, brown, septate, irregular at the tips, and tufted. The conidia are brown, borne in chains, and typical of Alternaria (fig. I9 s).

Control. Blight may be effectively kept in check by spraying with a 3-3-50 Bordeaux mixture. 


\section{Family Araliaceæ}

Strong solutions will not injure the plants but are unnecessary.

\section{Root Knot, see Nematode \\ PAPery Leaf Spot}

Caused by drought.

Symptoms. The trouble appears as thin, papery whitish to yellowish, transparent spots between the veins and along the margins of the leaves. This spotting is often mistaken for Bordeaux injury or for Alternaria blight.

Cause. Papery leaf spot is brought about by a lack of sufficient moisture in the soil. Drought, large tree roots in the beds, or insufficient shading may deprive the plants of the amount of soil moisture which they require. Control measures should consist in eliminating as far as possible those factors which are conducive to drought.

\section{BORDEAUX INJURY}

This form of injury is brought about when spraying with Bordeaux mixture which is followed by frost. Affected plants appear scalded, soft rot, and finally they dry and become papery (fig. $19 \mathrm{~m}$ ). As a precaution plants should not be sprayed during periods when frost is predicted. 


\section{CHAPTER $X$}

\section{FAMILY CHENOPODIACEÆ}

THIs family comprises the beet, chard, spinach, and the Strawberry Blite. The latter is not generally known to American truckers. In England it is cultivated as a pot herb. The first three, however, are extensively grown in home gardens on a small scale, or in trucking on a large scale for market. According to the Thirteenth Census of the United States the 1909 area in beets was 3202 acres, New York leading with 834 acres to her credit. The States which follow according to rank are: Massachusetts, California, Louisiana, Illinois, Pennsylvania, New Jersey, and Nichigan. The remaining States each devote a very limited acreage to beets and are hence omitted. The area devoted to spinach in the United States in 1909 was 6668 acres. Of theleading States in the production of this crop may be especially mentioned Virginia with $305 \mathrm{~S}$ acres. The other spinach States are classified according to rank as follows: Maryland, New York, New Jersey, Massachusetts, Illinois, and Pennsylvania. The money value in the United States of the beet crop in 1909 was $\$ 352,6,6$ and of the spinach crop $\$ 817,069$. 


\section{Family Chenopodiaceæ}

We have no available statistics of the money losses to beets and spinach from the various diseases about to be mentioned.

\section{DISEASES OF THE BEET (Beta vulgaris)}

Beets are subject to numerous diseases, some of which are of great economic importance, while others are insignificant and need not be feared by the trucker or gardener.

\section{WATER-CORE SPOTS}

\section{Cause unknown.}

Arthur ${ }^{\mathrm{I}}$ has described a disease of beets which he named water-core spots.

Symptoms. The disease is characterized by well defined spots in the interior of the root. These spots greatly resemble the water-core spots of the apple. The spots generally occur between the fibrous rings. They are sharply defined and do not grade into the adjoining tissues. The spots range from a pin-head to half an inch in size, and resemble a pea in shape. Sometimes there are but one or two spots in the root, but more generally several are present. The disease does not seem to be of any great cconomic importance, and it is not likely that any financial losses will be attributed to it.

${ }^{2}$ Arthur, J. C., Indiana Agr. Expt. Sta. Bul. 39, vol. 3 : 54-62, I892. 
SoFT RoT

Caused by Bacterium teutlium Met.

This disease was originally described by Metcalf. ${ }^{x}$ It is not known whether the garden beet is seriously affected by it. The trouble, however, is of economic importance where sugar beets are grown extensively.

Symptoms. The disease in its initial stage is characterized by a soft rot at the lower portion of the root. At this stage the crown and leaves remain normal, but later the outer leaves die and fall off. The disease is primarily a root trouble; the decayed tissue is soft, yellowish gray, and contains a sour smelling liquid which exudes at the least pressure. It is most prevalent in wet and poorly drained lands. The cause of soft rot is a bacterial organism, Bacterium teutlium.

Control. Since the disease works on the root underground it is clear that no exterior treatment will be effective. Thorough drainage, careful cultivation, and crop rotation are the only methods of control known.

\section{Crown Gall}

Caused by Pseudomonas tumefaciens Sm. and Town.

Crown gall is a very important disease because of its cosmopolitan nature. It prevails widely and attacks a large number of hosts.

x Metcalf, Haven, Nebraska Agr. Expt. Sta. I7th Ann. Rept.: 69I 2 , 1904. 



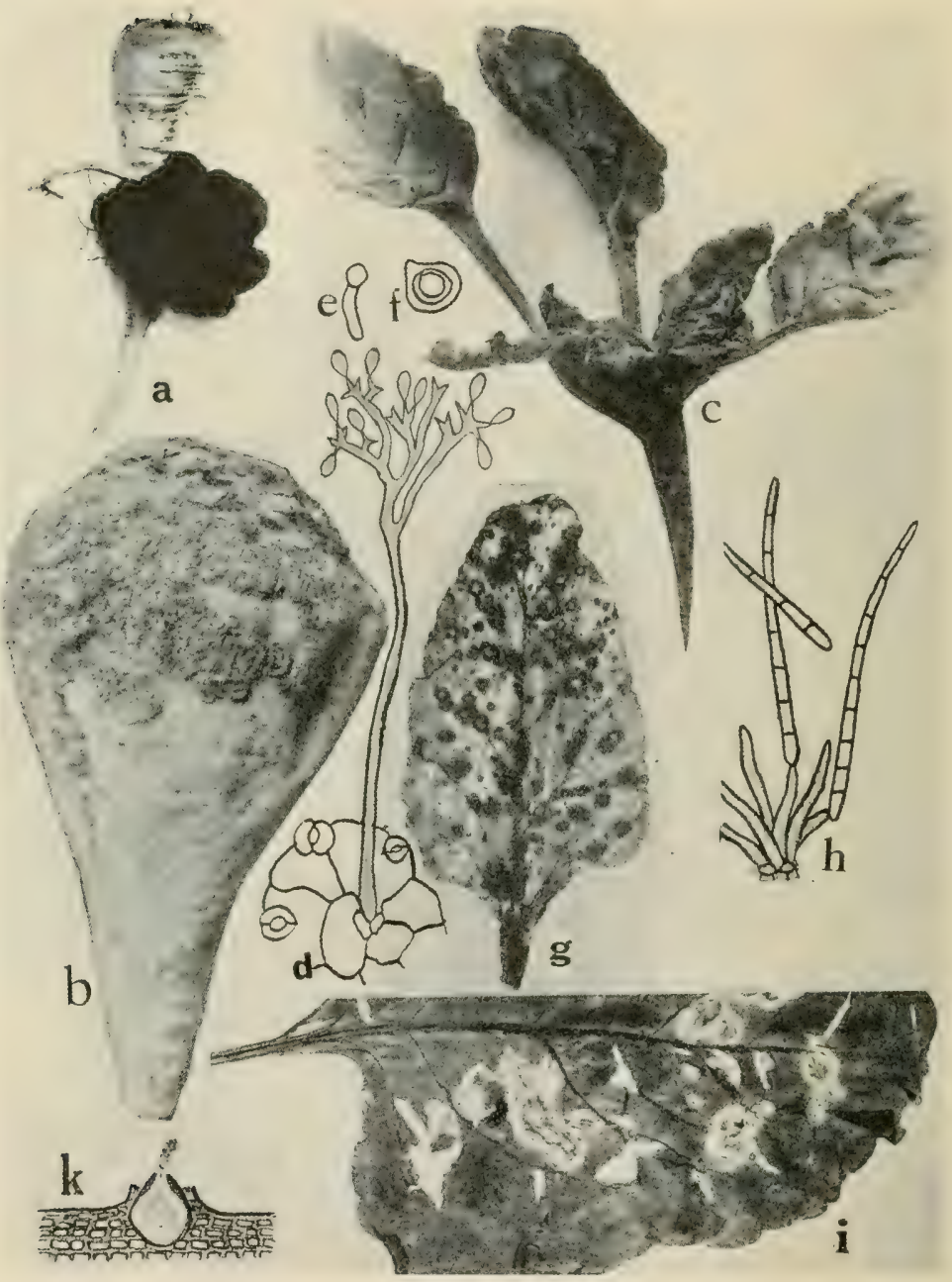

Fig. 20. Beet Diseases.

$a$. Crown gall, $b$. scab, $c$. downy mildew, $d$. Conidiophore of Peronospora schachtii arising from a stomate of an infected beet leaf, $e$. germinating zoospore of $P$. schachtii, $f$. oospore of $P$. schachti $i, g$. Cercospora leaf spot (after Halsted), $h$. conidiophore and conidia of Cercospora beticola (after Duggar), $i$. Phoma leaf spot (after Pool and McKay), $k$. pycnidium of Phoma beta (after T. Johnson) (d.-f. after Prillieux). 


\section{Family Chenopodiaceæ}

Symptoms. The disease does not usually manifest itself until the roots are nearly half grown. Abnormal outgrowths or galls (fig. 20 a) appear which vary in size from that of a garden pea to nearly two inches in diameter, depending on the severity of the attack. The galls are usually attached to the beet by a narrow string. In light cases of infection there may be but one gall on the root; in severe cases, however, the roots may be covered with numerous galls.

The Organism. The cause of crown gall is a bacterial organism, Pseudomonas tumefaciens Sm. and Town. It is a short rod, multiplying by fission, which moves about by means of polar flagella. On agar or gelatine it forms small round white colonies. Under unfavorable conditions it readily develops involution forms; in pure culture the organism is short lived. $P$. tumefaciens lives over in the soil from year to year.

Control. Although crown gall is known to attack a large number of plants, it has never been found as a parasite on grain crops. Gardens or fields which refuse to grow beets because of the disease, should be given a rest for at least three years by planting sweet corn instead. According to Dr. Smith ${ }^{\mathrm{I}}$ the following truck crops are susceptible to crown gall: Tomato, potato, cabbage, beet, radish, and salsify. In infected fields, these crops should be left out when planning a rotation which is aimed at starving out the organism in the soil.

${ }^{x}$ Smith, E. F., et. al., "Crown Gall of Plants," U. S. Dept. Agr., Bur. Pl. Ind., Bul. 213 : I3-200, I91 I. 


\section{TUBERCULOSIS}

Caused by Pseudomonas beticola Ew. Sm.

Tuberculosis differs from the crown gall by the formation of small tubercules on the root. The part of the root nearest to the tubercule is brown and watersoaked and broken into hollow cavities. The diseased tissue is mucilaginous and stringy when touched.

The Organism. Tuberculosis is induced by an organism, Pseudomonas beticola. In pure culture of agar the colonies are circular, smooth or wrinkled, and in color are yeilow. The organism is rod shaped, single or in pairs, and moves about by means of polar flagella.

Control. The cisease, so far as is known, does not seem to be of any economic importance. Diseased material shonld be destroyed by fire and the infected soil soaked with formaldehyde made up of one pint of the chemical in twenty gallons of water and applied at the rate of one gallon of the solution to each square foot of space. The organism seems able to gain entrance only through wounds. Care is therefore necessary to prevent cutting or bruising the roots during cultivation or at harvesting.

\section{ScAB}

\section{Caused by Actinomyces chromogenus Gasp.}

Scab on beets is the same as the scab of the Irish potato. The disease is of the greatest economic im- 


\section{Family Chenopodiacea}

portance in localities where potatoes suffer heavily from the disease.

Symptoms. The symptoms of the disease on beets (fig. $20 \mathrm{~b}$ ) do not differ much from those of the Irish potato (see p. 317). Occasionally, the scabs which arise before the beet is full grown disappear entirely, leaving merely a small scar. This is somewhat sunken and has a definite outline. In normal cases of infection, the scabby areas on the beet are greater in area, and thicker; the corky layer of the spots decidedly bulging out. Immediately below the scabby areas the tissue is a discolored reddish brown.

The Organism. The cause of beet scab is the same as that of the scab of the white potato (see p. 3I7). The parasite is a soil organism, and thrives best under alkali conditions.

Control. Beets should not grow where Irish potatoes, carrots, or radish are known to suffer from the same disease. Lime and fertilizers which tend to make the soil alkaline should be avoided.

\section{ROOT TUMOR}

Caused by Urophlyctis leproides (P. Mag.) Trab.

This trouble fortunately is as yet unimportant in the United States. The disease is characterized by the formation of nodules or outgrowths often the size of a walnut on the rootlets or leaves. The fleshy root itself is seldom attacked. The tissue of the tumors contains numerous cysts or spore-bearing cells. 
Control. All infected plants must be removed or destroyed. To be successful this must be done early enough before the winter spores of the fungus are liberated in the soil.

\section{DAMPING OFF AND RoOT RoT}

\section{Caused by Pythium de Baryanum Hess.}

Symptoms. Damping off of the seedlings just as they emerge from the ground is often a common trouble under poor cultural conditions. The young seedlings topple over and die in the characteristic way so familiar to truckers. The greatest damage occurs after heavy rains when a hard crust is formed on the surface preventing the seedlings from emerging normally. On old and mature roots, Pythium de Baryanum may cause a rot. According to Clinton, ${ }^{\mathrm{r}}$ the disease is found to be severe on mangels. A peculiarity of the rot is that it seldom starts at the top of the crown. The latter appears to be perfectly healthy, although the leaves turn yellow, indicating a diseased condition further down. Rotted roots are found to be overrun by a varied flora, although Pythium de Baryanum is the original cause of the trouble. For a further description of the organism see p. 43 .

Control. The disease is more prevalent during wet weather, and in heavy soils which are poorly drained. Thorough drainage of the land and careful cultiva-

× Clinton, G. P., Connecticut Agr. Expt. Sta. 39th. Ann. Rept.: $433-436$, I9I 5 . 


\section{Family Chenopodiaceæ}

tion will greatly help to control the rot on the mature roots. To prevent seedlings from damping off care should be taken that no hard crust be allowed to form on the soil. After a rain the soil should be worked as soon as possible.

\section{WHITE RUST}

Caused by Cystopus bliti (Biv.) Lev.

This disease is of little economic importance as far as the trucker is concerned. Its occurrence on beets has been reported but once by Pammel. ${ }^{\mathrm{r}}$ In appearance, infected leaves show white raised pustules or sori on the under side. When the surface cover of the pustules bursts open a powdery mass of snowwhite spores is liberated. The same disease also attacks "pigweeds." Clean culture is recommended.

\section{Downy MiLdew}

\section{Caused by Peronospora schachtii Fckl.}

This disease, like white rust, is of little economic importance in the United States. The trouble, however, is very prevalent in Europe. The mildew attacks the young seedlings in grayish patches on the under side of the foliage. On older plants the mycelium of the causative fungus works downwards into the root where it is carried over winter (fig. 20c-f).

s Pammel, L. H., Iowa Agr. Expt. Sta. Bul. 15 :234-254, I891. 


\section{DROP}

\section{Caused by Sclerotinia libertiana Fckl.}

Drop on beets, which attacks young seedlings, but not older plants, is otherwise not very different from a similar trouble on lettuce. Clinton ${ }^{\mathrm{I}}$ reports a case of beet drop in an outdoor seed bed. The warm condition of the soil, soon after making the seed bed, was important in favoring the disease. Sterilizing the soil with formaldehyde, careful regulation of soil temperature and watering are methods to be observed in the control of the trouble.

\section{RusT}

Caused by Uromyces betce Kuhn.

This disease has been reported only on beets in California. In Europe it is especially common on the wild beet (Beta maritima).

The Organism. The cause of this rust is a fungus, Uromyces betce, the latter having three spore stages, all of which occur on the same host, but at different times of the year.

I. Spring or Cluster Cup Stage. This is seen as small, whitish, raised cups, grouped on a yellow spot. When opened, these cups emit a yellowish powder which is made up of large quantities of the yellow colored aecediospores. The latter germinate

${ }^{x}$ Clinton, G. P., Report of the Botanist for 1915, Connecticut Agr. Expt. Sta. 39th Ann. Rept. : 433-436, I9I5. 


\section{Family Chenopodiaceæ}

by means of a germ tube which enters the beet leaf again. 2. Uredo Stage. The result of infection from the aecediospores is manifested as raised small pustules which are thickly scattered over the leaf. When these burst open, uredo or summer spores are liberated. These are round, one celled, and spiny, and the cell wall is perforated at several places. 3. Teleutospore Stage. As soon as infection of the beet leaves takes place as a result of the penetration of the germinated uredospore infection, other darker pustules are formed. These when rupturing liberate the wintcr or teleutospores, which are one celled, thick walled, smooth, and darker in color. Their function is to carry the fungus over winter. The infection from the teleutospores the following spring again results in the cluster cup stage.

Control. It is doubtful if spraying will control the beet rust. The better way is to plow deeply under the affected leaves. This will prevent the germination of the teleutospores in the spring.

\section{LEAF Spot AND HEART Rot}

Caused by Phoma betce Frank.

This disease is more prevalent as a storage rot, although it also produces a leaf spot in the field. The trouble is as yet of little economir importance. It is not certain whether this rot is the same as that described by Halsted ${ }^{\mathrm{I}}$ as root rot of beet which he attributed to a species of Phyllosticta.

s Halsted, B. D., New Jersey Agr. Expt. Sta. Bul. 107 : 3-13, 1895. 
Symptoms. It is characterized by minute brownish spots on the leaves (fig. $20 \mathrm{i}$ and $\mathrm{k}$ ). On the roots it is manifested as a dry black rot extending deep in the interior. The outside of the root has a shrunken appearance which closely follows the seat of the interior rotting.

Control. In the field, the disease first starts in the seed bed. Spraying with 4-4-50 Bordeaux is recommended. Two applications may suffice. In the field, spraying has not as yet given promising results. Clean culture and rotation will eventually free a field from the disease.

The disease is introduced upon the seeds which frequently bear the fruiting bodies of the fungus. It has been shown that disinfection of the sced will prevent the carrying over of the disease.

\section{LEAF Spot}

Caused by Cercospora beticola Sacc.

There is perhaps no beet disease that is of greater economic importance than leaf spot. The trouble is well known to truckers and it seems to be found whereever beets can thrive.

Symptoms. The disease first makes its appearance on the leaves as tiny circular whitish spots. These gradually increase in size and assume a brownish color. The spots soon increase in numbers and involve the entire area of the leaf (fig. $20 \mathrm{~g}$ ), which becomes dry and brittle. Leaf spots attack the outer 
and older leaves. As the inner foliage advances in age, it becomes infected in turn. As serious as the disease may appear, it never kills the plant. The result, however, is noticeable on the roots, which are undersized and elongated instead of round. Leaf spot generally appears during a moist spell followed by a period of dry weather. The disease increases in severity as the plants are weakened by heat and drought.

The Organism. The fungus, Cercospora beticola, like most fungi, is composed of a vegetative part of mycelium and of spores. The latter are microscopic in size, somewhat needleshaped, and divided by means of a cross wall into two to seven cells (fig. $20 \mathrm{~h}$ ). Each of these cells may germinate by sending out a threadlike tube, which penetrates the leaves through the stomata. The spores are borne on a cluster of stalks or conidiophores, at the base of which is formed a small stroma. The temperature and relative humidity of the air influences the production and infection of conidia. According to Pool and $\mathrm{McKay}^{\mathrm{x}}$ a temperature of 80 or 90 degrees $\mathrm{F}$. with a minimum of not less than 60 degrees at night is most favorable to the production of conidia. They are, however, checked by a temperature of Ioo degrees or higher, or of 50 to 80 degrees $\mathrm{F}$. Conidia are generally formed on the lower surface of the leaves, no doubt because these are subject to a higher humidity. Control. For practical purposes leaf spot may

s Pool Venus, and McKay, M. B., U. S. Dept. Agr. Journ. Agr. Research, 7 : 21-60, I916. 
be controlled by deep fall plowing and crop rotation. No hard and fast system of rotation can be laid down for the trucker. He himself must be the best judge. It seems that the conidia of the fungus are unable to live over winter. The parasite, however, winters over as mycelium within the affected leaves. Deep plowing, therefore, not only improves the land but will also help to bury the débris of infested leaves, thereby removing the fungus as a source of infection for the following year. Spraying will also help to control leaf spot. The formula recommended is 4 pounds copper sulphate, 4 pounds fresh slaked lime, to 50 gallons of water. To succeed in keeping the disease in check, spraying must be carefully carried out. The leaves should be thoroughly coated with the mixture both from the upper and under sides. Clean culture and constant cultivation will also check leaf spot. This will tend to maintain the moisture in the soil, at the same time preserving the vigor of the plant. Any operation which tends to weaken the plant will also favor infection.

\section{Root Rot}

\section{Caused by Corticium vagum $\mathrm{B}$. and $\mathrm{C}$.}

This disease is very prevalent in the United States, attacking a large number of truck crops in which the beet is included. It has been carefully studied by Duggar and Stewart ${ }^{ \pm}$and by others. It produces

× Duggar, B. M., and Stewart, F. C., New York (Cornell) Agr. Expt. Sta. Bul. 186 : 50-76, Igor. 


\section{Family Chenopodiaceæ}

a damping off of the young seedlings, and on older plants a rotting of the crown. In pulling out an infested plant, we find that the outer leaves are dead and dry, while the inner ones are somewhat curled. The roots of such plants invariably are rotted at the crown, the rot generally working inwards to a considerable extent. The peculiarity of this disease is that the lower half of the root is generally sound. Frequently the rotted crowns are also found to be cracked at various places. Beets thus affected are worthless for the market. This condition naturally indicates a sick condition of the soil, due to the presence of Rhizoctonia solani. For a description of the fungus see p. 45 .

Control. There are no methods of control known. The factors which favor the trouble are poor drainage, an excess of soil moisture, and lack of sufficient aeration. Every step taken to overcome these will in a degree help to control the rot.

\section{Root KNoT}

Caused by Heterodera radicicola (Greef) Müller.

This disease is different from crown gall or tuberculosis. Although the symptoms are sometimes manifested as knots or outgrowths on the main roots, usually the knots are found at the tip end of the roots, thereby leaving unmolested the main root. The effect of this disease, however, is to reduce the size of the marketable beet. Affected 
plants in the field may be detected by their stunted growth, smallness and paleness of foliage.

Cause and Control. The cause of this trouble is not a bacterium or a fungus but a minute microscopical worm, Heterodera radicicola. For further description of the parasite and for methods of control see p. 49-5I.

\section{DISEASES OF SPINACH (Spinacia oleracea)}

Spinach is an important truck crop in the United States but one subject to numerous diseases.

\section{MALNUTRITION}

The result of an excess of acidity or of a lack of soil humus.

This condition causes great losses in those districts where commercial fertilizers are used exclusively, at the expense of organic manures.

The margins of the veins of the leaves become yellow and the central part takes on a mottled appearance. The outer leaves are usually the first to suffer; soon, however, the entire plant exhibits similar symptoms and ceases to grow.

Control. Spinach, like lettuce and other crops which are eaten for their foliage, cannot be sprayed with poisonous fungicides. The trucker must look to other sources for relief. The methods for controlling malnutrition have already been considered on pages $8 \mathbf{I}-82$. As regards the other diseases men- 


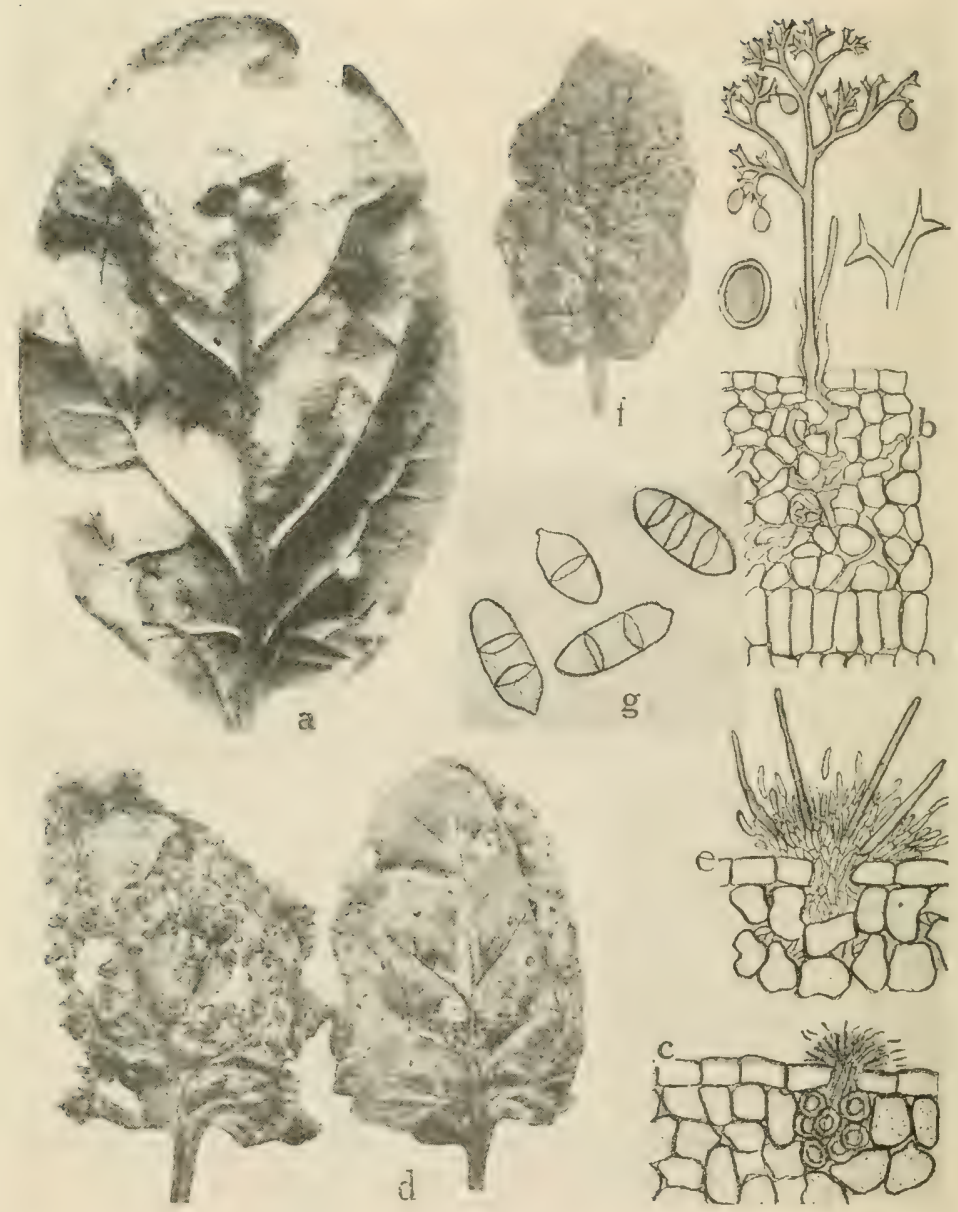

Fic, 21, Spinach Diseases.

$a$. Downy mildew, $b$. cross section showing fruiting stalk of the downy mildew fungus on infected spinach leaf, $c$. cross section showing leaf affected with white smut, d. Anthracnose of spinach, $e$. cross section showing acervulus of Collctolrichum spinacice. $f$. leaf spot, $g$. spores of the leaf spot fungus IIcterosporium variabile. (b. c. e. after Halsted, d, after Reed). 


\section{Family Chenopodiaceæ}

tioned above, clean culture is an important consideration. Diseased leaves should be collected and destroyed by fire; the diseased refuse should never find a place in the manure pile. Where spinach has been grown too long on the same land a rest must be given by rotating with other crops.

\section{Downy MiLdeW}

Caused by Peronospora effusa Rabenh.

The downy mildew of spinach is of widespread occurrence. The disease causes great damage during seasons of heavy rainfall or during dry weather accompanied by heavy dews at night. It is rare in dry weather and absence of dews.

Symptoms. The trouble is characterized by yellow spots of conspicuous size on the upper part of the leaves (fig. 2I a). On the under side of the leaves and corresponding to the spots above, is seen a mat of dirty white to violet gray fruiting bodies of the fungus.

The Organism. Downy mildew is caused by the fungus Peronospora effusa. The spores of the parasite are borne on branches which generally emerge through the breathing pores or stomata of the lower part of the leaf (fig. 2I b) and germinate by sending out a slender germ tube. Infection takes place when the germ tube penetrates the upper side of the leaf, generally through the stomata. The winter stage or oospores may be found in the affected leaves. The 


\section{2 \\ Diseases of Truck Crops}

fungus also seems able to pass from year to year as viable mycelium in the late infected leaves of the spinach.

\section{ANTHRACNOSE}

\section{Caused by Colletotrichum spinacice Ell. and Hals.}

This disease is apparently limited to New Jersey and Virginia, although it probably occurs also in other States where spinach is grown.

Symptoms. It appears as minute round watersoaked spots on the leaves. These quickly enlarge and become gray and dry (fig. $2 \mathbf{I}$ d). In the spots will be found evenly scattered minute dark tufts; these are merely fruiting pustules which also contain minute black bristles or setæ (fig. 2I e). The onset is not limited to any particular part of the plant. Infection may take place anywhere on the foliage, stems, or petioles. The spore pustules may be formed on the upper as well as on the lower surface of the leaf. In wet moist weather the pustules take on a salmon tinge, indicating that there is an abundance of spores formed at that time. The spores may be carried from leaf to leaf and from plant to plant by insects, wind, or rainwater. In badly infected fields, picking should never be done during wet rainy weather, neither should spinach from infected fields be allowed to be shipped long distances, as in this case the product may rot before reaching its destination. 


\section{Family Chenopodiaceæ}

\section{White SMUT}

\section{Caused by Entyloma Ellisii Hals.}

Spinach smut is closely related to the smut of onions or even to the grain smuts. The disease is of rare occurrence.

Symptoms. Instead of turning black, the leaves assume a white frosty appearance, which renders them, of course, worthless. The fungus has two forms of spores. Those within the leaf are spherical and grouped in small clusters just beneath the stomata, while the second form is needleshaped and is borne at the end of the minute threads on the surface of the affected leaf (fig. 2I c).

\section{Phyllosticta Leaf Blight}

\section{Caused by Phyllosticta chenopodii Sacc.}

This is a common disease, especially with older plants. Like Anthracnose, leaf blight causes great damage when once introduced in a field.

Symptoms. Numerous minute spots appear, more distinctly in the lower part of the leaf. Within them are found scattered minute black bodies known as pycnidia. These are microscopical, saclike bodies, within which the spores of the fungus are borne. During moist weather, the spores are seen to ooze out as long white tendrils. The latter are made up of millions of spores held together by a mucilaginous 


\section{I34 Diseases of Truck Crops}

substance which is dissolved by the least contact with rainwater or dew. The spores are then carried about by the same agencies as mentioned for the organism of spinach anthracnose.

\section{BLACK MOLD}

\section{Caused by Cladosporium macrocarpum Preuss.}

This disease attacks the oldest leaves of the plant in dark patches which are covered with numerous irregular dark spore-bearing branches or conidiophores. It is of little economic importance.

\section{LEAF SPOT}

\section{Caused by Heterosporium variabile Cke.}

This disease is very prevalent on winter spinach in Eastern Virginia. It generally attacks plants which have been weakened by downy mildew, or by other diseases. Reed and Cooley, ${ }^{\mathrm{I}}$ who have studied it carefully, find that indirectly it causes considerable losses to the growers. It necessitates, for instance, the trimming off of dead or diseased leaves, this requiring extra labor and reducing the quantity of marketable spinach. The disease is at its height when the plants attain their maximum, beginning in January and continuing until about March, the close

I Reed, H. L., and Cooley, J. S., Virginia Agr. Expt. Sta. Ann. Rept. I909 and I9I0. 


\section{Family Chenopodiaceæ}

of the season. Leaf spot does not develop to any appreciable extent under dry conditions. In dry winters it is of no economic importance. It is best favored by poor soil conditions, that is by an excc ; of acidity or a lack of humus.

The Organism. It is caused by Heterosporinn. variabile, a semi-parasitic fungus which causes circular, or subcircular, sooty brown spots, having a definite outline (fig. 2I f) on both sides of the leaf, surrounded by a brown area of dead leaf tissue. The spots at first have a light color, becoming darker with age, finally turning velvety to olive black. This color is largely due to the appearance of the spores on the surface of the spots. These occur singly, although they may involve the entire leaf when a great number coalesce. The mycelium grows in the host cells and consists of septate branches, the cells of which are olive green in color, irregular in shape, granular and oily in content. Conidiophores proceed vertically from cracks in the epidermis of the spot, and at the tip end of each a spore is borne on a small short pedicel. As the conidiophore continues in growth, new spores are formed at the tip end, thus giving the fruiting stalk a twisted appearance. The mature spore is three celled (fig. $21 \mathrm{~g}$ ), cylindrical, with round or slightly pointed ends, spiny, and sooty or olive green in color. On pure culture the fungus may produce only one-celled spores. The latter seem to retain their vitality for at least six months.

The very serious spinach blight of the Norfolk, Va., trucking region should be mentioned. It was 
erroneously confused by Harter with the true malnutrition which is also found there (but rather rarely). The blight has been shown by McClintock and Smith to be a true mosaic, communicated by aphids.

\section{WEEDS}

Disease is not confined to cultivated crops only, but it also attacks weeds. In attempting to control the diseases of cultivated crops, we cannot lose sight of the various weed pests of the truck garden, inasmuch as they are liable to several important diseases in common with the cultivated crops. Clean culture tends to destroy those weeds which act as carriers of some of these diseases. The more important weeds in this family are lamb's-quarters (Chenopodium album), the wormseed (Chenopodium anthelminticum), orache (Artriplex patula), and Russian thistle (Salsola tragus, Salsola kali, and Salsola pestifer). As far as we know, none of the diseases which attack beets are known to prey on these weeds. However, the downy mildew of spinach, Peronospora effusa, attacks also the lamb's-quarters, the worm seed, and the orache. From this fact may be seen the importance of clean culture in the control of downy mildew. In trucking, as in every system of intensive culture, weeds are seldom tolerated. But they are often overlooked on the roadside and around old fences, where they cause clean culture to be of no avail. Weeds should never be tolerated anywhere within the reach of the trucker or gardener. 


\section{CHAPTER XI}

\section{FAMILY COMPOSITAE}

THis important family includes the artichoke (globe and Jerusalem), chicory, endive, lettuce, salsify, and sunflower. As far as we know, there are no available statistics of the acreage and money value in the United States of artichoke, chicory, salsify, and sunflower. They are, nevertheless, of considerable economic importance. According to the Thirteenth Census of the United States (I909) the area in lettuce was 5489 acres, and the crop is estimated at \$I,595085. Florida leads with 1450 acres and New York follows with IOI 2 acres. The other States in order of importance are California, Louisiana, Massachusetts, Illinois, New Jersey, Missouri, Pennsylvania, Ohio, Virginia, and Maryland. States with less than Ioo acres of lettuce are omitted.

\section{DISEASES OF ARTICHOKE, JERUSALEM (Helianthus tuberosus)}

Jerusalem artichoke is subject to the attack of but few diseases. With the exception of downy mildew, none needs to be feared by the trucker or gardener. 


\section{Downy Mildew}

Caused by Plasmopara Halstedii (Farl.) B. and D.

This mildew attacks the Jerusalem artichoke as well as the sunflower. The disease is of little economic importance. The trouble is apparent as downy whitish patches on the under side of the leaves which soon spread, involving the entire area of the affected foliage. This soon turns yellowish, becomes dry and brittle, and dies.

\section{RusT}

Caused by Puccinia helianthi Schw.

This rust is supposed to be the same as the rust of the sunflower. However, the work of Arthur ${ }^{\mathrm{I}}$ shows that no infection takes place when the teliospores from the sunflower are sown on the Jerusalem artichoke. It is probable that we deal with physiological races. The rust on the artichoke is characterized by numerous spore pimples, yellow at first but later turning to dark brown.

\section{LEAF BLOTCH}

Caused by Ramularia cynarce Sacc.

This disease has as yet proved to be of little economic importance in the United States. In Europe, however, leaf blotch seems to cause con${ }^{2}$ Arthur, J. C., Mycologia, II : 53, 1905. 


\section{Family Compositæ}

siderable damage. Grayish irregular spots appear on the leaves and often become so numerous as to involve the entire surface, in which case the affected leaf becomes brown and eventually dies.

\section{DISEASE OF ARTICHOKE, GLOBE (Cynara scolymus)}

The globe artichoke is little cultivated and very little known to the people of the United States. In Europe and especially in Asia this delicious truck crop is more extensively grown. Globe artichoke is, as far as known, attacked by few diseases.

\section{LEAF SPOT:}

Caused by Cercospora obscura H. and W.

Heald and Wolf ${ }^{\mathrm{I}}$ found this disease on the globe artichoke in Beeville, Texas. The disease is characterized by minute gray spots on the upper surface of the leaf. The gray color is brought about by the appearance of the tufts of conidiophores and conidia on the surface of the spots.

The conidiophores of the fungus are non-septate, borne in groups of four to seven, and hyaline at the tips. The conidia are cylindrical in shape, straight or curved.

Control. None of the diseases of the Jerusalem or the globe artichoke are ever serious enough to attract attention. However, where these crops are grown

${ }^{2}$ Heald, F. D., and Wolf, F. A., Mycologia, $3: 5-22$, 191 r. 
extensively, spraying with Bordeaux $4-4-50$ is recommended for downy mildew (Plasmopara Halstedii) of the Jerusalem artichoke, and for leaf blotch (Ramularia cynarce). In damp weather it may be necessary to spray from three to four times during the season.

\section{DISEASES OF LETTUCE (Lactuca sativa)}

Lettuce is subject to numerous diseases in the field on account of the extreme tenderness of the foliage. None of the diseases to be mentioned should be allowed to gain a foothold in the fields.

\section{BACterial BLight}

Caused by Pseudomonas viridilividum $\mathrm{Br}$.

This is a serious disease, common especially in Louisiana and in other States where lettuce is grown extensively. The disease was first described by Brown ${ }^{x}$ who found that large acreages of lettuce were ruined by the blight. The growers at first believed that the trouble was brought about by the use of cottonseed meal. However, this was proven to be not true, since the trouble was also found to a very serious extent where no cottonseed meal was used as a fertilizer. The writer has found the same trouble in the lettuce fields in Texas.

Symptoms. The disease seems to attack only the

s Brown, Nellie A., U. S. Dept. of Agr. Jour. Agr. Research, 4 : $417-478,1915$. 


\section{Family Compositæ}

outer leaves of a head. The affected foliage is first covered with numerous watersoaked spots which enlarge, fuse together, and involve the entire area of the affected leaves. The latter either soften or dry up, opening up the way for the entrance of other decay organisms, which may now attack the otherwise sound head.

The organism is rod-shaped, occurring singly or in pairs, or in chains, and it moves about by means of polar flagella. On agar, the young colonies are round with entire smooth margins; they are translucent cream white in reflected light but bluish in transmitted light. The older colonies are not always uniform in color, but may take on yellowish bands or become mottled. The organism does not form gas and it liquefies gelatine slowly. It is not especially sensitive to sunlight.

Control. It is not as yet known whether Bordeaux mixture will control the disease. The disease should not be allowed to gain any headway in the field. Diseased plants should not be fed to cattle nor allowed to find a place in the manure pile, but should be destroyed by fire. In severely affected fields other crops should be grown and the land be given a rest from lettuce for at least three years.

\section{Downy Mildew}

\section{Caused by Bremia lactuce Reg.}

Downy mildew is a disease which is more troublesome in Europe than in the United States, and it is 
more serious on greenhouse lettuce than on that grown in the open. In the field it usually attacks fall lettuce.

Symptoms. Affected leaves lose their natural green color and turn yellow. A careful examination will disclose a delicate downy web on the under side of the foliage which will have a wilted appearance. The downy web consists of the conidiophores of the fungus. These appear singly and are much branched. The conidia germinate by means of a germ tube. Downy mildew attacks not only lettuce, but also chicory and numerous other Compositæ.

Control. Spraying lettuce is not recommended. Clean culture and careful regulation of the soil moisture will help to control this trouble. Downy mildew is seldom found on well drained lands. In greenhouses, the disease may be checked by the sudden lowering of temperature for a day or two. Soil sterilization with formaldehyde (see p. 53) will also be effective.

\section{Gray Mold}

\section{Caused by Sclerotinia Fuckeliana De Bary}

Gray mold attacks grapes in Europe but in the United States it is commonly met with in the lettuce fields, especially on plants which are fully developed and somewhat overgrown.

Symptoms. The disease is manifested by soft, watersoaked spots on the foliage causing a wilting. The spots soon become coated with the fruit of a 


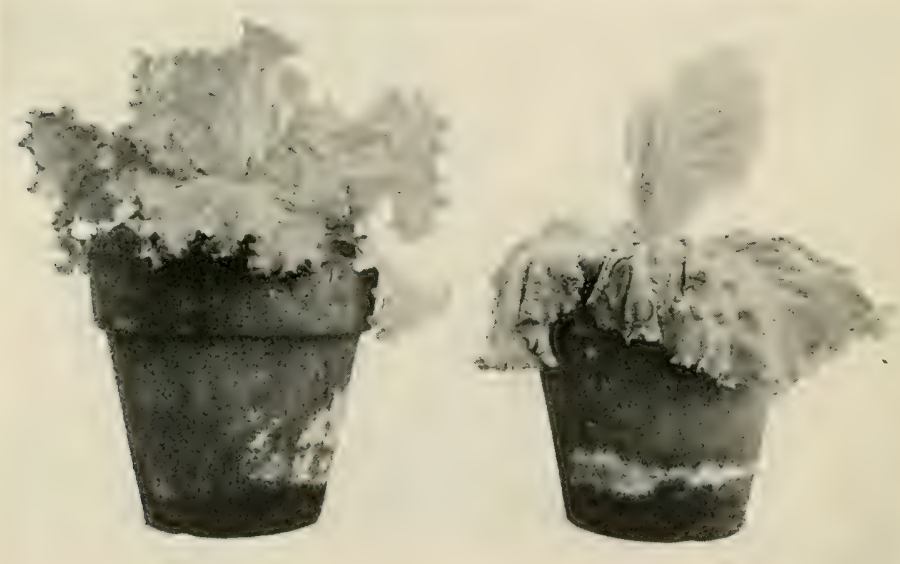

Fig. 22. LetTuCE Drop.

To the right, artificially inoculated plant; to the left, healthy. 


\section{Family Compositæ}

gray mold. The fungus has two stages. Botrytis cinerea Pers. of wilted lettuce leaves appears as a gray mold, the other is the winter or apothecial stage. American botanists have not as yet been able to connect these two forms. It seems, however, that Istvanffi ${ }^{x}$ was able to confirm the work of De Bary, who first indicated the relationshp of Botrytis cinerea with Sclerotinia Fuckeliana.

\section{Lettuce Drop}

\section{Caused by Sclerotinia libertiana Fck1.}

Drop is a disease which is found wherever lettuce is grown. The greatest damage is reported from the South Atlantic States, North and South Carolina, Alabama, Georgia, Florida, Louisiana, although the trouble extends also to such States as Massachusetts, New York, Ohio, Pennsylvania, Connecticut, Rhode Island, Wisconsin, Iowa, Washington, Vermont, Maine, Maryland, Delaware, and Virginia.

Symptoms. The term drop best describes the symptoms of the disease. The first sign is a wilting of the lower leaves (fig. 22), which is immediately followed by a drooping of upper ones until the entire plant is involved. The affected plant has a sunken appearance as if scalded with boiling water. In examining a dead plant, a white cottony fungus growth is found on the under side of the lower leaves, and near the moist regions at the stem end.

${ }^{x}$ Istvanff, G. De, Ann. de l'institut central ampél. roy. Hongrois: 183-360, 1915. 


\section{I44 Diseases of Truck Crops}

When the plants are fairly rotted, there appear on the cottony mycelial growth mentioned above, black bodies, or sclerotia, which vary in size from a pinhead to a grain of corn. The three definite symptoms of the disease may be summarized: (I) drooping, (2) cottony-like mycelial growth on the under surface of the affected leaves, (3) the appearance of sclerotia (fig. $23 \mathrm{c}$ ). The latter help to carry over the fungus during the winter. After the sclerotia have been in the soil over winter, they germinate in the following spring by sending out small mushroom-like fruiting bodies known as apothecia (fig. 23 a). The latter contain small sacs or asci which bear the spores (fig. $23 \mathrm{~b}$ and $\mathrm{d})$.

Control. The work of Stevens ${ }^{x}$ seems to show that lettuce drop may be controlled by the following method: The field is inspected as often as possible during the season. Every plant which shows indications of disease is pulled out and burned and the place where it grew is drenched with a solution of one pound of bluestone dissolved in seven gallons of water. If these directions are carried out for three years the disease will be controlled. The simplicity of the method should make it appeal to truckers and gardeners.

\section{LEAF Spot}

Caused by Septoria lactuca Pass. and Septoria consimilis $\mathrm{E}$. and $\mathrm{M}$.

${ }^{2}$ Stevens, F. L., North Carolina Agr. Expt. Sta. Bul. 217 :7-21, I917. 

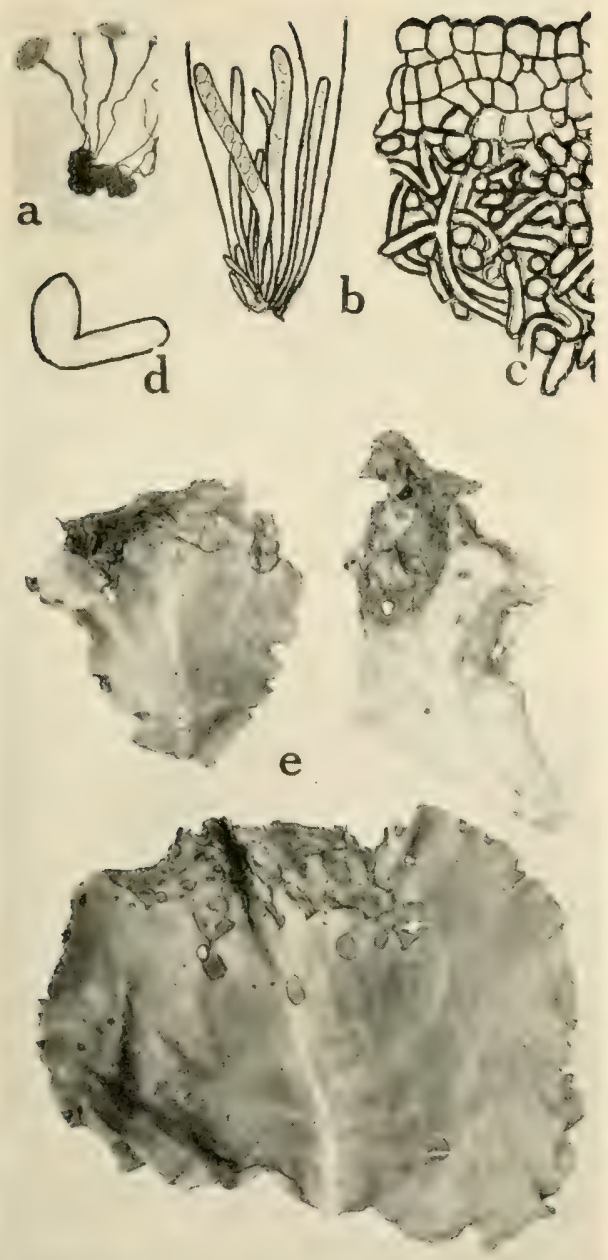

Fig. 23. Lettuce Diseases.

a. Germinating sclerotium of Sclerolinia liberliana the cause of lettuce drop, $b$. section of fruiting cup (apothecium) showing asci, ascospores and paraphyses of $S$. libertiona, $c$. section through sclerotium of $S$. libertiana, $d$. germinating ascospore of S. libertiana $(a$, to $d$. after F. S. Stevens), $\varepsilon$. Cercospora leaf spot. 



\section{Family Compositæ}

This disease is induced by two species of Septoria fungi. The symptoms produced by both are so nearly alike that it is difficult to distinguish one from the other, except by microscopic examination. Pale brown discolored spots appear on the older leaves with numerous black pycnidia in the center. The disease is of little economic importance, as it usually occurs late in the scason, on plants which have nearly passed their usefulness. The Boston variety is considered resistant, while the Salamander and the Wonderful are more susceptible to leaf spot.

\section{SHot Hole}

Caused by Marsonia perforans E. and E.

The disease is of little economic importance. Affected leaves are covered with dry spots which drop out, leaving irregular perforations. Along the border of these holes, the causative fungus may be found abundantly fruiting. The disease attacks the midribs of the leaves as well as the stem of the plants. It seems to be more prevalent under conditions of surface irrigation. With sub-irrigation, on the other hand, it is not found to cause any damage.

\section{Cercospora Leaf Spot}

Caused by Cercospora lactuca Stev.

This disease is as yet of no importance in the United States. The trouble occurs in Porto Rico, 
where it has been recently described by Stevenson. ${ }^{\mathrm{x}}$ The causative fungus attacks the older and lower leaves, forming numerous irregular, ragged spots (fig. $23 \mathrm{e}$ ).

Rosette, see Rhizoctonia, p. 45

\section{RoOT KNOT}

Caused by Heterodera radicicola (Greef) Müller.

This disease is prevalent in the light sandy loams which are infected with eelworm. Small, stringy, bead-shaped knots form on the roots and rootlets. Lettuce thus affected seldom succeeds in heading out, but remains dwarfed and sickly looking. For a further description of the trouble and its control see p. 49 .

\section{DISEASES OF SALSIFY (Tragopogon porrifolius)}

Salsify, or oyster plant as it is commonly known, is subject to but few diseases, all of which are generally of little economic importance. This is perhaps due to the fact that it is little grown and that its edible qualities are little appreciated by the American consumer.

\section{SOFT RoT}

Caused by Bacillus carotovorus Jones

¿ Stevenson, J. A., Journal Department of Porto Rico, x :93117, 1917. 


\section{Family Compositæ}

Soft rot of salsify is more a storage trouble than a field trouble. The disease, as it has been studied by Clinton, ${ }^{1}$ was found to be the same as the soft rot of the carrot and of various other vegetables. It was found in salsify roots stored in poor cellars, lacking the necessary ventilation.

Symptoms. Soft rot usually begins at the crown and works downwards into the heart of the root. The outside and harder tissue remains sound and seems to form a firm coating to the centrally decayed tissue. The bacteria work first in the fibro-vascular bundles, the soft rotted portion being found in the center of the root. The germ Bacillus carotovorus, the cause of the soft rot of carrots, is responsible also for this disease of the salsify.

Control. It is suggested that roots which show soft rot should not be used for seed crops. Diseased roots should not be fed to cattle nor should they be dumped on the manure pile. The storage cellar should be allowed plenty of ventilation, especially during the first three weeks of storage.

\section{WHITE RUST}

Caused by Albugo tragopogonis (D. C.) Gray.

White rust is a field disease that seldom gives any trouble in dry seasons, nor is it found to any appreciable extent on new lands. The disease is charac-

× Clinton, G. P., Connecticut Agr. Expt. Sta., 38th. Ann. Rept.; 25-27, 1914 . 
terized by whitish blisters or sori on the leaves. When these blisters are mature, they burst open, liberating a white dust composed of the spores of the parasite. In badly infected plants diseased leaves turn black and split and tear lengthwise. The rust attacks leaves only, resulting indirectly in small and dwarfed roots. To keep this trouble in check salsify should be planted on new land.

\section{RusT}

\section{Caused by Puccinia tragopogoni (Pers.) Cda.}

This rust resembles the white rust in appearace, except that the blisters here are brown instead of white. It is found wherever salsify is grown, but it does not seem to have caused considerable damage. The life history of the fungus is little known.

Southern Blight (Fig. 24), see Pepper, p. 305

\section{DISEASES OF THE SUNFLOWER}

\section{(Helianthus annuus)}

The sunflower can hardly be considered a truck crop. Nevertheless, this plant finds a place in trucking, as it is often grown for its seed as a poultry feed. Sunflower seedlings are subject to damping off, Pythium de Baryanum Hesse. For a detailed description of this trouble, see pages 42-44.

Downy Mildew (Plasmopora Halstedii Farl.) of the sunflower is not different from the same disease on Jerusalem artichoke, p. I38. 


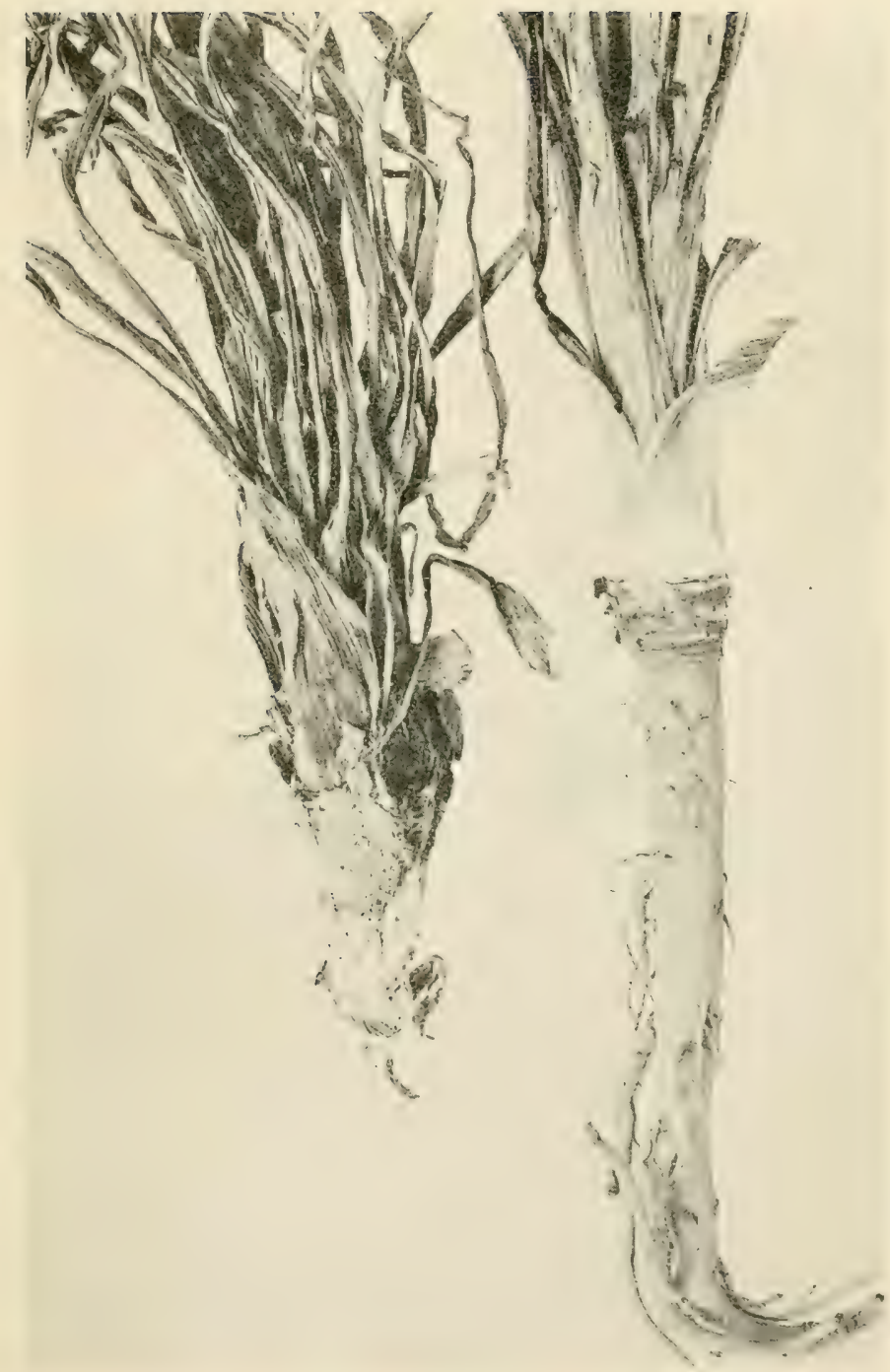

Fig. 24. Southern Blight of the Salsify.

To the right lealthy plant, to the left diseased plant, wit? root rotted off. 



\section{Family Compositæ}

\section{RUST}

\section{Caused by Puccinia helianthi Schw.}

Rust attacks the wild as well as the cultivated sunflower, producing blisters or sori on the leaves. The former are at first yellow or brown, but later in the season become black. Badly infected leaves turn yellow, then curl and dry up. This results in a reduction in the yield of seed, which for the most part fails to fill out properly. This rust seems to attack the sunflower only and is apparently unable to infect the Jerusalem artichoke. Clean culture and destroying the refuse by fire is advised.

\section{WEEDS}

The family Compositæ contains a large number of weeds. The following are often troublesome: ragweed (Ambrosia artemisifolia), great ragweed (Ambrosia trifida), Nayweed (Anthemis cotula), burdock (Arctium minus), ox-eye daisy (Chrysanthemum leucanthemum pinnatifidum), blue sailors (Cicorum intybus), bull thistle (Cirsium lanceolatum), fireweed (Erechtites hieracifolia), wild or tall lettuce (lactuca canadensis), prickly lettuce (Lactuca scariola), fall dandelion (Leontodon autumnalis), Canada goldenrod (Solidago canadensis), dandelion (Taraxacum officinale), cocklebur (Xanthium commune).

Of the weeds which are attacked by downy mildew, Plasmopara Halstedii Farl., may be mentioned the ragweed, the great ragweed, and Canada goldenrod. 
I5O

\section{Diseases of Truck Crops}

None of the weeds here mentioned is attacked by rust, Puccinia helianthi Schw. If downy mildew is to be kept in check the truck patches must be kept free from weeds. 


\section{CHAPTER XII}

\section{FAMILY CONVOLVULACE}

This important family includes but one truck crop, the sweet potato. The latter is of great economic importance to truckers who are situated in sandy or sandy loam regions. Sweet potatoes cannot thrive in heavy clay soils.

According to the Thirteenth Census of the United States, the total acreage of sweet potatoes in 1909 was 641,255 acres, with a total production of 52,232,o7o bushels, worth $\$ 35,429,176$. North Carolina has the distinction of having the largest acreage in sweet potatoes, 84,740. The other States which follow, according to rank, are, Georgia, Alabama, Louisiana, Mississippi, South Carolina, Texas, Virginia, Tennessee, New Jersey, Arkansas, Florida, Kentucky, Illinois, Maryland, Missouri, Delaware, Oklahoma, Kansas, Iowa, and West Virginia. States with less than 2000 acres are here omitted.

\section{DISEASES OF THE SWEET POTATO}

\section{(Convolvulus batatas)}

Sweet potatoes are subject to numerous field and storage diseases, many of which may be controlled. 


\section{Slime Mold}

Caused by Fuligo violacea Pers. and Physarum plumbeum Fries.

Very often the plants in the seed beds are covered with white, yellowish, or purple jellylike growths. These patches may vary from three to six inches or more in diameter and cover the foliage, peduncles, and stems. In 12 to 24 hours this slime thickens and becomes covered with a white or yellowish crust which readily cracks and liberates the spores in the form of a dark brown powder. The growth, which is a slime mold, has been determined as Fuligo violacea Pers. (fig. 25 a). The organism is not a parasite on the sweet potato plant; nevertheless its presence in a seed bed is not desirable. The slime mold covers the plant, shutting off light which is essential for its proper nutrition. There is another slime mold, Physarum plumbeum Fries., which often grows on the foliage (fig. 25 b). These molds are seen only in seed beds in the open or on sweet potato beds in the greenhouse.

$$
\text { "SoIl Rot," "Pox," or "Pit" }
$$

\section{Caused by Cystospora batatas E.}

The term soil rot is somewhat misleading, as the disease does not produce a rot. The name "pox" or "pit" is a better description of the disease. 

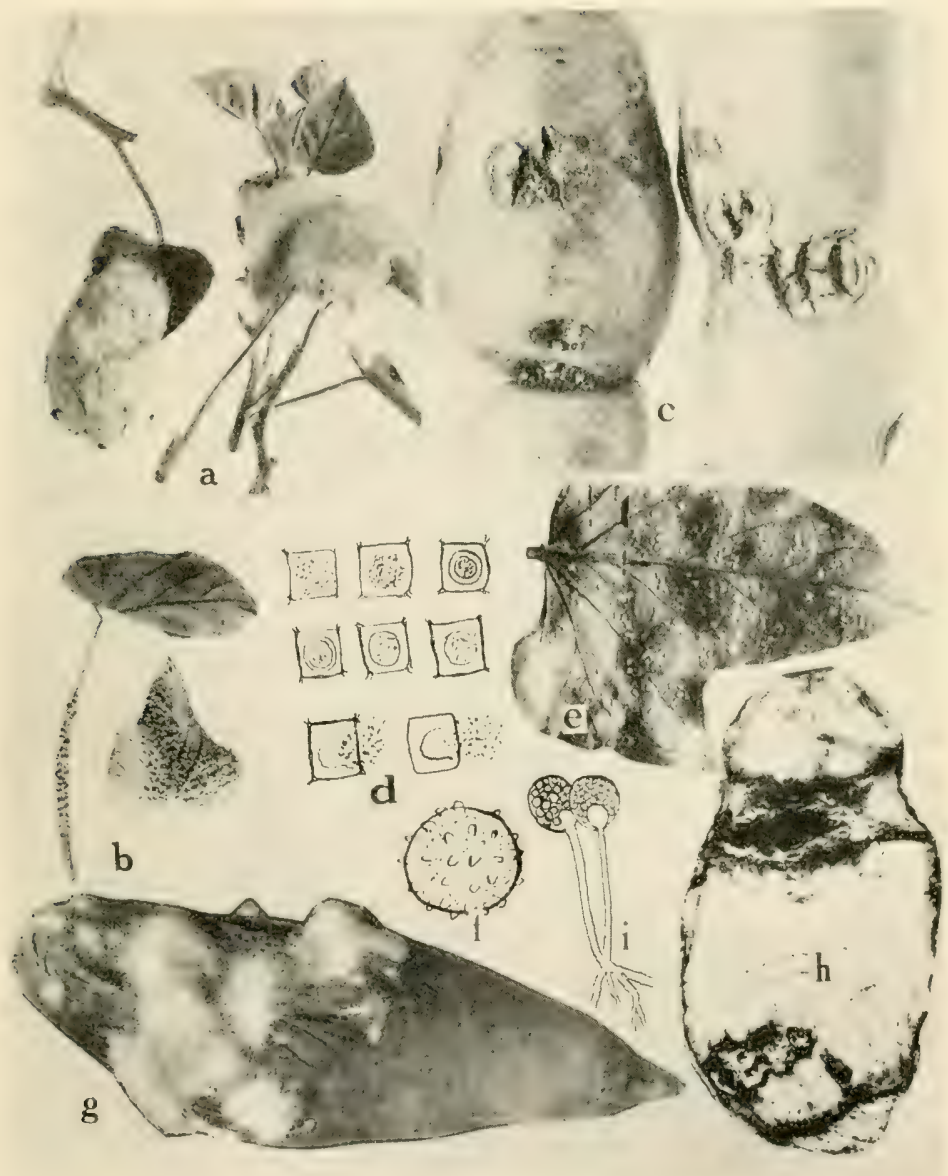

Fig. 25. Sweet Porato Diseases.

a. Slime mold (Fuligo violacea), b. slime mold (Physarum plumbeum), c. pox or pit, $d$. formation of a cyst and liberation of spores of Cystospora batala (after Elliot). $e$. white rust, $f$. oospore of the white rust fungus, $g$. soft rot, $h$. ring rot, $i$. fruiting stalks of Rhizopus nigricans. 

Symptoms. This disease is early marked by small, dark, dry spots on the surface of the potato (fig. 25 c). Later the infected portion in most cases cracks, dries, and falls out, leaving a pit with a newly formed, roughened skin. It is an underground trouble and is not detected in the field until late in the season, at a time when healthy hills have formed well developed vines. At this time the lack of an abundant vine growth is a characteristic symptom, and the rather meager stem development gives the impression that the soil is very poor and exhausted in plant food. The symptom appears when the sweet potato is beginning to form. At this stage the spotted portion ceases to grow, while the healthy portion on each side continues to develop. Frequently roots that are very badly spotted cease to grow altogether, and if they are stored, the spots usually dry and fall out. Unlike black rot, roots affected with soil rot do not lose their food value, as the disease is only skin deep and imparts no bad taste to the potato. The disease also attacks the young rootlets of the plant, and when this is the case there is practically no crop formed. This, however, happens only in badly diseased fields, and especially where lime is used. The latter should never be applied to lands infected with the pox organism. The trouble, unlike many others, seems to be worse in dry weather.

Besides affecting the sweet potato, pox also causes circular shallow pits on the white potato, and on turnips, the pits on the latter being even more shallow than on the former. It is also suspected of at- 
tacking beet and tomato plants, although complete proof is still wanting.

The Organism. The cause of pox was first thought to be the fungus Acrocystis batatas $\mathrm{E}$. and $\mathrm{H}$. Investigations of the writer showed that this was not the case. Finally Elliot ${ }^{\mathrm{I}}$ found that pox was caused by a slime mold organism which he named Cystospora batatas $\mathrm{E}$.

The swarm spores of the slime mold are very small, round, but slightly pointed at both ends. They often fuse in pairs, forming spherical bodies with a single nucleus. The amœbæ soon become circular, and four central nuclei together with a distinct wall membrane become apparent. Nuclear division takes place and many nuclei are now formed within the cyst body. As the cyst advances in age, a cell wall is laid down, and each nucleus with its surrounding protoplasm now begins to round up into individual spores. The latter when mature break through the wall of the cyst, which dissolves apparently through the secretion of an enzyme within (fig. $25 \mathrm{~d}$ ).

It is very doubtful if the organism is carried with infected sweet potatoes, since the spots nearly always dry and fall out. The organism is carried over in the land from year to year. The exact means by which it is carried from place to place is not definitely known. The organism does not seem to spread very rapidly to adjoining neighboring fields, nor to places on the same farm.

× Elliot, J. A., Delaware Agr. Expt. Sta. Bul. 114 : 3-25, 1916. 


\section{Family Convolvulacex}

\section{White Rust}

\section{Caused by Cystopus ipomece-pandirance Farl.}

White rust is a disease of the foliage only. It is present in nearly every field where sweet potatoes are grown. Although prevalent, the disease is almost unrecognized as such by the growers. The losses from it are indirect. While it is true that the sweet potato is grown only for its roots, nevertheless, a good crop depends upon a healthy and abundant stand of leaves. The sugar and the starch in the potato are not manufactured from the soil, but are made by the leaves from the air and sunlight, and are then stored in the roots. The effect of white rust is to kill much of the foliage, thereby curtailing the amount of sugar and starch manufactured, and this in turn results in a shorter crop and poorer keeping roots. It is generally agreed that the more starch a root has, the better it keeps. The White Southern Queen variety is one of the best keepers, being richest in starch content.

Symptoms. White rust appears late when the plants have usually made most of the vine growth and when the hills are beginning to set, i.e., to form new sweet potatoes in the soil. A typical symptom of white rust then is the yellowing of leaves in the center of the hill, which later turn brown, shrivel, and die.

In carefully examining the center leaves as they begin to yellow, we see that on the under side of such leaves there are many minute white raised pimples, (fig. $25 \mathrm{e}-\mathrm{f}$ ) each of which when touched with the 


\section{Diseases of Truck Crops}

finger sheds a white dust made up of millions of spores of the fungus. Each white pimple on the under side of the leaf is denoted by a small yellow area on the upper surface. In case of mild infection there are usually few pimples on the upper leaf, but when the disease is bad, the leaves are literally peppered with them. White rust is severest when the weather is dry and the nights are cool. It is also more abundant in the shaded portions of the field. With the exception of the Southern Queen, all varieties of the sweet potato grown are subject to it.

\section{Soft Rot}

\section{Caused by Rhizopus nigricans Ehr.}

Soft rot is mostly a storage trouble, although it is commonly met with in the field at digging time and in the seed bed. It is constantly associated with poorly ventilated houses, causing more damage to stored sweet potatoes than all other diseases combined. On an average, fully twenty per cent. of the total crop in storage is lost from diseases and nine tenths of this loss may be attributed to soft rot.

Symptoms. The term "soft rot" best describes the symptoms of the disease. Affected roots are very soft and watersoaked, and when pressed, a clear liquid oozes out. Its presence in the bins may be detected in the wetting of adjacent healthy roots. Under storage conditions, infected roots do not produce the sporangia of Rhizopus unless broken or 


\section{Family Convolvulaceæ}

bruised. Where this is the case, a black mass of short-stemmed sporangia or fruiting bodies of the fungus are formed at the crack (fig. $25 \mathrm{~g}$ ), through which opening the liquid from the root drips. When no such cracks are formed, the fungus fails to fruit, and the roots dry by gradual evaporation through the epidermis.

Resistance to Soft Rot. While soft rot causes the greatest damage to sweet potatoes in storage, not all the roots alike are susceptible to its attack. There is a certain per cent. of the crop which when housed poorly will soft rot shortly after the potatoes are taken into storage, while another per cent. seems to possess a degree of resistance. These latter will usually keep for a month or two and then rot, particularly if the winter is mild and the roots undergo what is known as the second sweat. There is a third class of root which seems to be resistant for a long time.

Odor of Soft Rot. Often storage men claim that soft rot emits strong, disagreeable odors. Observations show that soft rot in bins is odorless for a week or ten days, after which time fermentation sets in, and an odor is quite noticeable. After a short time, the affected potatoes will become fairly dried out and other fungi such as Diaporthe batatis, Fusarium batatatis, Sclerotium bataticola, and a number of saprophytic fungi gain entrance. Sometimes putrefaction follows the acetic fermentation.

Soft rot is not carried from year to year in the dried-out roots which were previously destroyed by 
Rhizopus; however, the spores of the fungus preserve their vitality for a considerable time. When we consider how abundant these spores are in nature, it is not difficult to conceive how easy it is for soft rot to get a start every year. The storage house is undoubtedly the place where the greatest amount of Rhizopus spores are carried over from year to year. The main problem, therefore, is to prevent the Rhizopus spores from germinating or to use some fumigant which will kill them all together.

\section{RING Rot}

\section{Caused by Rhizopus nigricans Ehr.}

Ring rot is a form of soft rot. The disease is prevalent as soft rot and is found in poorly ventilated houses. The amount of loss varies from I to 20 per cent.

Symptoms. There are two forms of ring rot. The first stage is the soft ring which is characterized by a rotted area which girdles the root at any point (fig. $25 \mathrm{~h}-\mathrm{i}$ ). As the roots are usually put in bins in bulk and as soft ring, like soft rot, is confined to the roots more or less buried in the bulk of the bin, the onset of the disease is usually overlooked. It is at first odorless, but in a week or ten days it is followed by a characteristic fermentation. The soft ring gradually begins to dry, resulting in a shrinkage and contraction of this area, and thus a slight groove is formed (fig. $25 \mathrm{~h}$ ). In two to six weeks, it becomes 



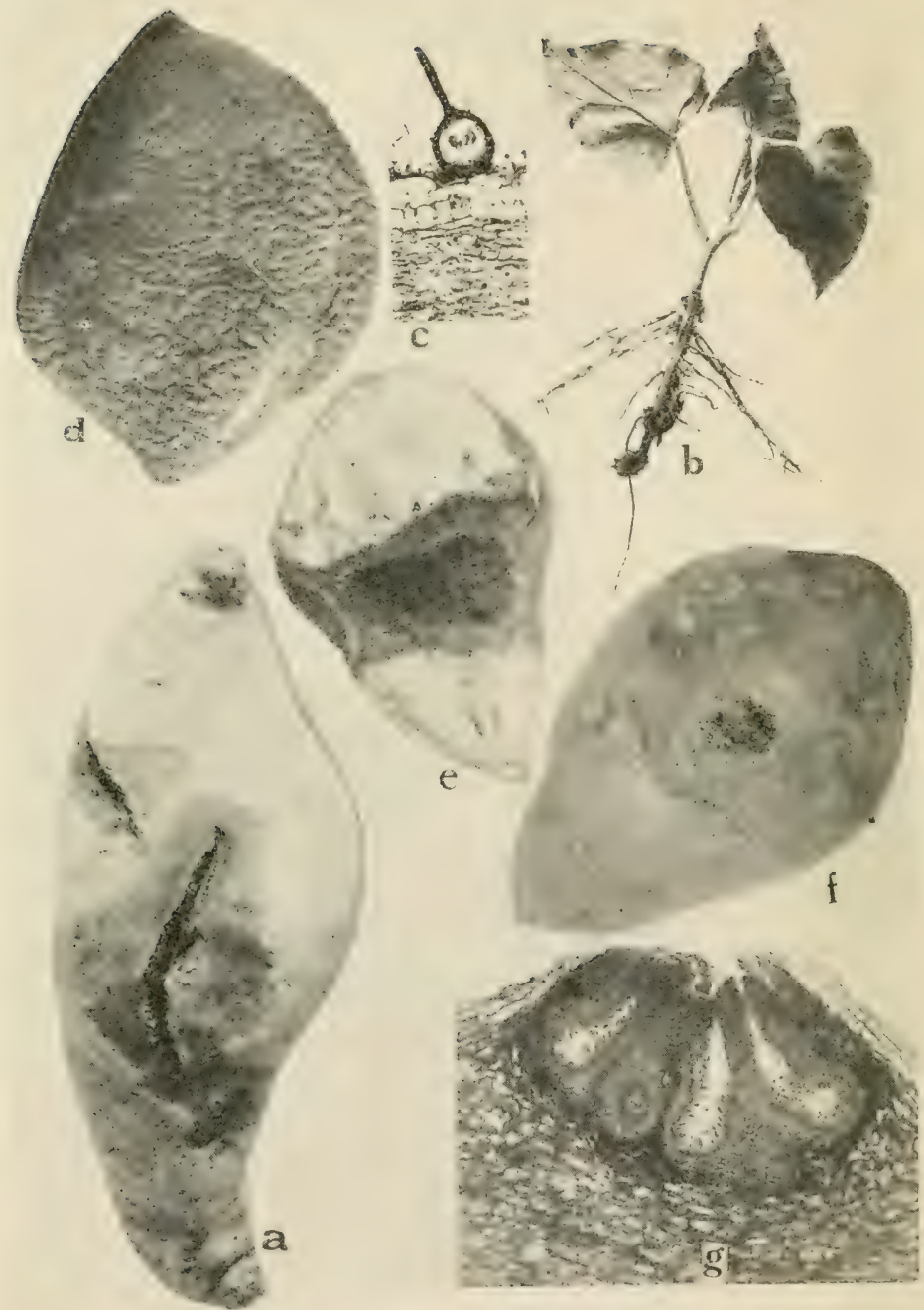

Fig. 26. Siveet Potato Diseases.

a. Black tot at place of a bruise, $b$. black shank, $c$. showing a pycnidium of the black rot fungus, $d$. dry rot, $c$, cross section throug $1, f$, to show the effect of the disease on the root, $f$. java black rot surface view, showing strings of spores oozing out from the center of spot, g. cross section through diseased sweet potato root to show pyenidia of the fungus Diplodia tubericola. 


\section{Family Convolvulaceæ}

very dry and more or less hardened, varying with the nature of the fungi which act as secondary invaders. The second form, or dry-ring rot, is nothing more than the last or dried-out stage of the soft ring in which the primary parasite has died.

\section{DRY ROT}

Caused by Diaporthe batatis (E. and H.) H. and F.

Dry rot is a disease of stored sweet potatoes. Although it has a wide distribution, the trouble is not considered of great economic importance. The disease usually follows a complication of others. It begins at the end of the potato, producing a firm dry rot which progresses slowly. The rotted potato is brown, finally becoming hard and shriveled. The surface later becomes black, rough, and uneven (fig. $26 \mathrm{~d}$ ) and when examined under the microscope will be found to be studded with numerous pycnidia. From the mouths of the latter are seen to ooze out whitish strings which are made up of millions of the pycnidia or summer spores. The Diaporthe or ascospores are formed only when the infected roots are allowed to hibernate.

\section{Foot Rot}

\section{Caused by Plenodomus destruens Hart.}

Foot rot is a disease which, so far as is known, is found only in Virginia, Ohio, Iowa, and Missouri. 
Wherever present it causes serious losses to sweet potatoes in the field.

Symptoms. The disease first manifests itself as sunken brown to black spots at the stem end of the plant near the soil line. The spots gradually enlarge, girdling the stem and working upwards. In a diseased field, all the ends of the vines nearest the soil line are rotted, so that the entire hill may be easily pulled out. Although the feet of the vines in a diseased hill rot off, the vines manage to remain partly alive, owing to the nourishment obtained from the secondary rootlets produced at the leaf nodes on the vines which lie flat on the ground. Diseased hills fail to produce any sweet potatoes, since the underground roots are cut off from the main vines. Infection takes place in the field or in the seed bed. Moisture appears to favor the disease. With the death of the vines appears a pimply growth consisting of numerous pycnidia. It is believed that foot rot, like many other sweet potato diseases, is carried with the seed. The fungus Plenodomus destruens so far as we know possesses only the pycnidial or summer fruiting stage. No ascospore stage has as yet been found.

\section{BLACK ROT ${ }^{\text {I }}$}

Caused by Sphceronema fimbriatum (E. and H.) Sacc.

Of all the diseases of the sweet potato, black rot is the most dreaded by growers. It is found in all

s Material drawn from the author's work. Taubenhaus, J. J., Delaware Agr. Expt. Sta. Bul. 109 : 3-56, 1915. 


\section{Family Convolvulaceæ}

sections where sweet potatoes are grown. Not infrequently the disease is mistaken for other troubles, and too often its nature is unknown to the truckers.

Symptoms. Black rot is a seed-bed disease, a field disease, and a storage trouble. Irregular dark areas or circular spots, varying in size from that of a dime to a silver dollar, appear on the seed (seconds) or on the prime potatoes. These spots extend only through the skin and are hard to the touch. When the roots are injured through cultivation, by rodents, or through rough handling in the field or in storage, the spots lose their circular outline and follow the line of injury (fig. 26 a). In this case the bruise is invaded by secondary parasites which may induce rotting of the entire root.

The symptoms shown by the sprouts are a dwarfing in growth and yellowing of the foliage. In this latter case the end of the shank is blackened and charred from $I / 2$ to $I$ inch in distance (fig. $26 \mathrm{~b}$ ). Where this stage (known as the "black shank") is present, the leaves of the infected sprouts wither, and turn black and crisp. Frequently the disease affects the stem and even the petioles and is indicated by black areas on them. In early stages of infection, and in the absence of the black shank stage, the rootlets are usually affected. For this reason it is essential to examine carefully the appearance of the rootlets when sprouts are pulled from the field. The early symptoms in the field are the same as those described for the sprouts in the seed bed. Black girdling spots on the vines, which are confined to areas usually 
between two leaves, are the first symptoms on the plant. The disease seldom blackens the full length of the stem. The part below the black spot remains healthy, while the part above wilts and dies, since the infected area prevents the upward flow of water and plant food to the part beyond the killed area. Stem infection does not always indicate underground infection. Often where the vines are affected, the roots, when pulled out, seem to be free from black rot. In case of underground infection, sometimes every root in the hill is black rotted and there may not be the least indication of the disease on the stem of the plant. At digging time, roots which show the disease are somewhat paler in color than the healthy ones of the same variety, a symptom which seems to be general in some soils and not in others. When roots are infected with black rot, the edible qualities are poor because of the bitter taste. This becomes more marked the longer the roots are kept in storage. Although the black rot spot is only superficial, the bitter taste in cooking is imparted to the entire root, showing that it is soluble and easily diffused into adjacent tissue.

Introduction and Spread of Black Rot. In the seed bed, the trouble begins with diseased seed. Even though the greatest care is exercised in discarding the seed, some infected roots will find their way into the bed. Not all growers are careful in their selection of seed, and often through lack of knowledge of the malady, diseased roots are used in bedding, or are discarded and thrown out near the bed. These seeds 
are then trampled upon and crushed and make a good starting point for the spread of black rot. As the seed begins to germinate, the sprouts on or near a mother diseased root will contract the disease. On pulling out this root, nearly every sprout will show the black shank which, upon careful examination with a hand lens, will be found to be strewn with the long-necked pycnidia of the fungus. At the tip of these roots are seen minute waxy droplets which consist of the pycnospores. Small mites, white minute spider-like animals, crawl about everywhere, especially on and around the pycnidia. These mites, as well as watering, help to spread the pycnospores in the seed bed and result in the further infection of new sprouts.

In storage, black rot is first introduced with diseased roots and is spread from one to another, fruiting best in the presence of moisture. In poorly ventilated houses, it is invariably noticed as soon as the roots begin to sprout. These sprouts turn black and die at the tender tip or throughout. In the first stage, while growing in the interior tissue, the fungus does not produce pycnidia. Therefore, as long as the epidermis on the spot is unbroken and the roots are kept dry, the disease cannot spread. However, if the skin is broken or accidentally bruised, or if the roots are kept in a house which is overheated and damp, the black rot fungus will produce fruit by the formation of pycnidia which appear as minute raised dots in the center of the spot.

The Organism. The parasite consists of a vegeta- 
tive portion known as "mycelium" which, when young, is hyaline, but which becomes gray with age. Whether young or old, they are capable of breaking up into as many cells as there are septa, and each cell may assume the function of a spore, since it will readily germinate. In another stage, chains of hyaline spores are born and pushed out from within long terminal cells of the mycelium. The chlamydospores apparently serve as resting spores to carry the fungus over winter, and the cells of the infected tissue are usually filled with these brown thick-walled spores. A last stage is that of pycnospores which are born within long-necked spore sacks called pycnidia (fig. $26 \mathrm{c})$. These are minute globular spores oozing out in a gelatinous mass which stick to the open end of the long neck of the pycnidium. In pure cultures the spores ooze out in strings just as in the case of certain species of Phoma or Phyllosticta. The spores can germinate in water or in any nutritive fluid.

\section{Phyllosticta Leaf Blight}

\section{Caused by Phyllosticta batatas E. and M.}

Leaf blight appears as roundish to angular spots on the upper side of the leaf and is separated from the healthy tissue by a dark line. Inside this line is a strip of brownish tissue which has lost most of the green color. Within this ring is a circular area much lighter in color in which the pycnidia are found 


\section{Family Convolvulaceæ}

protruding. The fungus, so far as is known, lives only on sweet potato foliage.

\section{Septoria Leaf Spot}

Caused by Septoria bataticola Taub.

Leaf spot is a disease which is of little economic importance. The trouble appears as soon as the plants attain full growth and are beginning to lose in vigor. The disease has been found in New Jersey, Delaware, Maryland, Virginia, Iowa, and other States.

Symptoms. Leaf spot is characterized by small whitish spots scattered indiscriminately over the leaf. The spots are nearly always surrounded by a brown border (fig. $27 \mathrm{~b}$ ). On the surface of the dead tissue are found the pycnidia which are usually few in numbers, often not more than one or two to a spot. The pycnospores are carried about from leaf to leaf by winds or insects.

Septoria bataticola attacks only sweet potato foliage. It is very likely that the fungus hibernates on the dead leaves in the field. Leaf spot is never serious enough to warrant special methods of control.

\section{JAVA BLACK ROT}

Caused by Diplodia tubericola (E. and E.) Taub.

The disease was first found on some sweet potatoes that were brought to the Louisiana station from Java in the spring of 1894 . The potatoes appeared 
sound, but failed to grow when planted. Upon examination the roots were found to be rotted. The fungus which caused the rot was sent to Ellis, who identified it as a new genus and gave it the name of Lasiodiplodia tubericola. Sweet potatoes brought from Java in the spring of $\mathbf{I} 895$ were found to be affected with the same fungus when they were received at Baton Rouge. This seems to indicate that the fungus was introduced in the United States from Java.

Symptoms. Sweet potatoes affected by the fungus show dark shriveled patches over which are scattered numerous pycnidia. These emit either mature oneseptate dark spores of Diplodia type, heaped together, or white strings (fig. 26 f), which are made up of hyaline Macrophoma spores, or both (fig. $26 \mathrm{f}$ ). In making longitudinal sections through different stages of affected roots, it will be found that the fungus attacks the interior tissue, beginning at the point and gradually invading the whole of the interior of the root. The infected tissue is jet-black (fig. $26 \mathrm{e}$ ), somewhat resembling the charcoal disease. Infected roots dry and shrivel and become brittle. Complete rotting of the root is effected in four to eight weeks. The active enzyme from the fungus precedes the mycelium some distance, for in a longitudinal section of a newly infected root two zones may be observed, one, a dark area which is occupied by the fungus, and the other, a brown zone which precedes the dark patch in which the mycelium is absent. The pycnidia are born singly or in groups 



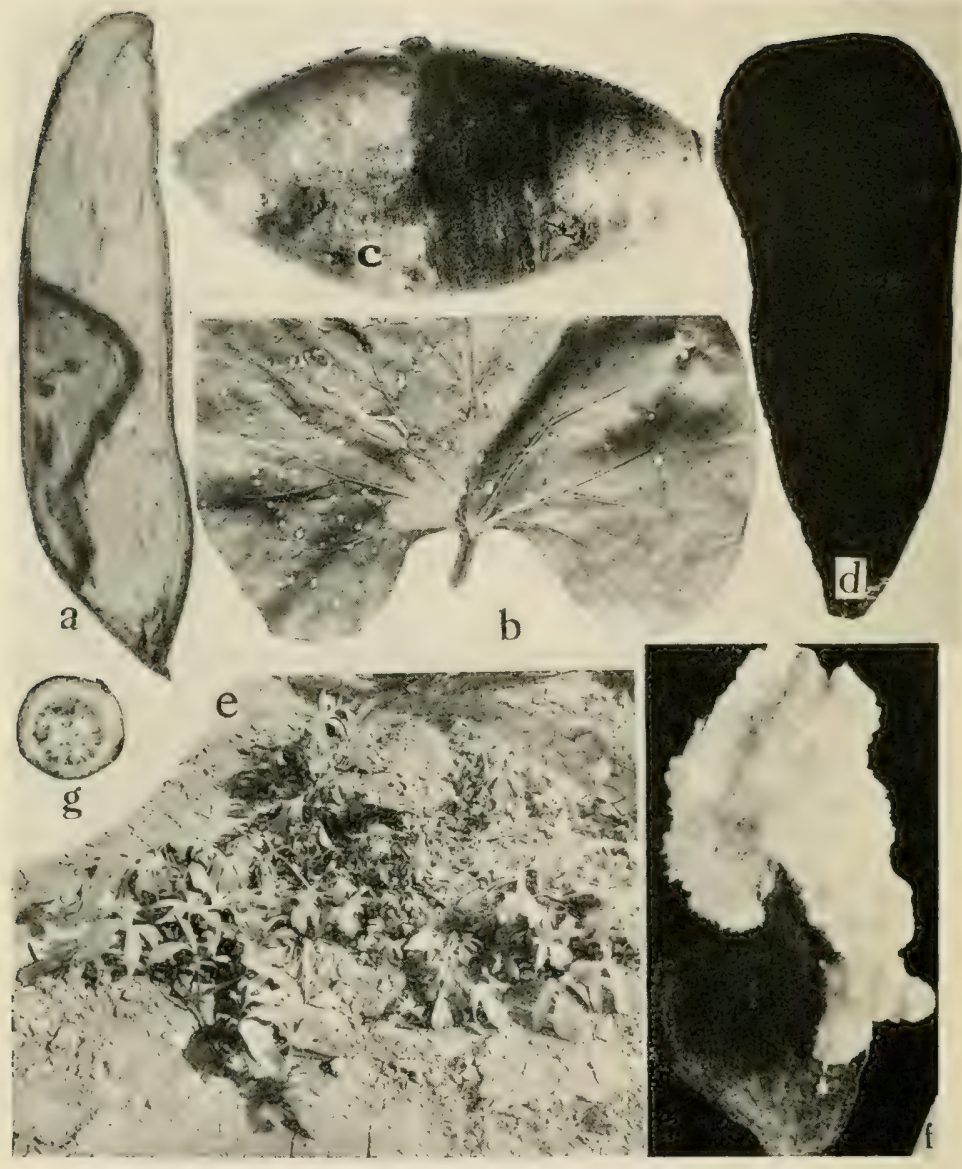

Fig. 27. Siveet Potato Diseases.

$a$. Trichoderma rot, $b$. Septoria leaf spot, $c$. soil stain, d. Charcoal rot, $e$. Texas root rot: notice the center of the hill is dead, while the side shoots are alive as they are supported by the secondary roots formed at the nodes of the vines, $f$. sweet potato artificially inoculated with Sclerotium Rolfsii, g. net necrosis. 


\section{Family Convolvulaceæ}

under the epidermis, and the latter is ruptured at an early stage (fig. $26 \mathrm{f}$ ). They are also formed through the interior tissue of the infected root, and it seems that in this case the spores can escape only when the roots break up and disintegrate. ${ }^{\mathrm{x}}$

\section{Trichoderma Rot}

Caused by Trichoderma Köningi Oud., and Trichoderma lignorum (Tode.) Harz.

The symptoms of several of the different rots on the sweet potato are often so similar that it is difficult to find appropriate, popular names with which to characterize each disease. Trichoderma rot by itself does not exist under the average storage conditions. But it follows other rots, particularly ring rot, and soft rot, causing further destruction of the partially affected roots. Trichoderma rot is a storage trouble only, and the causative organism is no doubt brought in from the field adhering to particles of soil.

Symptom. In the earliest stages, the spots are circular, and of a light brown color, with a tendency to wrinkle. The flesh is hard and watersoaked, brown in color with a black zone in the region between the healthy and diseased tissue (fig. 27 a). The spot enlarges in all directions and eventually destroys the entire root. When the decay is well advanced, a very luxuriant, white, mycelial growth is formed on the surface. Spores are produced very

I For further details of this fungus see Taubenhaus, J. J., American Jour. of Bot., 2 : 324-33I, 1915. 
sparingly from this growth when in contact with the decayed tissue, but very abundantly on that part of the mycelium which has spread over the healthy surface or into the glass or filter paper of the moist chamber. Trichoderma lignorum is common and widely distributed on decaying wood and various other substances. Trichoderma Köningi was originally isolated from the soil by Oudemans and is still looked upon as a soil organism. The spores are elliptical and are borne on characteristic conidiophores (fig. 28 p).

\section{SOIL STAIN OR SCURF}

\section{Caused by Monilochaetes infuscans E. and E.}

Soil stain is not a disease to be feared in the sense that it may produce a direct rot in the mature roots. Nevertheless, it is economically important. Growers whose lands are badly infected assert that stained roots keep better in storage. Others find consolation in saying, "There is no such thing as stain, the dark color of the skin being merely a varietal characteristic." The fact remains, however, that many Eastern markets discriminate against stained roots. In years of over-production the New York market refuses stained roots altogether. The Western buyers, on the contrary, are lax on this point; otherwise, many growers in the United States would be forced to cease producing sweet potatoes for want of a market, since soil stain is prevalent on practically all sweet-potato land.

Symptoms. Soil stain is characterized at first by small, circular, deep clay-colored spots on the surface 


\section{Family Convolvulaceæ}

of the sweet potato root. These spots occur singly; but usually several occur in a given area. When very numerous, the spots coalesce, forming a large blotch, which sometimes takes the form of a band, or which may cover the entire root. Soil stain is particularly conspicuous on the white-skinned varieties, such as the Southern Queen. Here the color of the spots is that of a deep-black clay loam. On the darker-skinned varieties the color of the spots does not appear so conspicuous. Soil stain is a disease of the underground parts of the plant. The vines and foliage are never attacked so long as they remain free from the soil. But when they are covered, the petioles as well as the stems become infected.

After several months of storage, badly affected roots become a deep brown, contrasting strongly with non-infected potatoes. Occasionally, badly stained roots seem to be subject to more rapid drying and shrinking. This, however, is not often the rule. Usually soil stain is prevalent in over-heated storage houses. It may be, therefore, that the rapid shrinkage is due to the overheating and not to the effect of the disease itself. More data are necessary to determine this point. Soil stain is a disease not only of the epidermis that considerably reduces the market value of the mature roots, but it also attacks the very young rootlets, preventing their further development and indirectly reducing the yield. In badly affected fields the writer has estimated a loss of ro per cent. of the crop from the rootlet infection.

The type of soil seems to be a determining factor 
in the development of soil stain. Sweet potatoes, grown on very light sandy soils, especially those which are hilly, are usually free from the disease. Heavier lands, or those rich in humus, rarely produce a clean crop. The application of manure favors the spread of the fungus and increases the stain. In fact, the manure itself is often a carrier of the disease, since diseased roots of all sorts find their way ultimately to the manure pile. The trouble is also carried directly with the seed stock. This, when planted in the seed bed in diseased condition, will produce roo per cent. of diseased sprouts. Wet weather is favorable to the spread and increase of stain. During wet seasons the disease is more plentiful than in dry seasons.

The Organism. The spores are born in distinct chains which break up very readily when moistened (fig. $28 \mathrm{a}-1$ ). The conidiophores are born on the surface of the epidermis (fig. $28 \mathrm{n}$ ). Careful observation of these chains have shown them to be made up of from Io to 28 conidia. The spores (conidia) are one celled, hyaline, with a greenish tinge, but never dark or brown. The spores readily germinate in water or in any nutrient medium (fig. 28 o).

\section{Vine Wilt or Yellows (Stem Rot)}

Caused by Fusarium batatatis Woll. Fusarium hyperoxysporum Woll.

The terms "stem wilt," "vine wilt," or "yellows" are commonly used to describe this disease, and 

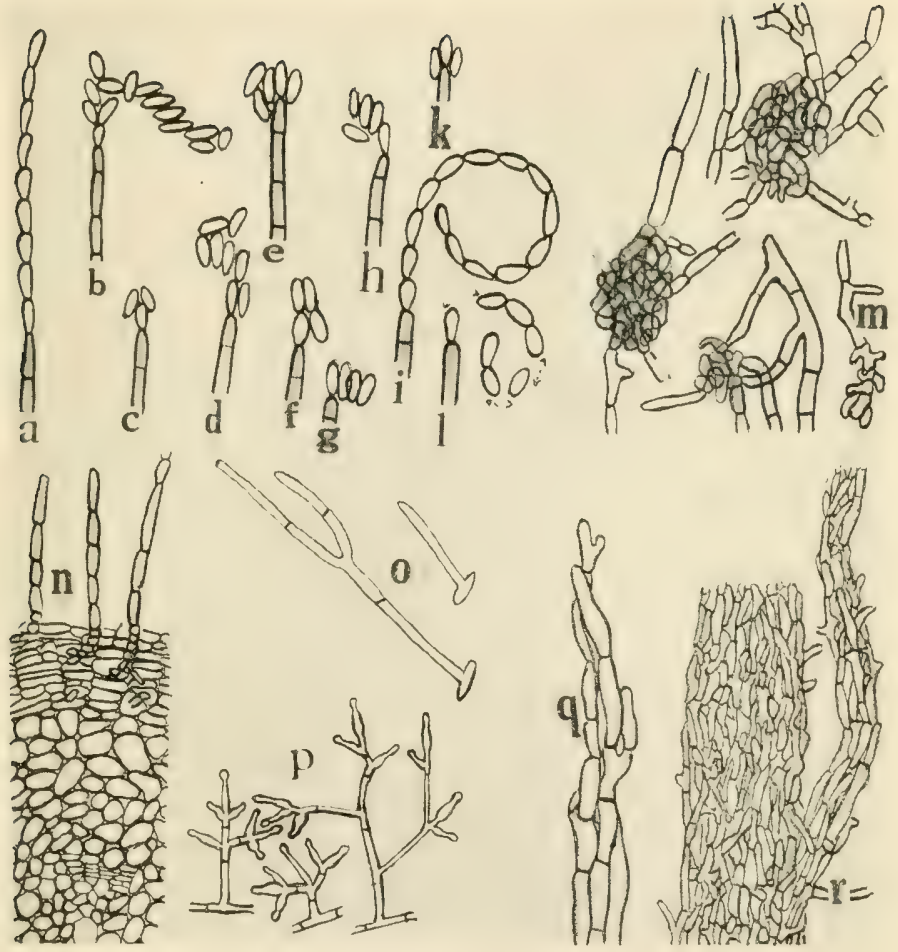

Fig. 28. Sweet Potato Diseases.

a. and $i$. Chains of conidia of the soil stain fungus Monilochates infuscans, $b$. to $l$. manner in which the chains of conidia of $\mathcal{H}$. infuscans are breaking up into individual spores, o. germinating conidia of $M$. infuscans, $n$. part of a cross section of a sweet potato root showing the relationship of $\boldsymbol{M}$. infuscans to the epidermis of the host, $p$. conidiophores of Trichoderma Koningi, $a$, young strands of mycelium of Phymutotrichum omnivorum, $r$. mycelial strands of the Texas root rot fungus, Osonium omnivorum from dead cotton plant ( $q$. and $r$. after Duggar), $m$. sclerotia of Sclerotium balaticola. 



\section{Family Convolvulaceæ}

they are more appropriate than the name "stem rot."

Symptoms. There is no doubt that "stem wilt" has its origin in the seed bed. In badly infected soils, it is often difficult for the plants to get a stand, as they die a week or two after being put out. They first lose their green color, and turn pale, and when they are pulled out, they will be found to be cracked lengthwise because of the swelling. The presence of stem wilt may easily be determined by inserting the nail into the stem and peeling off a piece of epidermis and cambium; the vessels will be found to be a brown color. Frequently the stem is covered with a pinkish layer of sickle-shaped spores of the Fusarium parasite. Often, and particularly in moist seasons, infected sprouts continue to grow, sometimes until digging time, and even produce fair sized roots, provided no secondary invaders set in to destroy the hill. Sometimes black rot, as a secondary parasite, sets in at the base of the stem near the ground, killing the bark or covering of the stem, thus shutting off all food supply, and resulting in the dying of the entire hill in a short time. Frequently a wet bacterial rot starts in the base of the plant where black rot has followed stem wilt. This stage helps to convey the erroneous impression that stem wilt induces an actual rotting in the field. Yellowing of the affected stems and vines, while a frequent symptom, is not always pronounced. Often the disease in plants can hardly be detected, as the fungus is hidden internally in the fibro-vascular bundles and the roots main- 
tain a thriving green appearance. In clipping the tip end of such a root, the bundles appear brown in color, and usually the disease may be traced through the entire length of the root. Sometimes only a few bundles in the root are affected, while in others each shows the brown ring near the cambium. It is better that the affected sprouts should die early, for if they grow and produce roots of the No. 2 type, they carry the disease to the seed bed. This is more of a field than a storage trouble. In large and badly infected roots in storage, the fungus may produce a punky, dry rot which has a peculiar cinnamon odor and a deep chocolate color which may make the roots light and shriveled (see fig. $27 \mathrm{a}-\mathrm{e}$ ).

A diseased hill one year will mean several diseased hills the following year. In plowing up the land for sweet potatoes the original hill is broken, and the stem wilt fungus is carried some distance in both directions by the plow and the harrow. The cultivator, too, may, during the season, help to carry the disease and induce new infections by injuring the sprouts. Dead sprouts and dead hills, if left over in the field, furnish material on which the fungus will fruit abundantly.

The two organisms greatly resemble each other in spore form (fig. $7 \mathrm{c}-\mathrm{d}$ ). Yellows is prevalent in New Jersey, Maryland, Virginia, Illinois, Iowa, Alabama, Arkansas, Missouri, North Carolina, Ohio, Georgia, Texas, Oklahoma, and Mississippi. A conservative estimate of the losses from yellows would be at least 


\section{Family Convolvulaceæe}

three quarters of a million for the entire sweet potato crop of the United States.

\section{Charcoal Rot}

\section{Caused by Sclerotium bataticola Taub.}

"Charcoal rot" is a new name for an old trouble. It is mainly a storage trouble and is found most commonly in overcrowded houses and in bins nearest the stoves. It is especially plentiful in houses which lose heavily from soft rot. After the work of Halsted, from I 890 to I9I3, the fungus which caused charcoal rot was believed to be a stage of the black rot fungus. But it has been shown by the writer that charcoal rot is a distinct disease and that the fungus which causes it is in no way connected with or related to the black rot organism, Spharonema fimbriatum (E. and $\mathrm{H}$.) Sacc.

Charcoal rot is commonly mistaken for black rot. While black rot produces only superficial spots on the roots, and does not produce a rot of the entire root, charcoal rot is a disease which penetrates the entire root. The parasite does not produce surface spots, but turns the interior tissue into a black charcoal mass (fig. $27 \mathrm{~d}$ ) caused by the formation of minute colored sclerotia (fig. $28 \mathrm{~m}$ ). With the exception of drying and slight shrinkage, there are no external symptoms to distinguish the disease unless the skin is bruised, showing the blackened contents. It can be recognized when the roots have been completely invaded. Recent studies on this disease seem to 
indicate that infection takes place from a bruise on the epidermis and from there the fungus works slowly inward. It is not uncommon, therefore, in slight cases of infection, to find, upon making a cross section of the root, a jet black ring ranging from one third to one half an inch in diameter immediately under the epidermis, the color grading off from dark to a light ash as it nears the center of the root. At this stage the infected sweet potato is watersoaked but quite solid. A liquid, brownish in color, may be squeezed from such roots. Charcoal rot is almost unknown in well ventilated houses. There seems little doubt that the fungus $S$. bataticola is a common field saprophyte, which may be brought into the storage house with the sand or soil which clings to the roots. Diseased roots kept dry for one year will readily yield a pure culture of the fungus, thus showing that these roots carry the fungus from year to year.

The Organism. The sclerotia are jet black, very minute, smooth, and made up exteriorly of anastomosed black hyphæ. The interior of the sclerotia is light to dark brown, composed of thick walled cortical hyphal cells (fig. $28 \mathrm{~m}$ ). The sclerotia appear singly, and oftentimes in long chains, and abound throughout the entire affected root.

\section{Cottony Rot}

\section{Caused by Sclerotium Rolfsii Sacc.}

Cottony rot is mostly a disease of the seed bed. Infected sprouts suddenly wilt and topple over, giv- 


\section{Family Convolvulaceæ}

ing the effect of damping off. In examining an infected sprout it will be found that in the earlier stages of attack the foot of the plant is soft, watersoaked, and covered at the exterior by fungus threads. Later this growth becomes thick, giving the appearance of fluffy cotton placed at the foot of the sprout. Soon after, the cottony mycelial growth anastomoses, then disappears, giving birth to small roundish brown bodies like mustard seed known as sclerotia.

Sclerotium Rolfsii seldom attacks mature sweet potato roots. However, when the fungus is artificially inoculated in sound roots, a punky dry but slow rot is the result (fig. $27 \mathrm{f}$ ). For further discussion of this fungus as it attacks other hosts see p. 305.

\section{Texas Root Rot}

\section{Caused by Ozonium omnivorum Shear.}

So far as is known, this disease occurs only in Texas, New Mexico, Oklahoma, and Arizona. The disease is of great economic importance in these States, since numerous other crops are subject to its attacks. The symptoms of Texas root rot are a girdling of the vines at the stem end, and a similar effect on the roots (fig. $27 \mathrm{e}$ and fig. $28 \mathrm{~g}$ and r). In these cases, the epidermis and cambium may be readily slipped off from the main body of the infected stem and root. For a more detailed account of the Texas root rot, see okra, p. 297. 


\section{RoOTKNOT}

Caused by Heterodera radicicola (Greef) Müll.

Root knot of sweet potatoes is commonly found in the Southern States in light sandy soils. It is characterized by small swellings on the lateral feeding roots. For further description, see p. 49.

\section{Methods of Controlling Sweet Potato Diseases}

The grower in dealing with sweet potato diseases has a fourfold problem. No amount of care will suffice to keep down his losses from disease, unless he handles the problem thoroughly, beginning with the seed and continuing through the seed bed, the field, and the storage house. No one method of control will suffice alone; each phase must be dealt with separately.

Methods of Obtaining Seed Free from Disease. The selection of clean seed from bins, while working successfully with other crops, is not to be practiced in the case of sweet potatoes, since much disease is carried inside of the roots or in the dust which coats them. Seed treatment should be preceded by seed selection. The use of seconds for seed is not satisfactory, since they may be the small roots produced from diseased hills, and hence carriers of disease.

The use of slips is very desirable, since in this case a beginning is made with healthy cuttings from which hills of slip seed are produced. These in turn are healthy, since they are not hampered by disease 


\section{Family Convolvulaceæ}

from the mother cuttings. However the growing of slip seed every year is a tedious process. To improve the strain and avoid disease slip seed may be grown every second or third year, from hill selected primes. Following the use of such slip seed, primes may be used for one or two seasons, to be followed again by a high strain of slip seed. Roots which are round, chunky, and smooth should be chosen. Seeds which have sprouted in storage should be discarded, as these roots often carry diseases. The seed of some varieties, however, are known always to sprout, no matter under what storage conditions they are kept. In these cases, the sprouts should be broken or rubbed off and the seed be treated with corrosive sublimate before being bedded. No injury results from this process and new sprouts soon follow. As the seeds are being carefully selected one by one, the stem end of each root should be clipped off with a sharp knife to a distance of one third of an inch. Every cut surface should present a clean white appearance. Brown spots in the interior of the root mean the presence of disease in the vessels. Such seeds should be discarded, even though the exterior is healthy looking. In using primes for seeds, selection should be made in the fall at digging time. The roots from the highest yielding and healthiest hills should be chosen, marked, and stored separately under the best possible conditions. Before bedding, these should be sorted over again and the stem ends of the most choice should be clipped to make sure of their freedom from internal disease.

Seed Treatment. Having selected good sound seeds, 


\section{I78 Diseases of Truck Crops}

it is not wise to bed them untreated. In using prime seed they might easily soft rot in the bed. This rotting may be increased where the ends are clipped. To obviate this possibility and to destroy the spores of disease, the seed should be disinfected with a solution of corrosive sublimate made up of one ounce of the chemical dissolved in eight gallons of water, and the seed soaked for ten minutes. Usually it is advisable to treat one bushel at a time. For large quantities of seed, 100 to 200 gallons of the solution may be prepared in several fifty gallon barrels.

Besides treating the seed, the soil in the seed bed must be disinfected. This may be done with the steam method, see pages $54-56$, or with the formaldehyde method, page 53 .

Where flue, hot water, or manure heated beds are used permanently, the wooden framework should be disinfected every year by thoroughly sprinkling or soaking with corrosive sublimate solution or the formaldehyde solution of the same strength as used for the seed. As soon as the framework begins to rot, it should be discarded.

\section{FIELD METHODS OF CONTROL}

The grower's efforts to stamp out the diseases of the sweet potato cannot stop with care that the seed shall be healthy and the seed bed clean. It has already been shown that several diseases like black rot, stem wilt, ground rot or pit, and soilstain may be and are carried over in the soil. These diseases con- 


\section{Family Convolvulaceæ}

stantly spread and increase in the land, as the sweet potato is grown continuously on the same ground. This being the case, we cannot expect healthy plants to thrive or be free from disease on land that is badly infected with disease. Cleanliness is, therefore, the only means of keeping out disease from fields devoted to sweet potatoes.

Sprout Treatment. Before being planted, sprouts should be treated, in order to insure the best stand. Not only are untreated sprouts subject to chance contamination, but they are also the prey to flea beetles as soon as they are planted. When the sprouts are pulled from the seed bed they should be taken at once to a shaded place and dipped into a Bordeaux mixture, 3-3-50.

Other Field Control Measures. Growers will do well to make it a point to inspect their fields every week or two and pull out and burn stunted plants which are yellow, sickly looking, and which fail to grow. These should never be left near the seed bed, but should be destroyed so that the disease cannot spread to the healthy plants. Clean cultivation is essential in preventing field diseases with the sweet potato. In cultivation, great care should be taken to prevent injury to the roots, as an injury means a possible opening for disease.

\section{STORAGE METHODS OF CONTROL}

Before satisfactory conditions can be found for the proper storing of sweet potatoes, there must be a 
clear understanding of the storage problem. Investigations have shown definitely that the greatest loss from disease in storage is due to soft rot. It has been estimated that $90 \%$ of the loss is due to this one disease, $9 \%$ to black rot, and $\mathrm{r} \%$ to all other rots.

Table I4 gives part of the data collected in November, I909, at the storage house of Huston Darbee, Seaford, Del. The thermometer readings are recorded in Fahrenheit degrees and the comparative moisture readings are taken with Mitthof's hygrometers. Whenever the readings of the hygrometer run over 70 and remain there for some time, soft rot sooner or later sets in.

Table I4 also shows that not only is the temperature different in the different parts of the same floor, but that it differs on different floors. Any ventilation which will bring down the moisture content ten or twelve per cent. will help keep sweet potatoes. However, natural ventilation will not always accomplish this, since the moisture content of the outside air is the great governing factor. For instance, it is seen in Table 14 that from the Ist to the 5 th of November, I9I3, the weather was fair and the air dry; hence by opening up doors and windows in the morning, the moisture readings were greatly reduced. However, on the 7 th, the moisture increased when the ventilators were opened on the first floor. A fair day, therefore, does not always indicate dry air, just as a cloudy day does not always mean moist air, as is indicated by the hygrometer readings on both floors during the I4th of November. Rainy days and damp weather 
offer no opportunity for the lowering of the moisture, as will be seen on November I6th, when opening the

\section{TABLE I4}

Storage Temperature and Moisture Reading for November, Igog, for Ist and $3 d$ Floors.

\begin{tabular}{|c|c|c|c|c|c|c|c|c|c|c|c|c|c|}
\hline \multirow{3}{*}{ Dute } & \multicolumn{4}{|c|}{$\begin{array}{c}\text { Thermometer Reading } \\
\text { First Floor }\end{array}$} & \multirow{2}{*}{\multicolumn{2}{|c|}{$\begin{array}{l}\text { Ther. } \\
\text { Read. } \\
\text { Third } \\
\text { Floor }\end{array}$}} & \multirow{2}{*}{\multicolumn{2}{|c|}{$\begin{array}{l}\text { Moist. } \\
\text { Read. } \\
\text { First } \\
\text { Floor }\end{array}$}} & \multirow{2}{*}{\multicolumn{2}{|c|}{$\begin{array}{l}\text { Moist. } \\
\text { Read. } \\
\text { Third } \\
\text { Floor }\end{array}$}} & \multirow{2}{*}{\multicolumn{2}{|c|}{$\begin{array}{l}\text { Outdoor } \\
\text { Temp. }\end{array}$}} & \multirow{3}{*}{ Kind of Day } \\
\hline & \multicolumn{2}{|c|}{$\begin{array}{l}\text { East Side } \\
\text { of House }\end{array}$} & \multicolumn{2}{|c|}{$\begin{array}{l}\text { West } \\
\text { Side }\end{array}$} & & & & & & & & & \\
\hline & A.M. & P.M. & A.M. & P.M. & A.M. & P.M. & A.M. & P.M. & A.M. & P.M. & A.M. & P.M. & \\
\hline I & 54 & 50 & 50 & 54 & 57 & 57 & 62 & 49 & 66 & 46 & 32 & 48 & Fair \\
\hline 2 & 46 & 53 & 50 & 58 & 57 & 62 & 65 & 55 & 67 & 57 & 38 & 54 & Fair \\
\hline 3 & 42 & 53 & 45 & 60 & 55 & 60 & 67 & 46 & 70 & 42 & 33 & 52 & Fair \\
\hline 4 & 52 & 56 & 56 & 63 & 57 & 62 & 68 & 54 & 65 & 50 & 54 & 60 & Fair \\
\hline 5 & 46 & 52 & 48 & 57 & 56 & 60 & 63 & 52 & 65 & 48 & 37 & 54 & Fair \\
\hline 6 & $4 \mathrm{I}$ & 53 & 44 & 60 & 52 & 62 & 67 & 60 & 68 & 47 & 30 & 60 & Fair \\
\hline 7 & 43 & 54 & 49 & 60 & 54 & 64 & 68 & 72 & 67 & 60 & 35 & 64 & Fair \\
\hline 8 & 53 & 58 & 58 & 64 & 59 & 66 & 80 & 77 & 70 & 67 & 54 & 60 & Fair and cloudy \\
\hline 9 & 58 & 54 & 65 & 57 & 62 & 54 & 70 & $7 \mathrm{I}$ & 72 & 60 & 63 & 50 & Rain \\
\hline 10 & 50 & 50 & 54 & 54 & 45 & 52 & 70 & 55 & 60 & 52 & 38 & 45 & Cloudy and fair \\
\hline II & 45 & 47 & 50 & $5 \mathrm{I}$ & 51 & 50 & 65 & 54 & 62 & 48 & 33 & 38 & Fair and windy \\
\hline 12 & 45 & 50 & 49 & 55 & 50 & 54 & 65 & 56 & 63 & 55 & 36 & 42 & Fair \\
\hline 13 & 48 & 55 & 54 & 60 & 52 & 62 & 71 & 55 & 64 & 42 & 45 & 62 & Fair \\
\hline I1 & 54 & 58 & 50 & 64 & 57 & 63 & 70 & 62 & 65 & 56 & 52 & 63 & Cloudy \\
\hline 15 & 46 & 50 & 42 & 52 & 54 & 56 & $6 \mathrm{I}$ & 62 & 65 & 62 & 38 & 43 & Cloudy and rainy \\
\hline 36 & 52 & 54 & 56 & 58 & 56 & 58 & 75 & 79 & 68 & 70 & 50 & 52 & Rainy \\
\hline 17 & 50 & 50 & 56 & 55 & 54 & 56 & 72 & 62 & 68 & 60 & 42 & 48 & Fair \\
\hline Is & 47 & 55 & 50 & $6 \mathrm{I}$ & 54 & 60 & 72 & 50 & 63 & 45 & 37 & 62 & Fait \\
\hline 19 & 55 & 60 & 58 & 68 & 58 & 68 & $7 \bar{I}$ & 59 & 66 & 49 & 42 & 67 & Fair \\
\hline 20 & 58 & 63 & 62 & 70 & 58 & 72 & 68 & 65 & 63 & 55 & 55 & 70 & Fair \\
\hline $2 \mathrm{I}$ & 58 & 65 & 62 & 69 & 62 & 72 & 67 & 71 & 65 & 58 & 49 & 68 & Fair \\
\hline 22 & 55 & 65 & 61 & 70 & 64 & 68 & 68 & 65 & 67 & 53 & 48 & 70 & Fair \\
\hline 23 & 57 & 65 & 62 & 71 & 64 & 72 & 74 & 62 & 66 & 57 & 50 & 73 & Fair \\
\hline 24 & 50 & 58 & 56 & 62 & 64 & 72 & 59 & 46 & 63 & 44 & 50 & 73 & Fair and windy \\
\hline$=5$ & 47 & 55 & 52 & 59 & 62 & 60 & 55 & 47 & 54 & 55 & 38 & 50 & Fair and cloudy \\
\hline 26 & 50 & 55 & 55 & 58 & 60 & 60 & 64 & 64 & $\begin{array}{l}34 \\
56\end{array}$ & 62 & 34 & 46 & Cloudy and rainy \\
\hline 27 & 52 & 54 & 60 & 60 & 58 & 63 & 62 & 65 & 65 & 65 & 45 & 50 & Cloudy \\
\hline 28 & 57 & 58 & 62 & 62 & 60 & 55 & 72 & 75 & 70 & 70 & 46 & 45 & Rainy and cloudy \\
\hline 29 & 60 & 68 & 62 & 62 & 58 & 60 & 75 & 74 & 70 & 74 & 50 & 53 & Cloudy \\
\hline
\end{tabular}

house increased the moisture reading from 75 to 79 degrees. During certain rainy and damp days, the outside air is more moist than the air of the storage house. To ventilate on such days means to bring in 
an excess of moisture and not to ventilate has the same result, since by shutting off all ventilation the inside moisture will accumulate. Thus on days when the inside air is moist, natural ventilation is insufficient. Hence the many critical periods during the storage season.

How to Meet the Ventilation Problem in Storage. The best means of natural ventilation is from the sides, either through doors and windows or through special ventilators (fig. $29 \mathrm{a}-\mathrm{c}$ ). The bins should be constructed with false slat-bottoms, raised from three to four inches from the floor; the sides should be slatted, and at least eight inches from the wall, this space being connected directly with the opening to the floor below.

The ventilation between the floors must be provided by means of trap-doors. In small houses with one row of bins on each floor, these ventilators may be I 2 to 16 inch trap-doors running parallel and adjacent to the side walls. In medium sized houses with two rows of bins and the main aisle through the center running lengthwise through the house, the bins should be 12 to 16 inches from the wall and the trapdoor alongside the wall should occupy the distance between the wall and the bin. In the center aisle, which is usually three feet wide, this entire walk could well be converted into two parallel trap-doors, each $I / 2$ feet wide. Large houses should have their main aisle along the side walls. These should be at least $3 \frac{x}{2}$ feet wide. A center aisle between the two rows of bins should be three feet wide. All these 


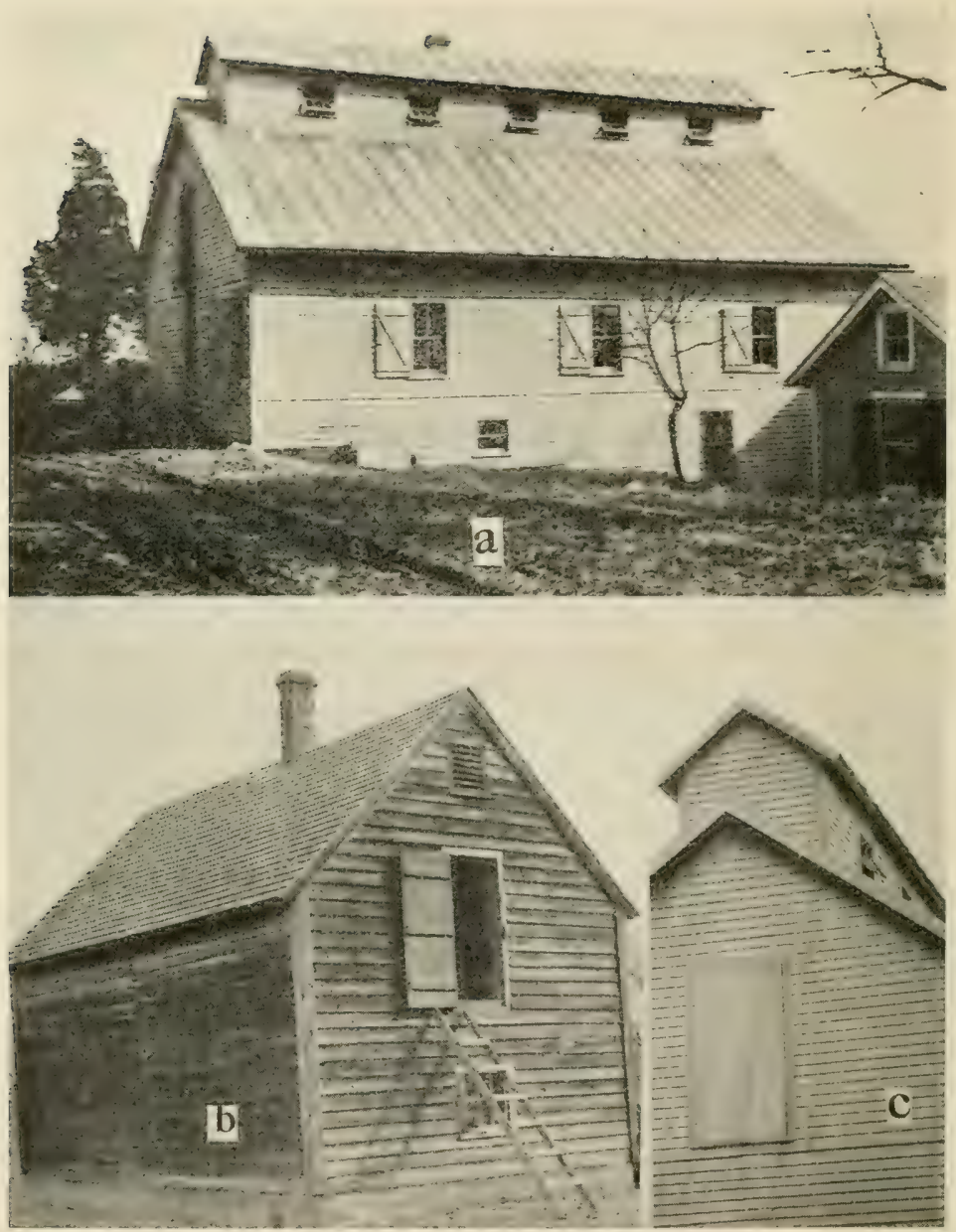

Fig. 29. Siveet Potato Storage Houses.

a. An ideal large commercial dry kiln potato house, showing windows and top ventilators, $b$. a small poor potato house lacking means of ventilation, $c$. a close side view of the top of the ventilator shown at $a$. 
aisles should be converted into trap-doors of two pairs, at least $\mathbf{I} / 2$ feet wide, opening by means of weights either way from the center, and occupying the entire length.

A series of roof ventilators should be provided, sufficient to carry off at least most of the moisture. In small houses there should be at least two such ventilators, each about three feet square and about five feet high. In medium sized houses there should be three of similar dimensions. In large houses from four to six ventilators should be provided (fig. $29 \mathrm{a}$ and c).

Where sweet potatoes are stored in bins, they should first be put into every other one, beginning with the lowest and finishing with the top floor. Thus the filled bins will have a chance to dry out. Bins deeper than seven feet should be divided by two partitions, leaving a two or three inch air space between them. The inner bins throughout should be filled first. It is a mistake to close doors and ventilators when the potatoes are sweating, for during this stage all the ventilation possible should be given, even at night, provided of course that the temperature does not go so low as to cause chilling.

Artificial Aids in Storage. Each floor should be provided with an accurate recording thermometer and hygrometer. With the help of these two instruments, the critical point of excess heat and moisture may be easily determined. It is possible that in order to bridge over these critical periods in storage some system of artificial drying may be required. This 


\section{I84 Diseases of Truck Crops}

may be accomplished by the use of fans or blowers run by electricity or by a small gasoline motor.

\section{WEEDS}

There are but few weeds in this family which are subject to the same diseases as the sweet potato. The wild morning-glory (Ipomcea purpurea), the wild sweet potato (Ipomoa pandurata), and the small and great bindweed (Convolvulus arvensis and C. sepium) are all subject to black rot, Sphceronema fimbriatum. All these weeds are also attacked by white rust, Cystopus ipomaca-pandurana. Whether this rust is the same as the white rust of the sweet potato, or whether it is another physiological species or race, still remains to be determined. But in any case, these weeds must be kept out of sweet potato fields if we desire to keep the black rot of sweet potato in check. 


\section{CHAPTER XIII}

\section{FAMILY CRUCIFERA}

THIs family ranks high in the number of important cultivated plants that it contains. Of the truck crops of economic importance may be mentioned the Brussels sprouts, cabbage, cauliflower, collard, horseradish, kale, kohlrabi, mustard, radish, rutabaga, sweede, turnip, and watercress.

According to the Thirteenth Census of the United States, the area devoted to cabbage in 1909 in all the States was I25,998 acres, and the total crop was valued at \$9,7I9,64I. The important cabbage States, ranked according to area, were as follows: New York, Wisconsin, Virginia, Ohio, Pennsylvania, Illinois, New Jersey, Texas, Michigan, California, Maryland, Florida, Colorado, Iowa, Massachusetts, Minnesota, Louisiana, South Carolina, Mississippi, Alabama, Tennessee, and Kansas. States with less than Iooo acres are omitted.

The total area of cauliflower in 1909 in the United States was estimated at 3466 acres and the total crop was valued at $\$ 602,885$. The States which produced most of the crops are: New York, California, Illinois, Massachusetts, and Florida. 
The total 1909 area in horseradish was estimated at I475 acres, and the total crop valued at $\$ 233,885$. The crop is grown mostly in North Dakota, Pennsylvania, New York, New Jersey, and Illinois.

The total $\mathbf{I} 909$ area in kale was estimated at $\mathbf{I} 495$ acres, and the total crop valued at \$146,oIo. The crop is principally grown in Virginia, Kentucky, Maryland, and New York.

The total 1909 area devoted to radish was estimated at 2269 acres, and the total crop valued at $\$ 293,062$. The crop is grown in the following States, ranking in order according to acreage: New York, Alabama, Virginia, Illinois, Mississippi, Louisiana, Missouri, and Texas.

\section{DISEASES OF CABBAGE (Brassica oleracea)}

The cabbage, although a hardy plant, is nevertheless subject to numerous diseases. Disease may reduce the profits of the crop by fifty per cent., or even mean total failure.

\section{Club Root}

Caused by Plasmodiophora brassica Wor.

Club root is a field disease only. Few plant diseases are as cosmopolitan as this trouble. It is found in many of the European countries, and in Australia, New Zealand, and in the United States. The loss from club root ranges from forty to seventy 



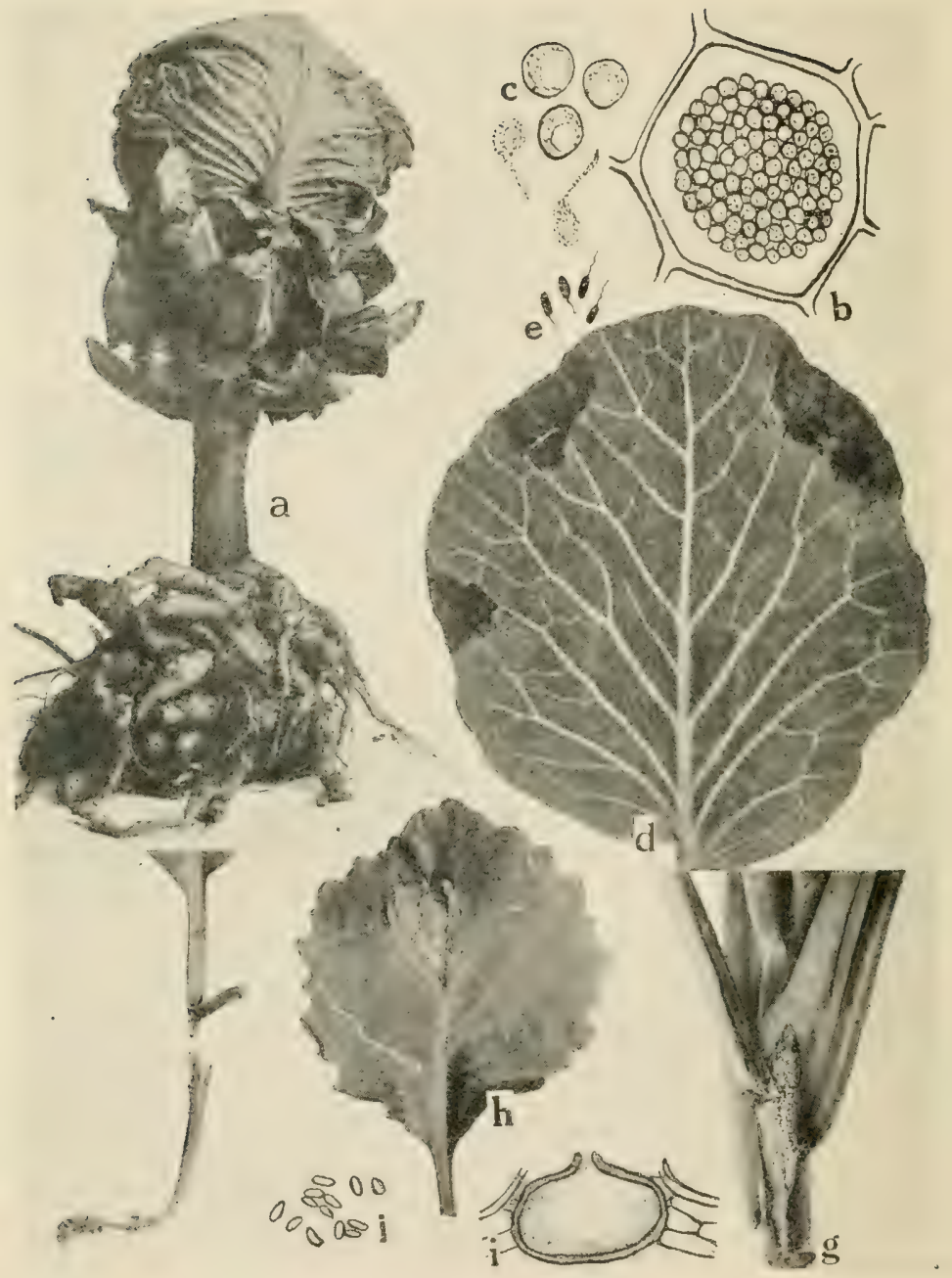

Fig. 30. Cabbage Diseases.

$a$. Club root (after Cunningham), $b$. cell filled with spores of the club root organism, $c$. spores and swarm spores of P'lasmodiophora brassica (b. and $c$. after Chuff), $d$. black rot of cabbage (after F. C. Stewart), $e$. individual black rot germs of $P$ seudomonas campestris, $f$. black-leg on young cabbage seedling, g. black-leg lesion on foot of older cabbage plant, $h$. black-leg lesion on cabbage leaf, $i$. pycnidium of Phoma oleraces, $j$. pycnospores of $P$. oleracece ( $i$, and $j$. after Manns). 


\section{Family Cruciferæ}

per cent. of the crop, although most of it may be prevented.

Symptoms. Affected plants show a wilting of the foliage in the day, although recovering in the evening or during cloudy weather. Diseased plants are dwarfed, pale, and sickly looking. The seat of the trouble is at the roots. The latter swell considerably in size, often taking on the form of a hernia (fig. $30 \mathrm{a}$ ). The disease is more severe on seedlings in the seed bed, from whence it is carried to the field.

The Organism. Club root is caused by a slime mold. The spores of the parasite (fig. $30 \mathrm{~b}$ ) are nearly round and possess a transparent and refractive cell wall. According to Chupp, ${ }^{1}$ the first signs of germination are a swelling of the spores, followed later by a bulging at one side. The inner pressure exerted splits the spore wall, thus permitting the protoplasm (swarm spores) to ooze out. The latter is without a cell wall (fig. $30 \mathrm{c}$ ), and is capable of motion by means of a thick flagellum at the small end. The germination of the spores is improved by exposing them for a short time to cold and drying. The best medium is water which has been filtered through muck soil.

Infection of the host takes place through the wall of the root hair while the organism is in a uninucleate stage. Entrance of the parasite is evidenced by the browning and shriveling of the root hair. The disease does not seem to be spread from place to place

'Chupp, Charles, New York (Cornell) Agr. Expt. Sta. Bul., $387: 421-452,1917$. 
by the wind. But infected manure in the seed bed will result in infected seedlings carrying the disease into a new field. Club root is known to attack a large number of cruciferous hosts, the more susceptible of which include all of the cultivated species.

Control. The best method of controlling club root is to grow cabbage on new land, or on land that was rotated with other crops, and given a rest from cruciferous crops for some time. Where it is not possible to do this, infected fields should be limed. Table I5, adapted from Cunningham, ${ }^{\text {I }}$ clearly shows the effect of lime in controlling club root.

From Table 15, it is seen that the use of fresh or air-slaked lime lowers the percentage of club root as compared with the calcium chloride on check plats. Moreover, when clubbing appeared in the limed areas, the disease seemed to be confined to the lowest roots and outside of the reach of lime. This then enabled the affected plants to make a crop in spite of the disease. The best effect of liming may be expected when the lime is thoroughly incorporated in the soil to a depth of six to nine inches. As far as possible the trucker should avoid susceptible varieties of cabbage, among which may be mentioned: Mammoth Rock Red, Dark Red Erfurt, American Savoy, Perfection Savoy, All Seasons, and Volga. Of the more resistant varieties of cabbage may be mentioned Hollander, Stone Mason, Large Late Flat Dutch, and Henderson's Early Summer. Finally, care

${ }^{x}$ Cunningham, L. C., Vermont Agr. Expt. Sta. Bul., 185:67-96, I9I4. 


\section{Family Cruciferæ}

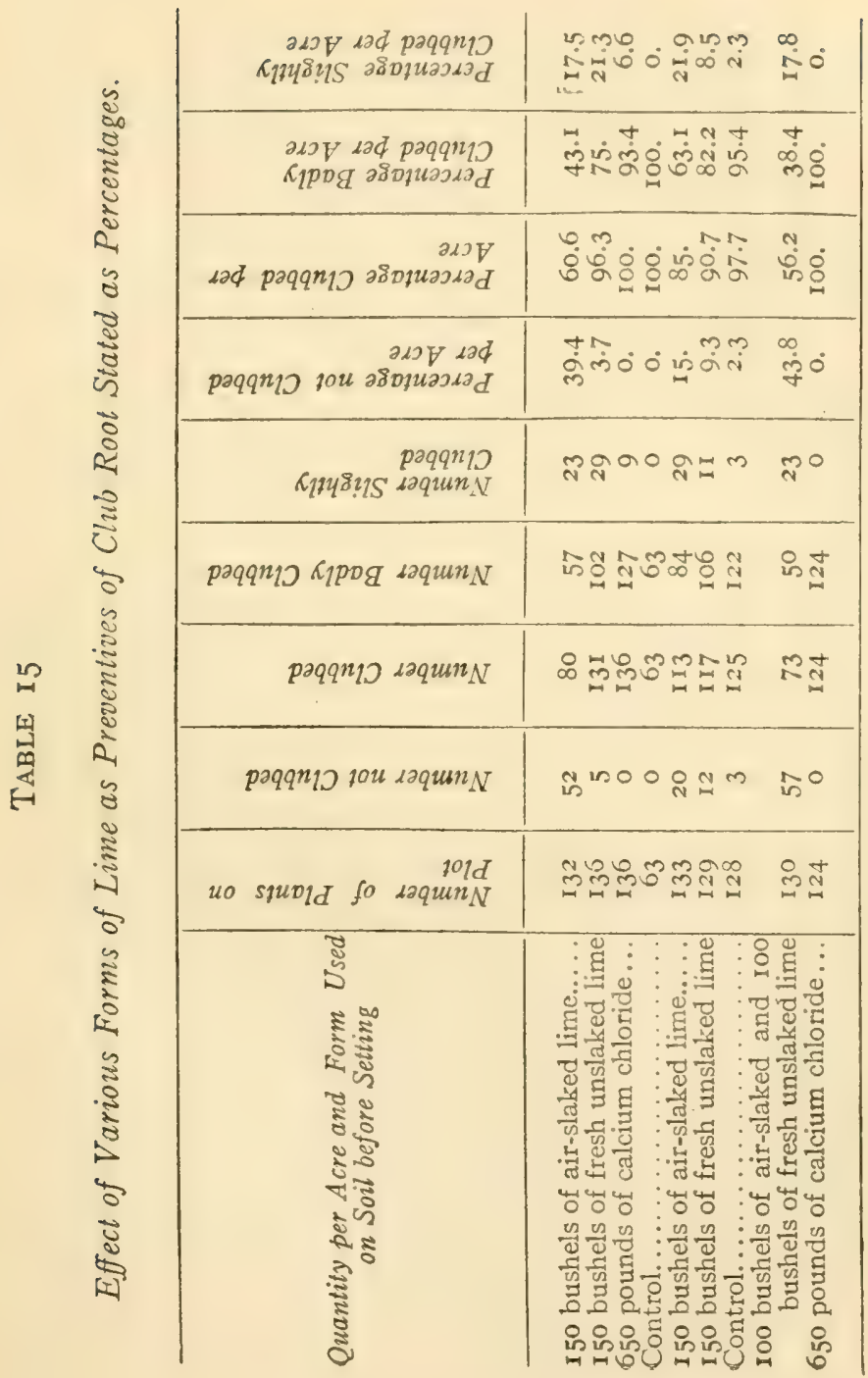


should be taken to exclude club roots from the seed bed, since many an outbreak of this trouble may be traced back to the use of previously infected seedlings.

\section{Black Rot}

\section{Caused by Pseudomonas campestris (Pammel)} Ew. Sm.

The disease is known to growers as stem rot and black rot. The latter perhaps is the more common name. The trouble may now be found wherever cabbage is grown on a large scale.

Symptoms. Black rot has distinct symptoms which cannot easily be confused with other cabbage diseases. On the leaves, the symptoms are manifested as a burning appearance on the edges (fig. $30 \mathrm{~d})$ and a yellowing of all the affected parts except the veins, which remain blackened. From the margin of the leaves the disease works downwards to the stalk. From there the disease travels up again to the leaves and from there to the stems. The parasite works in the fibro-vascular bundles of the leaves and main stalk, causing a premature defoliation. Occasionally, the disease enters one side of the stalk, the latter becoming dwarfed and the cabbage head becoming one sided. In severe cases of attack, there is a total lack of head formation. In splitting open a stump of an affected plant, we will find a black ring which would correspond to the places of the fibrovascular bundles invaded by the organism. Smith ${ }^{x}$

'Smith, E. F., U. S. Dept. of Agr. Farmers Bul., 68: 5-2I, I898. 


\section{Family Cruciferæ}

found that the infection takes place through small openings naturally found on the leaves and known as water pores which are found scattered over the teeth of the leaves. Infection by means of insect bites is also a very common occurrence. Outbreaks of black rot in new fields may undoubtedly be traced back to the use of infected manure. Black rot also attacks broccoli, Brussels sprouts, cauliflower, charlock, collard, kale, kohlrabi, black mustard, rape, rutabaga, radish, sweede, and turnip.

The Organism. Pseudomonas campestris is a rodshaped organism, slightly longer than it is broad. When young it is actively motile by means of long polar flagella (fig. $30 \mathrm{e}$ ). It is found single or in pairs and produces no spores. It liquefies gelatine completely in about fifteen days. On agar plates the colonies are round, yellow in color, and the margin entire. On potatoes a copious growth is produced with no odor and no browning of substances. The investigations of Harding ${ }^{\mathrm{I}}$ and others have proved that the black rot germ may be introduced into the seed bed and into new fields from infected cabbage patches. The virulence of black rot is largely dependent on the weather. It is unfortunate that favorable weather conditions for the cabbage plants are also favorable for the disease.

Control. Before planting, cabbage seed should be disinfected for fifteen minutes in a solution of $1 / 4$ pint of pure $(40 \%)$ formaldehyde diluted in seven gallons

'Harding, H. A., New York (Geneva) Agr. Expt. Sta. Bul., 251: 178-194, 1904. 
of water. In making the seed bed, manure known to be free from cabbage refuse should be used. All insect pests should be kept in check by spraying, and no animals should be allowed to roam in sick patches. Insects and farm animals act as carriers of black rot. The disease cannot be controlled by merely cutting off diseased foliage. If anything, this operation aggravates the trouble. Diseased plants should be pulled out and destroyed. Crop rotation should be practiced wherever the disease is well established.

\section{SoFt Rot}

\section{Caused by Bacillus carotovorus Jones.}

Soft rot, although a field trouble, causes great damage to stored cabbage. The greatest losses are reported from New York and Wisconsin where cabbage is stored on a large scale.

Symptoms. The disease is characterized by a soft, mushy to slimy decay of the entire plant. The disease works very rapidly under favorable conditions of moisture and temperature. The causal organism can gain entrance only through a wound or bruise. Rough handling of the crop during hauling and storing therefore opens the way to heavy infection and consequently loss from soft rot.

The Organism. The Bacillus is rod-shaped, long or short, and usually formed in chains. It moves about by peritrichous flagella. It completely lique- 


\section{Family Cruciferæ}

fies gelatine in about six days. Gas is produced with a majority of strains.

Control. The greatest loss in storage occurs where the temperature is maintained much above the freezing point and where the facilities for ventilation are poor. To remedy this, the temperature, as far as possible, should be maintained one or two degrees above freezing. The crop should be thoroughly dried and exposed to the sunlight before being entered into storage. Diseased fields should be rotated to other crops.

\section{DAMPING OFF}

\section{Caused by Olpidium brassicce (Worr.) Dang.}

The symptoms of damping off are similar to those produced by Pythium de Baryanum, p. 43. The sporangia of the parasite may be found singly or in groups in each infected host cell. The zoospores are globose, uniciliate. The resting spores are globose, wrinkled, and star-like in appearance.

The disease is found mostly in seed beds, where it does considerable damage. For methods of control see p. 43 .

\section{White Rust}

Caused by Cystopus candidus (Pers.) Lev.

White rust of cabbage is seldom troublesome enough to attract attention. The symptoms of the disease are the same as on other cruciferous hosts such as mustard or radish, p. 2II. 
DOWNy MILDEW

Caused by Peronospora parasitica (Pers.) De By.

Downy mildew, while a common field disease, causes considerable damage to young seedlings. It is characterized by whitish downy patches on the under side of the leaf. Seen from above, the affected areas are angular, pale yellow, and somewhat shrunken. The spots seem to be limited by the veins of the leaf. The disease is common in damp weather. Besides the cabbage, cauliflower, radish, turnips, and numerous other cruciferous hosts are known to be susceptible to downy mildew.

The sporophores of the fungus are stout and numerously branched, each branch repeatedly forked. The tips of the smaller branches are slender and curved. The conidia are broadly elliptical, and the resting spores are globose and smooth, becoming wrinkled with age.

In the seed bed or in the field, spraying with 4-4-50 Bordeaux will control the disease. The first application should be given as soon as the disease makes its appearance. Later the application will be governed by weather conditions.

\section{DROP}

\section{Caused by Sclerotinia libertiana Fckl.}

Drop is a disease fairly common on cabbage. The trouble may be recognized by a drooping and wilting 


\section{Family Cruciferæ}

of the leaves. The bases of the affected foliage are covered with a white weft of mycelial growth, later by sclerotia. For a more extended discussion of the disease see lettuce drop, p. I43.

\section{BLACK LEG OR FOOT ROT}

\section{Caused by Phoma oleracea Sacc.}

Black leg, first noticed in the United States by Manns $^{x}$ in Ohio, was undoubtedly introduced here from Europe.

Symptoms. The disease is usually manifested in the seed bed about two to three weeks before transplanting in the field. The trouble at first appears as white elongated sunken lesions on the stem and below the leaf attachment (fig. $30 \mathrm{f}$ ). Scattered over the lesions are minute black specks which constitute the pycnidia or fruiting sacs of the fungus (fig. $30 \mathrm{i}$ and $\mathrm{j}$ ). Infected seedlings usually collapse and take on a bluish color. In the field, the foliage of the older but affected plants (fig. $30 \mathrm{~h}$ ) usually take on a mottled, metallic, bluish-red color at the margins, and the lower outer leaves wilt. On examining such plants there will always be found sunken lesions (fig. $30 \mathrm{~g}$ ) which often girdle the foot of the plant. In wet weather affected plants attempt to produce new roots above the infected area, which, however, are never able sufficiently to support the plant. Foot rot is often confused with forms of injury brought about by maggots.

${ }^{x}$ Manns, T. F., Ohio Agr. Expt. Sta. Bul., 228: 255-297, 191 I. 


\section{Diseases of Truck Crops}

Treatment. Manns recommends treatment of the seed bed with $4-4-50$ Bordeaux to be applied immediately after planting, at the rate of one gallon to each ten square feet of bed space. The bed is again sprayed with Bordeaux about two weeks before and once again at transplanting.

\section{Black Mold}

Caused by Alternaria brassica (Berk.) Sacc.

Black mold is a serious disease of the cabbage in the Southern States. It also attacks collards.

Symptoms. Affected leaves are covered with spots which are nearly black on the under side of the leaf. The spots are composed of a series of rings, the smaller ones enclosed within the larger (fig. $3 \mathrm{I}$ a). There is no distinct border separating the diseased from the healthy, the spots gradually shading off into the healthy tissue. Little is known of the causative fungus or of the control of this disease. It is probable that spraying with $4-4-50$ Bordeaux will be of value.

\section{LEAF SPOT}

Caused by Cercospora bloxami B. and $\mathrm{Br}$.

Leaf spot is of little economic importance. It only attacks the leaves of weak or languid plants. The spots are pale, somewhat circular, surrounded by a slightly raised, faintly purple border. The conidial 

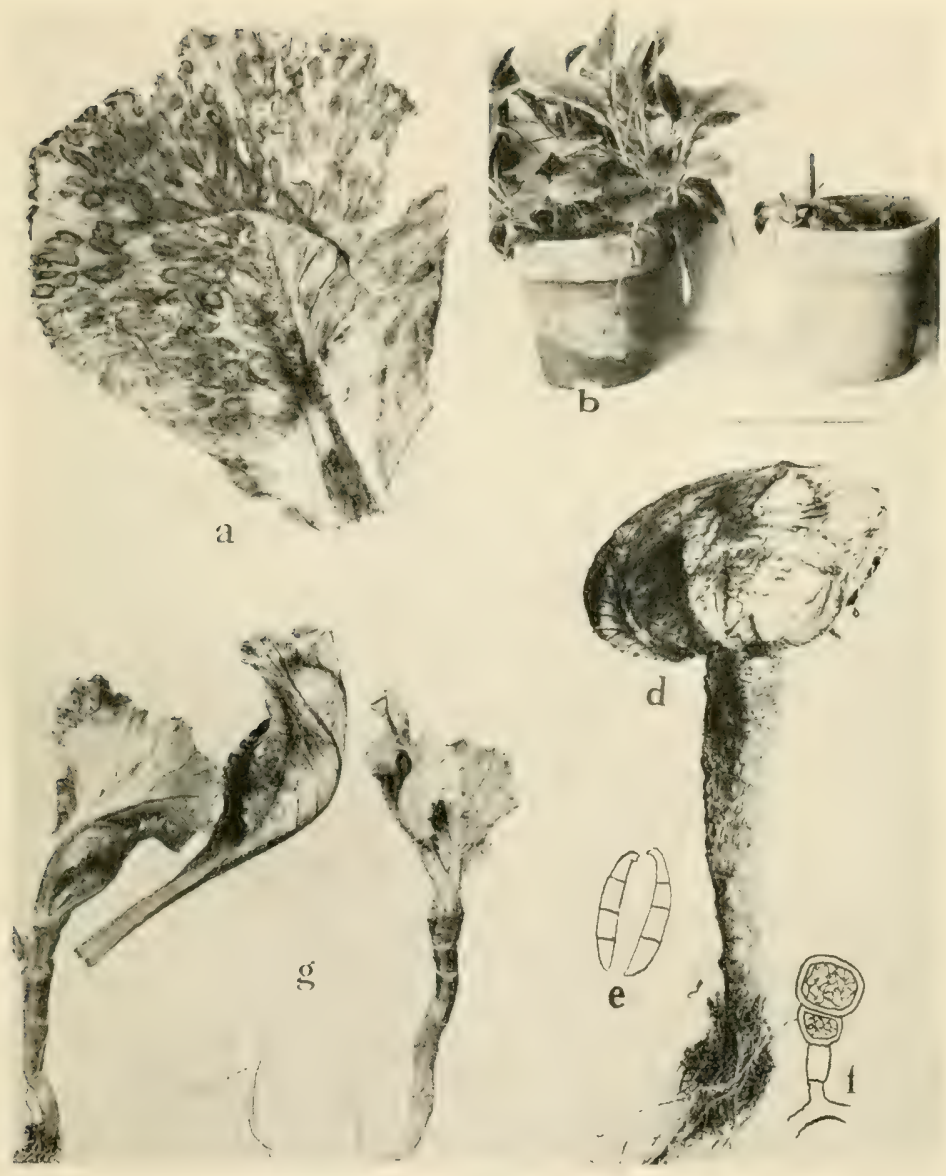

Fig. 31. Cabbage Diseases.

a. Alternaria black mold, $b$. cabbage seedlings growing in a cabbage sick soil which has been steam sterilized, $c$. sick cabbage seedlings in a cabbage sick soil, (after Jones and Gilman), $d$. an old wilt infected cabbage plant: notice bare stalk, $e$. conidia of Fusarium conglutinans, $f$. clamydospores (resting spores), of $F$. conglutinans, $g$. wilt infected cabbage seedlings: notice how the leaflets drop off as a result of the disease. 



\section{Family Cruciferæ}

tufts are prevalent in the center of the spots, and are pale brown and sparingly septate. The conidia are long clavate, tapering, straight to curved, many septate, and hyaline to faint smoky color.

\section{WILT OR YELLOWS}

\section{Caused by Fusarium conglutinans Woll.}

There is no other cabbage disease that is economically so important as wilt. This trouble is threatening the cabbage industry in many parts of the United States. In the cabbage centers of Ohio and Wisconsin, truckers lose so heavily from wilt, that in many sections, the growing of the crop has been made very unprofitable.

Symptoms. The term "yellows" well describes the disease. Affected seedlings are yellowish and stunted in growth with a tendency to drop their lower leaves at the least touch (fig. 3I g). Such plants when transplanted in the field either die outright or make very slow growth. The symptoms in the older affected plants are the same as on the seedlings. The outer leaves turn yellow and drop off one by one, until a bare stump and top head are left (fig. 3 I d). Usually the plant is uniformly attacked; but the infection may be confined to one side. This one-sided check results in the lateral warping and curving of the stems and leaves. Under field conditions, high temperatures are very favorable for the spred and development of yellows.

The Organism. The best description of Fusarium 
conglutinans Woll. is given by Gilman. ${ }^{x}$ Sporodochia, lacking or greatly reduced, pionnotes never present, conidia borne on short conidiophores strewn throughout the mycelium. The majority of spores are non-septate, a few are one to three septate (fig. 3I e); conidia with higher septation are rare. In old cultures, chlamydospores are produced in great abundance (fig. $31 \mathrm{f}$ ).

Control. Cabbage yellows cannot be readily controlled. Naturally a clean seed bed should be chosen (fig. 3I b-c). However, the healthy seedlings when transplanted into infected fields will soon contract the disease. The same also holds true even when the seeds are disinfected. Neither is crop rotation a sure method of control. It is doubtful if fifteen years' rest from cabbage will free a soil from the causative parasite. The best method of control is the development of resistant varieties. This has already been accomplished by Jones and Gilman ${ }^{2}$ who selected a strain from the Hollander which they named Wisconsin Hollander No. 8. This strain is said to be nearly 100 per cent. resistant to wilt. The same is also true for the Volga (fig. $32 a-b$ ). The question arises as to whether a cabbage selected for resistance under Wisconsin soil will show it in a like degree in other climatic conditions and soil. For the cabbage the answer may be given in the affirmative. For instance, the Houser and the Volga, which

${ }^{1}$ Gilman, J. C., Annals Missouri Bot. Garden, $3: 2-84$, 1916.

2 Jones, L. R., and Gilman, J. C., Wisconsin Agr. Expt. Sta. Bul., $3^{8}: 1-69$, 1915 . 

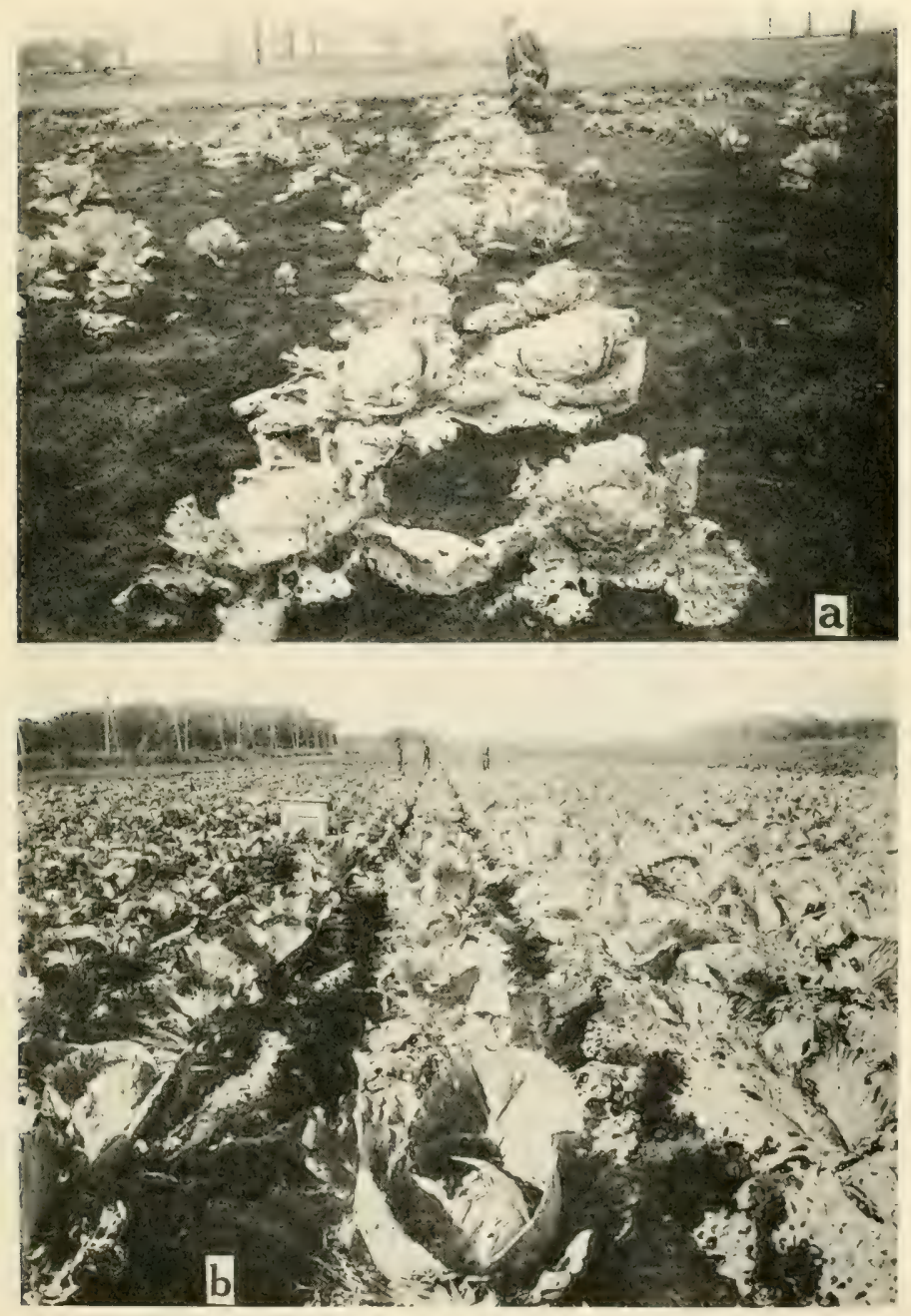

Fig. 32. Cabbage Diseases.

a. Two rows of Volga, a highly resistant commercial cabbage growing in a cabbage sick soil (yellows), $b$. resistant cabbage strains in a cabbage sick soil ( $a$. and $b$, after Jones and Gilman). 



\section{Family Cruciferæ}

have proved wilt proof in Maryland, have proven equally resistant under $W$ isconsin conditions. It is, however, advisable to grow seed in the same locality where the resistant cabbage has been developed. The method of developing resistant varieties is given more fully on p. 374 .

\section{RoOT KNOT}

\section{Caused by Heterodera radicicola (Greef) Müll.}

Root knot is very widespread in the Southern States, but is confined mostly to the light sandy soils. It is often mistaken for club root. Careful observation will show the differences. Root knot is characterized by small stvellings on the lateral feeding roots. For a description of the parasite and methods of control see p. 49.

\section{Decay of Cabbage in Storage}

Not all field-grown cabbage is consumed when harvested. A large part of the crop is stored away for winter use. It is estimated by Harter ${ }^{\mathrm{I}}$ that of the thousands of tons stored every fall, from ro to 50 per cent. is annually lost from decay. With the exception of yellows, practically all the other field rots of cabbage may be active also under storage conditions. Therefore, to store a clean crop we must produce a clean crop in the field and on no account should infected cabbage be allowed in the x Harter, L. L., U. S. Dept. Agr.'Bur. P1. Ind. Circ., 39: 3-8, 1909. 
storage house. Cabbage from badly diseased plants should be disposed of early.

Poor Storage Conditions. Cabbage houses are usually built as permanent structures. When this is the case, they must be thoroughly cleaned out and disinfected every year before storing a fresh crop. All indoor framework should be sprayed with a solution of one pint of formaldehyde in forty gallons of water. This is done a week or two before storing in order to allow the house to dry thoroughly.

In harvesting and handling the crop, every care should be taken to prevent unnecessary bruising of the heads. Storers of cabbage are confronted with the same difficulties as storers of sweet potatoes. With both, the great problem is the ventilation and the elimination of excess of moisture given off by the crop in storage. In warm houses quantities of moisture soon accumulate in the house, which, if not carried off, soon deposit on the cabbage.

Storage houses may be so constructed as to take care of the ventilation and moisture under normal conditions. The walls of the buildings should provide a dead air space to prevent the penetration of the outdoor moisture. With brick walls, two fourinch walls could be laid and tied up by a header course, thus providing an air space of two to three inches between them. Wherever possible thick walls should be preferred, as these make it possible to keep the interior cool during hot weather. The roof should be provided with a good outer covering of shingles, and with an inner lining so built as to 


\section{Family Cruciferæ}

provide a dead air space. If the inner lining is made up of lumber, the boards should run parallel with the rafters, rather than at right angles to them, so that any condensed water may run off to the eaves rather than fall from each joint. Ventilation should be encouraged by means of top ventilators on the roof. These should be provided with dampers, manipulated and controlled by ropes extending to the passageway. Small windows installed above the foundation line in the walls will admit air from below and induce a better circulation. The windows may be screened with an iron netting in order to keep out mice.

There are two ways of storing cabbage-in bins or on shelves. The latter is preferred because there is less bulk to undergo a sweat, and each individual cabbage being exposed to more air prevents rotting. In storing, the cabbage should be placed with the stem end upward so that all possible moisture may readily run off and not be caught and held by the head leaves.

So far as possible, the temperature of the storage house should be maintained at about thirty-four degrees $F$. throughout the storage period. As soon as the house is filled, it should be kept closed during the day and be opened at night in order to benefit from the cool outdoor air. During extremes of cold weather, ventilation should be reduced to a minimum and the house kept warm by an oil heater to prevent freezing of the cabbage. The Danish Ball Head, from imported seed, seems to be an ideal cabbage for storage. 


\section{DISEASES OF THE CAULIFLOWER (Brassica oleracea var. botrytis)}

The cauliflower with few exceptions is subject to the same diseases as the cabbage. For a discussion of black rot, see p. I90; soft rot, p. I92, club root, p. I86, and drop, p. I43.

\section{BActerial Leaf Spot}

\section{Caused by Pseudomonas maculicola $\mathrm{McC}$.}

Bacterial leaf spot was first studied and described by $\mathrm{McCulloch}{ }^{\mathrm{I}}$ who found it to be prevalent in southeastern Virginia and in Florida. The disease undoubtedly must have a wider and more geographical distribution than is generally known. The author has met with this disease in New Jersey, Delaware, Maryland, and Texas.

Symptoms. The disease is characterized by numerous small brownish to purple-gray spots (fig. 33 a). When the small spots coalesce, the entire leaf surface may be involved. Practically all parts of the leaves are affected. When the midribs and veins are attacked, the tissue becomes shrunken, and the leaves have a puckered appearance. In early stages of infection, the spots on the leaves are watersoaked, later becoming dry and dark to purplish gray. In transmitted light the centers of the spots are thin, almost colorless, and surrounded by a dark border.

${ }^{x}$ McCulloch, Lucia, U. S. Dept. of Agr. Bur. Pl. Ind. Bul. 225 : 715, I9II. 

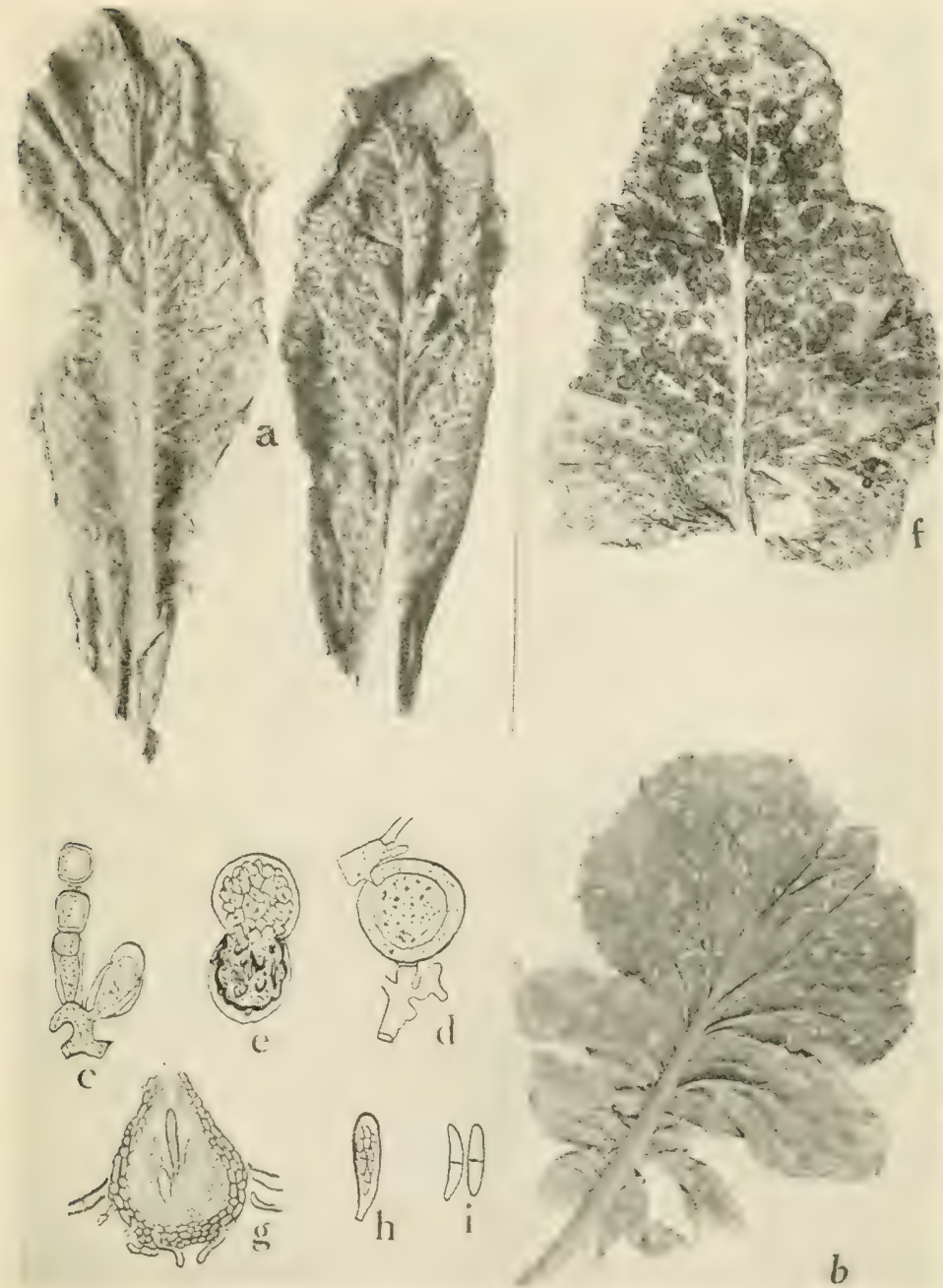

Fig. 33. Diseases of the Cauliflower and Radist.

a. Spot disease of cauliflower (after McCulloch), $b$. white rust of radish, $c$. conidiophore of the white rust fungus, Cyslopus candidus, $d$. fertilization in Albugo candida, e. germination of the oospore of Albugo candida, $f$. ring spot on cauliflower head, $g$. perithecium of Mycospherella brassicicola, $h$. ascus of Mycospharella brassicicola, $i$ ascospores of Mycospharella brassicicola ( $\mathrm{g}$. to $i$. after Osmun and Anderson). 



\section{Family Cruciferæ}

The diseased leaves become yellow and drop off prematurely. The trouble apparently does not attack the cauliflower head. The same disease may also attack cabbage, but not radish, rutabaga turnip, or mustard.

The Organism. Pseudomonas maculicola is a rod-shaped organism, with rounded ends, usually forming long chains in certain media, but producing no spores. The organism is actively motile by means of polar flagella. Involution forms are produced in alkaline beef bouillon; and pscudo-zoogloexe occur in acid beef bouillon. No gas is produced and the organism is aerobic, and is killed by drying and exposure to light.

Control. Badly diseascd plants should be pulled up and destroyed. Spraying with 4-4-50 Bordeaux is recommended. In spraying cauliflower with copper compounds, and cspecially if the latter are in a concentration somewhat stronger than the plant can stand, numerous warts will appear on the leaves in about three days after spraying. These warts should not be mistaken for a disease induced by a parasitic organism. The wart formation is apparently due to a stimulation by the salts absorbed by the host cells. Von Schrenk ${ }^{\mathrm{I}}$ found that warts on cauliflower leaves may be readily produced by spraying them with a solution made up of $5 \mathrm{oz}$. copper carbonate dissolved in a mixture of three pints of ammonia to fifty gallons of water. He further found

IVon Schrenk, H., Missouri Bot. Gard., 16th Ann. Rept. : 125, 1905. 
that leaf warts may be produced by spraying with weak solutions of copper chloride, copper acetate, copper nitrate, and copper sulphate.

\section{RING Spot}

Caused by Mycosphcerella brassicola (Duby) Lind.

The exact distribution of this disease is as yet unknown. The trouble was studied by Osmun and Anderson $^{\mathrm{I}}$ on cauliflowers shipped from California to Boston.

Symptoms. On the leaves, the disease appears as numerous small spots and the affected foliage turns yellow. Most of the spots are formed on the laminæ, but others are also formed on the large midribs. The spots are definite in outline, round and visible on both surfaces of the leaf (fig. $33 \mathrm{f}$ ). The color is light brown to gray, with dry centers surrounded by olive green or blue green borders which shade off in the natural color of the leaf. The outer edge of the spot is covered with the fruit of the fungus (fig. 33 $\mathrm{g}-\mathrm{i}$ ). Ring spot also attacks the cabbage. Spraying with $4-4-50$ Bordeaux is recommended.

\section{DISEASES OF THE HORSERADISH (Cochlearia} armoracia)

The horseradish is generally considered a hardy plant. However, it is subject to numerous diseases.

${ }^{2}$ Osmun, A. V., and Anderson, P. G., Phytopath. 5: 260-265, 1915. 
The black rot, Pseudomonas campestris, is the same as that of the cabbage, p. I90, and the white rust, Cystopus candidus, is the same as that of the mustard, p. 2 II.

\section{Root Rot}

Caused by Thielavia basicola (B. and Br.) Zopf.

Root rot of horseradish is of little economic importance. The disease is confined to the roots of the plant. In advanced stages the normal root system may be entirely lacking, leaving a charred, blackened stub. New roots are constantly formed above the diseased area, but these in turn become affected and die. It is these new roots which the plant attempts to produce that manage to keep the infected host alive in a stunted and useless form. For a description of the organism and methods of control, see p. 275 .

\section{Ascochyta Leaf Spot}

\section{Caused by Ascochyta armoracia Fckl.}

This form of leaf spot is rather scarce in the United States and may be easily overlooked. The disease is manifested as brownish leaf spots of various sizes. Within the spots numerous pycnidia are formed which bear numerous elliptic-oblong, hyaline oneseptate spores. 


\section{SHOT Hole}

Caused by Septoria armoracice Sacc.

Shot hole is a very serious disease which attacks the foliage of horseradish. Diseased leaves turn yellow and become peppered with round spots, whitish in the center, surrounded by a pale yellow border. The spots drop out and give the leaves a ragged shaggy appearance. The pycnidia of the fungus are formed in the center of the spots previous to their dropping out or on the remaining margin of the spot.

\section{MAcrosporium BLACK MOLD}

Caused by Macrosporium herculeum E. and M.

This mold is confined to the leaves only. Late in the summer the leaves are attacked by round spots which at first are whitish, and later become coated with a black mold made up of the spore bodies of the fungus. Horseradish may also be attacked by another form of black mold, Alternaria brassica (Berlz.) Sacc., see p. 196.

\section{WhITE MOLD}

Caused by Ramularia armoracia Fckl.

White mold is frequently met with on foliage of the horseradish. The spots are indefinite, irregular, 



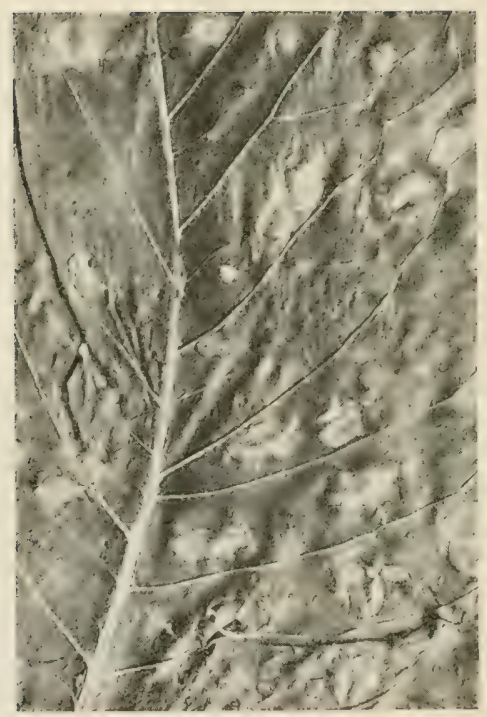

Fig. 34. Cercospora Leaf Spot of Horse Radisi. 


\section{Family Cruciferæ}

and usually occupy large areas of the leaf. At first they are yellowish red in color; but they become gray with age.

\section{LEAF SPOT}

Caused by Cercospora armoracice Sacc.

Leaf spot is characterized by pale spots on the leaves (fig. 34). The spots are usually confined to weakened leaves. The disease is of no importance.

Control. Usually the diseases of the horseradish are not serious enough to warrant treatment. However, when the crop is grown on a large scale, it should not be planted anywhere near cabbage or other cruciferous plants in order to protect it from black rot. If any of the leaf spots become serious the affected parts may be removed and destroyed and the plants sprayed with $4-4-50$ Bordeaux. The plants should be carefully cultivated and fertilized in order to maintain their vigor, thereby also preventing the leaf diseases from getting troublesome.

DISEASES OF THE KALE (Brassica oleracea var. acephala)

Kale is considered a very hardy plant; it is, however, subject to black rot, Pseudomonas campestris (Pam.) $\mathrm{Ew} . \mathrm{Sm}$. On the leaves, black rot is characterized by dark discoloration of the veins, and on the root, 
by a blackening and decaying of the stem; see also p. 190. Kale is also attacked by club root Plasmodiophora brassica Wor., see p. I86.

\section{DISEASES OF THE MUSTARD (Brassica Japonica)}

Garden mustard Brassica Japonica is cultivated for its foliage. It is used as a green, relished for its edible qualities, and as a spring tonic. Mustard is subject to the following diseases:

Black Rot, see CABbage, p. I90.

Club Root, see Cabbage, p. I86.

White Rust (fig. 35 b-e), see Radish, p. 193.

\section{DISEASES OF THE RADISH (Raphanus sativus)}

Radish is subject to many diseases in common with the cabbage and numerous other crucifers.

Club Root, see Cabbage, p. I86.

\section{Black Rot}

Caused by Pseudomonas campestris (Pam.) Ew. Sm.

Black rot on radish is confined mostly to the tender white-rooted varieties, especially the Icicle. The black-rot germ penetrates the lateral feeding rootlets, from which it works its way in the main root. In cutting across a diseased radish, its interior fibrovascular bundles are found to be blackened. Such 


\section{Family Cruciferæ}

radishes are useless for the market. The disease seldom attacks the red or the black-skinned varieties. For further consideration of black rot see p. 190.

\section{SCAB}

Caused by Actinomyces chromogenus Gasp.

Scab is not a common field disease of radishes. It is, however, found to be troublesome on the crop grown in greenhouses. The French Breakfast is commonly susceptible to the disease. The trouble may be expected if the crop is planted in a soil which previously produced a potato crop that was badly scabbed or where infected manure was used, or too much lime applied. For further description of scab, see p. 317 .

\section{DAMPING OFF}

\section{Caused by Rheosporangium aphanidermatum Ed.}

This disease, which was studied and described by Edson, ${ }^{{ }^{2}}$ is very troublesome, attacking radish and beet seedlings alike.

Symptoms. The disease is confined to the root system, seldom appearing above ground. Diseased plants have a flabby appearance, and the normal green of the foliage is displaced by a slightly yellowish tinge.

$\checkmark$ Edson, H. A., U. S. Dept. of Agr., Jour. Agr. Research, 4:279292, I9I5. 
In severe cases the entire stand may be wiped out. On carefully pulling out a diseased plant, we shall find the side rootlets blackened, shriveled, and dead (fig. 35 a). Frequently the plant attempts to produce new roots above the diseased area. In this case, however, there is only partial recovery. The disease is most prevalent in the heavy soils.

The Organism. In general characters, the organism may be mistaken for Pythium de Baryanum, but it differs from the latter in its asexual fruiting bodies. The mycelium of Rheosporangium aphanidermatum is hyaline, non-septate (fig. $35 \mathrm{c}$ ), and grows profusely on solid media. Mycelium of cultures one or two days old exhibits considerable streaming of protoplasm which seems always directed toward the tip end of the hyphæ. This protoplasmic streaming results in the final accumulation in protoplasmic material, and in consequence of a considerable enlargement of the tip of the thread. Finally a cell wall is laid down which cuts off the swollen portion from the rest of the mycelium. This swollen body which Edson named presoporangium (fig. 35 b) has the appearance of a zoosporangium but in reality it differs from it since it gives rise not to zoospores, as might be expected, but to an independent body which later gives rise to zoospores. The presoporangium now absorbs water and its outer wall ruptures, from which is seen to flow out a mass of protoplasm enclosed in a thin cell wall. This escaped mass is really the young zoosporangium, the cytoplasm of which finally cleaves into zoospores. 

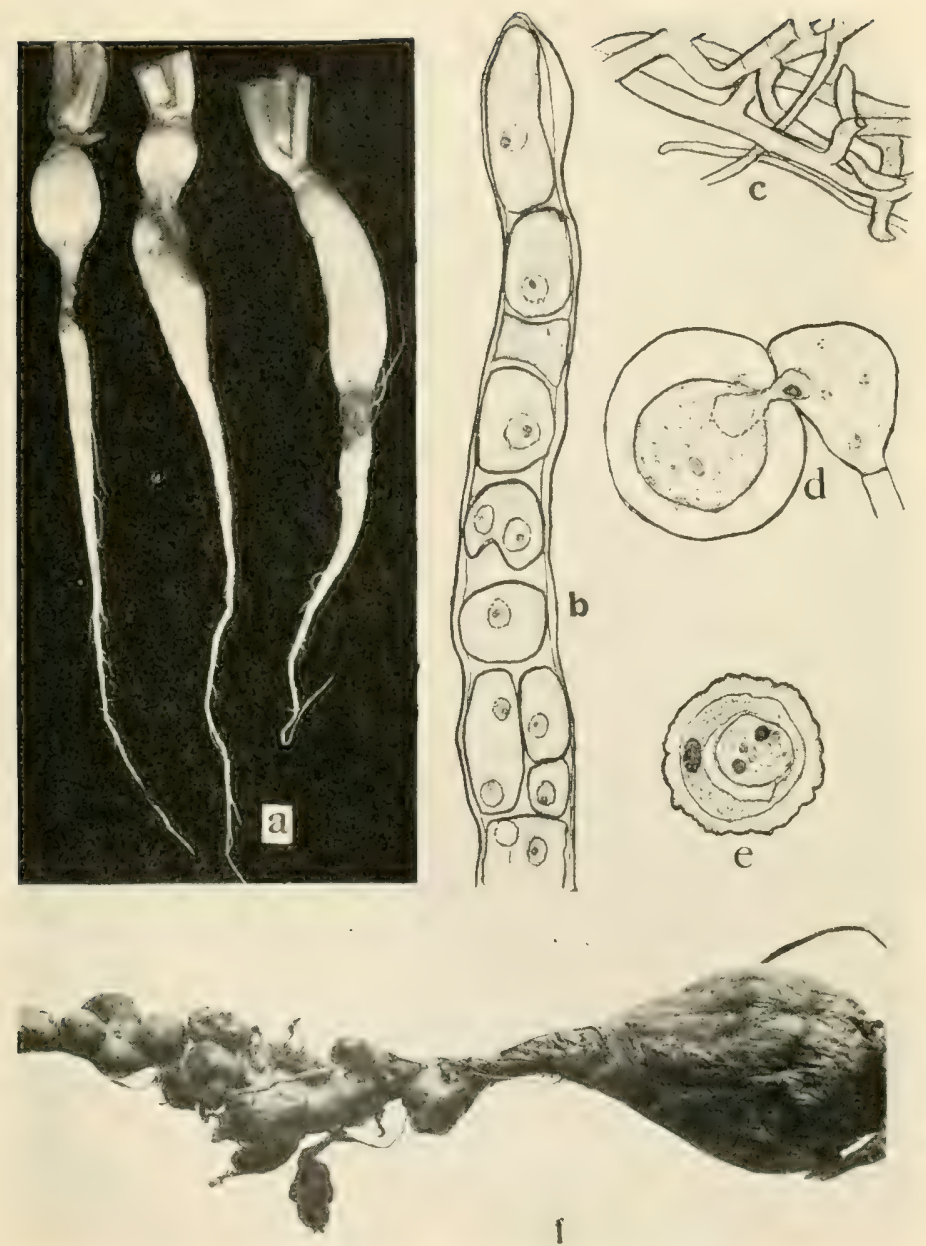

Fig. 35. Radish Diseases.

$a$. Young radishes attacked by Rheosporangium damping off, $b$. presporangium, c. mycelium of Rheosporangium aphanidermatum, $d$. fertilization of the female oogonium by the male antheridium, $e$. mature oospore, $f$. root knot ( $b$, to $e$. after Edson). 



\section{Family Cruciferæ}

With the maturity of the sporangium its cell wall dissolves, liberating the swarm spores which swim about for a time, then come to rest, round up, and increase in size and germinate by sending out a germ tube. Oospores are produced in a fashion somewhat similar to Pythium. The oogonia are formed as terminal spherical bodies. The antheridium develops terminally, lying close to the oogonium. The content of the antheridium is emptied into the body of the oogonium (fig. $35 \mathrm{~d}$ ) and fertilization is effected. The mature oospore (fig. 35 e) is spherical with a thick smooth or undulated wall and germinates by means of a germ tube.

Control. When the disease is present on a large scale, it is useless to attempt to control it. The fungus, as we have seen, is a soil parasite, hence soil treatments discussed on p. 53 could not be considered on a large scale. As far as we know, this disease attacks only radish and beet seedlings. Badly infected fields should be devoted to other crops for several years until the parasite is starved out. On a small scale, infected soils may be treated with formaldehyde (see p. 53), or fire (see p. 56).

Downy Mildew, see CabBage, p. I94.

\section{White Rust}

Caused by Cystopus candidus (Pers.) Lev.

The damage caused by white rust depends largely on seasonal conditions. The disease is most preva- 
lent on early spring or fall radish. The greatest damage done by this trouble is to the seed crop.

Symptoms. On the leaves, white rust is manifested as white raised pimples or sori (fig. $33 \mathrm{~b}$ ) characteristic of all white rusts. When the surface of the sori breaks open a white powder, which consists of the spores of the fungus, is liberated. On the flower organs of the radish, the symptoms of the disease are especially striking. The ovary sacs, the stamens, corolla, and calyx become hypertrophied and distended, resembling abnormal leaves.

It has been questioned whether the white rust of the radish is the same as that which attacks other crucifers such as cabbage, mustard, etc. While much remains to be learned, the investigations of Melhus throw much light on the subject. Melhus ${ }^{x}$ had no trouble in infecting the rat-tail radish ( $R a p h$ anus caudatus) with conidia taken from ordinary radish (Raphanus sativus). Melhus also secured infection by sowing conidia from the radish on white mustard (Brassica alba) and cabbage (Brassica oleracea). At no time, however, was it possible to infect more than fifty per cent. of the cotyledons or leaves of the white mustard which were inoculated. With the cabbage it was still more difficult to secure infection. Of the fifteen varieties inoculated less than one per cent. of the plants became infected.

No infection could be obtained when sowing spores of Cystopus candidus from radish on ten varieties of

${ }^{2}$ Melhus, T. E., Wisconsin Agr. Expt. Sta. Research Bul., 15: 2583,1911 . 
turnips (Brassica rapa), black mustard (Brassica nigra), rutabaga (Brassica campestris), shepherd's purse (Capsella bursa-pastoris), garden cress (Lepidium sativum), wild pepper grass (Lepidium virgini$\mathrm{cum}$ ), hedge mustard (Sisymbrium officinale and $S$. altissimum), candy-tuft (Iberis umbellata), water cress (Nasturtium officinale), and wall flower (Cheiranthus cheiri). From the above experiments, it would seem that in dealing with the white rust fungus, Cystopus candidus, it is possible that there exist distinct races or strains, all of which are specialized to certain special hosts of the various crucifers. The best infection is secured when the seedlings of the host plant are chilled. This is why white rust is more prevalent in cool seasons.

The Organism. Cystopus candidus has two fruiting stages. The summer or conidial stage is made up of simple chains of spores (fig. $33 \mathrm{c}$ ). The latter are separated one from the other by a minute beak-like projection. Each spore or zoosporangium germinates by six or more swarm spores, or zoospores. These, when set free, swim around, then come to rest and germinate by means of a germ tube. The oospore or sexual spore of the Cystopus is formed later in the season. The oogonia and antheridia (fig. 33 d) are developed within the infected host tissue. Fertilization proceeds in the same way as in Pythium. The mature oospore has a thick, sculptured wall, and is brown in color. The oospores germinate in the same way as the zoosporangium, $i$. e., by the formation of zoospores (fig. $33 \mathrm{e}$ ). 
Control. Burning of all infected trash and crop rotation are the best effective remedies.

ROOT ROT, see BEET p. I22, I28.

Root Knot (fig. 35 f), see BeEt p. I29.

\section{DISEASES OF THE TURNIP (Brassica Rapa)}

Club Root, see Cabbage, p. 186.

\section{Black RoT}

Caused by Pseudomonas campestris (Pam.) Ew. Sm.

Black rot in turnips is apparently confined to the roots. Infected plants may live a long time, and show no symptoms on the leaves. The roots of such plants, however, are stunted, abnormal in shape, and very narrow. The interior tissue is dry rotted and blackened, emitting a characteristic strong odor. For further description of the black rot, see p. 317 .

SCAB, see BeET, p. I2O, and Potato P. 3 I 7.

WHITE RUST, see RADISH, p. 2 II.

Downy MIldew, see CabBage p. 194.

Drop (fig. 36 g), see CABBAGE, p. 194.

\section{ANTHRACNOSE}

Caused by Colletotrichum Higginsianum Sacc.

Anthracnose is a new disease which has recently been studied and described by Higgins ${ }^{\mathrm{I}}$ in Georgia.

s Higgins, B. B., U. S. Dept. of Agr., Jour. of Agr. Research, Io: I57-16I, 1917. 



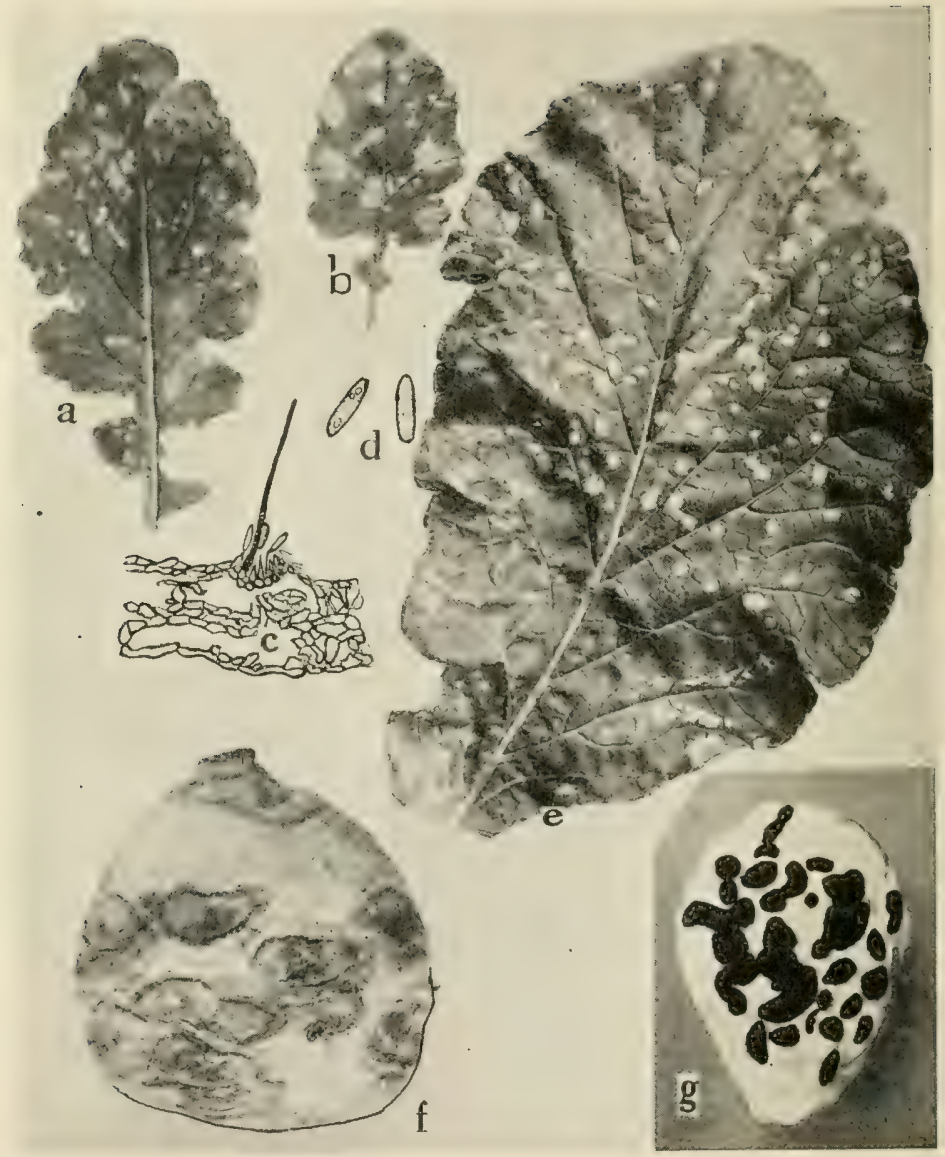

Fig. 36. Turnip Diseases.

$a$ and $b$. Anthracnose, $c$. cross section through acervulus, $d$. anthracnose spores, e. Cylindrosporium leaf spot, $f$. Phoma rot, $g$. Sclerotinia rot (c. and $d$. after Higgins). 


\section{Family Cruciferæ}

The disease attacks the leaves (fig. 36 a-b), causing small circular gray or straw-colored spots. The acervuli and the salmon-pink spore clusters appear only under moist conditions. The causative fungus differs from Colletotrichum brassica Sch. and Sacc. The acervuli are small, scattered on both surfaces of the spots. The conidiophores are short (fig. $36 \mathrm{c}$ ), conidia hyaline cylindrical one celled (fig. 36 d), setæ dark brown to black, slender, I to 3 septate (fig. 36 c). On the stems the spots are more elongated. On the leaves the spots are said to be much smaller than those produced by Cylindrosporium brassice F. and R. (fig. 36 e). Anthracnose is not carried with the seed. No method of control is as yet known.

\section{Phoma Rot}

\section{Caused by Phoma napobrassica Rost.}

Phoma rot is a disease which is common in the north of England. It is also found in New Zealand and in Canada. In the United States it has been reported but once, by Clinton ${ }^{\mathrm{T}}$ of Connecticut.

Phoma rot seems to be a storage trouble, although the disease is first introduced from the field.

Symptoms. In the field, the disease is first noticed at digging as a rot around the crown, the top of the plant readily pulling off. In storage the disease is

${ }^{2}$ Clinton, G. P., Connecticut Agr. Expt. Sta., 36th. Ann. Repl. : $355-358,1912$. 


\section{I6 Diseases of Truck Crops}

manifested on the roots as a dry rot which appears first as scattered sunken spots bordered by dark areas (fig. $36 \mathrm{f}$ ). The pycnidia of the fungus are generally absent from the spots, but they appear in great abundance when the roots are placed under favorable conditions of moisture.

Control. It is doubtful if Phoma rot can be controlled by spraying the foliage in the field. Since the disease is carried over in the roots, it would be dangerous to feed them to stock or dump them on the manure pile. Rotation should be practiced where the disease has appeared more than once in the same field. Care should be taken that no diseased roots be permitted to enter the storage house or cellar. The roots should be thoroughly dried before storing, and the house or cellar should be kept moderately cool and ventilation resorted to wherever possible.

\section{Powdery MiLdew}

Caused by Erysiphe polygoni D. C.

Powdery mildew has not been known to cause any considerable damage to turnips in the United States. It is characterized by the presence of powdery white patches on both surfaces of the leaf. Besides affecting the turnip, Erysiphe polygoni has been recorded on about three hundred different hosts, especially the garden pea. For methods of control, see p. 367 . 


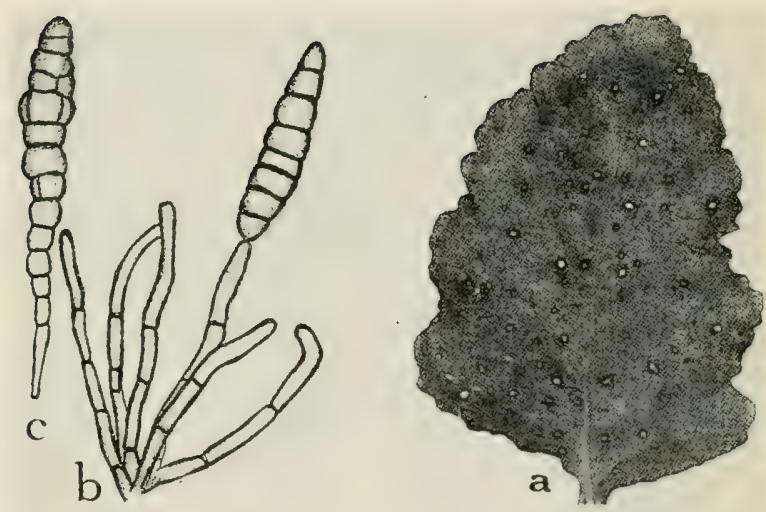

Fig. 37. Turnip Disease.

a. Macrosporium leaf spot, b. Macrosporium herculeum, showing conidiophores and conidia, $c$. individual conidium of 11 . herculeum (a. to c. after F. C. Stewart). 


\section{Family Cruciferæ}

\section{Macrosporium LeAF Spot}

Caused by Macrosporium herculeum E. and M.

Leaf spot often attacks the flat turnip and horseradish. On turnips it is manifested as brittle circular spots on the leaf (fig. 37 a). When numerous, the spots usually fall out, giving a shot-hole appearance. The long club-shaped spores (fig. $37 \mathrm{c}$ ) of the fungus are borne on long conidiophores (fig. $37 \mathrm{~b}$ ) on the exterior of the dead tissue. Should treatment seem advisable, spraying with Bordeaux mixture is recommended.

\section{WEEDS}

Of the many cruciferous weeds which truckers have to contend with, the following few may be mentioned: Winter cress (Barbarea vulgaris), shepherd's purse (Capsella bursa-pastoris), cow cress (Lepidium campestre), pepper grass (Lepidium virginicum). The above mentioned weeds and many other crucifers are subject to club root, black rot, white rust, and downy mildew.

It is evident therefore that clean culture is important. These weeds must not be tolerated if we are completely to eradicate the diseases of the cultivated crucifers. 


\section{CHAPTER XIV}

\section{FAMILY CUCURBITACEAE}

THE Cucurbit family contains numerous valuable truck crops. Those grown for their economic value may be mentioned: cantaloupe, cucumber, pumpkin, squash, and watermelon. According to the Thirteenth Census of the United States, the total area devoted to cantaloupes and muskmelons in America was 52,419 acres, and the total crop valued at $\$ 3,604,636$. The States, ranked according to the acreage devoted to these crops, were California, New Mexico, New Jersey, Indiana, Maryland, Florida, Georgia, Illinois, North Carolina, Michigan, Colorado, Missouri, Texas, Ohio, Tennessee, and Delaware. States with less than one thousand acres are omitted.

The total area in the United States in 1909 given up to cucumbers was estimated at 32,310 acres, and the total crop valued at $\$ 2,7$ I 9,340. The States ranked according to the area devoted to cucumbers were Michigan, New York, Illinois, Indiana, Florida, Virginia, New Jersey, Wisconsin, Texas, and Minnesota. States with less than one thousand acres are omitted. 


\section{Family Cucurbitaceæ}

The total area devoted to watermelons in the United States in 1909 was estimated at 137,005 acres, and the total crop valued at $\$ 4,453$, IOI. The States which lead in rank according to acreage devoted to watermelon were: Texas, Florida, Georgia, Missouri, Indiana, Illinois, California, Oklahoma, North Carolina, South Carolina, Alabama, Iowa, Arkansas, Kansas, Virginia, Tennessee, Maryland, New Jersey, Mississippi, Kentucky, and Louisiana.

\section{DISEASES OF THE CANTALOUPE} (Cucumis melo)

The cantaloupe is subject to numerous diseases which often reduce the yield of the crop and entail heavy money losses. Fortunately most of the diseases may be controlled.

\section{BACTERIAL WILT}

Caused by Bacillus tracheiphilus Ew. Sm.

Bacterial wilt may be regarded as one of the most serious diseases of the cantaloupe. It has a very wide distribution, but it is said to be restricted in its Southern distribution. The same disease also attacks the cucumber, pumpkin, and squashes. The trouble is not known to occur on hosts outside of the Cucurbitaceæ. Even in this family there are plants which are not subject to its attack. Dr. Erwin Smith succeeded in artificially inoculating the following cucurbits: Cucumis odoratissimus, C. anguria, 
Benincasa cerifera, Cucurbita fotidissima, C. californica, Echinocystis lobata.

Symptoms. The symptoms of bacterial wilt are very striking. At first a few leaves of the plant are wilted. Soon after the entire plant wilts and dies. In cutting through an infected stem, a whitish viscid exudate oozes out from the vascular bundles of the cut surface. In placing one finger on the viscid substance and then gently removing it, the bacteria will be strung out into numerous delicate threads resembling cobwebs. The disease works quickly and the change of leaf color from bright to dull green is also" sudden. Cantaloupes, unlike squash, show no tendency to recover temporarily from wilt.

Bacterial wilt is spread about through the bites of leaf-eating beetles, such as striped cucumber beetle, (Diabrotica vittata).

The Organism. B. tracheiphilus is a short straight rod with rounded ends. The organism occurs singly in pairs and rarely in chains of four; it is motile by means of flagella. It grows slowly on gelatine which is not liquefied. On potato cylinders growth is vigorous, resulting in a gray-white film with no changes manifested in the substratum. There is no gas production and the organism is aeorobic.

Control. Infection begins at a place of injury produced by the bite or puncture of insects. Hence any attempt at controlling wilt should first aim at controlling insect pests. For further control, see p. 232. 



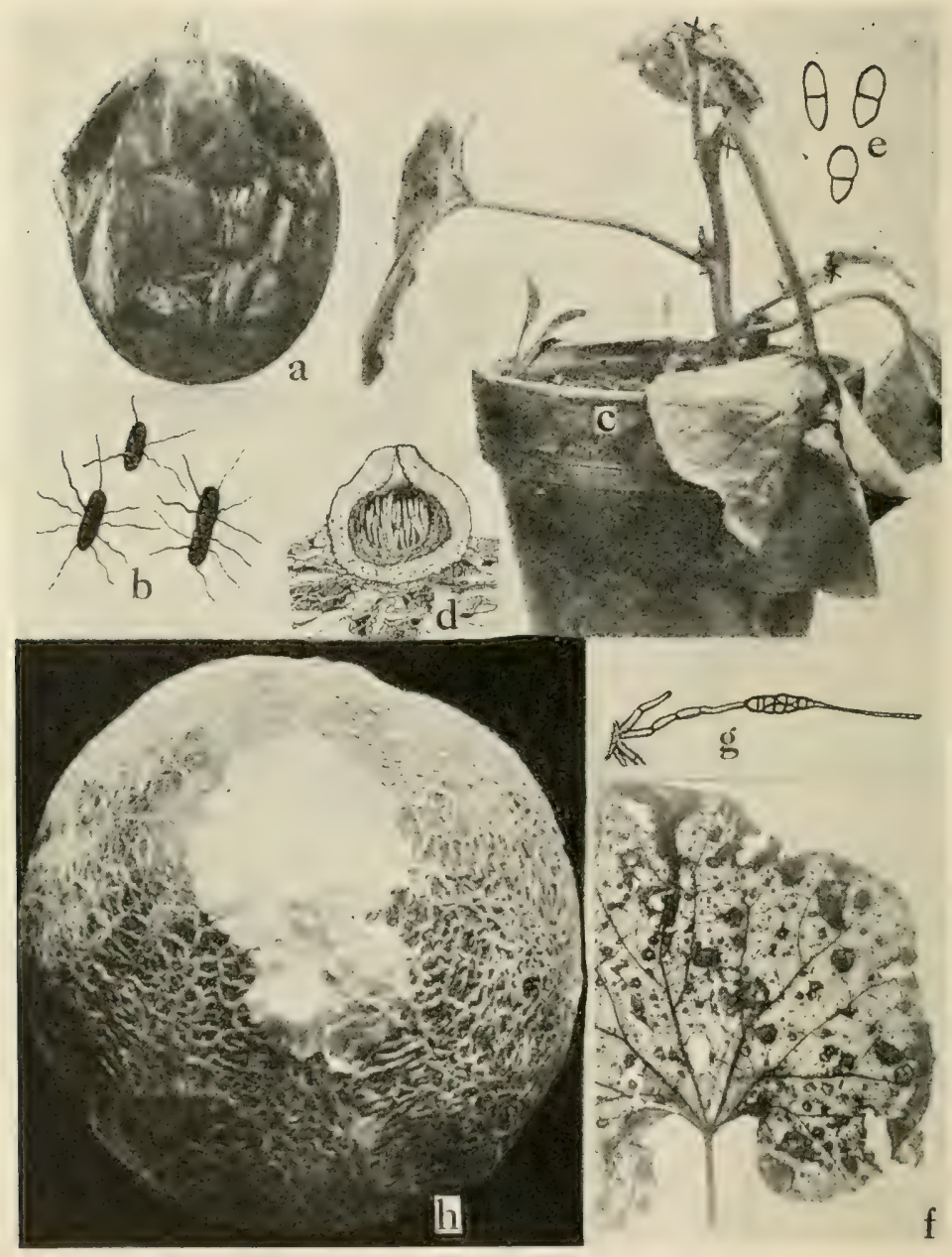

Fig. 38. Cantaloup Diseases.

$a$. Soft rot, $b$. individual germs of soft rot ( $a$. and $b$. after Giddings), $c$. young cantaloup plant artificially inoculated with Mycosphærella wilt, $d$. section through

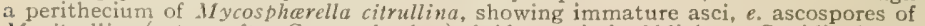
M. cilrullina (c. to $e$ after Grossenbacher), $f$. Alternaria leaf blight, $g$. Conidiophores and spore of Macrosporium cucumerinum (after Chester), h. Southern blight. 


\section{Family Cucurbitaceæ}

\section{SoFt Rot}

\section{Caused by Bacillus melonis Gid.}

Soft rot is a disease which attacks the melon fruit only. The losses from this trouble often run as high as twenty-five per cent. of the crop. It is prevalent in seasons with prolonged dry weather followed by a wet spell. This results in the uneven growth and development of the fruit and hence in various crackings in its surface. Infection follows the place of injury, especially when the crack (fig. 38 a) occurs at a place where the cantaloupe touches the ground. The rot produced is soft with an offensive odor.

The Organism. Bacillus melonis is a short rod (fig. 38 a) with rounded ends, occurring singly or in short chains of two to three, and motile by means of flagella. It forms no endospores, no capsule, and no involution forms. It completely liquefies gelatine in fourteen days. No gas is formed, and no very distinct odor is noticed. It dies by drying and exposure to light.

Control. Wherever possible, irrigation should be resorted to in dry weather. This will encourage even growth and prevent cracking of the fruit. In wet weather spraying with Bordeaux mixture is recommended. Occasional turning of the melons to expose them to light on all sides will also help. Diseased refuse should be destroyed and not be fed to stock.

Downy Mildew, see Cucumber, p. 230. 


\section{POWDERY MILDEW}

Caused by Erysiphe polygoni D. C.

This disease is the same as the mildew which attacks garden peas, cucumbers, and numerous other hosts. Mildew is more prevalent on greenhouse melons and cucumbers than on those grown outdoors. It is characterized by powdery white patches on the leaves. The trouble is seldom serious enough in the field to warrant treatment.

\section{Mycospherella WiLT}

Caused by Mycosphcerella citrulina (Sm.) Gr.

Although this form of wilt is often a greenhouse trouble, it is nevertheless a serious disease on outdoor cantaloupes and watermelons. Grossenbacher ${ }^{\mathrm{I}}$ found that infection is localized at the nodes and not at the internodes (fig. 38 c). The injury from Red Spider or other sucking insects is perhaps responsible for opening the way to this disease. A characteristic of the trouble is that the edges of the infected areas are oily green to raisin-colored gum. The older parts of the spots are either dark and gummy or gray and dry, bearing numerous brown pycnidia.

The Organism. The perithecia (fig. 38 d) are globular to inverted top-shaped, rough, dark brown

r Grossenbacher, J. G., New York (Geneva) Agr. Expt. Sta. Tech. Bul. 9 : 197-229, I909. 


\section{Family Cucurbitaceæ}

to black, erumpent, and finally almost superficial. The necks of the perithecia are papillate. The ascospores are cylindrical, two-celled, hyaline, and slightly constricted at the septum (fig. 38 e).

Control. Spraying with Bordeaux mixtures when the plants are about half grown and before the disease appears is recommended. Spraying should be continued so that the growing parts are kept covered with the fungicide.

Anthracnose, see Watermelon, p. 240.

\section{LEAF BLIGHT}

Caused by Alternaria brassicce var. nigrescens Peg1.

Leaf blight is a very destructive disease, often ruining entire patches which otherwise looked very promising. In some seasons, it is the greatest drawback to successful melon culture.

Symptoms. The disease begins as small round spots which gradually enlarge. These spots are dry, brown in color and made up of concentric rings or zones (fig. $38 \mathrm{f}$ and g). Usually the spots are very numerous and their presence causes the leaves to curl and dry up prematurely, leaving bare vines and unprotected fruit. As a result, the melons ripen early and have an insipid taste, and are very poor shippers. Leaf blight is most serious in fields where cantaloupes are grown too long on the same field.

Blight Resistant Cantaloupes. In selecting for blight resistant cantaloupe (fig. $39 a-b$ ), we must con- 
sider (I), the yielding quality of the strain; (2), the earliness in maturing; (3), resistant qualities; (4), form, size, and netting; (5), texture and edible qualities; (6), shipping qualities. Blinn ${ }^{\mathrm{I}}$ found that resistance in cantaloupes seems to go hand in hand with the netting of the rind. Good netting seems also to favor good shipping melons with fine flavor. It seems that the closer the netting the better will the fruit be protected from loss of weight from evaporation. The Rocky Ford Pollock strain is claimed to be resistant to blight. Control by spraying, see cucumber, p. 232.

\section{Phyllosticta Leaf Spot}

\section{Caused by Phyllosticta cucurbitacearum Sacc.}

This disease has not proved as serious as leaf blight. It is characterized by spots which are light in color. The pycnidia are pointed, the spores oblong and curved, hyaline and one-celled. The disease may be controlled by spraying, see p. 232 .

\section{Cercospora Leaf Spot}

\section{Caused by Cercospora cucurbitce E. and E.}

This disease behaves very much like leaf blight. In the former, however, the spots are usually of a

${ }^{x}$ Blinn, P. K., Colorado Agr. Expt. Sta. Bul. 104: 3-15, 1905. 
lighter color, and are more angular in form, being limited by the veins of the leaf. The methods of control are the same as for leaf blight, see p. 223.

\section{SOUTHERN BLIGHT}

Caused by Sclerotium Rolfsii Sacc.

Southern blight, a disease that attacks a large variety of hosts, is a serious cantaloupe disease in the Southern States. The injury in most cases is confined to the foot of the stem, resulting in its girdling and rotting and the final dying of the affected plant. With the cantaloupe, the disease attacks the fruit, infection usually taking place at a point where it touches the ground (fig. $3^{8} \mathrm{~h}$ ). The disease appears first as a slight soft spot which enlarges quickly, changing the entire mass of the fruit to a mushy pulp. The exterior of the affected melon is seen to be covered with a white cottony growth consisting of the mycelium of the fungus. Later there appear numerous whitish bodies known as sclerotia which turn yellowish and then brown. They help to carry the fungus over the winter. For methods of control, see tomato, p. 353.

ROOT KNOT, see NEMATODE, p. 49.

\section{Care in the Shipping of Cantaloupes}

As a rule, the greatest per cent. of the cantaloupe crop is shipped to distant markets. Growers often 
lose heavily from rotting of the fruit before it reaches its destination. Most of the loss may be reduced to a minimum or entirely prevented, provided growers are willing to devote more attention to certain fundamental considerations suggested by More and Branch. ${ }^{\text {I }}$

a. Need of Quality. No one can deny the fact that products which are poorly grown, poorly harvested, and poorly packed and shipped, are a direct loss to the grower and a serious drawback to the market. The consumer to-day insists on quality, and the grower who is to succeed cannot ignore this demand. Cantaloupes to-day are grown more extensively than formerly. Competition therefore is more keen, and growers in the West are more handicapped, because their products must travel longer distances, and therefore require more care in handling. By selecting fruit which matures early and at the same time possesses better edible and shipping qualities the difficulty will be at least partly solved.

b. Care in Picking and Handling. Success in shipping depends largely on proper picking and handling. With the "Netted Gem" or "Green Nets," the melons should not be harvested until completely netted. The netting should be well raised and rounded out on the surface. With immature melons the netting is flat and creased on top. For shipping short distances the melons may be picked "full slip," $i . e$. just as soon as the stem separates cleanly from

${ }^{x}$ More, C. T., and Branch, G. V., U. S. Dept. of Agr. Farm. Bul. $707: 1-23,1916$. 
the melon, leaving a cuplike cavity and tearing with it none of the rind. When shipping long distances the melons are picked on "half slip," in which case only part of the stem pulls away from the fruit, the rest breaking. It is essential that the fruit be handled carefully in the field, avoiding bruises and cuts. At the packing shed, the same care should be observed.

c. Care in Packing. Good shipping also depends on careful packing. Only standard containers for shipping should be used. The crate has become the standard container for shipping melons. Crates should be made of clean, smooth, strong lumber, with all knotty and cross-grained slats discarded. Dirty and second-hand crates should not be used. Crates used in the field in harvesting should not be used for shipping.

d. Need of Grading. Up-to-date growers take pains to grade their product carefully before packing. A careful grading excludes melons which are poorly netted, also known as "slickers." It is also essential to exclude melons which are cracked, bruised, diseased, ill-shaped, over ripe, as well as those that are immature and those with soft stems. In packing, melons of the same size and grade only should be put in the same container.

$e$. Care in Handling. In hauling melons from the packing sheds to the car, only wagons with good springs should be used. Hauling wagons should also be provided with tarpaulin covers to protect the fruit from the sun, rain, or dust. The crates should be 
carefully unloaded into cars which are iced, if the melons are to be shipped long distances. When the cars have been properly filled, they should be dispatched as early as possible. Freight agents should see that cars are not delayed on the road.

\section{DISEASES OF THE CUCUMBER (Cucumis sativus)}

Cucumbers, like cantaloupes, are subject to various diseases which render them unfit for the market or for pickling.

Mosaic or "White" or "Little Pickle"

Cause unknown.

Mosaic has been found in Wisconsin, Michigan, Indiana, Ohio, Iowa, Illinois, Vermont, New York, Louisiana, New Jersey, Minnesota, Massachusetts, and Virginia.

Symptoms. The first sign appears as a yellow mottling near the stem end of the fruit. Later the light areas are found all over the cucumber, and the darker portions frequently form protuberances. Some fruits retain their green color and show the disease only by being distorted. The leaves too become mottled, light to dark green (fig. $40 \mathrm{a}$ ), and sometimes wrinkled; the stems and petioles too are dwarfed and distorted. Affected leaves die prematurely and are replaced by others, which in turn con- 


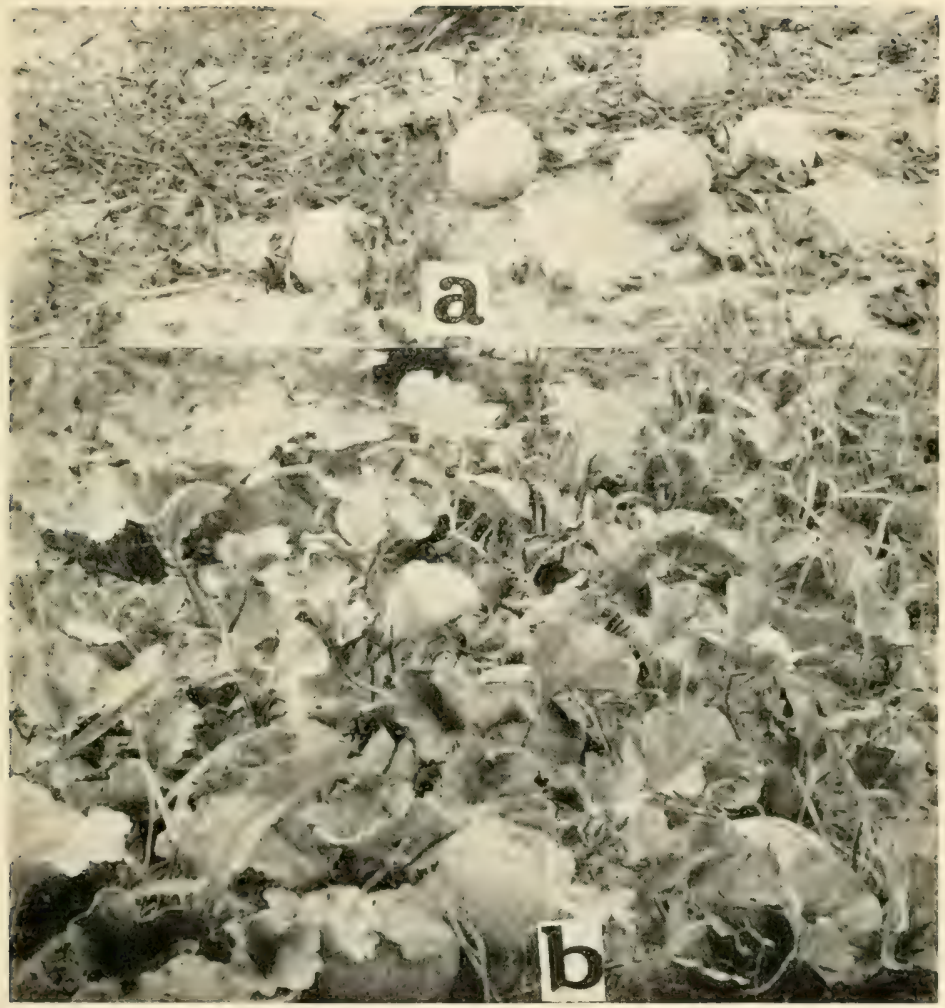

Fig. 39. Resistant Cantaloup Strain.

a. Cantaloup hill, destroyed by Alternaria leaf blight, $b$. cantaloup hill resistant to Alternaria blight. $a$. and $b$. same variety (Rockyford) growing in same fielrl under equal condiitions. 



\section{Family Cucurbitaceæ}

tract the disease. The troulle is spread by insects, the principal of which is the melon louse, Aphis gossypii Glov., as well as the striped cucumber beetle, Diabrotica vittala. Satisfactory control methods are still wanting. Diseased plants should be destroyed and the field sprayed for insect pests.

\section{BACTERIAL WILT}

Caused by Bacillus tracheiphillus Ew. Sm.

The symptoms and damage caused by this wilt have already been discussed under the cantaloupe, p. 2I9. Recent investigations by Rand and Enlows ${ }^{\mathrm{r}}$ have shown that seeds from diseased plants fail to reproduce wilt. This is true not only for the cucumber, but also for all the other cucurbit hosts which are subject to this trouble. Of the numerous varieties of cucumber and cantaloupe tested, none shows promise of resistance. While the Marblehead, Golden Bronze, and Boston Marrow are very susceptible varieties of the squash, the Mammoth White Bush and the Early White Bush seem to be immune to wilt.

\section{ANGULAR LEAF SPOT}

Caused by Pseudomonas lachrymans Sm. and Bry.

This disease seems to be common on cucumbers in Florida, Michigan, and in Wisconsin. It has been

${ }^{x}$ Rand, F. V., and Enlows, E. M. A., U. S. Dept. of Agr., Jour. Agr. Research, $6:$ 417-434, 1916. 


\section{Diseases of Truck Crops}

recently studied by Smith and Bryan, ${ }^{\mathbf{T}}$ who described it as a new disease occurring in the Eastern and Middle-Western States.

Symptoms. The trouble is characterized by angular brown spots which tear or drop out when dry (fig. $40 \mathrm{~b}$ ), giving a ragged appearance to the infected leaves. In the early stages, a bacterial exudate collects in drops on the lower surface of the spots. These exudates usually dry and become whitish. It seems that angular leaf spots attack only the foliage but rarely the fruit.

The Organism. The parasite is a short rod with rounded ends (fig. $40 \mathrm{c}$ ), occurring singly, or in pairs with a decided constriction; and occasionally in chains of twelve individuals or more. It is motile by means of polar flagella, produces capsules on agar and milk; no spores, and no gas is formed. The organism completely liquefies gelatine in about three or four weeks.

Damping OfF, see Pythium, p. 43.

\section{DOWNy MILDEW}

\section{Caused by Pseudoperonospora cubensis (B. and C.) Rost.}

Downy mildew is prevalent in New Jersey, New York, Florida, Texas, and possibly other States. It

${ }^{x}$ Smith, E. W., and Bryan, M. K., U. S. Dept. of Agr., Jour. Agr. Research, 6: 465-476, 1915. 


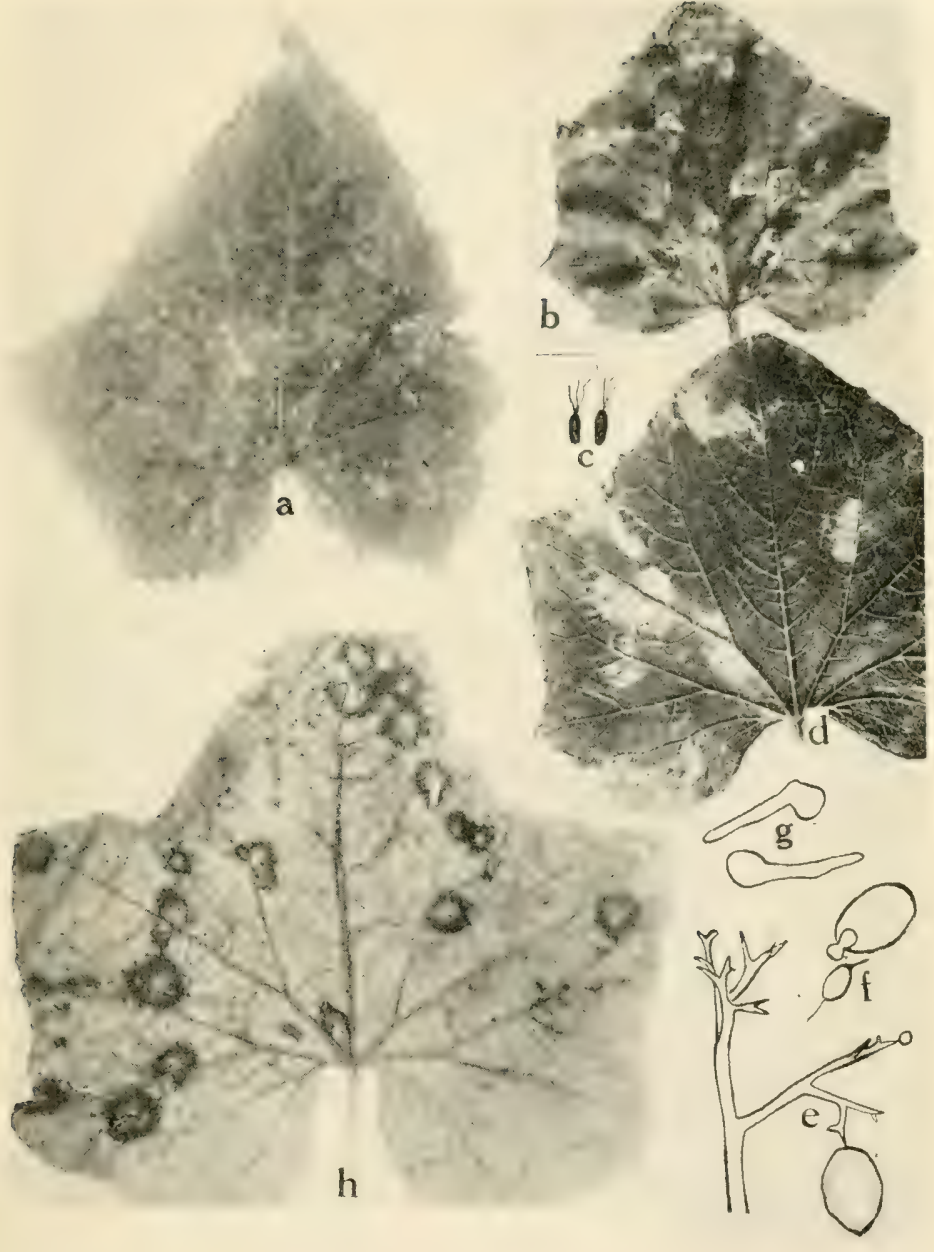

Fig. 40. Cucumber Diseases.

$a$. Mosaic, $b$, angular leaf spot (after Smith and Bryan), $c$. individual germs of Pseudomonas lachrymans, $d$. downy mildew (Manns), e. conidiophore and conidia of Plasmopara cubensis, f. germinated conidia and swarm spore, g. germinated swarm spores (e. to $g$. after Clinton), $h$. anthracnose. 

attacks cantaloupes, gourds, squashes, pumpkins, and watermelons.

Symptoms. The disease appears as yellowish spots on the leaves, which have no definite outline (fig. $40 \mathrm{~d})$. With warm moist weather, numerous spots coalesce, and soon the affected leaves turn yellow and die. With cool weather the spots seem to spread less rapidly. The disease appears to work on the older leaves, beginning on those on the center of the hill and working outward. With infected plants the center of the hill is clearly marked by a cluster of yellow leaves. Diseased plants may flower profusely, but no fruit is produced. The few cucumbers which set are small, deformed, and unfit for the market.

Downy mildew is most prevalent in August with moderate rainfall and hot weather. The disease spreads very rapidly and a large cucumber field may be a total loss in less than from eight to ten days.

The Organism. The fungus derives its food from the host cells by means of suckers or haustoria. The mycelium is hyaline, non-septate; the conidiophores (fig. 40 e) arise in small clusters through the leaf stomata and are branched and flexuous. The zoösporangia are hyaline but slightly violet, tinted in mass. Germination of zoösporangia is by means of motile zoöspores (fig. $40 \mathrm{f}-\mathrm{g}$ ). The oöspore, or sexual fruiting stage, was first found on the host by Rostovtsev. Downy mildew may be kept in check by spraying with Bordeaux mixture. 


\section{PoWdery Mildew}

\section{Caused by Erysiphe cichoracearum D. C.}

Powdery mildew of cucumbers is not a serious trouble, since it usually attacks plants which have somewhat passed their usefulness. Like all powdery mildews, the causative fungus grows on the surface of the leaf, giving it a white mealy appearance. From the mycelium are produced erect threads which bear the summer spores of the fungus. According to Humphrey, ${ }^{\mathrm{I}}$ the ascus or winter stage appears as minute dark-brown rounded capsules enclosing a group of spore sacs within which are formed the ascospores.

Anthracnose (fig. 40 h), see Watermelon, p. 240. Root KNot, see Squash, p. 237.

\section{Spraying Cantaloupes and Cucumbers}

Cantaloupes and cucumbers cannot always be grown profitably unless the crops are sprayed. It is fortunate that most of the foliage and fruit diseases may be kept in check by spraying with Bordeaux mixture. The work of $\mathrm{Orton}^{2}$ and others has shown that not only does spraying control the various diseases, but viewed from the point of view of dollars and cents it undoubtably pays.

${ }^{x}$ Humphrey, J. E., Massachusetts Agr. Expt. Sta. Ioth Ann. Rept.: 225-226, 1892 .

${ }^{2}$ Orton, W. A., U. S. Deft. of Agr. Farm. Bul. 231: 5-24, 1905. 


\section{Family Cucurbitaceæ}

Cucumbers grown for pickles, however, should not be sprayed, as spraying reduces the number of fruit, although it is so beneficial for fruit which are to be left to grow to market size.

For an area less than one acre, a small hand pump sprayer, or preferably a good small compressed-air sprayer will answer the purpose. For fields of one to five acres a barrel sprayer is recommended. For fields above five acres or more, a good power sprayer must be able to apply at least one hundred gallons per acre. To do thorough spraying, a slow walking team should be chosen, but the pump should be geared correspondingly high so as to maintain full pressure at a low speed.

The strength of Bordeaux recommended by Orton as safe from burning is a $3-6-50$ formula. From the writer's experience, he would not advise using formulas stronger than this, especially under Southern climatic conditions. The time to spray first is when the vines begin to run. The number of succeeding applications should be governed by climatic conditions. In damp warm weather, spraying should be repeated every second or third week. The object is to keep all growing parts of the plant thoroughly covered with the fungicide. For further directions on spraying and the preparations of the ingredients, see p. 36I.

In some seasons, the melon louse, Aphis gossypii, causes great damage to cantaloupes and cucumbers. The pest sucks the life of the plant by feeding on its juices. Durst" recommends spraying with "Black

× Durst, C. E., Illinois Agr. Expt. Sta. Bul. 174 : 321-334, 1914. 
Leaf 40," used at the rate of one part to one thousand of water. This will control the aphids. "Black Leaf 40 " readily mixes with Bordeaux mixture. To control both fungus and plant lice, add to every one hundred gallons of Bordeaux one pint of "Black Leaf 40." To control chewing insects, such as the cucumber striped beetle or caterpillars feeding on the plants, add to each one hundred gallons of Bordeaux three pounds of powdered arsenate of lead.

\section{DISEASES OF THE CITRON (Citrullus vulgaris)}

Citrons are not grown commercially. They are found as weeds in melon patches or anywhere in the farm where permitted. The citron is a very hardy plant, and it is subject to but few diseases.

ANthracnose, see Watermelon, p. 240.

Leaf Spot, see Watermelon, p. 243.

Gourd Disease, see SQuash, p. 234.

Muskmelon Diseases, see Cantaloupes, p. 2 I 9.

Pumprin Diseases, see Squash, p. 234.

\section{DISEASES OF THE SQUASH (Cucurbita} maxima, $C$. pepo, and C. Moschata)

Squashes, with but few exceptions, are subject to the same diseases as affect the cantaloupe and the cucumber. Squashes are usually grown for local markets, and because of their diseases in many places their culture has been abandoned.

Bacterial Wilt, see Cucumber, p. 22. 


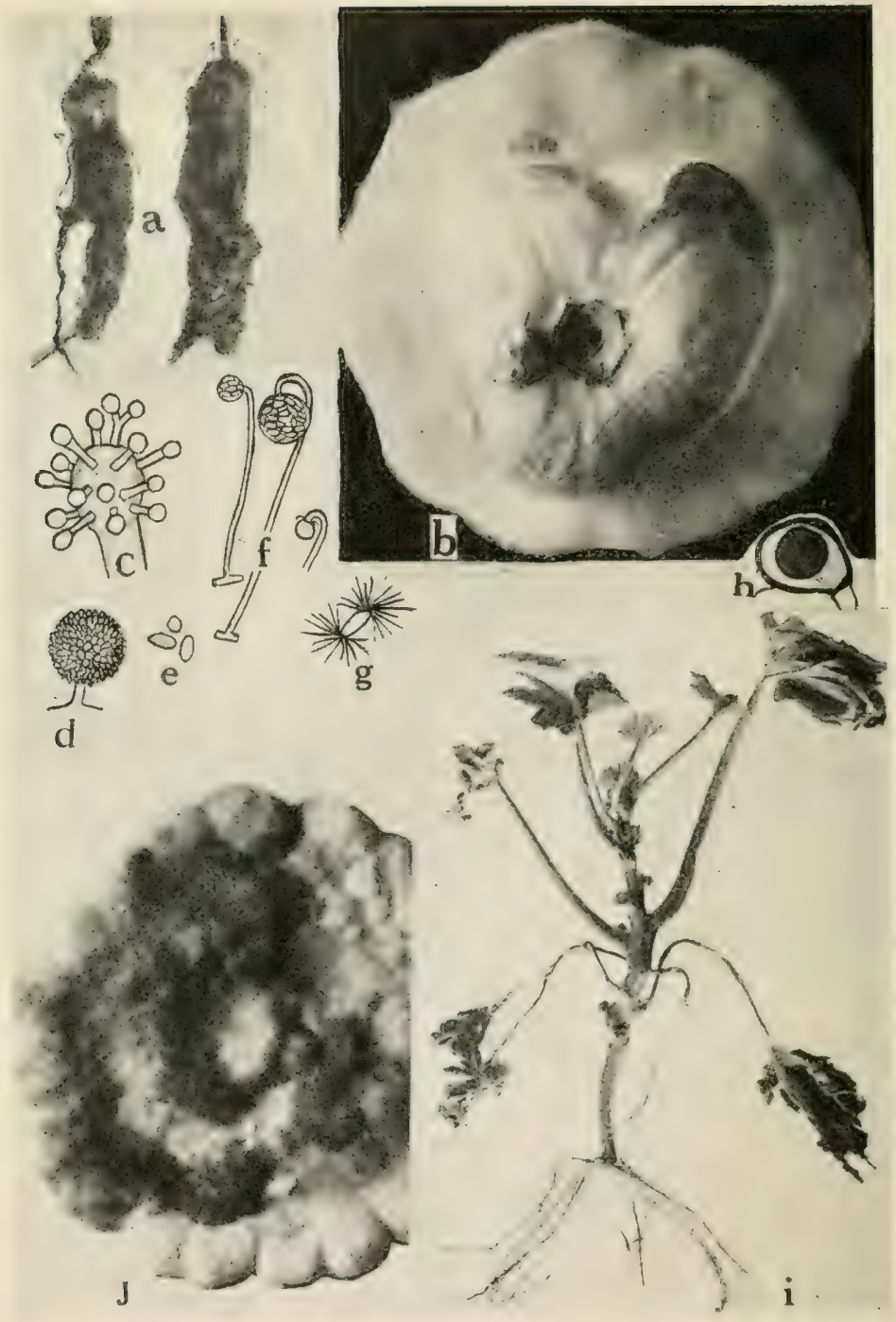

Frg. 4r. Squash Diseases.

a. Showing squash blossoms invaded by the fungus Choanophora cucurbilarum, b. squash entirely rotted by the Choanophora fungus, $c$. young conidiophore of Choanophora with ramuli developing on the primary vesicle, $d$. mature capitulum covered with a layer of conidia, $e$. conidia, $f$. sporangia and columella, $g$. sporangio spores with tufts of hair-like appendages, $h$. matire zygospore $(a, c$. to $h$. after Wolf), $i$. Fusarium wilt of young squash plants, $j$. Rhizopus rot. 


\section{FruIt Rot}

\section{Thax.}

Caused by Choanophora cucurbitarum (B. and Rav.)

Fruit rot is a common disease of the summer squashes. It has been found in North and South Carolina, Massachusetts, New York, Ohio, Michigan, Connecticut, Florida, and Texas. The disease is of little importance in dry seasons. It is, however, favored by conditions of high humidity and excessive rainfall, or by heavy dews at night.

Symptoms. It usually attacks the flowers, or especially the remnants, of the old calyx (fig. 4I a). The latter when affected become shriveled and covered with a thick crop of brown conidiophores of the causative fungus. From the floral parts, the mycelium works downward and into the young squash, which wilts very rapidly, turning into a soft rot and later covered by a gray growth of conidiophores (fig. $4 \mathrm{I} \mathrm{b).} \mathrm{As} \mathrm{far} \mathrm{as} \mathrm{is} \mathrm{known,} \mathrm{the} \mathrm{fungus} \mathrm{does} \mathrm{not}$ attack any other part of the squash plant except the floral parts and the fruit.

The varieties of squash most affected by fruit rot are the "patty pan" types, commonly known as cymblings. Wolf ${ }^{x}$ has found Choanophora cucurbitarum on fading flowers of cucumber, Althea, scarlet hibiscus, okra, and cotton.

The Fungus. The conidiophores when young are whitish, but at maturity take on a metallic luster.

× Wolf, F. A., U. S. Dept. of Agr., Jour. Agr. Research, $8: 319-328$, 1917. 
The top end is broadest, becoming dilated into a caputate vesicle. From this head are produced from a few to a dozen small branches, the tips of each in turn becoming vesicular (fig. 4I c). Each vesicle now becomes covered with a dense layer of conidia (fig. 4I d). The latter are light to reddish brown in color (fig. 4I e). The conidia germinate by means of a germ tube. Sporangia are formed in pure culture but not on the host. Sporangia are first evident as white pendant enlargements, becoming separated from the sporangiophore by a globular columella (fig. 4I f). Mature sporangiospores are larger than the conidia, are smooth, and possess terminal hyaline appendages (fig. 4I g). The spores germinate by means of the germ tube, as is the case with the conidia. Chlamydospores are not uncommon and they have often been observed during the winter. The formation of zygospores is a common occurrence on culture media, but not on the host. The method of zygospore formation and germination has not as yet been definitely worked out.

Control. The spores of Choanophora cucurbitarum are undoubtedly carried from flower to flower by insects. Spraying, as outlined for cucumbers, is also recommended for the squash, p. 232.

\section{SOFT RoT}

\section{Caused by Rhizopus nigricans Ehr.}

Soft rot very often cannot be distinguished from the fruit rot above mentioned (fig. $4 \mathbf{I}$ j). The symp- 


\section{Family Cucurbitaceæ}

toms in both diseases are very much alike. The only disparity consists in the difference of the two causative organisms. For a further study of Rhizopus nigricans, see soft and ring rot of the sweet potato, pp. $156-159$.

Powdery Mildew, see Cucumber, p. 232.

Anthracnose, see Watermelon, p. 240.

Leaf Spot, see Cantaloupe, p. 224.

\section{WILT OR YELLOWS}

Caused by Fusarium cucurbitce Taub. ${ }^{\mathrm{I}}$

One of the greatest drawbacks to squash culture in many of the Southern States, especially in Texas, is a disease known as wilt (fig. 4I i) or yellows. The symptoms of the squash wilt are identical with those of the watermelon wilt, see p. 244. However, the organism $F$. cucurbitce is different and distinct from the three species of Fusarium which are capable of producing a wilt on watermelon. The name Fusarium cucurbite n. sp. is therefore given to the squash wilt organism to distinguish it from other species of Fusarium. From investigations by the writer there has been found no variety which is resistant to wilt. On the other hand, the pumpkin Cucurbita pepo, and the "sugar through" gourd Lagenaria vulgaris will thrive in soils where squashes are known to fail from wilt. Watermelons, cowpeas, cotton, and okra will also thrive well in Fusarium-sick soil of squashes. Occasionally it is found that cowpeas and okra will

$\therefore$ From unpublished data of the author. 
die from a wilt in the same field where squashes are not thriving. However, the writer has been able to prove that the wilt of cowpea and okra are diseases caused by two distinct species of Fusarium, and that both of these parasites may be found in the same field also infected with Fusarium cucurbite of the squash.

Root Rot, see RHizoctonia, p. 45.

Root Knot, see Nematode, p. 49.

\section{DISEASES OF THE WATERMELON (Citrullus} vulgaris)

\section{MALNUTRITION}

Cause, physiological.

Malnutrition seems to occur in fields deficient in potash. The trouble is apparently new, brought about by the scarcity of potash, due to war conditions. The disease is characterized by light brown spots located around the veins and margins of the leaf. The disease must be further investigated before remedial measures may be suggested.

Bacterial Wilt, see Cantaloupe, p. 219.

Downy Mildew, see Cucumber, p. 230.

Powdery Mildew, see Cucumber, p. 222.

\section{HoNey DeW oR Sooty Mold}

Caused by Capnodium sp.

Watermelon stems, petioles, and leaves often become coated with a black sooty growth. This is 


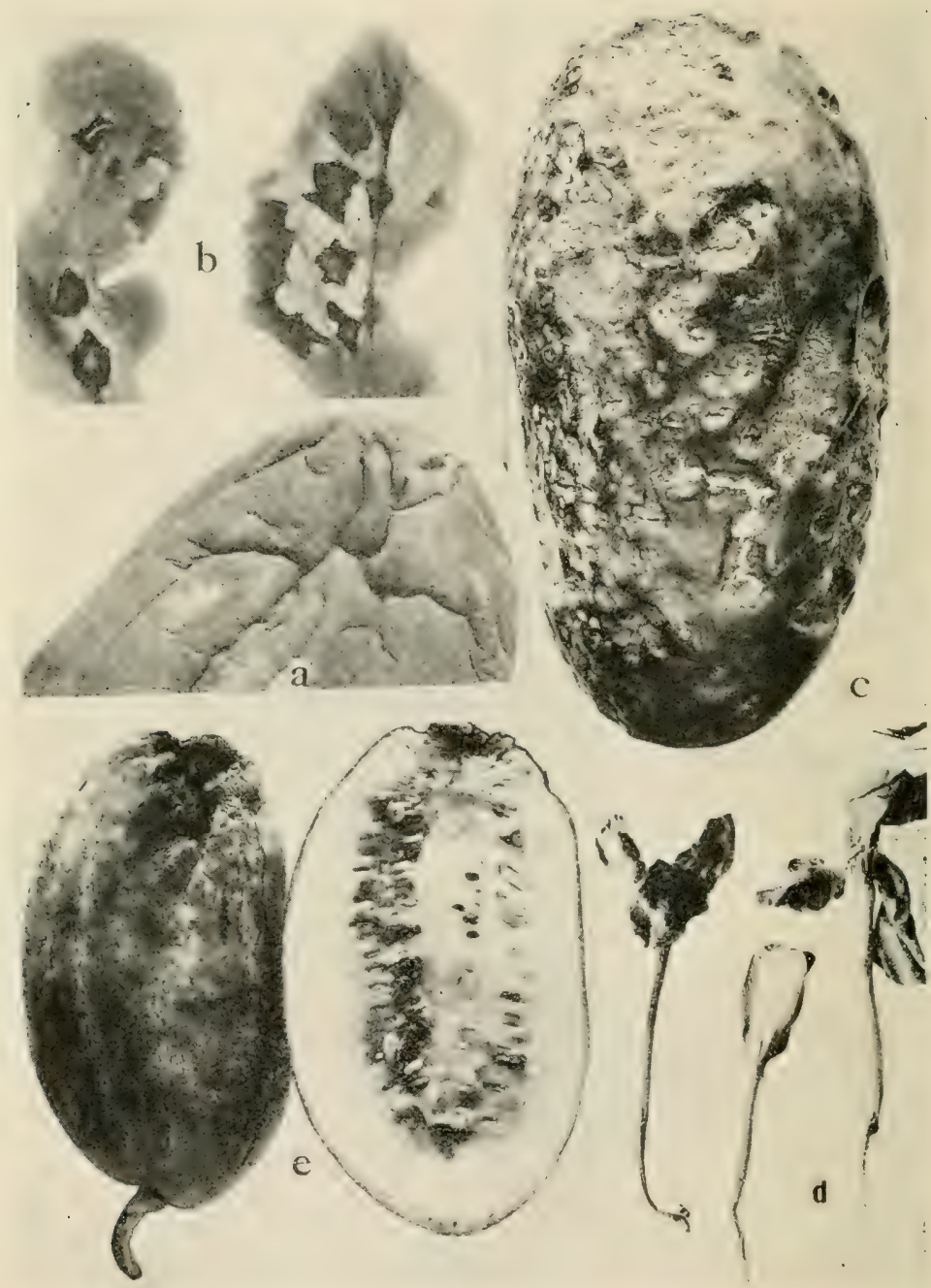

Fig. 42. Watermelon Diseases.

a. Stem enc rot (after Meier), $b$. anthracnose of foliage, $c$. anthracnose on fruit, $d$. Fusarium wilt of young seedlings, $e$. blossom end rot. 


\section{Family Cucurbitaceæ}

more abundant on the older leaves, or even on the nearly mature melon fruit. Although the mold seems to grow superficially on the outside of the affected parts, the result is a general suffocation, since sunlight and free circulation of air are interfered with. Sooty mold undoubtedly grows on the sweetish excreta of plant lice, and is severest during seasons of Aphis epidemics. Spraying with "Black Leaf 40" to control A phis gossypii will also control sooty mold. The fungus Capnodium apparently does not derive any nourishment from the watermelon, but from the honey excreted by plant lice.

Mycosphaerella Wilt, see Cantaloupe, p. 222.

\section{STEM END Rot}

\section{Caused by Diplodia tubericola (E. and E.) Taub.}

This disease was first studied by Meier ${ }^{\mathrm{I}}$ who found the trouble confined mostly to watermelons in transit. Many carloads when reaching their destination showed a loss from it of $75 \%$ to $95 \%$.

Symptoms. The first indication of the rot is a browning and shriveling of the stem end of the fruit (fig. 42 a). Rotting begins at the point of attachment of the melon to the stem of the plant. The flesh of the affected melon blackens, softens, and becomes watersoaked and then slimy. Such melons when left to themselves become black, wrinkled, and mummified. Infection undoubtedly must take place

r Meier, F.C., U.S. Dept. of Agr., Journal of Agr. Research, $6: 149^{-}$ 152, 1916. 
in the field before loading. The disease incubates while in transit and makes its appearance when the assigned shipment reaches its final destination.

The Organism. The organism which causes stem end rot of watermelon is the same which is responsible for the Java black rot of the sweet potato. This has been proved by Meier and by the writer. For further discussion of the fungus, see p. 165 .

Control. Diplodia tubericola may easily live over from year to year on the cull melons left in the field, on the sweet potato refuse or on any other trash. Therefore infected culls and refuse should be destroyed. In hauling melons to the car, only wagons with springs should be used. The cars should be carefully swept and cleaned before loading. Rough handling or bruising should be avoided as much as possible and only sound melons should be loaded in the car. The fruit should be carefully packed so as to avoid bruising from shaking when the cars are moved.

\section{ANTHRACNOSE}

Caused by Colletotrichum lagenarium (Pass.) E. and $\mathrm{H}$.

Anthracnose is a disease the seriousness of which depends on weather conditions, it thriving best during hot, moist weather. It is very prevalent in many 


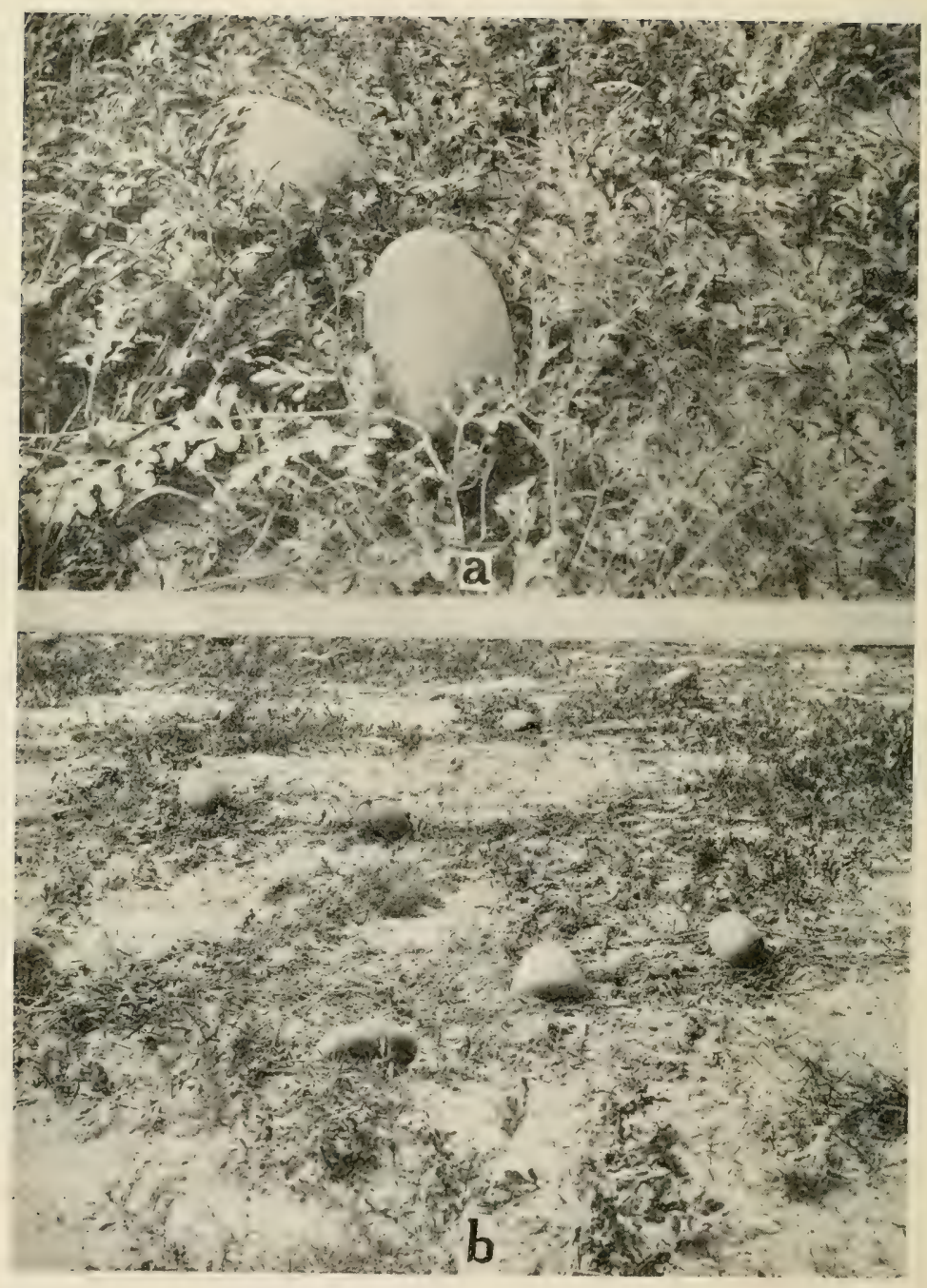

Fig. 43. Watermelon Anthracnose.

$a$. Healthy watermelon hill, $b$. field destroyed by anthracnose. 


\section{Family Cucurbitaceæ}

States, although it has not as yet been found to be serious in Texas.

Symptoms. It attacks all parts of the plant except the root. On the stems it causes watersoaked spots, which in time turn brownish and become depressed and cracked. On the leaves, somewhat circular dark spots become so numerous as to involve the entire area (fig. $42 \mathrm{~b}$ ), resulting in the death of the leaf. Diseased leaves soon crinkle, turn black, and have the appearance of being burned by fire. On the fruit, anthracnose is manifested on the rind as circular deep depressions (fig. 42 c) which soon become covered with a salmon-colored coat made up of the spores of the fungus. Ordinarily the spots do not go deeper than the rind. Under improper methods of shipping, the fungus eats into and penetrates the flesh of the melon which decays rapidly. Anthracnose reduces the market value of the melons, and makes shipping a very risky affair, since the disease readily spreads in the car. This is especially true when the cars are sidetracked and held too long in transit. In the field, anthracnose may ruin the entire stand (fig. $43 \mathrm{a}-\mathrm{b}$ ).

Besides attacking watermelons, anthracnose also attacks cucumbers, cantaloupes, citrons, and gourds. The disease is not usually serious on new land; but on land where watermelons have been grown in succession for a period of years, or where melons followed cantaloupes or cucumbers, the disease may become serious.

The Organism. In structure, Colletotrichum lageI6 
narium resembles the organism of bean anthracnose, see p. 263. The watermelon fungus has a peculiar ability to remain dormant during dry weather; but it is easily revived by rains or dew. This is why anthracnose often appears overnight in carloads shipped to market. The fruits of the fungus are borne in masses on the pustules which take on a salmon color. The spores are typical of all Colletotrichums - that is, oval, one-celled, and hyaline. The setæ in C. lagenarium are not very plentiful. In pure culture it resembles $C$. lindemuthianum; however, pathologically it is distinct from the latter, since numerous attempts by the writer and by others have failed to infect growing bean plants with the watermelon anthracnose or the watermelon with that of the bean.

Control. With this disease, prevention is, of course, the cheapest method of control. From what has been said, it is evident that it is never wise to grow watermelons too long on the same land. In preventing the disease from gaining a foothold on the land, a three-year rotation will probably answer the purpose. On lands in which the crop has suffered severely from anthracnose, a longer rotation, say six years, may be necessary. The disease is carried over in the soil from year to year on the dead leaves, vines, and diseased fruits which remain in the field. These, therefore, should never be plowed, but destroyed by fire. Spraying, too, will help to keep the disease in check. Bordeaux in this case is the standard fungicide to use. However, it should be borne in 


\section{Family Cucurbitaceæ}

mind that watermelon leaves are very tender and hence susceptible to injury. Recent experiments by the writer have shown that a very weak Bordeaux with a large excess of lime should be used in order to prevent the burning of the foliage. Where this precaution is overlooked, a greater injury will result from the use of the fungicide than from the disease itself (fig. 44 b). A Bordeaux made up of three pounds of copper sulphate, eight pounds of lime, and fifty gallons of water, to which is added one pound of powdered arsenate of lead, will answer the purpose well. The lead arsenate in this case is used against various caterpillars which often feed on the leaves of the plants. Paris green should not be used because of its tendency to burn the foliage.

Cercospora leaf Spot, see Cantaloupe, p. 224.

\section{Cercospora leaf Spot}

Caused by Cercospora citrullina Cke.

This form of leaf spot is induced by a species of Cercospora different from that which attacks cantaloupes. The trouble usually appears on the oldest leaves as circular spots bordered by a dark brown or purplish zone beyond which is an area of yellow. The mature spots have gray centers. This form of leaf spot is prevalent on watermelons in Texas. It may be controlled by spraying in the same way as recommended for anthracnose. 


\section{Vine Wilt or Yellows}

Caused by Fusarium niveum Ew. Sm.; Fusarium citrulli Taub. ${ }^{\mathrm{r}}$; Fusarium Poolensis Taub. ${ }^{2}$

Failure of the watermelon crop in many of the Southern States may be safely attributed to wilt. There is no other watermelon disease that is so difficult to control. The reason is obvious. The causative fungi live in the soil as semi-saprophytes. The longer watermelons are grown on that soil, the worse the disease becomes. In severe cases the crop may be a total failure, or the loss run as high as fifty per cent. of the crop.

Symptoms. There is no outside spotting nor are there any lesions to indicate the presence of wilt. The source of the trouble is confined entirely to the interior of the roots and stems. The leaves of an affected plant suddenly droop; this is followed by a rapid wilting of all the vines in that hill (fig. 44 a) from which they never revive. The wilting is more intensified during a warm dry spell. Occasionally only one or two vines in the hill wilt and die while others in the same hill remain alive for some time before succumbing to the disease. In pulling out a plant that has recently died, its roots are found to be sound with the exception of a dull yellowish color which the exterior exhibits. In splitting open a vine

${ }^{x}$ From unpublished data by the writer, the organism was carried as Fusarium No. Io6.

2 The organism was carried as Fusarium No, I I6. 


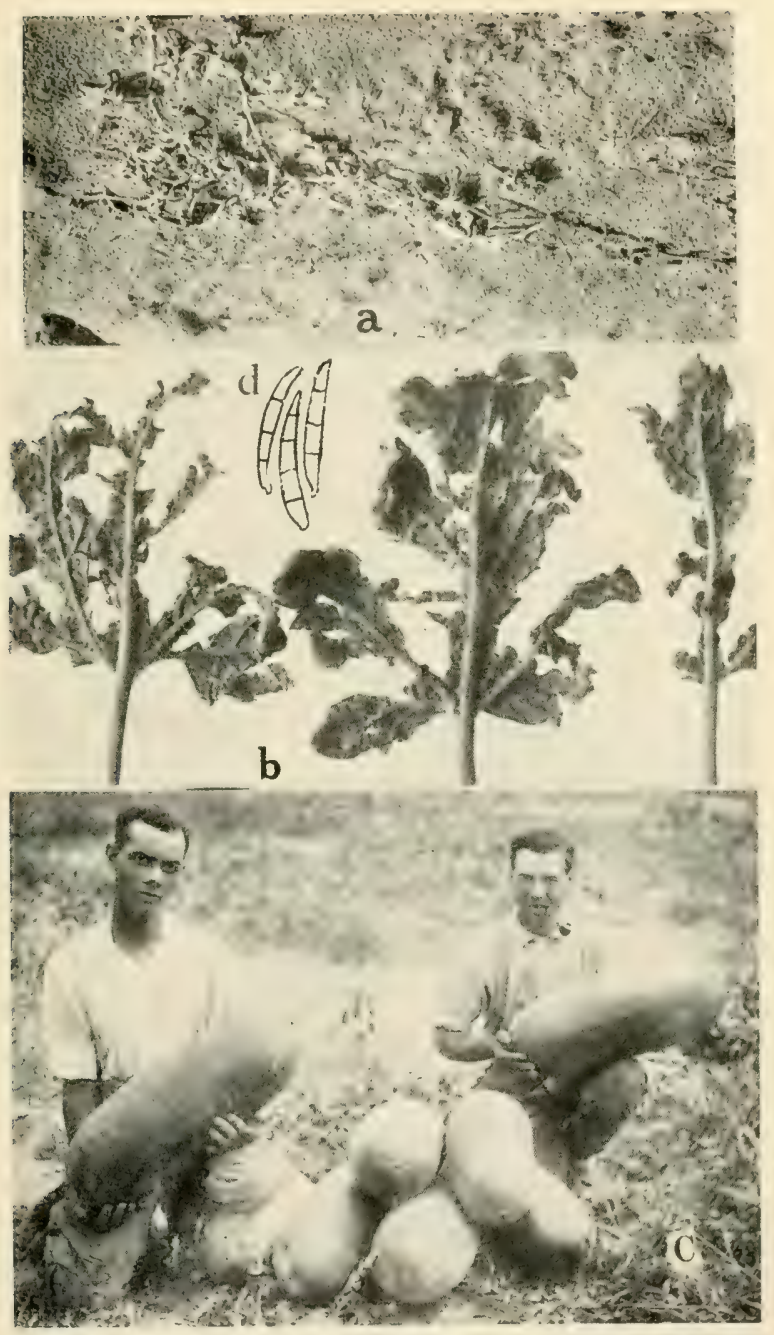

Fig. 44. Watermelon Diseases.

a. Wilt (Fusarium niveum), b. Bordeaux injury, c. Tom Watson, an ideal shipping melon, d. macroconidia of Fusarium niveum. 



\section{Family Cucurbitaceæ}

or root of the diseased plant, its interior fibrovascular bundles will be browned. The browning indicates the presence of the parasite.

Wilt is not always confined to the older plants. In badly infected fields young seedlings begin to die at an early age (fig. 42 d), resulting in a very poor stand. From the investigations of the writer, it has been found that Fusarium citrulli is more active on seedlings than are the other two species of Fusarium. This, however, is not intended to convey the idea that $F$. niveum and F. Poolensis are not capable of producing wilt on the younger seedlings.

The Organisms. The three species of Fusarium which produce wilt of watermelon may be readily distinguished when grown in flasks on cornmeal. Fusarium citrulli is entirely different from the two others in that it forms a glistening, flat, compact, flesh-colored dry growth confined to the surface of the cornmeal. Growth is slow, and no color is produced in the substratum for a considerable time, about two months or more. Fusarium Poolensis at first greatly resembles $F$. niveum in growth and in color. Later, however, F. Poolensis takes on a deep blue to almost indigo which is retained indefinitely. The three species of Fusarium have been definitely proved by the writer to be the cause of the watermelon wilt. Infection can take place only on watermelons and not on any other cucurbit hosts, nor on cotton, okra, or cowpea, the wilts on all of which are caused by different species of Fusarium. It is possible, however, that a sick watermelon field may also be 
infected with Fusarium cucurbitce, thus making it also sick to squashes.

Control. Since the disease works in the interior of the plant, it is obvious that spraying would be of little help. Rotation of crops is the only practical method of control. It usually takes from two to three years for wilt to establish itself very seriously in the field. Because of this, growers often fail to appreciate its importance until too late. Any possible profits made during the time the crop has been grown in succession on the same land are more than offset by the fact that the infected soil is rendered sick and unfit for watermelons for ten years or longer. Watermelon plants suffering from wilt should never be plowed under, but should be pulled out, dried, and burned. Wilt may be spread by cattle and horses which are allowed to pasture in the sick melon patches, and then brought to healthy fields. Finally a method which promises great relief is the development of resistant varieties which are able to grow in sick soils. The United States Department of Agriculture has developed a wilt resistant variety named Conqueror. This is a cross between the citron and the Eden. The Conqueror, however, is not as yet popular with the market because of the uncertain qualities of the citron which it still has. Resistant varieties may no doubt be obtained by selection with the best commercial varieties. For methods of selection for resistance see p. 374 .

Root Knot, see Nematode, p. 49. 


\section{Family Cucurbitaceæ}

\section{FruIt Rot}

\section{Caused by Sclerotium Rolfsii Sacc.}

This form of rot is seldom serious enough to warrant any treatment. The fungus does not seem to find the watermelon fruit as suitable a host as the cantaloupe. On watermelons, rotting starts at a bruise and at points where the melon touches the ground. Decay is slow and is always indicated by a cottony growth at the rotted area.

\section{BLossom END Rot}

\section{Cause: probably due to fungi.}

This is a disease which attacks the blossom end of the fruit (fig. 42 e) and causes a dry rot, but which does not usually penetrate very deep. Nevertheless, affected melons are unfit for the market, although they ripen earlier and have a much sweeter taste. The cause of this trouble is as yet unknown. However, numerous observations seem to indicate that with at least one form of blossom end rot it seems to be brought about by a dry spell and a lack of moisture in the soil. This is especially the case in fields where coarse manure is used instead of good compost. In dry seasons, the coarse manure fails to decompose properly and, at the same time, dries, and hence results in injury to the fruit. To prevent this, so far as possible, only well rotted manure should be 
used. If the coarser manure has to be used, care should be taken to apply it from four to eight weeks before planting, thus giving it ample time to decompose. To have the greatest effect, manure should be applied as deep in the furrows as possible, since the tap-root grows very deep in the soil. It should be remembered that the watermelon plant has numerous long secondary roots which are heavy feeders and which do not benefit from manure if it is applied in the center of the hill. Such superficial application, therefore, often results in starved plants, which become further weakened by spells of dry weather, or by other unfavorable conditions. To obviate this condition, some chemical fertilizer should be applied broadcast. The amount of manure necessary for one acre is about seven tons, applied at the rate of one good forkful to each hill. In connection with this, about four hundred pounds of well balanced fertilizer should also be worked in. In very dry seasons, small amounts of nitrate of soda, applied broadcast, will decidedly benefit the plants. The aim in fertilizing should be to supply sufficient humus to the soil, thus also taking care of the soil moisture at a time when the plant needs it most. Moreover, the use of proper food supply will result in more vigorous plants, with an abundance of foliage protecting the plants from burning and, at the same time, reducing blossom end rot.

There are other forms of blossom end rots. Some may possibly be attributed to imperfect fertilization or weak pollen, while others are undoubtedly caused 


\section{Family Cucurbitaceæ}

by parasitic bacteria and fungi. However, without further knowledge it is impossible to suggest other methods of control. The best shipping melon is the Tom Watson (fig. 44 c). This melon, however, is no less susceptible to diseases than any other variety grown under similar field conditions.

\section{WEEDS}

The wild cucumber Micrampelis (or Echinveyster) lobate is subject to cucumber mosaic and to bacterial wilt. With this exception no cucurbit weeds are subject to the diseases which attack the cultivated species. 


\section{CHAPTER XV}

\section{FAMILY GRAMINEE}

OF this great family the only crop that concerns the trucker and gardener is sweet corn. This is grown to a great extent in the more northern States. In the South, the ordinary field corn is grown instead of sweet corn and is sold for "roasting ears" or on the cob in the milky stage. The present discussion will limit itself to sweet corn only. It is estimated in the Thirteenth United States Census that the total area of sweet corn in the United States in 1909 was I 78,224 acres and the crop was valued at \$2,719,340. The States ranked according to area in sweet corn were: New York, Illinois, Maryland, Ohio, Iowa, Pennsylvania, New Jersey, Maine, Indiana, Michigan, Massachusetts, Wisconsin, Kansas, Nebraska, Missouri, California, Minnesota, Virginia, Connecticut, Delaware, Louisiana, Vermont, and Kentucky. States with less than one thousand acres are omitted.

\section{DISEASES OF THE SWEET CORN (Zea Mays)}

Although corn is considered a hardy plant, it is nevertheless subject to numerous diseases. Of the 250 



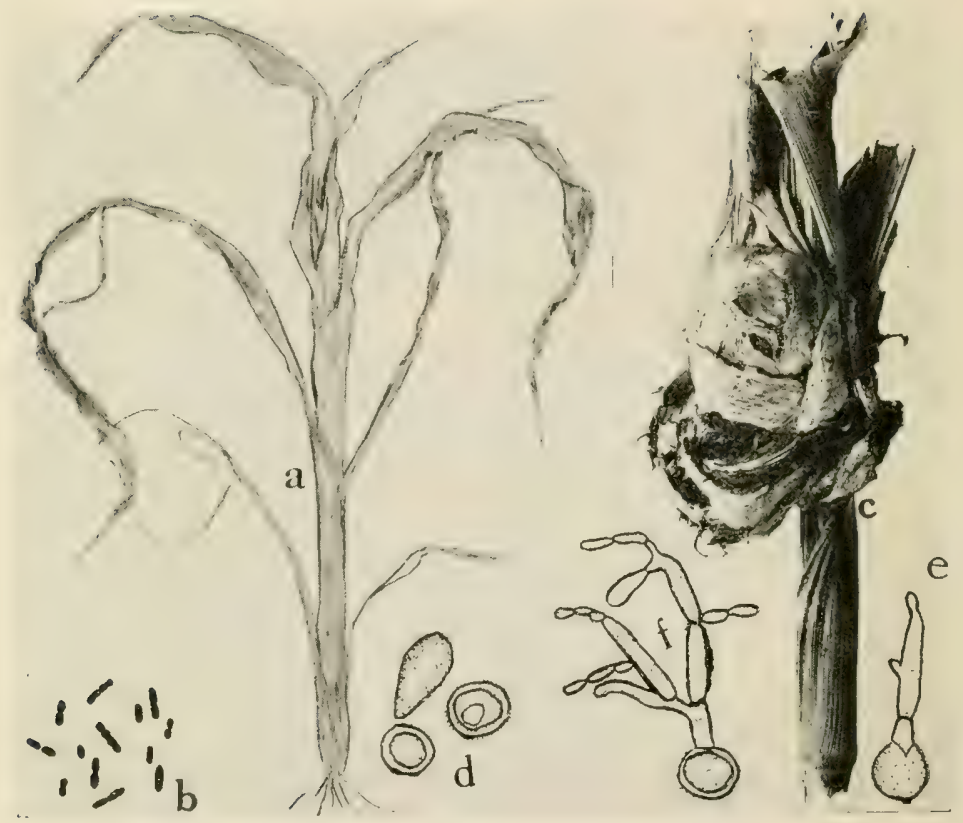

Fig. 45. Sweet CORN Diseases.

$a$. Bacterial blight, $b$. individual blight organisms ( $a$. to $b$. after F. C. Stewart), c. smut, $d$. smut spores, $e$, and $f$. germinating spores of $U$ stilago zece ( $d$. to $f$, after J. B. S. Norton). 


\section{Family Gramineæ}

sweet corn but three diseases need concern the trucker.

\section{BACTERIAL WiLT}

Caused by Pseudomonas Stewarti Erw. Sm.

Bacterial wilt is perhaps one of the most serious diseases of sweet corn. The trouble is very prevalent in Long Island, New York, where it was first studied by Stewart." It is also prevalent in New Jersey, Maryland, West Virginia, Ohio, Iowa, Illinois, and probably many other States.

Symptoms. Bacterial wilt has been carefully studied by Dr. Erwin F. Smith, ${ }^{2}$ who finds that the symptoms of this disease are very distinctive. The first mark on good sized plants is a drying out and whitening of the tassel, giving the top of the plant a peculiar whitish appearance. Another sign is a dwarfing of the plant, followed by a drying of the basal leaves which gradually works upwards (fig. 45 a). The affected leaf dies from the tip downwards or from the margin inwards. The disease often attacks young plants and even seedlings, in which case they dry and die out at an early stage. If an infected plant is cut across the stem, we find a yellow slime oozing out from the bundles; this slime is teeming with the bacteria. In cutting through a

${ }^{2}$ Stewart, F. G., New York (Geneva) Agr. Expt. Sta. Bul. I30 : 424-439, I897.

${ }^{2}$ Smith, E. F., Bacteria in Relation to Plant Disease, $3: 89-174$, Washington, D. C. 
stem longitudinally, it will be found that the bundles from which the yellow slime oozes out are browned or bright yellow. This shows that the germ is confined to the fibrovascular bundles of the stem and leaves.

The Organism. Psendomonas Stewarti is a short rod with rounded ends (fig. 45 b). It occurs singly, in pairs, or fours, and moves about by means of polar flagella. It grows slowly on gelatine without liquefaction. On agar plates it grows slowly, forming small round colonies. It produces no gas and is strictly aerobic; the organism is very sensitive to light.

Control. It is likely that the disease is carried with the seed. Hence the latter should be secured from localities free from wilt. Before planting, seed should be disinfected in formaldehyde, see p. 99. Not all varieties of sweet corn are equally subject to wilt; hence truckers are advised to try to develop a resistant strain or strains of commercial varieties. On the methods of selection for resistance, see p. 374 . Finally, fields badly infected should be rotated and devoted to other crops for about three to four years. As far as is known the disease only attacks corn, so other cereals may be used in the system of rotation.

\section{SMUT}

Caused by Ustilago zece (Beck.) Ung.

Corn smut is different from any smut which attacks other cereals. The greatest damage is experi- 


\section{Family Gramineæ}

enced when the disease attacks the ear, destroying or rendering it useless for market purposes.

Symptoms. Corn smut does not usually make its appearance before the plants are about three or four feet high. It is manifested as boils which may attack any part of the leaves (fig. 45 c), stalks, tassels, or ears. The boils are whitish to glossy, then purple, finally rupturing and liberating a black powdery mass of the spores (chlamydospores) of the fungus.

The Organism. Within the tissue of the affected host the smut mycelium consists of short slender branched filaments closely interwoven. These slender filaments swell, gelatinize, and portions of them round off as spores. The latter retain their vitality for more than one year. The chlamydospores (fig. 45 d) germinate by sending out a tube which in turn bears true conidia (fig. $45 \mathrm{e}, \mathrm{f}$ ). The latter germinate by sending out a tube which penetrates the host.

Control. Corn smut is not carried with the seed as is the case with oat or wheat smut. Seed treatment in this case will therefore be useless. The disease is carried with the manure or in the soil. The best remedy, therefore, is to cut out and destroy by fire all smut boils as they appear. This must be done before the boils are ruptured. If this is carefully practiced by everyone in each community corn smut will soon disappear. Smutted ears or stover should never be fed to animals, as this is a common way of infecting the manure pile. 


\section{Diseases of Truck Crops}

\section{RUST}

Caused by Puccinia sorghi Schw.

Corn rust is a disease which is of restricted distribution and which is never serious enough to warrant treatment. It is characterized by chocolate colored pustules on the leaves and leaf sheaths. The æcidium of this rust occurs on oxalis and is known as Ecidium oxalidis Thum. The uredo and puccinia stages both occur on the corn.

\section{WEEDS}

So far as is known, none of the Graminaceous weeds are subject to the three diseases of the sweet corn here mentioned. Nevertheless, weeds should never be tolerated. 


\section{CHAPTER XVI}

\section{FAMILY LABIATE}

THIs family contains numerous plants which are of very slight economic importance. If grown at all, they are cultivated on a very small scale, and sold for condiments. Many of them are tropical or semi-tropical, but most of them could be grown in frames or indoors. The following is a list of plants which belong to the Labiatæ: Balm, catnip, clary, horehound, hyssop, lavender, mint, peppermint, pennyroyal, rosemary, sage, spearmint, summer savory, sweet basil, and sweet marjoram. Of all these hosts, peppermint and spearmint alone are extensively grown in the United States. The volatile oil distilled from these plants is the principal marketable product, although there is also a limited demand for the dried herb, especially the spearmint, which is used as a culinary herb for flavoring sauces and cooling drinks. Of recent years, these herbs have come into extensive use for flavoring chewing gum and confectionery. The United States, Japan, Russia, Germany, and England produce all of the peppermint and spearmint oils. Fleet ${ }^{\mathrm{I}}$ has estimated

x Fleet, W. V., U. S. Dept. of Agr. Farm. Bul. 694 : I-I2, I9I 5. 


\section{Diseases of Truck Crops}

the total annual production of these oils to be 600,000 pounds, 250,000 of which are produced in the United States. Peppermint and spearmint are grown in Wayne County, New York, and in a few northern counties of Ohio, Maryland, and Indiana. According to the Thirteenth Census of the United States the 1909 area devoted to mint in America was estimated at 8,195 acres. The total crop was valued at $\$ 253,000$. Of the States growing most on a commercial scale may be mentioned Indiana, Michigan, New York, and Tennessee.

\section{DISEASES OF THE BALM (Melissa officinalis)}

\section{RUST}

\section{Caused by Puccinia menthe Pers.}

The disease attacks about thirty-five members of the mint family. All the three stages $i$. e., æcidiospores, uredospores, and teleutospores, occur on the same host. The disease is characterized by brown sori which are at first cinnamon colored and later chestnut brown. Diseased leaves curl and dry up. The disease is not sufficiently important to warrant treatment.

\section{LEAF Spot}

Caused by Septoria melissce Desm.

The disease is characterized by numerous brownish spots which are angular and apparently limited by the 


\section{Family Labiatæ}

veins of the leaves. Leaf spot has not been found in the United States, but it is said to be common in Europe.

\section{DISEASES OF THE CATNIP (Nepeta cataria)}

\section{STEM RoT}

Caused by Didymella cataria (C. and E.) Sacc.

This trouble causes spots on the stems. The disease was first found in New Jersey, but it is of little importance.

\section{LEAF Spot}

Caused by Septoria nepetce E. and E.

Leaf spot is characterized by purplish brown circular spots which are surrounded by a band of deeper brown. The disease was first found in Racine, Wisconsin, and is apparently prevalent on the CanadianAmerican border.

\section{STEM Rot}

Caused by Diplodinia herbicola (B. and C.) Sacc.

Stem rot was first reported from Pennsylvania, but it is of no economic importance. 
DISEASES OF THE HOREHOUND (Marrubium vulgare)

\section{POWDERY MILDEW}

Caused by Erysiphe galeopsidis D. C.

Powdery mildew is characterized by powdery white patches on the leaves and stems. The trouble is not known to occur in the United States.

\section{LEAF SPOT}

Caused by Diplodia herbarum (Corda) Lev.

The spots are roundish to irregular, numerous, brownish to dark in color. The disease attacks the older leaves, causing them to drop off prematurely.

\section{DISEASE OF THE MINT}

RUst, see BALM, p. 256.

\section{DISEASE OF THE PEPPERMINT (Mentha pepenta)}

Peppermint is a very hardy plant. With the exception of RUST (see BALM, p. 256), it is practically free from attacks of fungus diseases. The same is also true for the spearmint, Mentha viridis, which is known to be attacked by the same rust diseases as the balm and all the other Labiatæ. As far as we know the weeds in this family are not carriers of diseases which concern the trucker. 


\section{CHAPTER XVII}

\section{FAMILY LEGUMINOSÆ}

THIS important family includes crops which are greatly valued by the consumer. Of the numerous legume plants, we will consider only those which concern the trucker,-viz., bean, lima bean, cowpea, and the garden pea.

According to the Thirteenth Census of the United States, the total area devoted to dry edible beans in the United States in 1909 was estimated at 802,99I acres, and the total crop valued at \$2I,77I,482. That of green beans was 53,610 acres, the total crop valued at $\$ 2,844,95 \mathrm{I}$. The important leading bean States are Michigan, California, New York, New Mexico, Kentucky, and Maine. The estimated area in dry peas in 1909 was $1,305,099$ acres, and the total crop valued at $\$ 10,963,739$; while the area for green peas was 70,487 acres, yielding a crop valued at $\$ 2,785,502$. The States ranked according to largest area devoted to peas ${ }^{\mathrm{I}}$ were as follows: South Carolina, Georgia, North Carolina, Michigan, Alabama, Wisconsin, Mississippi, Arkansas, Texas, Illinois, Tennes-

"In the Thirteenth Census, no distinction is made between the garden pea and the cowpea. 
see, Louisiana, Colorado, Missouri, Indiana, Virginia, Kentucky, Florida, and Oklahoma.

\section{DISEASES OF THE BEAN (Phaseolus vulgaris)}

Bean growers annually lose heavily from various bean diseases. There is no other truck crop, potatoes excepted, which has received as much attention from plant pathologists as the bean. With our present knowledge, many of the diseases may be controlled.

\section{BLIGHT}

Caused by Pseudomonas phaseoli Ew. Sm.

Symptoms. If the weather is wet during planting time, the seed may rot in the ground and never germinate. At other times the root of the young seedlings may decay and the result will be a very poor and uneven stand. In dry weather a better germination is obtained, but the disease works on the older plants in irregular spots in the field. Due to the lack of a normal root system, the affected plants are yellowed and wilted at daytime, but they slowly revive at night. Should the weather become muggy in midsummer, infected fields appear as though they were drenched with hot grease, the leaves having a burned appearance (fig. $46 \mathrm{a}$ ). As a result, the injured plants seem to make a desperate attempt to produce new foliage which in turn becomes affected, hence the pods cease filling and ripening is very uneven.

In carefully examining diseased seed, it is found to be yellowed and shriveled; or, in light cases of attack, 


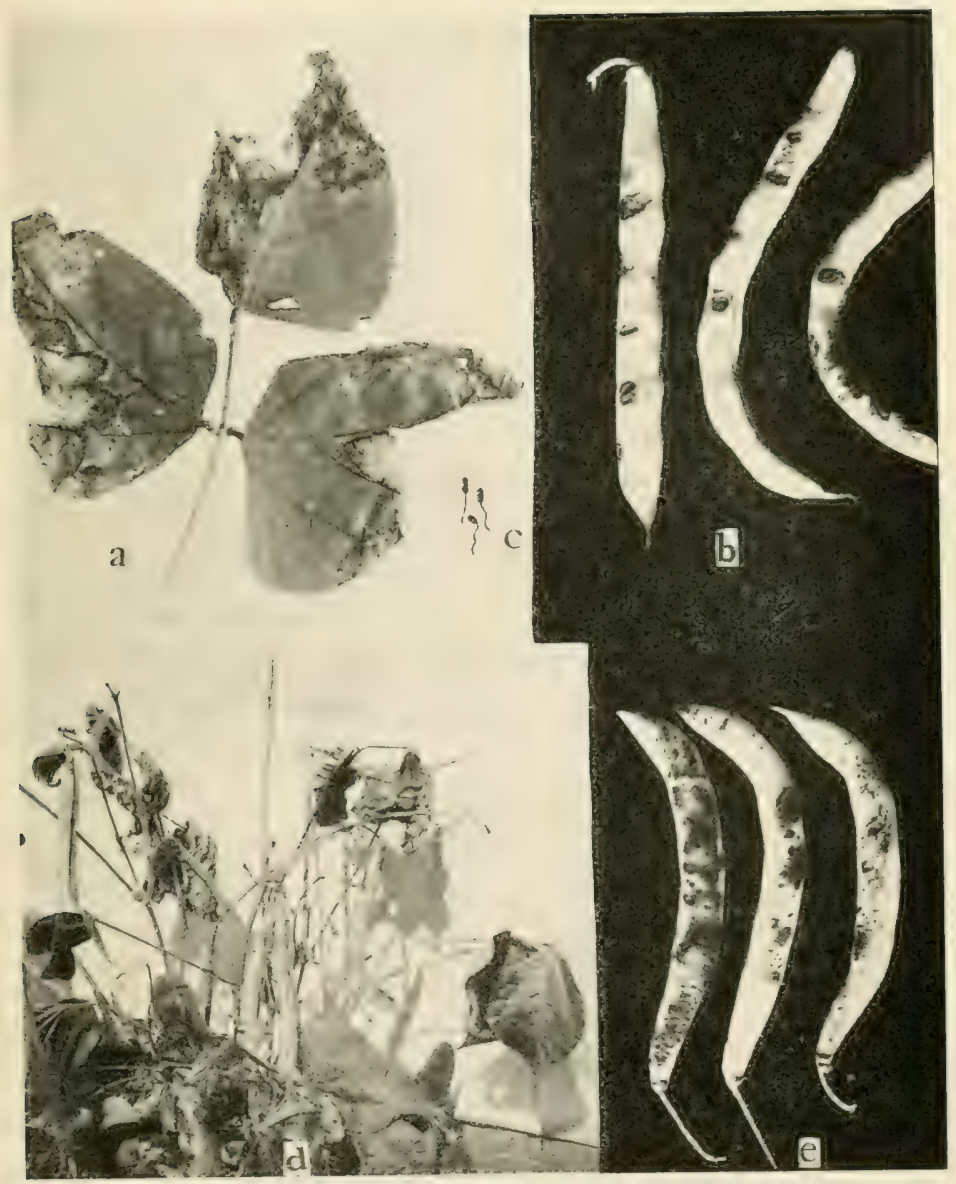

Fig. 46. BEAN Diseases.

a. Bacteriosis on leaf, $b$. bacteriosis on pods, $c$. individual germs of bacteriosis (after Smith), $d$. bean plant killed by streak ( $\%$. to $d$. after Sackett), $e$. streak on pods. 



\section{Family Leguminosæe}

there are found indefinite yellow spots or blotches. On the leaves the trouble appears as watersoaked spots which later are amber colored (fig. 46 a). On the stems and pods (fig. 46 b) a canker is formed which somewhat resembles the canker produced by Colletotrichum lindemuthiamum. From the stem the disease works down to the main root, causing it to rot.

The Organism. Pseudomonas phaseoli is a short rod rounded at both ends, motile by means of polar flagella. It liquefies gelatin slowly, coagulates milk, and the whey separates slowly with acidity.

Control. The same as for anthracnose, p. 265.

\section{STREAK}

Cause, Bacterial.

Streak is a disease which is little known. It has been recently studied by Sackett, ${ }^{\mathrm{T}}$ although the cause has not been definitely determined. The trouble may perhaps be the same as the streak of the sweet pea, caused by Bacillus lathyri Manns and Taub.

Streak attacks stems, leaves, and pods (fig. 46 d,e) of the bean plant. On the pod and on the leaves the disease appears as peculiar rusty to orange brown spattered spots which run down in streaks. Diseased foliage drops off prematurely, giving the plant a denuded appearance. For methods of control, see bean anthracnose, p. 265.

Damping Off, see Pythium, p. 43.

Downy Mildew, see Lima Bean, p. 267.

${ }^{x}$ Sackett, W. A., Colorado Agr. Expt. Sta. Bul. 226 : 27, 1917. 


\section{RUST}

Caused by Uromyces appendiculatus (P.) L.

Rust is seldom serious enough to warrant treatment. The disease attacks all parts of the bean plant except the roots. On the foliage, it appears as little brown pimples or sori (fig. 47 a) the size of a pin's head. These pimples soon appear on the pods (fig. 47 b), petioles, and stems, being more numerous however on the leaves and pods. The pimples as they get older turn from brown to black in color. The powder discharged from the sori is made up of countless numbers of the fungus spores. Rust does not live over on the seed, but rather on the dead refuse of the bean plants. Bean rust has the æcidiospores, uredospores (fig. $47 \mathrm{~d}$ ), and teleutospores (fig. $47 \mathrm{c}$ ) on the same host.

Clean culture, burning of trash and dead plants, and selection of resistant strains or varieties is recommended.

\section{Powdery Mildew}

Caused by Erysiphe polygomi D. C.

Powdery mildew is serious on fall beans in many of the Southern States, and on beans grown for the early market. It is characterized by white, mealy patches on the surface of the leaves and stems. The foliage soon turns yellow and dry. Powdery mildew may be controlled by dusting the plants with flowers of sul- 

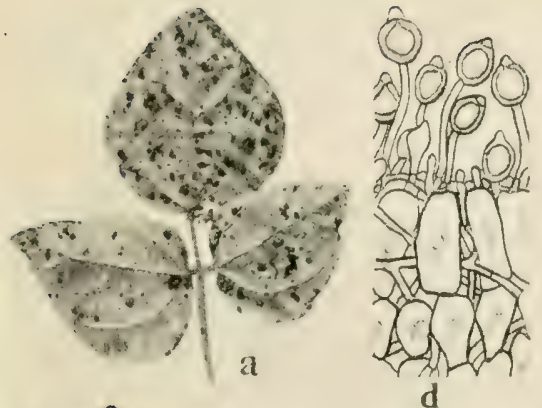

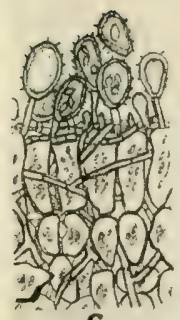

c

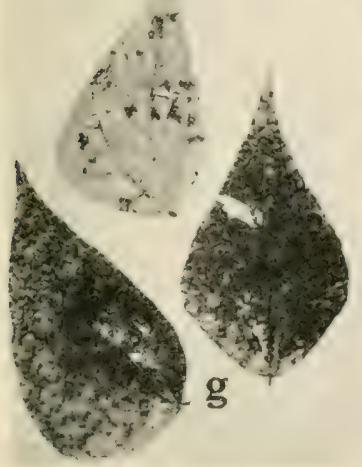

f
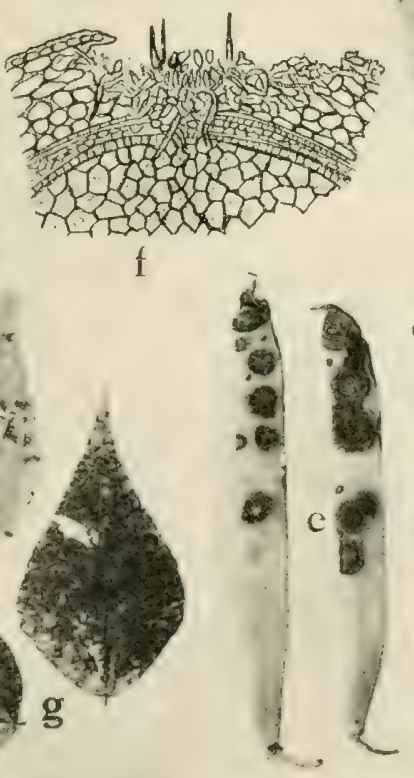

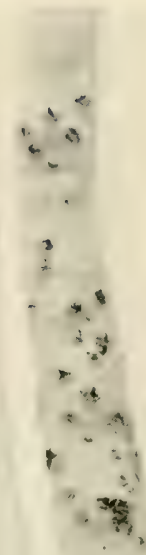

b
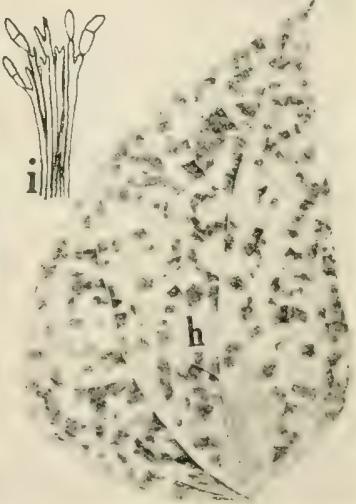

\section{Fig. 47. BEAN Diseases.}

$a$. and $b$. Rust on leaf and pods, $c$. section through bean leaf showing bean rust, summer spores, $d$. section through bean leaf, showing bean rust, winter spores, $e$. anthracnose, $f$. section through bean seed, showing relation of anthracnose to the host $(c . d$. and $f$. after Whetzel),$g$. Cercospora leaf spot, $h$. I suriopsis griseola leaf spot, $i$. conidiophores and conidia of Isariopsis. 

phur, or by spraying with potassium sulphide at the rate of three ounces of the chemical dissolved in ten gallons of water.

\section{SCLEROTINIA ROT}

Caused by Sclerotinia libertiana Fckl.

Sclerotinia rot is a disease which attacks fall snap beans. The trouble is prevalent in Norfolk, Virginia, where it has been studied by McClintock. ${ }^{*}$ During a period of hot humid weather in September the disease may suddenly break out in great severity. Usually withering and decaying of stems and pods where the plants are thickest is the first symptom that attracts attention (fig. $5 \mathrm{I} \mathrm{c}$ ). On closely examining infected stems and pods, we find that they are watersoaked, and overrun by the white mycelial growth on which appear numerous hard, black sclerotia. In the field, the Black Valentine snap bean seems to be more resistant to rot. For a description of the causative fungus and methods of control, see lettuce drop, p. I43.

\section{ANTHRACNOSE}

Caused by Colletotrichum lindemuthianum (Sacc. \& Magn.) B. and C.

Anthracnose may be considered one of the most destructive bean diseases. However the trouble

${ }^{2}$ McClintock, J. A., Phytopath. 6:436-44I, I916. 
depends on weather conditions. It is most prevalent during periods of heavy night dews, or during prolonged rains, and in hot muggy weather.

Symploms. Anthracnose is so characteristic, that it cannot be mistaken for any other disease, except perhaps the blight. In light attacks, the seeds are covered with sunken brown to black specks. These are especially evidenced on the black seeded varieties. In severe attacks, the seeds are covered with deep sunken black spots which are rifted in the center. On the leaves the disease attacks the veins, which become blackened and somewhat shrunken. Frequently it attacks the petioles, especially at the point of leaf attachment. In this case the foliage drops off, leaving the bare petioles or stems. Anthracnose on the leaves begins as small, circular, pin-point, dark red spots which enlarge, and later elongate into maroon colored pits, cracks, or cankers (fig. $47 \mathrm{e}$ ). On young seedlings the stem rots off a short distance above ground.

The Organism. Spores are formed on the spots or cankers on all parts affected (fig. $47 \mathrm{f}$ ). These are imbedded in a gelatinous substance and can become loosened only by rain splashing or dew. It is at this stage that the disease becomes serious, since it is then spread about from plant to plant. When the spores are lodged on a new bean plant or on a new part of the same plant, infection takes place through the penetration of the germ tube of the germinated spores. It is estimated by Edgerton ${ }^{\mathrm{I}}$ that from one

s Edgerton, C. A., Louisiana Agr. Expt. Sta. Bul. 119 : 3-55, 1910. 


\section{Family Leguminosæ}

half to a million spores are formed on one infected pod alone. The period of incubation usually varies from four to six days.

In culture media, the growth is at first white, but it soon becomes jet black in color. The mycelium of the fungus is hyaline, small at first, but later becoming larger and darker.

Control. Spraying has not given satisfactory results. The best control is to plant clean seed selected from clean pods. The latter before shelling may be dipped for ten minutes in a solution of one part of corrosive sublimate to a thousand of water. The treated pods are then dried in the sun, shelled, and the seed put away in dry mason jars until the following spring. Should weevils threaten these seeds, they may be fumigated with carbon bisulphide. By reserving a plot destined for bean seed, by carefully destroying infected plants, and by selecting clean pods and seed, anthracnose and blight may be kept in check.

Under no circumstances should an infected field be cultivated in damp weather, or when the dew is still on the plants. When this is done the spores of the fungus are scattered broadcast in the field. As for resistant varieties, there is very little to select from. However, Barrus ${ }^{r}$ found that the Wells red kidney bean is most resistant to anthracnose. It is therefore recommended for trial in localities where anthracnose prevails. In selecting for seed resistant varieties, these must of course be artificially inoculated

${ }^{x}$ Barrus, M. F., Phytopath. 5 : 303-31I, I9I5. 
with spores of the fungus. This will make sure that the parasite has been placed on the host. If there is any difference in resistance, it will be evidenced by the amount of infection developing on each variety tested. In this connection it should be remembered that there are numerous strains of $C$. lindemuthianum, some of which are very virulent while others are less so. In inoculating for resistant varieties, an attempt should be made to secure pure culture strains from various localities.

\section{StEm Anthracnose}

Caused by Colletotrichum caulicolum $\mathrm{H}$. and W.

A serious stem rot attacks the Kentucky Wonder bean. The disease differs from anthracnose described above in that the former destroys the stems of the plant. Observations made by Heald and Wolf ${ }^{\mathrm{r}}$ show that the disease girdles the stem, and also causes deep fissured cankers on one side of it. The trouble has been found in only one locality in Texas, and it is doubtful if it is prevalent elsewhere. Little is known of the control of this disease.

Angular Leaf Spot (fig. 47 g), see Cowpea, p. 27 I. Southern Blight, see Pepper, p. 305.

Root Rot (fig. 49 a), see Rhizoctonia, p. 45.

Texas Root, see Sweet Potato, p. 75.

Root Knot, see Nematode, p. 49.

${ }^{2}$ Heald, F. D., and Wolf, F. A., U. S. Dept. of Agr. Bur. Pl. Ind. Bul. $226: 35-36$, 1912 . 



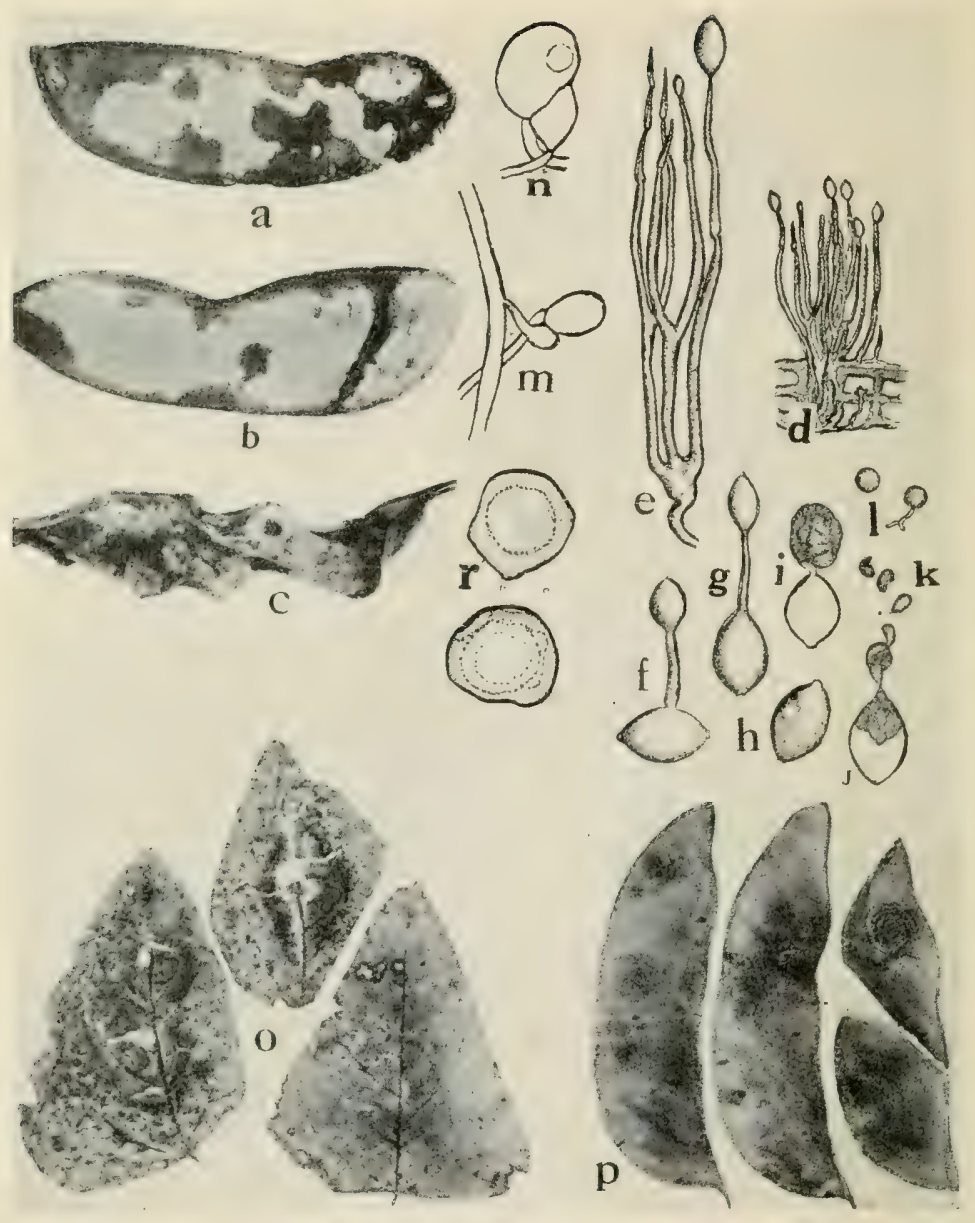

Fig. 48. Diseases of Lima Bean.

$a . b . c$. different stages of downy mildew on pods, $d$. tuft of conidiophores and conidia of Phythophthora phaseoli, e. same as $d$. but greatly enlarged, $f$. $g$. conidia germinating by means of a germ tube, $h, i, j . k$. germination of conidia by means of zoospores, $l$. germinating zoospores ( $d$. to $l$. after Thaxter), $m$. $n$. fertilization of the oogonium by the antheridium, $o$. Phoma blight on foliage, $p$. Phoma blight on pods (o. and $p$. after Halsted), $r$. mature oospores of $P$. phaseoli $(a$. to c., $m$. $n$. and $r$. after Clinton). 


\section{Family Leguminosæ}

\section{DISEASES OF THE LIMA BEAN (Phaseolus}

lunatus var. macrocarpus)

Lima beans, whether climbing or dwarf, are usually considered hardy. This is generally true under favorable weather conditions. But in hot moist weather, truckers may lose heavily from various diseases.

Blight, see BEAN, p. 260.

\section{Downy MILDEW}

Caused by Phytophtora phaseoli Thax.

Perhaps the greatest damage in wet seasons to lima bean culture of both the pole and the dwarf varieties is downy mildew. The damage from this disease equals that from the anthracnose on snap and other varieties of Phaseolus vulgaris.

Symptoms. It is most conspicuous on the pods, where it forms a dense, dirty white mycelial growth (fig. $48 \mathrm{a}-\mathrm{c}$ ). The trouble appears first on one side of the pod, and then works its way through to the other side. Infected pods wilt, shrink, and eventually dry up and die. In early cases of infection, the diseased area is separated from the healthy by a purplish border. Occasionally the blossoms are affected, in which case they wither and drop off. On the leaves the disease is manifested as irregular purplish discoloration, especially on the veins, but there seems to be no evidence of the fungus growth on it. 
The Organism. The mycelium is hyaline, non-septate, and in other respects not different from other downy mildews. The conidiophores are long and little branched (fig. 48 d, e), the conidia are hyaline, elliptical to ovoid in shape, germinating by means of motile zoospores (fig. $48 \mathrm{f}-1$ ). The oospores or sexual resting spores are formed in the same way as in Pythium (fig. 48 m, n, r), see p. 43 .

Control. Downy mildew is carried over in the seed as dormant mycelium. Hence all shriveled seed should be discarded. In badly infected fields, crop rotation should be resorted to. The burning of trash and old bean plants is also advised. Finally three sprayings with 4-4-50 Bordeaux mixture during the growing season will keep the disease well in check.

Rust, see BEAN, p. 262.

Powdery Mildew, see Bean, p. 262.

\section{POD Blight}

Caused by Phoma subcircinata E. and E.

As the name indicates, the disease chiefly attacks the pods. Blight is indicated on them by the appearance of large brown patches (fig. 48 o, p). The pycnidia of the fungus are arranged in concentric zones. In severe cases, the disease works from the pods to the seed, considerably reducing the yield. On the leaves the symptoms are the same as on the pods. Spraying with Bordeaux will control the trouble. 



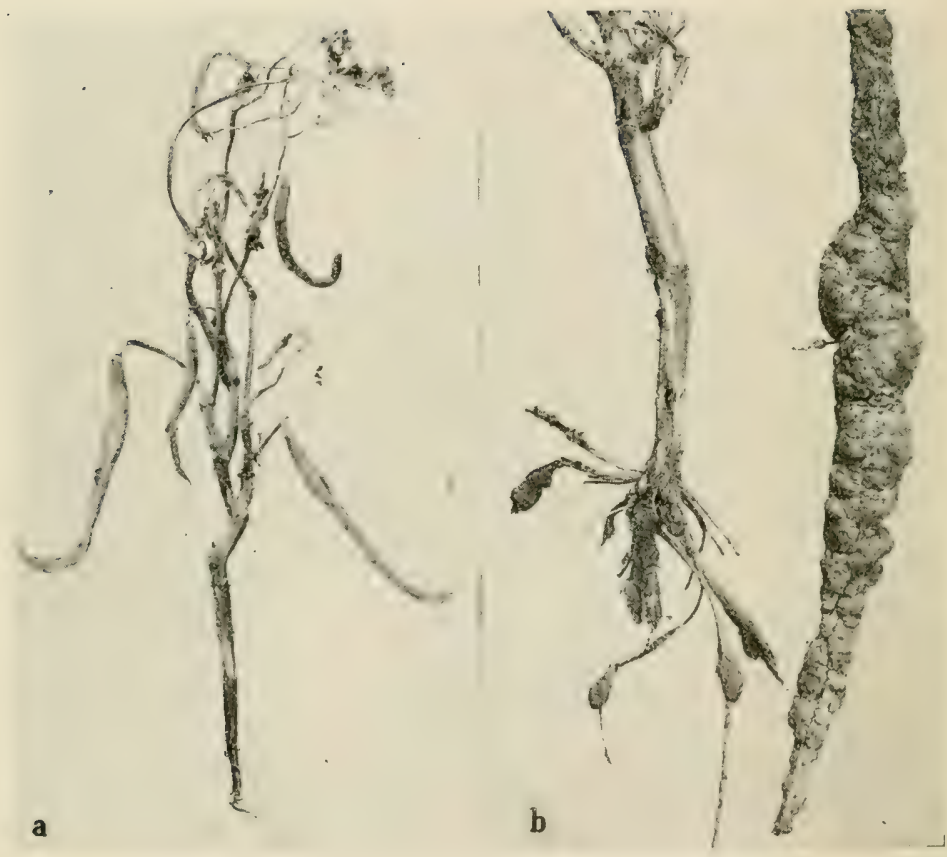

Fig. 49. Bean Diseases.

$a$. Rhizoctonia root rot, $b$. root knot on lima beans. 


\section{Family Leguminosæ}

\section{LEAF BLOTCH}

Caused by Cercospora canescens E. and M.

This disease, so far as is lnown, is not generally distributed. It is found in certain trucking centers in Texas. On the leaves the spots are circular, but somewhat angular. The center of the spots is gray with a reddish brown border, the outside of which divides the diseased from the healthy tissue. The conidiophores are equally abundant on both surfaces, the spores are hyaline, straight or curved, slender and one to many septate. While no experiments have been made on the disease, spraying with Bordeaux is recommended.

\section{LEAF Spot}

\section{Caused by Isariopsis griseola Sacc.}

The disease is confined to the foliage only. The spots produced are small and angular with no colored borders (fig. $47 \mathrm{~h}, \mathrm{i}$ ). On the under side of the leaf, the fungus forms a gray moldy growth on the spot, where large numbers of the spores are produced. The disease is not widely distributed, and may be controlled by spraying with Bordeaux.

Root Rot, see Rhizoctonia, p. 45.

Texas Root Rot, see Sweet Potato, p. I75.

Root Knot (fig. 49 b), see Nematode, p. 49. 


\section{DISEASES OF THE COWPEA (Vigna sinensis)}

In the South, the cowpea is extensively grown as a truck crop. It is cultivated for its edible green pods, and dried peas, and often takes the place of the bean.

\section{STREAK}

\section{Caused by Bacillus lathyri Manns and Taub.}

Streak is a serious disease which until now has usually been mistaken for other troubles. The disease is the same as streak on the sweet pea and clovers.

Symptoms. Like the bacteriosis of the bean, streak makes its appearance in a season of heavy dew. On the cowpea it usually appears just as the plant begins to bloom. It is manifested along the stems by light reddish brown to dark brown spots and streaks, the older of which are almost purple, having their origin usually near the ground. This indicates distribution by spattering rain and infection through the stomata or through insect injury. The disease becomes distributed quickly over the mature stems until the cambium and deeper tissues are destroyed in continuous areas, and the plant dies prematurely. From the stem the disease spreads to the petioles, peduncles, and pods, the symptoms in these cases being similar to those on the stems. On the leaves, however, the disease appears as small circular spots, which gradually coalesce and eventually involve the entire leaf. When killed, the leaf presents a dark brownish appearance. 
The Organism. Bacillus lathyri as worked out by Manns, ${ }^{\mathrm{I}}$ is rod-shaped, occurring singly, never found in chains, and seldom united by twos or fours, motile by means of flagella. It produces no spores, no capsules, no zooglea, liquefies gelatin completely in about three weeks, and produces no gas.

Control. Rotation of crops is helpful; but since streak attacks numerous leguminous crops, such as bean and clovers, these should be excluded. Other methods of control are as yet unknown.

RUST, see BEAN, p. 262.

Powdery Mildew, see Bean, p. 262.

\section{ANgular Leaf Spot}

Caused by Cercospora cruenta Sacc.; Cercospora dolichi $\mathrm{E}$. and $\mathrm{E}$.

Angular leaf spot is a common disease on cowpeas. When it attacks the leaves, they are covered with angular rusty red spots, the leaves turn yellow and drop prematurely. On the stems the spots are irregular, elongated, dark colored, slightly sunken, and later forming cankers. The latter often crack and expose the stems to the attacks of various other parasitic and even saprophytic fungi. Under favorable conditions of moisture, the spots on the leaves or stems are covered with a brownish downy growth made up of the conidiophores and conidia. No methods of control are known.

s Manns, T. F., Delaware Agr. Expt. Sta. Bul. 108 : 3-44, I915. 


\section{Wilt, Yellows}

\section{Caused by Fusarium tracheiphila Ew. Sm.}

In the light sandy to loamy soils, wilt is the greatest drawback to pea culture. The disease is most prevalent in the Southern States.

Symptoms. It does not seem to attack young seedlings, but appears only when the plant is about six weeks old and upwards. In the field, scattered plants turn yellow and begin to drop their leaves, the stems become bare (fig. $50 \mathrm{a}$ ), and the plants finally die. On pulling out a diseased plant, the main root will apparently be sound, but the lateral rootlets will be dead, marking the seat of infection. A more definite symptom of wilt is a browning of the interior fibrovascular bundles of roots, stems, and petioles. This may be readily ascertained by splitting open lengthwise a root or stem of a suspected plant.

The Organism. From unpublished work by the author, it is definitely proven that $F$. tracheiphila is distinct from Fusarium wilts of the cotton, okra, and watermelon. The Fusarium wilt of the cowpea is caused by $F$. tracheiphila, which produces only the conidial stage and has no relationship whatsoever with Necosmospora, or any other ascospore stage. The cowpea Fusarium may be found in fields which are also infected with olra Fusarium. In this case, the field is infected with two distinct organisms, thus making it sick to both cowpeas and okra. The cow- 

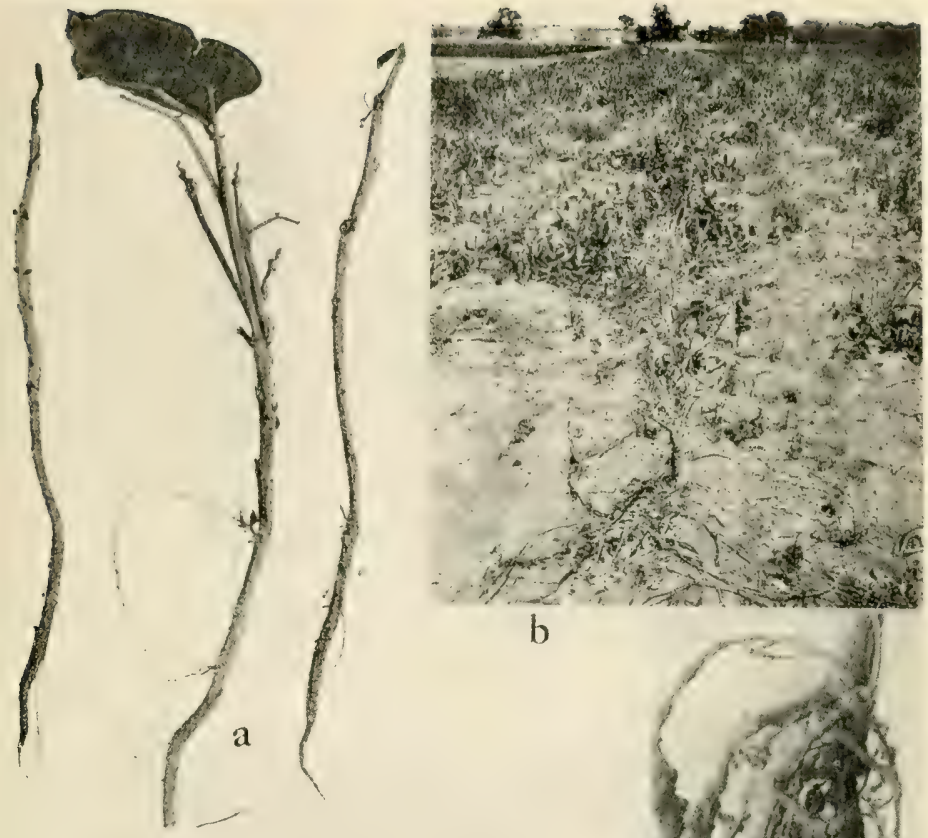

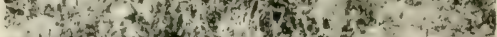

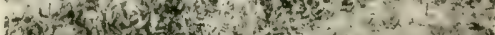

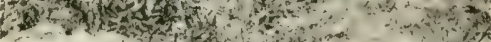

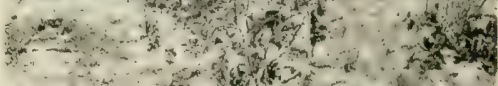

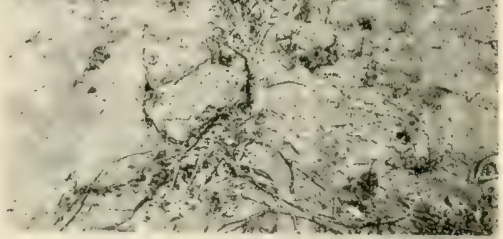

b

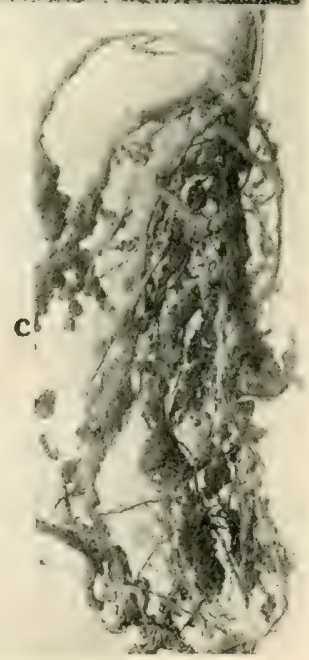

Fig. 50. Diseases of the Cow Pea.

$a$. Fusarium wilt, $b$. field of cow peas killed by Texas root rot, $c$, root knot, $d$. row of iron cow pea resistant to Fusarium wilt in sick field where other varieties of peas have died ( $a$, and $d$. after W. A. Orton). 



\section{Family Leguminosæ}

pea Fusarium is parasitic only on the cowpea, and so far as is known does not attack any of the other cultivated legumes.

Control. Diseased fields may be sown with beans or any other legume except cowpeas. Crops other than legumes may also be grown there. The development of resistant varieties is also a promising method of control. Orton ${ }^{x}$ has already developed the Iron cowpea (fig. $50 \mathrm{~d}$ ), a variety which is resistant to wilt and partly also to Nematode.

Root Rot, see Rhizoctonia, p. 45.

Texas Root Rot (fig. 50 b), see OKRA, p. I75.

Root Knot (fig. 50 c), see Nematode, p. 49.

\section{DISEASES OF THE GARDEN PEA (Pisum sativum)}

Like the bean and cowpea, the garden pea is subject to numerous diseases, some of which are of great economic importance. However many of these diseases may be controlled.

\section{Stem Blight}

Caused by Pseudomonas pisi Sack.

Blight is a new disease recently found by Sackett ${ }^{2}$ in the pea fields of Colorado. So far as is known, the

s Orton, W. A., U. S. Dept. of Agr. Bur. Pl. Ind. Bul. 17 :9-36, 1902.

${ }^{2}$ Sackett, W. G., Colorado Agr. Expt. Sta. Bul. 2 I8 :3-43, I9 I6. 
trouble does not seem to occur in the other States where peas are extensively grown. In Colorado, blight has suddenly made its appearance on a pea area of 500,000 acres, seriously threatening the profitable growing of the crop.

Symptoms. On the stems and leaves (fig. 5I b) the disease may be recognized by watery olive green to drab brown spots and by yellowish watery bruises on the leaflets and stipules. The roots seem to be free from the attacks of blight. Infection seems to start on the stem, near the ground level, and from there to work upwards. Lower leaves are usually the first to die. Occasionally the infected plants send out new shoots below the infected area. The new growth is sometimes unmolested but ordinarily it too becomes blighted.

The Organism. Pseudomonas pisi is a short rod, rounded at both ends, and motile by means of polar flagella. It produces no spores, no capsules, and no zooglea and no involution forms. It produces no gas, and can stand drying of thirteen days.

Control. Certain varieties seem to be more resistant than others. The development of resistant varieties is recommended. All trash and diseased materials should be destroyed by fire and not fed to animals. It is not known if spraying will control this disease. In badly affected fields, spraying with Bordeaux may be tried.

Damping Off, see Pythium, p. 43.

RUST, see BEAN, p. 262. 


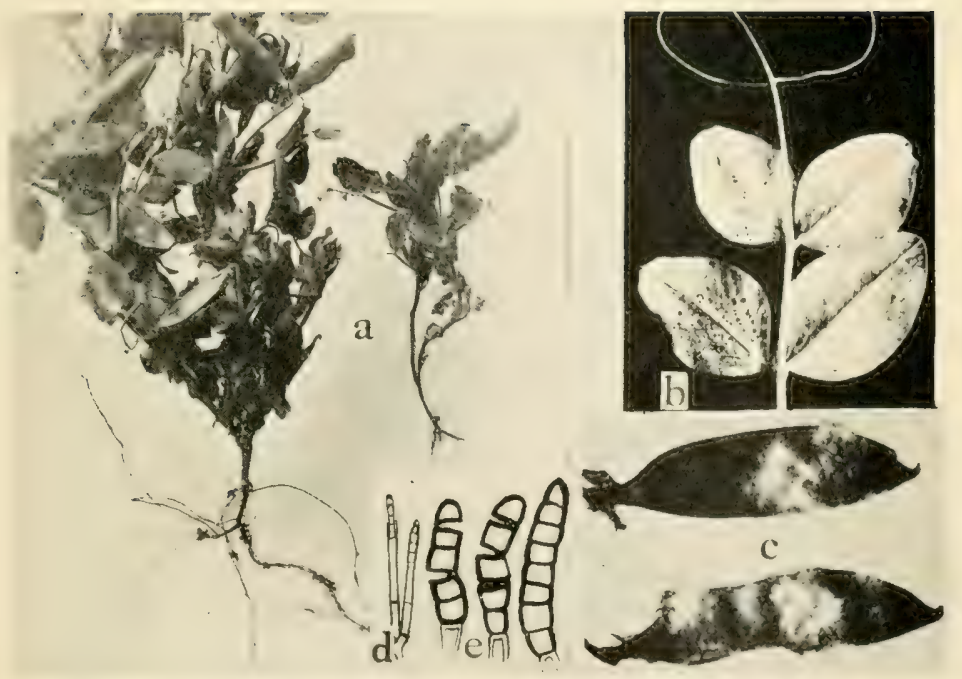

Fig. 51. Diseases of the Garden Pea and Bean.

a. Thielavia root rot, to the right diseased plant with no root system, to the left healthy, $b$. stomatal leaf infection by Pseudomonas pisi, c. Sclerotinia libertiana rot on bean pods, $d$. endospore of Thielavia basicola, $e$. chlamydospores of $T$. basicola. 



\section{Family Leguminosæ}

\section{Thielavia Root Rot}

Caused by Thielavia basicola Zopf.

Root rot is a common disease in fields devoted to peas for a period of years. The trouble on the garden and field pea is identical with that on the sweet pea.

Symptoms. Plants severely infected with Thielavia have practically no root system, since this is destroyed by the fungus as rapidly as formed (fig. 5I a). All that is left of the root system is a charred blackened stub. The diseased host constantly attempts to produce new roots above the injured part but these in turn also become infected. Such plants linger for a long time, but fail to set pods which are of any value.

The Organism. The mycelium of Thiclavia basicola is hyaline, septate, and branched. The mycelium becomes somewhat grayish with age. Three kinds of spore forms are produced-endospores (fig. 5I d), chlanydospores (fig. $5 \mathrm{I}$ e), and ascospores. Endospores are so called because they are formed inside a special thread of the mycelium. This is the spore form that commonly occurs in pure cultures of artificial media and on the host. The endospore case is formed on terminal branches with a somewhat swollen base and a long tapering cell. The endospores are formed in the apex of this terminal cell and are pushed out of the ruptured end by the growth of the unfragmented protoplasm of the base. They are hyaline, thin walled, and oblong to linear in shape. 
The chlamydospores are thick walled, dark brown bodies borne on the same mycelium as the endospores. This type of spore is formed in great abundance on the host and particularly within the affected tissue. The ascospores are lenticular in shape and are borne in asci or sacs within black perithecia. This stage however has not been found on the pea or in pure culture.

Control. Thielavia basicola is a soil-inhabiting fungus. With infected pea fields, soil sterilization is of course out of the question. The method of control suggested is crop rotation. Investigations by Johnson ${ }^{I}$ have shown that the following vegetable crops are not subject to Thielavia root rot: potato, sweet corn, sweet potato, cabbage, onion, parsnip, carrot, beet, eggplant, and peppers. These crops may therefore be safely used in a crop rotation, the system of which is best worked out by the trucker himself.

Powdery Mildew, see Bean, p. 262.

\section{Pod SPoT}

Caused by Spharella pinodes (Berk. and B1.) Niessl.

Pod spot is a disease which is of even greater economic importance than Thielavia root rot. The disease does not confine itself to the pods alone, but also involves the leaves and stems. The trouble however is known by truckers as pod spot.

'Johnson, J., U. S. Dept. of Agr. Jour. Agr. Research, 7 : 26I-300, I916. 


\section{Family Leguminosæ}

Symptoms. On the stem the trouble appears as numerous elongated lesions. These spread to such an extent as actually to girdle the affected stem. On the leaves are formed oval spots, grayish in the center, and limited by a dark band. The pods too become badly attacked and the symptoms there resemble those on the stems. The disease works its way from the pods to the seed within.

The Organism. The causative fungus has two spore stages. The pycnidia bear the hyaline, two celled spores and are formed within the dead tissue of the affected stems, leaves, or pods. The pycnidial stage is known as Ascochyta pisi Lib. The winter or ascospore stage has only recently been discovered by Stone, ${ }^{\mathrm{r}}$ who found it on pods and stems previously affected, and on culture media. The fungus may be carried from year to year as dormant mycelium within the seed, or in the ascospore stage.

Control. Seed treatment will not be of any value since the fungus is hidden within the seed. No outside treatment is capable of reaching the parasite within. Seed should be secured from localities known to be free from the disease. Rotation of crops is also recommended. Giving the field a rest from peas or hairy vetch for at least three years is recommended. In badly affected localities, susceptible varieties, such as French June, Market Garden, American Wonder, should be discarded. The Alaska variety is claimed to be more resistant.

×Stone, R. E., Annales Mycol., Io : 564-592, 1912. 


\section{Septoria Leaf Spot}

Caused by Septoria pisi Westd.

The disease greatly resembles pod spot. But a microscopical examination of the fruit of the two will reveal the difference. Septoria leaf spot is of little economic importance.

Root Rot, see Rhizoctonia, p. 45 .

Root Knot, see Nematode, p. 49.

\section{WEEDS}

Of the numerous legume weeds, few if any are troublesome in trucking. None are likely to be carriers of the diseases which attack beans and peas. 


\section{CHAPTER XVIII}

\section{FAMILY LILIACEA}

THIs family is an important one, since it furnishes such crops as asparagus, chive, garlic, leek, onion, and shallot. According to the Thirteenth Census of the United States, the total 1909 American area devoted to asparagus was estimated at 25,639 acres and the crop valued at $\$ 2,246,63 \mathrm{I}$. The States ranked according to largest area devoted to asparagus are as follows: California, New Jersey, Illinois, South Carolina, Pennsylvania, and New York. States with less than I,000 acres are here omitted. The total area in the United States devoted to onions in 1909, including chive, garlic, leek, and shallot, of which there are no records, was estimated at 47,625 acres, and the total crop valued at $\$ 6,709$,047. The States ranked according to acreage in onions were as follows: Ohio, New York, Texas, California, Illinois, Indiana, Louisiana, Massachusetts, Kentucky, New Jersey, Michigan, and Minnesota. States with less than one thousand acres are omitted.

\section{DISEASES OF THE ASPARAGUS (Asparagus officinalis)}

Asparagus may be considered a hardy host when grown under proper cultural and climatic conditions. 
Where this is not the case it soon becomes subject to a few, but serious, diseases.

\section{LEOPARD Spot}

\section{Cause, Unknown.}

The disease, as the name indicates, consists of large irregular ashen colored spots, each surrounded by a dark border. No treatment which keeps the disease in check is known.

\section{RUST}

\section{Caused by Puccinia asparagi D. C.}

Asparagus rust does not seem to be limited in its geographic distribution, as it has been found in all States where the crop is grown. It is especially serious in California, New Jersey, and all the other important asparagus regions.

Symptoms. Rust does not attack the asparagus tips which are cut for the market. It attacks the green tops which develop after cutting has ceased. Affected tops redden, and these when carefully examined will reveal reddish rusty pimples or sori on the stems (fig. $52 \mathrm{a}$ ) and needles. In severe infection, the reddened tops become bright yellow, the needles fall off prematurely, exposing a bare dead stalk covered with numerous rust sori. The symptom is generally found in September and the pimples are 
5

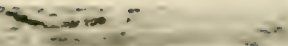

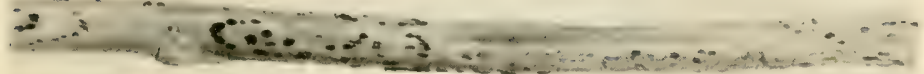

a

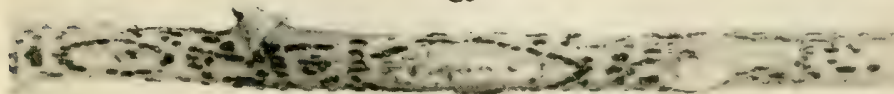

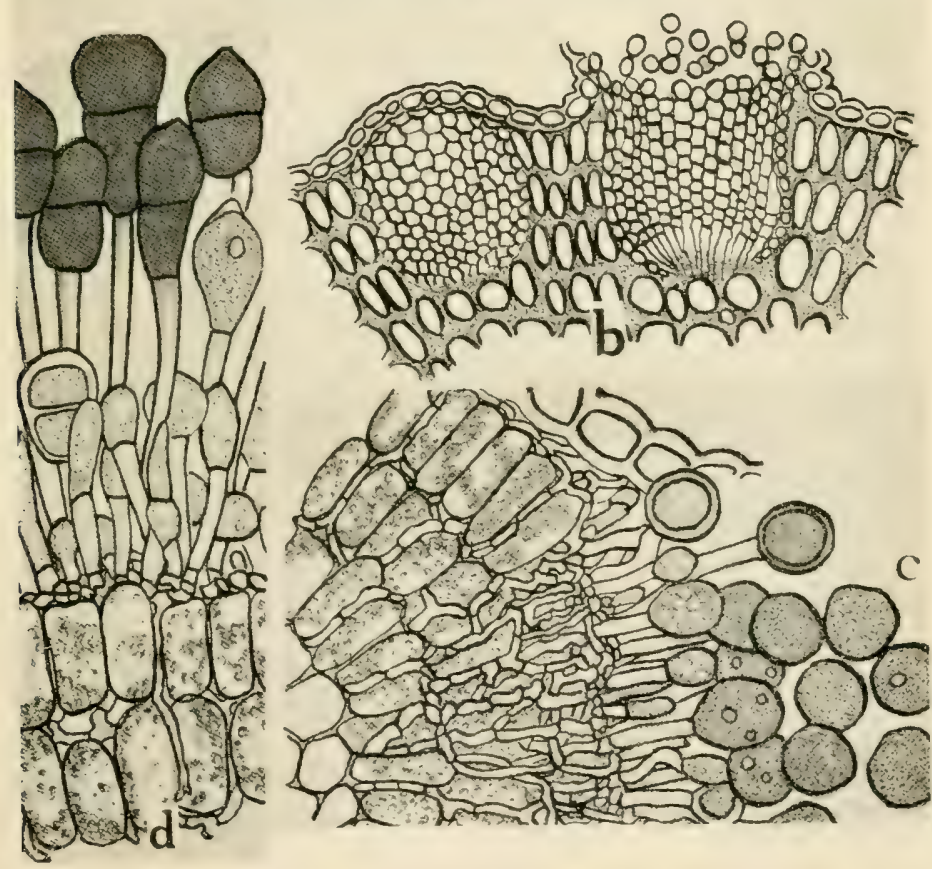

Fig. 52. Asparagus Diseases.

$a$. Asparagus rust on stems, showing sori with winter spores, $b$. cluster cup stage of $P$ uccinic asparagi, $c$. Uredo or summer spores of $P$. asparagi, $d$. Teleuto or winter spores of $P$. asparagi ( $b$. to $d$. after R. E. Smith). 

made up of the teleuto or winter spores of the fungus. In old asparagus fields, rust may appear early in the season. In this case instead of rusty brown sori there appear on the main stems and branches, but not on the needles, numerous bright cup-shaped bodies, containing the xcidial or spring spores. This form occurs about May but disappears in June or July. This stage is immediately followed by red pustules which contain the uredo or summer spores. Later in August and Septembcr, and as already stated the teleutospores appear. The latter help to carry the fungus over winter and unfavorable conditions. The effect of asparagus rust is an indirect weakening of the crowns of the plant. Affected tips fail to store up the necessary starches and sugars for the underground crowns. The latter being under-fed become weak, soft, and subject to the attacks of various, soil-inhabiting parasites.

The Organism. The life history of Puccinia asparagi has been carefully worked out by Smith $^{\mathbf{Y}}$ and others. The mycelium of the fungus is long and narrow, extensively branched, deriving its food by means of suckers or haustoria which penetrate the cells of the host. The æcidiospores are formed in chains, coming up from the mass of mycelium at the base of the cup (fig. 52 b). The uredospores (fig. 52 c) are dark in color and are borne singly in the uredo pustules. Both the æcidio- and uredospores are one celled, and both germinate by means of a germ tube which penetrates the host. The black rust or

${ }^{x}$ Smith, R. E., California Agr. Expt. Sta. Bul. 165 : 5-99, 1905. 
teleutospores (fig. 52 d) are two celled, thick walled, dark colored, and borne singly on long stalks. The teleutospores must first winter over before they can germinate. In germination each cell sends out a thick short germ tube which divides at the tip into four parts, each of which produces a side branch which bears secondary spores known as sporidia. The latter break away, and when falling on a fresh green asparagus top germinate by sending out a germ tube which penetrates the host. After proper incubation, the cluster cup stage appears, and the same life cycle is repeated over again.

Control. Asparagus rust may be kept in check by taking advantage of certain cultural conditions. Rust is more abundant in seasons with insufficient rainfall or on lands which dry out rapidly, while soils which have an abundance of moisture harbor little or no rust. In moist soils, asparagus plants are more vigorous than those grown under dry conditions and vigorous plants are less subject to rust than weak ones. Irrigation, therefore, wherever possible will help to keep the rust in check. Rust infection can never take place unless there is plenty of dew to enable the spores of the fungus to germinate. In low lying places, dew formation is heavier and hangs on longer than in more elevated regions. As far as possible, asparagus should be grown on high, well exposed moist lands. In regions subject to rains and heavy dews, spraying is recommended. Sirrine ${ }^{\mathrm{I}}$ has

- Sirrine, F. A.. N. Y. (Geneva) Agr. Expt. Sta. Bul. 188 : I22166, 1900. 


\section{Family Liliaceæ}

obtained good results by spraying with 5-5-40 Bordeaux to which was added 2 gallons of a resin mixture (made up of $5 \mathrm{lbs}$. resin, I lb. potash, or lye, I pint fish oil, and 5 gals. water) to each ro gallons of Bordeaux. Another good treatment is dusting the asparagus tops with flowers of sulphur. To be effective, this must be applied in the form of a fine smoke-like dust. If the tops are too dry they may be wetted with whale oil soap water, or the grower must wait for a heavy dew or rain. There are many "dust sprayers" on the market, many of which have their good qualities. There are two main types of dust sprayers, the "seed sower" and the "fan blower." The former throws a tremendous dust cloud. The fan blower sends out small clouds and covers less area. The number of applications will depend on the amount of dew in the season. In general, three applications using one half a sack of flowers of sulphur per acre during the season will suffice. The practice of applying ordinary salt $(\mathrm{NaCl})$ to the soil will not injure the asparagus crop but it will fail to control rust.

Resistant Varieties. It is a well-known fact that some varieties of asparagus are more resistant to rust than others. The Canovers Colossal which is the canning type is a variety which is badly subject to rust. The same is also true for the Columbian White and the Moore's Cross-Bred variety. On the other hand the Palmetto Type and the French or Argenteuil Barrs mammoth are fairiy resistant.

Natural Enemies. Puccinia asparagi, although 


\section{$284 \quad$ Diseases of Truck Crops}

itself a parasite, is in turn parasitized by three other fungi.

I. Darluca filum Cast. This fungus develops on the rust pustules, living directly on the mycelium and spores of its host.

2. Tubercularia persicina Dilt. This fungus is not as common as the first one.

3. Cladosporium sp. This is a common fungus which is often abundantly found on rust pustules. All or any of these three natural enemies may be readily grown in pure culture and spread about broadcast wherever the rust is abundant and of economic importance.

Damping OfF, see Rhizoctonia, p. 45.

\section{DISEASES OF THE CHIVE (Allium schoenopo- rasum)}

\section{RUST}

Caused by Puccinia porri (Sow.) Wint.

This rust, though prevalent in Europe, has been reported but once in the United States by Clinton ${ }^{x}$ as attacking also onions. It is characterized by a yellowing of the leaves which die prematurely. On carefully examining the infected leaves we find the uredo pustules, which are minute, reddish, and covered with a reddish powder. The teleuto pustules are black and 726.

Clinton, G. P., Connecticut Agr. Expt. Sta. Rpts. 1909-1910 : 


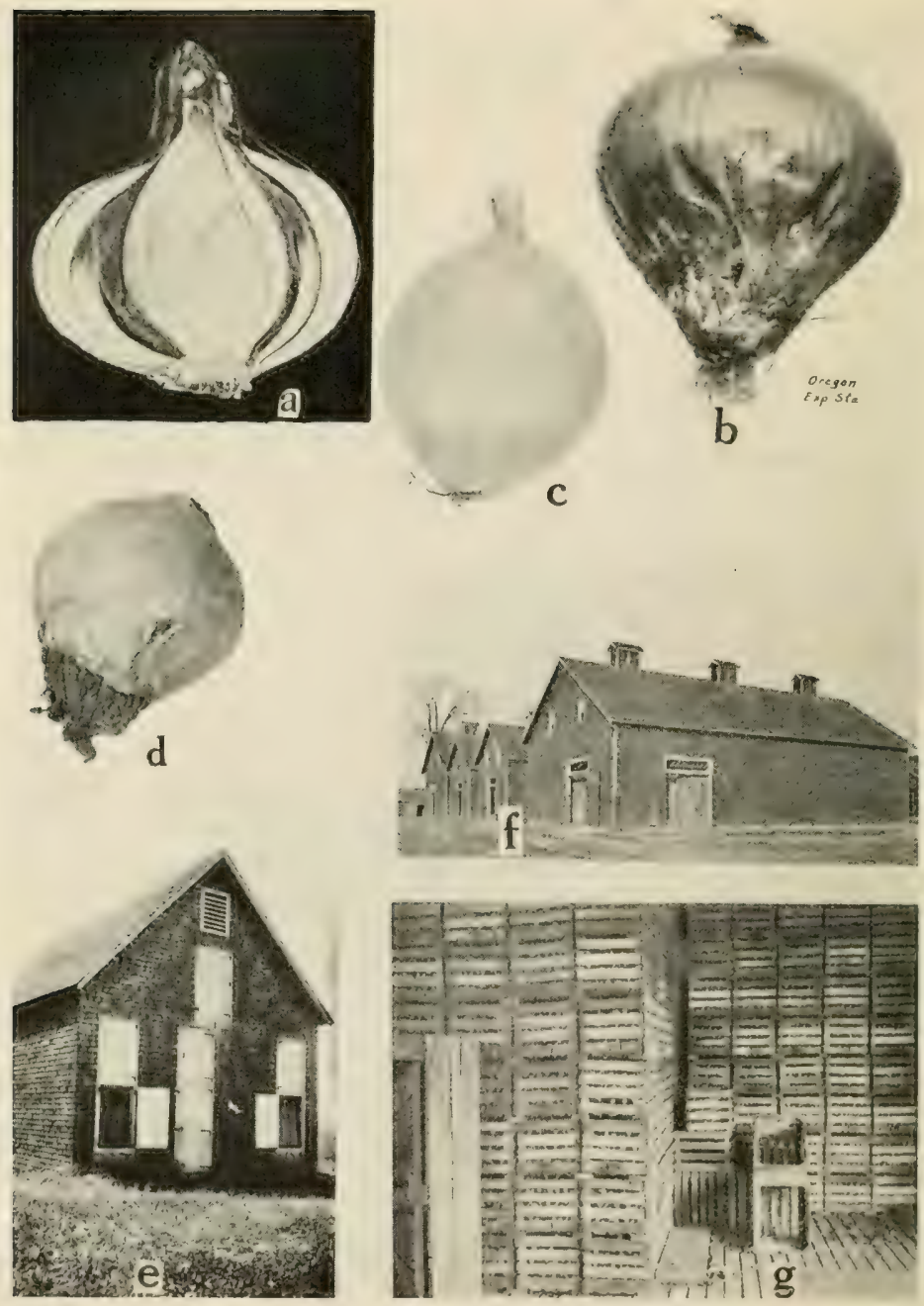

Fig. 53. ONION DisEases.

a. Bacterial rot (after Stewart), b. Botrytis rot, $c$. healthy, $d$. Sclerotium rot, e. onion storage house, $f$. type of commercial storage houses, $g$. interior of storage house, showing method of stacking crates $(f$. and $g$. after W. R. Beattie). 


\section{Family Liliaceæ}

covered by the host epidermis. Chive rust is distinct from the onion rust.

\section{DISEASES OF THE ONION (Allium cepa)}

The onion is commonly attacked by numerous diseases. Fortunately most of them may be controlled, by proper care, and timely preventive methods.

\section{SoFt Rot}

\section{Caused by Bacillus caratovorus Jones.}

The disease was first studied by Stewart, ${ }^{\mathbf{x}}$ who however did not determine the causative organism, but merely referred it to a species of Bacillus. The writer, however, was able to prove that soft rot of onions is caused by the same organism which causes a similar rot on carrots and other vegetables.

The rot on the onion often starts at the neck of the bulb which is spoken of as "weak in the neck." Sound bulbs are hard at the neck, but when rot sets in, the outer layer remains sound while the interior tissue soft rots (fig. 53 a). Sometimes a single scale is found rotted within the bulb, and the others apparently remain healthy. At other times a sound scale may be found between two rotted ones. Occasionally the rot is confined to the outer fleshy scale, in which case it is spoken of as "slippery onion." In storage,

'Stewart, F. C., New York (Geneva) Agr. Expt. Sta. Bul. 164: 209-212, 1899. 
under proper conditions of ventilation and temperature, the rot progresses very slowly. However, in poorly constructed houses the bulbs rot very fast and the disease then spreads by contact.

Damping Off, see Pythium, p. 43.

\section{Blight, Downy Mildew}

Caused by Peronospora schleideni, Ung.

Of all the onion diseases, blight (also known as downy mildew) is perhaps the most important from an economic standpoint. It may often wipe out from seventy per cent. of the stand to the entire crop. The disease usually accompanies muggy, damp, or rainy weather.

Symptoms. The disease is best diagnosed early in the morning when the dew is still present on the foliage. Diseased parts have a peculiar violet tint. This is due to the downy cover of the fruit by the fungus. Soon the affected leaves lose their green color, becoming yellow in spots, and by the second or third day they have all collapsed, and are entirely covered by the downy fruiting stalks of the causative fungus (fig. 54 a). If the weather is unfavorable the disease will be seen to work in restricted spots in the field with the tops of the affected plants collapsed. However, after several days the diseased onions begin to recover by sending out new top growths. The previously diseased leaves now dry and break away. 

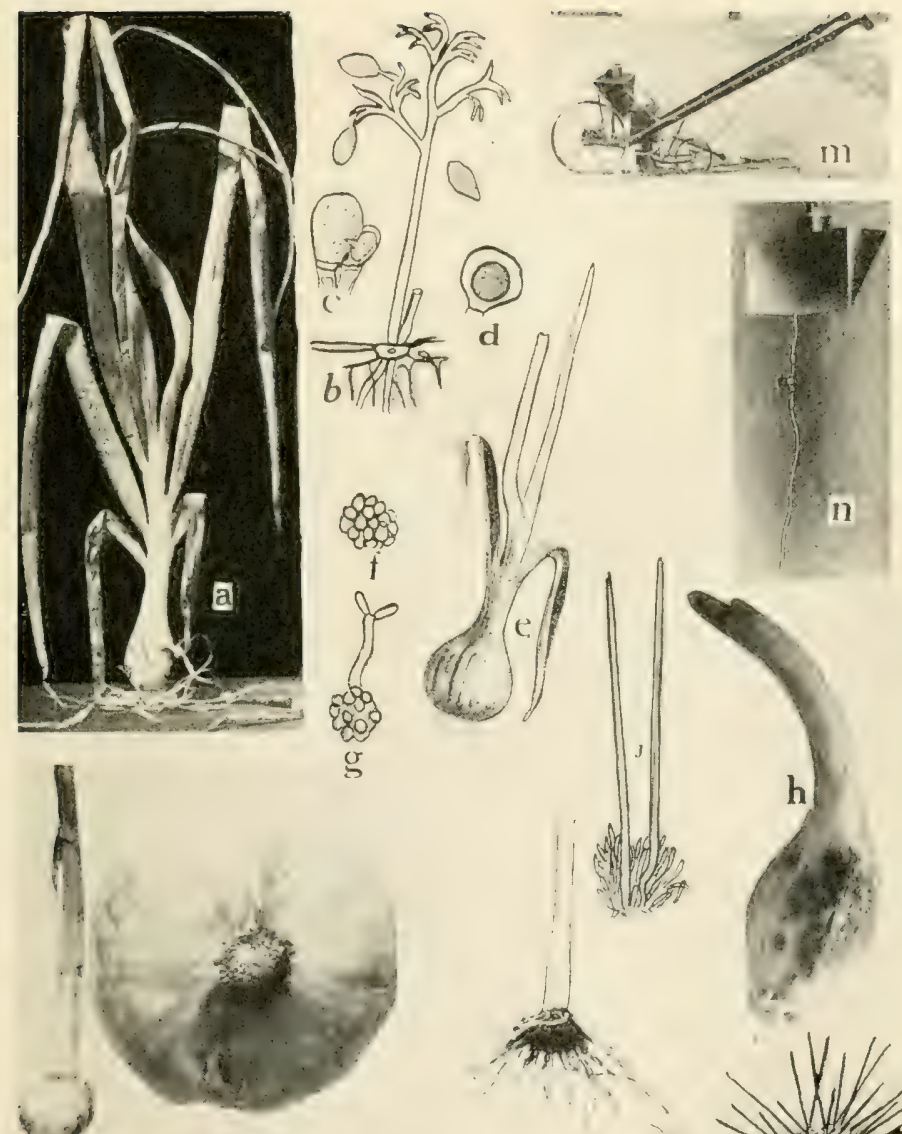

k
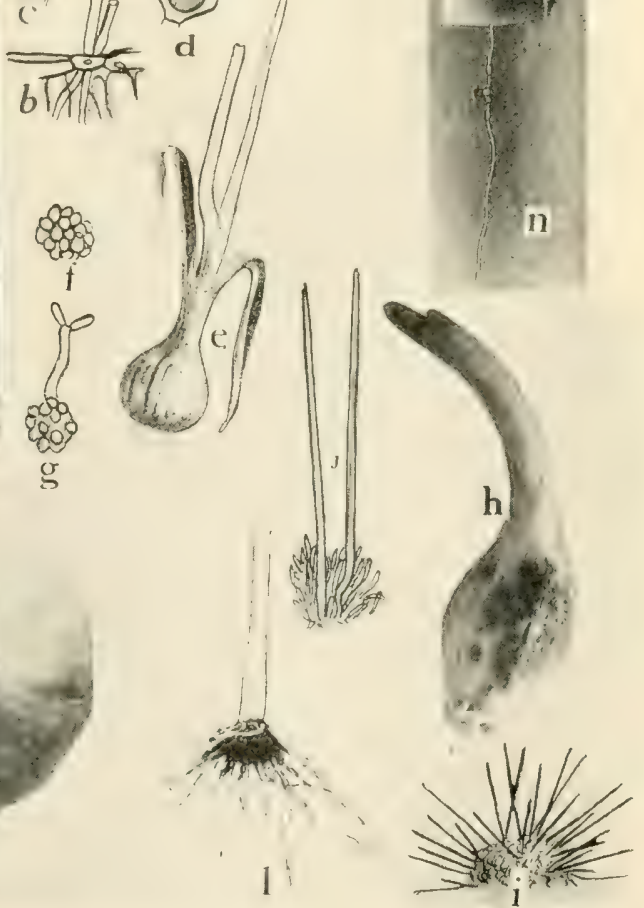

Fig. 54. Onion Diseases.

$a$. Downy mildew, $b$. mature conidiophore and conidia of Peronospora schleideni, c. fertilization of the female oogonium by the male antheridium, $d$. oospore $(a$. to $d$. after Whatzel), $e$. onion smut, $f$. spore ball of the smut fungus, $g$. spore germination, formation of sporidia at $x, h$. Vermicularia anthracnose, $i$. section through acervulis of Vermicularia circinans, $j$. setæ and spore formation in $V$. circinans $(e$. to $g ., i$. and $j$. after Thaxter), $k$. pink root of onion, healthy and diseased bulbs, $l$. pink root of onion showing nipple formation, $m$. a formaldehyde drip attachment to a planet junior seed sower, $n$. a copper tank drip with flexible black tin tube and valve $(m$, and $n$, after Stone). 

The blight in this case does not entirely disappear. With the coming of wet muggy weather the epidemic may begin a new course.

The seriousness of blight is usually overlooked by growers, because it usually works best when the onions have attained considerable bottoms. The latter are not disfigured or attacked in any way. But there is an indirect loss from the disease, because the food which is stored in the leaves is eventually dostined for the bulbs. When the foliage is destroyed there is bound to be a reduction in yield of marketable onions.

The Organism. The conidiophores or fruiting stalks come out on the surface through the leaf stomata (fig. 54 a). The conidia are borne at the tip end of branches of the main fruiting stalk. They germinate by means of a germ tube. The oospores or sexual spores (fig. 54 c, d) are formed in the same way as in Pythium. The contents of the antheridium is emptied into the oogonium, and fertilization takes place. The oospore is thick walled, granular and oily within. The mycelium of the fungus is non-septate, hyaline, and derives its food by means of suckers or haustoria which it sends to the host cells.

Control. Good results have been obtained by Whetzel ${ }^{\mathrm{x}}$ from spraying with Bordeaux. The formula recommended is $5-5-50$. The number of applications will vary with the climatic conditions and with the severity of the disease. It is doubtful if

'Whetzel, H. H., New York (Cornell) Agr. Expt. Sta. Bul. 2 r 8 : I39-161, 1904. 
one application will suffice; two to four applications may sometimes be necessary, especially in low, wet, and poorly drained lands where the disease is severest.

\section{SMUT}

\section{Caused by Urocystis cepulœe Frost.}

Next to blight, smut is the most important disease of the onion. The trouble is found wherever onions are grown, and it does not seem to be limited by climatic or soil conditions.

Symptoms. Smut is at first characterized by dark spots on the seedling leaves (fig. 54 e). When held up to the light these spots are opaque. Later longitudinal cracks appear on one side of the spot, which widen, exposing within a fibrous mass covered with a black powder made up of the ripe spores of the fungus. Young infected seedlings usually die early. Those which survive later show smut pustules on the leaves and the outer scales of the bulbs. The disease may be carried from infected fields with the seed, with infected manure, and by man himself on infected soil particles adhering to his shoes or implements.

The Organism. The spores of the fungus are able to retain their vitality for a long time, possibly twelve years. The spore ball (fig. $54 \mathrm{f}$ ) is made up of sterile cells and spores. The latter (fig. 54 g) germinate in the same way as spores of other smuts, see corn smut, p. 252. 


\section{Family Liliaceæ}

Control. A very effective treatment is to sow the seed in a seed bed and later transplant the sets. This method not only insures a crop free from smut, but the quality and the yield are benefited. Another method which generally gives good results is to apply to the soil at sowing time from 500 to 700 gallons per acre of a solution made up of one pint of formaldehyde in thirty gallons of water. This is applied with a drip attachment of the seed drill. For this method to be effective the soil must be in good condition of tilth.

\section{RusT}

\section{Caused by Puccinia allii D. C.}

Rust is a rare disease with onions in the United States, and very little is known about it. It is doubtful if it will ever cause damage serious enough to warrant treatment.

\section{ANTHRACNOSE}

Caused by Vermicularia circinans Berk.

This disease seems to be confined to the bulbs only. It is characterized by black spots (fig. $54 \mathrm{~h}$ ) which are made up of various rings one within the other. Each ring consists of minute black dots, which are the acervuli of the fungus and which possess numerous black hairs or bristles (fig. $54 \mathrm{i}, \mathrm{j}$ ). 
It causes the greatest damage under poor storage conditions. For methods of control, see p. 292.

Botrytis Rot (fig. 52 b) is a storage trouble usually of little importance.

\section{Black Mold}

Caused by Macrosporinm parasiticum Thuem.; Macrosporium porri E11.

Black mold frequently follows injury from downy mildews or any other causes which weaken the plant. Spraying to control downy mildew will also prevent this disease.

\section{Bulb Rot}

\section{Caused by Fusarium sp.}

This disease is usually a storage trouble; but the injury starts in the field and is favored by a wet summer season. The rot is prevalent in Ohio and Connecticut and possibly also elsewhere where onions are stored in bulk. It works inward, attacking the heart of the bulb so that the interior easily slips out. For methods of control, see p. 292.

\section{Sclerotium Rot or Black Neck}

\section{Caused by Sclerotium cepivorum Berk.}

Sclerotium rot is a serious storage trouble of white onions in Ohio. The disease seems to be favored by 


\section{Family Liliaceæ}

improper storage conditions, and by early topping in the field where a green neck offers a favorable entrance of the rot. The latter is of a dry nature, and the affected bulbs become blackened and wrinkled at the neck (fig. 52 d). Selby ${ }^{\mathrm{I}}$ recommends treating the bulbs with formaldehyde gas as recommended for the white potato, p. 336 .

\section{PINk Root}

\section{Cause Unknown fungus. ${ }^{2}$}

Pink root is a serious disease which is threatening the onion industry in the Laredo districts of Texas. The disease apparently is not new, but it has not been investigated before. The work of the writer is as yet incomplete, hence no complete statement can be made at this time relative to the disease.

The roots of affected sets first turn slightly yellowish, when they are known as "Yellow root," and then pink. Affected roots dry up, and the bulbs constantly make an attempt to produce new rootlets, which even under favorable conditions become pink and die. At the end of the season and because of the attempt of the bulb to produce new roots, a nipple is usually formed at the bottom of the center plate of the bulb (fig. 541 and k). The disease is carried with the young sets from the seed beds to the field. It

${ }^{3}$ Selby, A. D., Ohio Agr. Expt. Sta. Bul. 214 : 414, 1910.

2 Investigations by the author seem to show that pink root is caused by a pathogenic fungus. 
may also be introduced with infected soils clinging to the rootlets of the sets.

Control. It is severest in fields where onions have been grown too long in the same field. Crop rotation will not control nor reduce the losses from pink root in the field. The use of new land, especially for the seed bed, is strongly urged.

Pink root attacks the onion, chive, shallot, garlic, and leek.

\section{ONION Storage}

Since the greatest profits are derived when onions are sold at a time of greatest demand, it is necessary to store the crop. In the field, onions intended for winter storage should be allowed to ripen well. The degree of ripeness is indicated by a shriveling of the tops, and when the outer skin of the bulbs becomes dry before being pulled. The ripening process in the field may often be hastened by rolling a light roller on the tops to break them. After being pulled, the onions are allowed to lay in the rows for several days. They are occasionally stirred with wooden rakes to encourage an even drying of the bulbs. After the necks are clipped, the bulbs are put in crates and are either allowed to dry further in the field or they are carried to curing sheds where the crates remain for about two weeks until finally placed in storage. This method is preferred by most growers, as it is not desirable to expose the red and yellow varieties to the full sunlight in the field. The immature, 


\section{Family Liliaceæ}

soft, or "thick necks" should be disposed of early, as they keep very poorly in storage. Good storage onions will rattle like wood blocks when poured out from the crate.

After curing in the sheds, the bulbs are sorted over on the sorting racks where only the soundest are stored away. In some localities, onions are stored in pits. This may serve the purpose where only small quantities are grown. On a large scale storage plants (fig. $52 \mathrm{e}-\mathrm{g}$ ) are in operation.

Storage Conditions. The essentials necessary in storing onions are summarized by Beattie $^{\mathrm{I}}$ as follows: "Plenty of ventilation, storing in small quantities, a comparatively low temperature, dryness, and safety from actual freezing." The construction of a storage house is not different from that of a sweet potato house, see p. I82. The house should be double walled throughout, with plenty of felt or paper lining. In this way a dead air space in all the walls will permit of more even indoor temperatures. Top ventilation is provided by means of roof ventilators. Bottom ventilation is secured by means of bottom windows or drain pipes built into the foundation at the surface of the ground. A false floor is also constructed inside, leaving an air space of about two to three inches from the main floor.

The temperature of the storage house should be as low as possible, but kept above the freezing point, i. e. above 32 to 36 degrees F. During severe cold s Beattie, W. R., U. S. Dept. of Agr. Farm. Bul. 354: 5-36, 1909. 


\section{4}

\section{Diseases of Truck Crops}

weather all openings should be closed. Occasionally heat may be necessary and this can be applied by stoves. Onions are often stored in bags or in slat bins holding 100 to 300 bushels each. However, neither bags nor bins are satisfactory. The best method is storing in crates.

Of the Liliaceæ weeds, the only one of importince is the wild garlic, Allium vineale. It, however, is not known to harbor any of the diseases which attack onions and its other closely related species. 


\section{CHAPTER XIX}

\section{FAMILY MALVACE $\mathbb{E}$}

THIs important family has but one plant which is of interest to the trucker, i.e. the okra. This crop is grown more in the Southern States. It is to be regretted that more of the people of the United States have not as yet learned its great food value. According to the Thirteenth Census of the United States the area devoted to okra in 1909 was estimated at 347 acres and the value of the crops at $\$ 24,969$. Of the few States which grow this crop may be mentioned Georgia, Texas, Louisiana, Florida, and North Carolina.

\section{DISEASES OF THE OKRA (Hibiscus esculentus)}

Generally speaking, the okra may be considered a hardy plant. But it is subject to a few diseases which in severe cases may threaten the profitable raising of the crop.

\section{LEAF Spot}

Caused by Cercospora hibisci $\mathrm{T}$. and Earle.

The disease seems to be as yet restricted to Porto Rico. It is of no economic importance in the United 
States. According to Stevenson ${ }^{I}$ the trouble appears as indefinite sooty patches (fig. 54 c) on the lower surface of the leaves. This saps the vitality of the foliage, causing it to trim yellow and to drop off prematurely. Great care should be exercised not to allow the above disease to gain a foothold in the United States.

\section{WILT}

Caused by Fusarium malvacearum Taub. ${ }^{2}$

Wilt is perhaps the main drawback to okra culture. The disease is found in light sandy soils, and sometimes seems to work hand in hand with root knot.

Symptoms. The disease does not seem to attack young seedlings. It is common on older plants, which however remain stunted as the disease works slowly. In severe attacks, however, the lower leaves wilt, droop, dry, and fall off. This is followed by a drooping, wilting, and falling off of the upper foliage, leaving thus a bare stalk, which eventually dries up. On pulling up a diseased plant, we find that the root system is apparently sound. But on splitting a diseased root and stem lengthwise the interior fibrovascular bundles are found to be brown, indicating that the seat of the trouble is there localized.

The Organism. Unpublished work by the author has definitely established that okra wilt is caused by

I Stevenson, J. A., Jour. Dept. Agr. of Porto Rico, I : 93-II7, 1917.

${ }^{2}$ From unpublished work by the writer. 

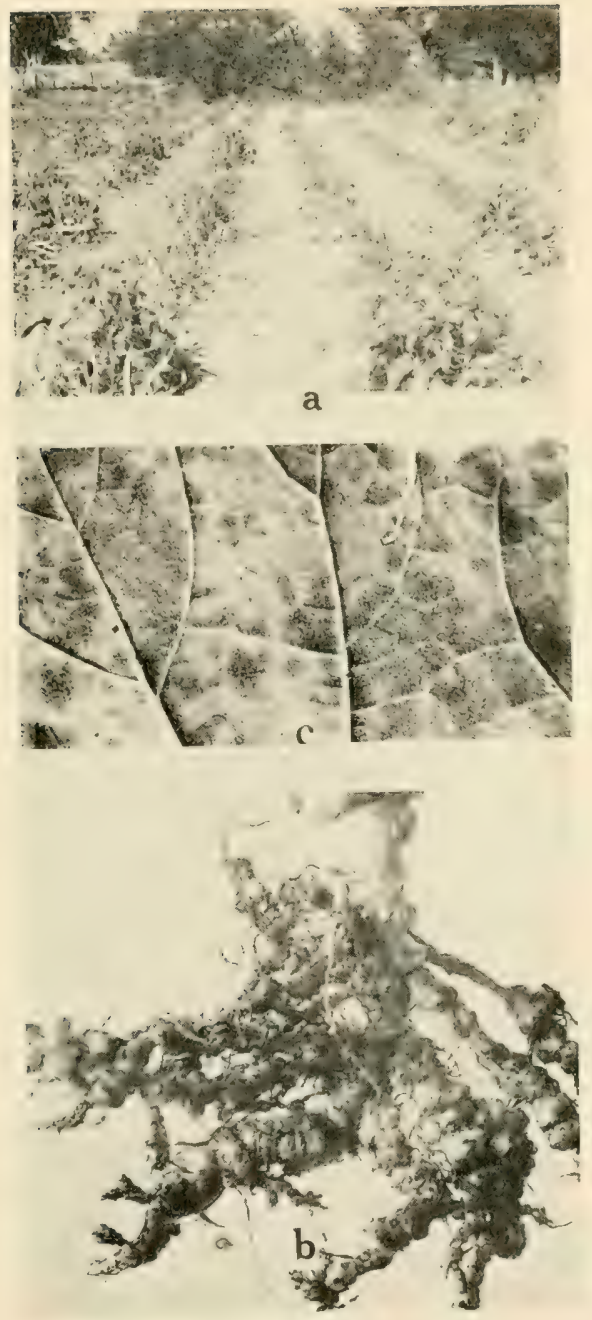

Fig. 55. Diseases of THE OKRA.

a. Okra field badly affected with the Texas Root rot, to the front two resistant hills, $b$, root knot, c. Cercospora leaf spot. 



\section{Family Malvaceæ}

a new species of Fusarium, technically named $F$. malvacearum. The okra wilt is distinct and different from the wilt of cowpea, cotton, or watermelon, all of which are caused by distinct species of Fusaria. A full description of the organism will soon appear elsewhere.

Control. The only remedy known for this disease is crop rotation. Since okra wilt attacks only the okra, any other truck crop may be used in the rotation system. It is also probable that wilt may be controlled by the development of resistant varieties.

Root Rot, see Rhizoctonia, p. 45 .

\section{Texas Root Rot}

\section{Caused by Ozonium omnivorum Shear.}

Texas root rot is a disease which is perhaps of equal importance with wilt. The disease is not found on sandy soils, but on okra grown on the typical waxy heavy lands such as are found in Texas. It appears after a rain or after irrigation.

Symptoms. The trouble does not appear until the plants have begun to bloom. At this stage infected plants suddenly wilt and the foliage drops off (fig. 54 a). On pulling out a diseased plant, we find that the trouble is localized at the crown and root of the plant. The infected surface is darkened, shrunken, but softened, so that the epidermis may be easily peeled off from the roots and crown of the plant. Occasionally, the diseased parts are covered with 
minute warts consisting of whitish to yellowish fungus threads. Very often in pulling out a plant which is partly infected, the young healthy rootlets or even those which are partly destroyed are found to be colored pinkish buff.

The Organism. The organism which causes Texas root rot is, as far as we know, sterile. By this is meant that the fungus reproduces by division and further growth of its mycelium, but produces no fruit (fig. $28 \mathrm{q}$ and r). Duggar ${ }^{\mathbf{I}}$ claims that the pink buff color mentioned above represents the colored spore masses of the fungus which he named Phymatotrichum omnivorum (Shear) Dug. However no inoculation experiments have been carried out to prove that this fruiting stage is in any way connected with Ozonium. In establishing the relationship of various stages of apparently the same parasitic fungus, inoculation experiments alone should be the crucial test.

Control. No definite methods of control are as yet known. Deep plowing undoubtedly retards the work of the disease, but it does not prevent it by any means. Crop rotation should be resorted to. In the system of rotation may be included sweet corn, cabbage, radish, spinach, kale, mustard, lettuce, and cauliflower. Crops to be omitted from the rotation are beans, beets, cowpeas, sweet potatoes, eggplants, tomatoes, and peppers. The latter two are only partly susceptible to Texas root rot.

Root Knot (fig. 54 b), see Nematode, p. 49.

${ }^{2}$ Duggar, B. M., Ann. Missouri Bot. Gard., 3: I I-23, I9 6. 


\section{CHAPTER XX}

\section{FAMILY PORTULACACEEE}

IN this family the only plant which may interest the trucker is the purslane. The latter is grown as a pot herb; but it is little known in the United States. It is comparatively free from diseases, only two of which need be mentioned.

\section{WHITE RUST}

\section{Caused by Cystopus portulacece (D. C.) Kze.}

In appearance, this rust is not different from the white rust of the radish. However the causative fungus is not the same. White rust is not prevalent in the United States and is of no economic importance.

Root Rot, see Rhizoctonia, p. 45.

Weeds. There are no weeds of importance in the Portulacaceæ family which carry diseases detrimental to truck crops. 


\section{CHAPTER XXI}

\section{FAMILY SOLANACEE}

IN this great family the trucker possesses crops which are of great economic importance. Some of them are the eggplant, pepper, potato, and tomato. According to the Thirteenth Census of the United States, the total area devoted to eggplants in 1909 was 895 acres, and the crop value was estimated at $\$ 154,643$. The two States which supply nearly all the markets with eggplant are Florida and New Jersey. The total area in 1909 devoted to peppers was estimated at 3,483 acres and the crop valued at $\$ 408,74 \mathrm{I}$. Of the leading States producing this crop are New Jersey, California, Florida, New Mexico, Illinois, Texas, and Louisiana. The area in white potatoes in 1909 was estimated at $3,668,855$ acres, and the crop valued at $\$ 166,423,910$. The leading potato States are New York and Michigan; the others following in their order are: Wisconsin, Pennsylvania, Minnesota, Ohio, Iowa, Illinois, Maine, Nebraska, Colorado, Indiana, Missouri, Virginia, New Jersey, Kansas, California, Washington, Kentucky, North Dakota, South Dakota, Oregon, West Virginia, Tennessee, Maryland, Texas, Oklahoma, 


\section{Family Solanaceæ}

Arkansas, Idaho, Vermont, Massachusetts, Connecticut, Montana, Louisiana, New Hampshire, Alabama, Utah, Georgia, Delaware, South Carolina, Florida, Mississippi, Wyoming, New Mexico, Nevada, Rhode Island, and Arizona. The area in 1909 devoted to tomatoes was estimated at 207,379 acres, and the crop valued at $\$ 13,707,929$. The leading producing States are as follows: Maryland, New Jersey, Indiana, Delaware, Florida, Virginia, Missouri, New York, Ohio, Texas, California, Tennessee, Pennsylvania, Illinois, Mississippi, Kentucky, Michigan, Iowa, West Virginia, Arkansas, Colorado, Utah, Kansas, and Massachusetts. States with less than one thousand acres are omitted.

\section{DISEASES OF THE EGGPLANT (Solanum} melongena)

Southern Wilt, see Tomato, p. 342.

Damping Off, see Pythium, p. 43.

\section{FruIt Rot}

Caused by Phomosis vexans (Sacc. and Syd.) Hart.

The disease is quite common in New Jersey, and it undoubtedly occurs in the more southern States. The trouble has been recognized as serious, but the cause has been only recently worked out by Harter. ${ }^{\text {I }}$

Symptoms. Fruit rot attacks all parts of the plant

s Harter, L. L., U. S. Dept. of Agr. Jour. Agr. Research, 2 : 33I$338,1914$. 
except the roots. On the seedlings it causes a damping off. Young plants are attacked at the stem end or an inch or two above the ground line as indicated by a constricted area at that place. On the leaves the trouble is manifested as large brown round spots which later become irregular and jagged (fig. 56 a). The older spots are light purple in the center and surrounded by a black margin. As they enlarge the spots also invade the veins, midribs, and petioles, forming depressions. Diseased fruits are at first soft and mushy, but later they become dry, shriveled, and mummified (fig. 56 b).

The Organism. Pycnidia (fig. $56 \mathrm{f}$ ) are usually found on all parts of the plant attacked. Within the body of the pycnidia and intermixed with the conidiophores (fig. $56 \mathrm{c}$ ) and pycnospores (fig. $56 \mathrm{e}$ ), are found filiform hooked-shaped bodies termed stylospores (fig. 56 d). Phomosis vexans has been erroniously referred to as Phoma solani Hals; Phoma vexans Sacc. and Syd., and Aschochyta hortorum Speg.

Control. The seedlings in the seed bed should be sprayed with Bordeaux at least once before transplanting. The plant in the field should be sprayed from four to eight times with either Bordeaux mixture or ammoniacal copper carbonate.

\section{ANTHRACNOSE}

Caused by Gleosporium melongence E. and $\mathrm{H}$.

Anthracnose on the eggplant attacks only the fruit. The trouble is characterized by numerous 


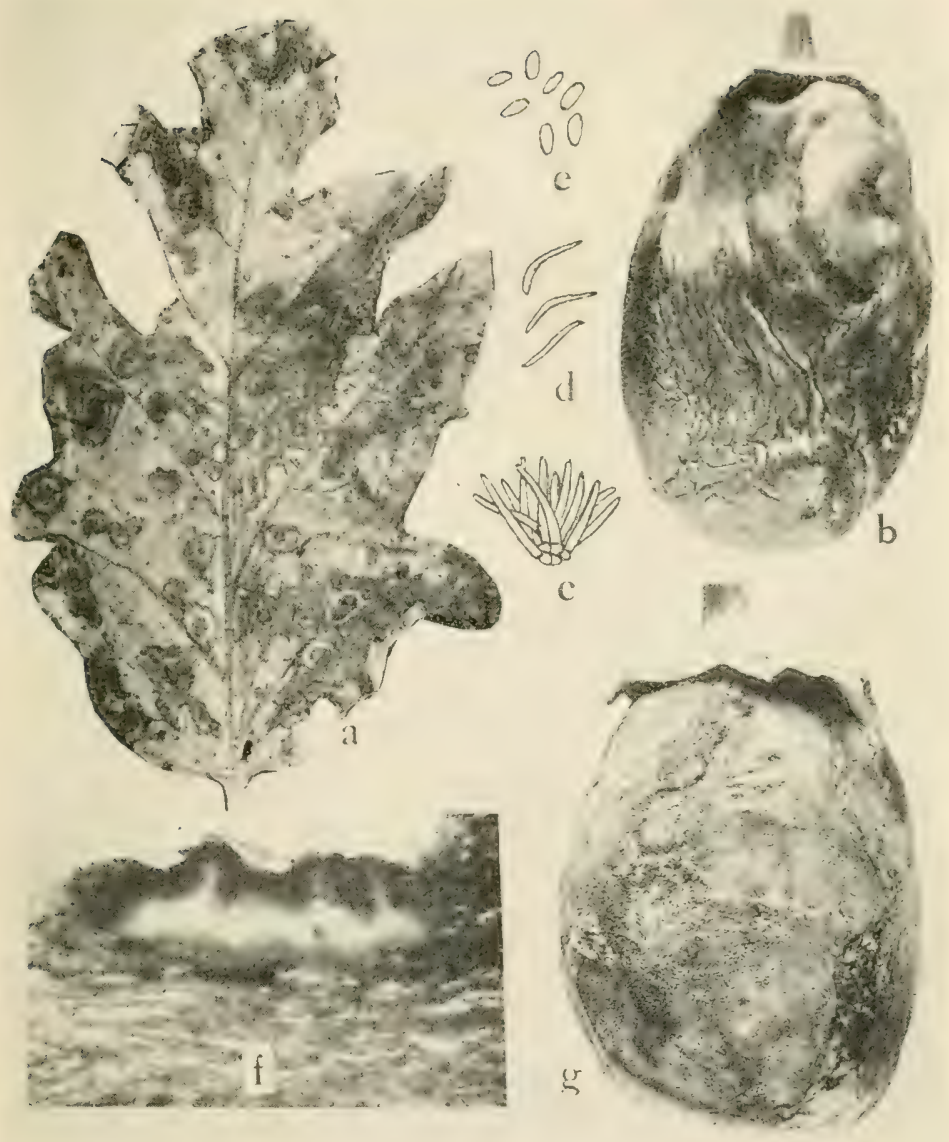

Fig. 56. EgG-Plant Diseases.

$a$. Phomopsis of leaf, $b$. Phomopsis on fruit, $c$, conidiophores, $d$. stylospores, $e$. pycnospores of Phomopsis vexans, $f$. photonicrograph of a cross section through an infected calyx of an egg plant showing pycnidia of $P$. vexans (c. to f. after Harter), R. anthracnose on egg-plant fruit. 



\section{Family Solanaceæ}

deep pits which later become covered with salmon colored acervuli (fig. $56 \mathrm{~g}$ ). The latter are made up of myriads of spores of the fungus. Spraying for fruit rot will also help to control anthracnose.

Stem Anthracnose, see Potato, p. 324.

SOUTHERN Blight, see PePper, p. 305.

Root Knot, see Nematode, p. 49.

\section{DISEASES OF THE PEPPER (Capsicum annum)}

The pepper plant is considered comparatively hardy, and its few diseases usually become troublesome only when the crop is grown too long on the same land.

\section{ANTHRACNOSE}

Caused by Glomerella piperata ( E. and E.) S.

Anthracnose is a serious disease which is usually confined to the fruit only. Its symptoms are characterized by round, soft, sunken, pale spots (fig. 57 a). The summer or conidial stage is known as Gleosporium piperatum $\mathrm{E}$. and $\mathrm{E}$. and is found as salmon colored pustules abundantly scattered over the spots (fig. $57 \mathrm{~b}-\mathrm{f}$ ). The ascospore stage may develop in pure cultures of the fungus.

\section{Black Anthracnose}

Caused by Colletotrichum nigrum $\mathrm{E}$. and $\mathrm{H}$.

This form of anthracnose differs from the disease described above only in that the spots turn jet black. 


\section{4 Diseases of Truck Crops}

The trouble attacks the young as well as the mature fruit. The winter or ascospore stage of the causative fungus has not as yet been found. It is very probable that the fungus is carried over as viable mycelium on the infected fruit left over in the field. Both forms of anthracnose may be controlled by spraying with Bordeaux mixture.

\section{Fruit SpoT}

\section{Caused by Macrosporium sp.}

This disease, which is as important as anthracnose, attacks the fruit at the blossom end. Attacked peppers are half rotted, black, and moldy. Little is known about the causative fungus. It is probable that the disease has the same origin as the blossom end rot of tomatoes, and that the Macrosporium fungus is only secondary. Spraying with Bordeaux is recommended.

\section{LEAF SPOT}

Caused by Cercospora capsisi $\mathrm{H}$. and W.

This disease is prevalent on peppers in Texas. The same trouble may be found also in the more southern States. It is characterized by roundish raised spots on the upper surface, at first brown, later becoming gray brown. They are limited by a dark zone, beyond which the leaf tissue is pale and chlorotic. Where the spots are abundant the leaves turn yellow, wilt, and fall off prematurely. 


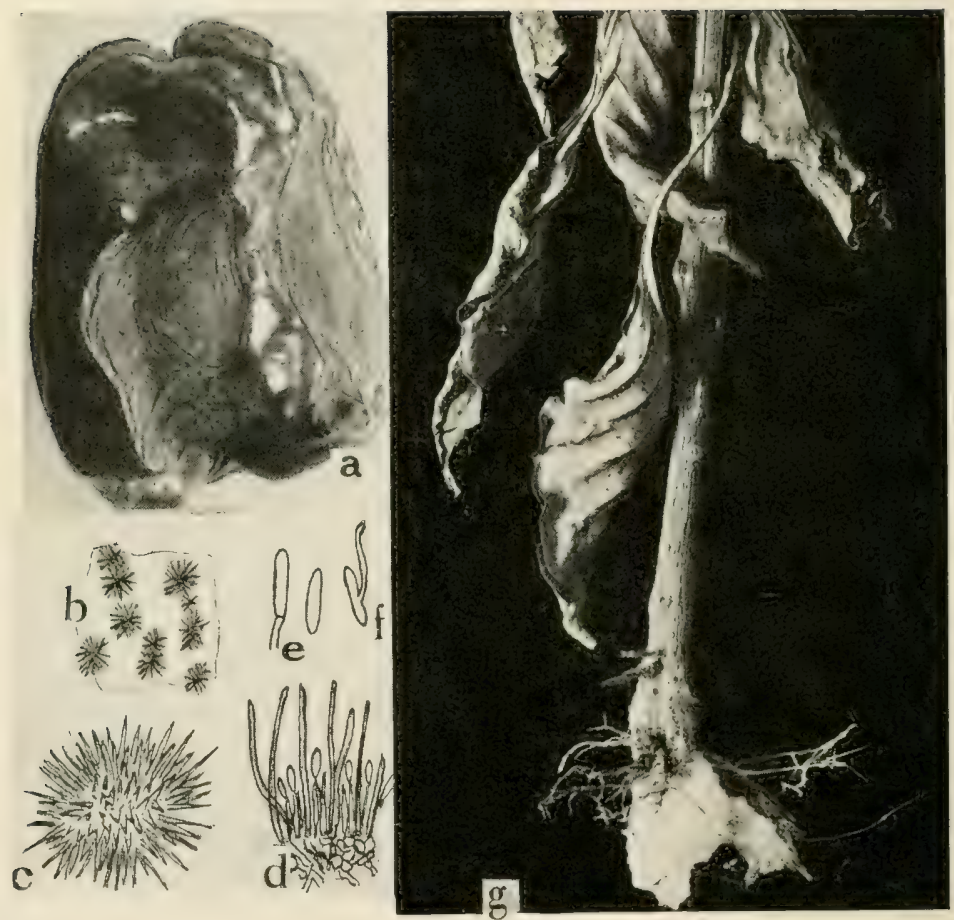

Fig. 57. Diseases of the PEPper.

a. Anthracnose on fruit, $b$, anthracnose spot showing acervuli, $c$, acervulus greatly magnified, $a$, section through acervulus of Glomerella piperata, showing setæe, conidiophores, and conidia, $e$. conidia, $f$. germinating conidium, $g$. Southern blight. 
The conidiophores of the fungus are formed in clusters on both surfaces of the spots. The conidia are dilutely brown, clavate, and several septate.

\section{SOUTHERN BLIGHT}

\section{Caused by Sclerotium Rolsfsï Sacc.}

Blight is a disease which is commonly met with in the Southern States. It often causes considerable losses, owing to the fact that a great percentage of the plants is killed at the bearing age.

Symptoms. Affected plants become apparent by the drooping of the young leaves at the tips of the branches. At night the plant recovers and it appears normal the next morning. This, however, is a temporary condition. Wilting generally progresses, and after three to four days the leaves yellow completely, wilt, droop, and die. In another day the stem of the plant loses its green color, dries, and dies. On pulling out a plant freshly wilted, we find a shrunken discolored area at the foot of the stem, slightly below ground level. In more advanced stages, the shrunken area is covered by a delicate web of white mycelial threads (fig. $57 \mathrm{~g}$ ), and after the death of the plant numerous brown mustardlike sclerotia are found on the surface of the affected tissue.

The seriousness of blight is that it attacks not only the pepper but also the tomato, eggplant, Irish potato, sweet potato, beets, beans, cowpeas, cabbage, squash, watermelon, rhubarb, and numerous other plants. 
Control. It may be controlled in a way similar to that recommended for lettuce drop, see p. I43.

\section{DISEASES OF THE POTATO (Solanum tuberosum)}

General Consideration. Potato diseases are caused for the most part by definite parasitic organisms. However, there are many indirect causes which may predispose the plant to various diseases.

Color. The shade of red or pink in the tuber is usually affected by the health of the plant and by its nutrition. Color is usually intensified in run out stock. The White Ohios, for instance, may show much red at the eyes and at the eye end under poor conditions, but are white under proper culture and climate. Deep eyed and poor shaped tubers are likely to be densely colored. The flesh of the Early Rose variety may become red under unfavorable conditions. Whiteness of flesh is also influenced by the degree of ripeness. The color therefore may often serve as a general indicator of the health of the tuber. Sharp and long eyed ends with numerous eyes usually indicate a weak and run out strain.

Position of the Eyes. On examining a tuber, we find a cluster of well developed eyes at the blossom end, generally termed the "seed end." The other is generally known as the "stem end" of the tuber and it contains but few if any of the eyes. Careful growers are in the habit of discarding the "stem ends." Plants resulting from the stem ends develop 


\section{Family Solanaceæe}

late and are poor yielders. On the other hand, plants resulting from the "seed ends" develop early, are much more prolific and vigorous, apparently more resistant to disease and less subject to running out. Market gardeners who aim at producing an early crop should depend on the "seed ends" for planting, and should discard the "stem ends," and even those pieces which come from the middle of the seed tuber.

It is common knowledge that potatoes soon run out when grown too long under Southern conditions. In the South, Northern grown seed must be depended upon, such seed being far superior to that grown in the South. The effect of one year's removal of the Northern seed to Southern conditions is noticeable in a decline in yield and vigor of the crop. Therefore except under favorable Northern latitudes, frequent changes of seed are necessary.

Germination Troubles. Conditions of poor germination are often met with. There may be several factors to account for this. When planting seed which is heavily infected with blackleg, wilt, or Rhizoctonia rot, a poor germination and stand should be expected. This is especially true in cool, damp springs.

Cutting the seed ten or fifteen days before planting, as is the custom with some growers, is a practice which may lead to much germination trouble. When this is done, the seed is held too long and is apt to undergo a heat. Frequently seed is cut too small and there are few or no eyes left to permit 
germination. Poor sprouting may sometimes be attributed to shipping of seed in overheated cars. In this case the seed when cut open will be seen to be blackened at the heart, a trouble soon to be considered.

\section{LEAF ROLL}

\section{Cause Unknown.}

Leaf roll is but an old disease with a new name. The trouble has been carefully studied by Orton. ${ }^{\mathrm{r}}$

Symptoms. As the name indicates, the characteristic symptom is a rolling of the leaves (fig. 58 a). The leaflets roll and curl upward on their midrib, often assuming a tube shape. This condition may involve the upper leaves of a plant or in serious cases the entire foliage. Rolled leaflets assume a sickly yellow reddish to purplish color. This is especially apparent on affected plants grown from tubers of a previously infected crop.

The effect of leaf roll is to interfere with proper growth. This generally results in a premature dying of the leaves. The effect of the disease on the tubers seems to be strongly marked. The tubers in the hill are small, unfit for market and the yield is often reduced by about one half. The disease is not contagious in the sense that it can spread from plant to plant; but the inherent weakness is transmitted to the seed. This when sown again will show new outbreaks of leaf roll the following year. True leaf roll s Orton, W. A., U. S. Dept. of Agr. Bul. 64 : 1-48, 1914. 


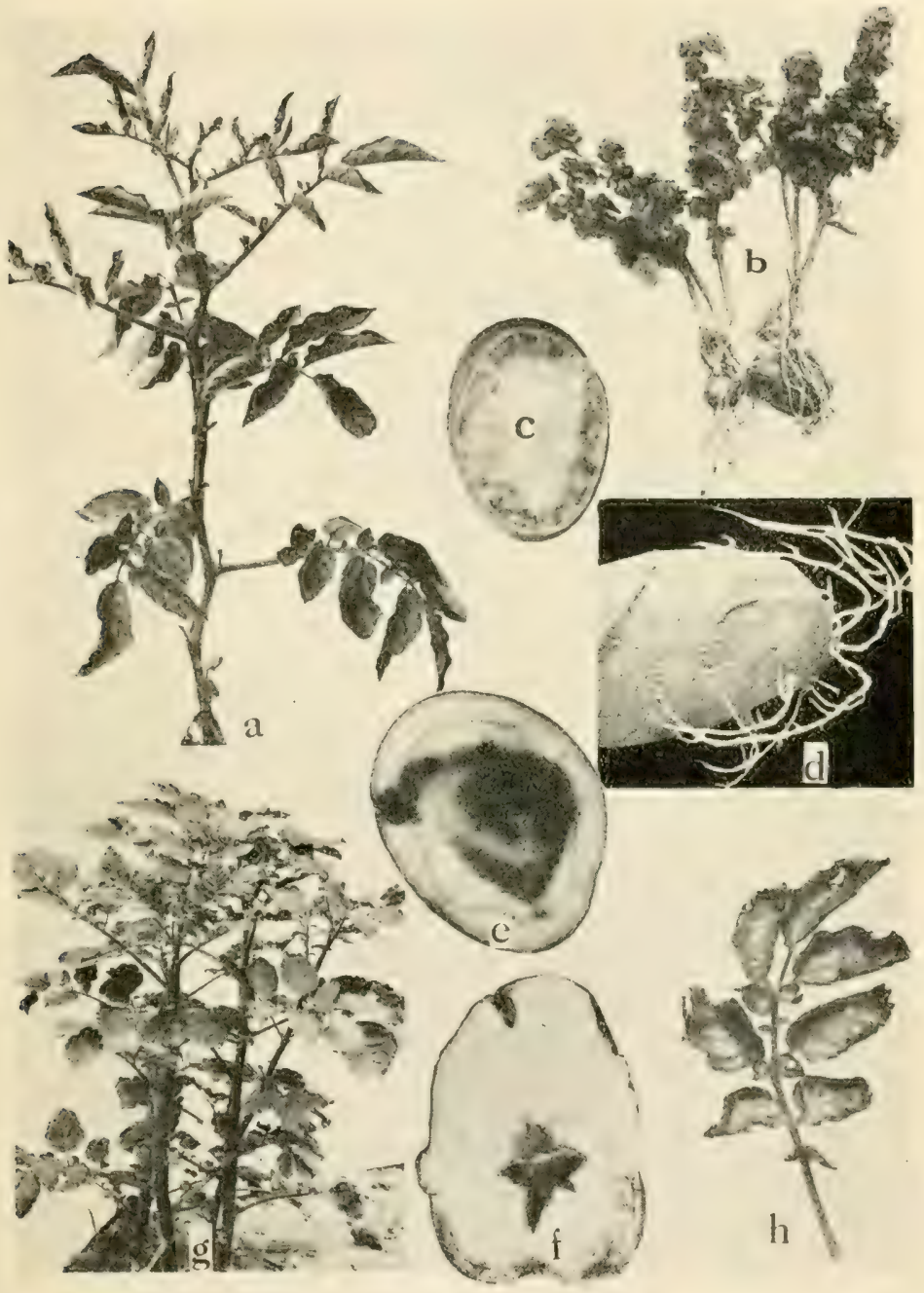

Fig. 58. Potato Diseases.

$a$. Leaf roll $b$, curly dwarf ( $a$. and $b$. after Appel), $c$. net necrosis, $d$. spindly sprout, e. black heart, $f$. hollow heart ( $d$, to $f$. after Stakman and Tolaas), $g$. mosaic, $h$. tip burn (c. g. and $h$. after W. A. Orton). 



\section{Family Solanaceæ}

should not be mistaken for a temporary rolling of the leaves that may be brought about by excessive humidity in poorly drained lands. Heat, drought, and excessive use of fertilizers, especially potash, may bring about a temporary leaf rolling. Leaf roll is prevalent in Germany, Austria-Hungary, Switzerland, the Netherlands, Denmark, and Sweden. In the United States it is found in Eastern Colorado, Western Nebraska, Virginia, and Maine. Since the trouble is carried with the seed, this should be secured from localities known to be free from the disease.

\section{CURLY-DwarF}

\section{Cause Unknown.}

This disease differs from leaf roll by a dwarfed development of the plant, and a wrinkled and downward curling of the leaves (fig. $5^{8} \mathrm{~b}$ ), resembling the natural curling of the foliage of kale or Savoy cabbage. A peculiarity of this disease is that the midribs, veins, and leaf petioles together with stems and branches are all dwarfed, giving the foliage a thickly clustered appearance. The foliage keeps its normal color and turgidity. There is also a tendency for the plant to send out numerous branches with brittle stems. The effect of the disease is to reduce the yield, and in severe cases there is an absence of tuber production altogether. Like leaf roll the disease is transmitted with the seed tubers, but it does not spread from plant to plant. The trouble is prevalent 
in potato fields, but not to such an extent as to be noticed. It is always found scattered in individual plants, indicating deterioration. Prevention of this trouble consists in careful selection of seed from unaffected hills.

\section{Spindling Sprout}

\section{Cause Unknoren.}

Spindling sprout is an abnormality common to Southern grown seed, which reduces the yield considerably. Instead of healthy sprouts, long, thin slender ones germinate (fig. $58 \mathrm{~d}$ ). No lesions of any kind are found on the sprouts or on the seed pieces. A weak tuber will produce only spindly sprouts. Both strong and spindly sprouts are never found on the same seed tuber. The character and the fertility of the soil seem to have no influence whatsoever on this trouble. The only remedy known is the use of Northern grown seed.

\section{INTERnAl BRown Spotting}

\section{Cause Unknown.}

This disease is peculiar to the Early Maine and is found in New York, Maine, Connecticut, and Minnesota.

Symptoms. Usually the trouble is internal without any symptoms apparent on the outside of the tuber. But occasionally its presence is indicated by 


\section{Family Solanaceæ}

reddish discoloration on the skin. In cutting across an affected tuber, the flesh is found to be spotted reddish in isolated and scattered places. The trouble usually starts at the stem end and works toward the bud end and inwards. In severe cases, the trouble is indicated by a discolored band, the outside of which may easily be mistaken for late blight injuries, Phytophora infestans.

\section{NET NECROSIS}

\section{Cause Unknown.}

Tubers often show minute black areas (fig. $5^{8} \mathrm{c}$ ) beginning near the stem end and extending about an inch inwards. It is not known whether the trouble, if such it may be called, has any influence in reducing the yield. However, it is safer not to use tuber seed which shows these minute internal browned specks.

\section{Black Heart}

\section{Caused by Overheating.}

This trouble is often met on tubers kept in storage pits which are poorly ventilated. In this case the sweating and overheating will cause the tubers to turn black at the heart (fig. 58 e). The same occurs when potatoes are shipped in overheated cars. The remedy is to keep the potatoes as cool as possible, and slightly above the freezing point. 


\section{Hollow Heart}

\section{Cause Uneven Growth.}

When potatoes are overgrown or when quick growth results from dry spells followed by moist weather, the heart of the tuber tears and a hollow center is formed (fig. $58 \mathrm{f}$ ). The trouble does not injure the edible quality of the tuber. Varieties such as Rural New Yorker and King are especially susceptible to hollow heart. So far as possible these should be avoided on heavy soils.

\section{TIP BURN}

\section{Caused by Unfavorable Soil and Weather.}

This trouble is prevalent in dry weather in midsummer, when the leaves transpire water more rapidly than the roots can take it in from the soil. As a result the tips and margins of the leaves dry up and die (fig. $58 \mathrm{~h}$ ). The uprolling of the margins of the leaflets is a characteristic of tip burn, also distinguishing it from late blight. The trouble may be considerably reduced by frequent shallow cultivation, making a shallow surface mulch which will prevent excessive evaporation. Spraying will also protect the foliage from tip burn.

\section{MosaIC}

\section{Cause Unknown.}

Mosaic is a disease which is not confined to the tubers, but which also affects the parts of the plant 


\section{Family Solanaceæ}

above ground. It is characterized by a mottled appearance of the leaves (fig. $5^{8} \mathrm{~g}$ ). The portions which are lighter in color seem to be thinner than those which are of a normal green. In advanced stages, brown spots of dead tissue may take the place of the light colored mottled leaf areas.

Mosaic undoubtedly reduces the yield, the losses often amounting to twenty per cent. The Green Mountain seems to be very susceptible to mosaic, while the Irish Cobler seems to be especially resistant. It has been proven by Worthley ${ }^{I}$ that the disease is carried with the tubers from diseased vines. As a matter of precaution these tubers should not be used for seed. Long before digging, the field should be carefully inspected, and hills which show mosaic infection should be pulled out and removed. This will prevent tubers from diseased plants from being mixed with healthy ones.

\section{ARSENiCAL InJURY}

Potato foliage is often injured when the plants are sprayed with Paris green. Within a few days dead spots similar to those occurring in early blight appear on the surface of the leaves. To obviate this, lime should be added to the Paris green. If the Paris green is used dry, one pound of powdered lime should be mixed with each half pound of Paris green. The same proportions are used when Paris green is applied as a spray.

Pox or Pit (fig. 60) see Sweet Potato, p. I 52.

× Worthley, E. I., Science, N. S., 42 : 460-46I, I9I5. 


\section{POWDERy SCAB}

Caused by Spongospora subterranea (Woll.) Johns.

Powdery scab may justly be considered a dangerous disease. The trouble has undoubtedly been of European origin. In the United States the disease is now found in Presque Isle, Me., Chateaugay, N. Y., Nehalem, Ore., Hastings, Fla., Inohomish, Wash., and Virginia, Minn. The trouble has been carefully investigated by Melhus and Rosenbaum. ${ }^{\mathrm{I}}$

Symptoms. Powdery scab attacks the young rootlets, forming galls resembling in size those of legume nodules (fig. $59 \mathrm{c}, \mathrm{d}$ ). At this stage infection does not take place on the tubers. In fact it is not unusual to find the total root system affected with galls, while the tubers remain free. Thus if we look for the disease in the field a search should be made for infection on the roots and rootlets.

Infection on the tubers is evidenced at first by minute discolored areas on the epidermis. Six to eight days later, the spots increase in size, become raised and somewhat jellylike. Powdery scab on the tubers cannot easily be mistaken for common scab, Actinomyces chromogenus. In powdery scab the sori are more often circular and not as extended as in common scab. In powdery scab, the border of the pustules is virtually raised, forming a cuplike sorus or pit (fig. $59 \mathrm{a}$ ), and the pits are deeper and at matu-

\footnotetext{
' Melhus, I. E., and Rosenbaum, J., U. S. Dept. of Agr. Jour. Agr. Research, 7 : 213-254, I9II.
} 

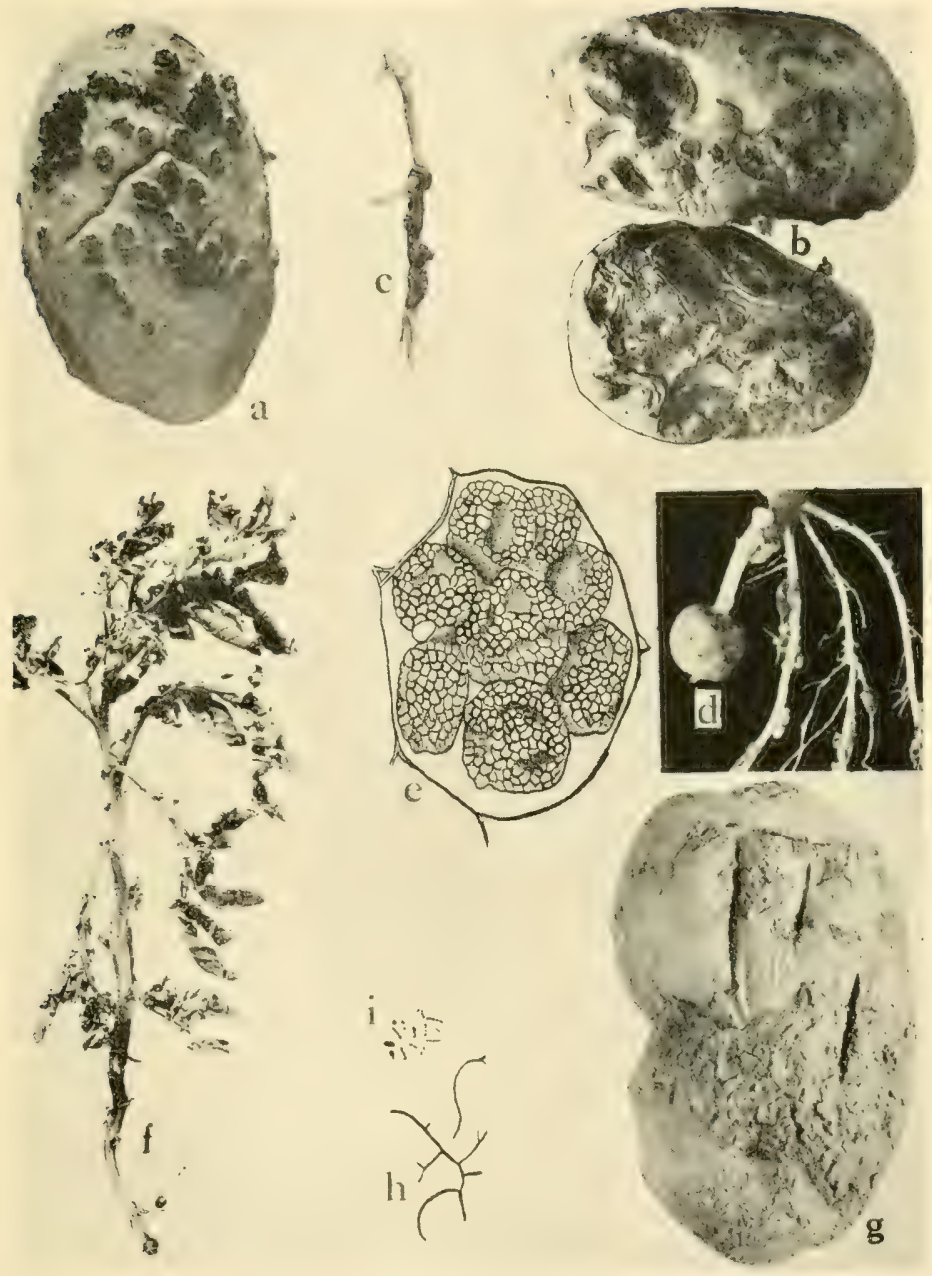

Fig. 59. Diseases of the Potato.

$a$. Powdery scab, early stage, $b$. powdery scab, advanced stage of rotting, $c$, and $d$. powdery scab, gall-forming stage on potato roots ( $c$. and $d$. after Melhus and Rosenbaum), $e$, single potato cell showing spore balls of the powdery scab fungus (after Melhus), f. black leg, $g$. common scab, $h$. to $i$. drawings of the organism of common scab, showing branching of threads and groups of spores or conidia (after Lutman and Cunningham). 



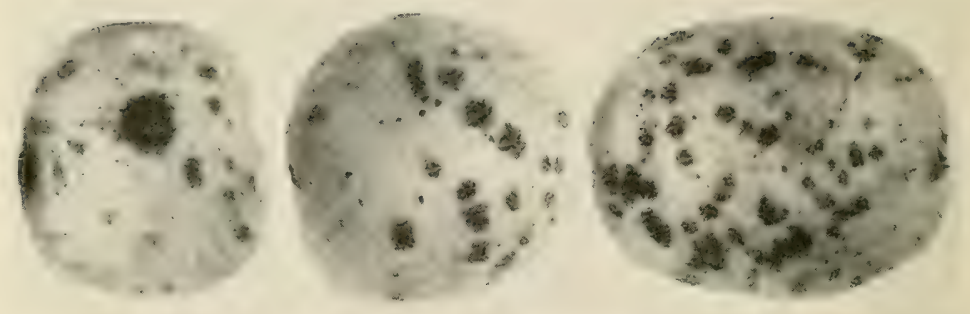

Fig. 6o. Pox or Pit of the IVhite Potato, Showing Different STAGES OF INFECTION. 


\section{Family Solanaceæ}

rity always filled with black spore balls. The sori of common scab are shallow and made up of corky compact tissue. After being handled or shipped long distances, potatoes infected with powdery scab cannot be distinguished from those suffering from common scab. However, a microscopical examination of the sori will soon reveal the difference.

In storage, potatoes infected with powdery scab will dry rot. This is but the final stage of the disease (fig. 59 b). While it is not uncommon for the dry rot to invade the whole tuber, it generally extends only in spots. The effect of powdery scab on stored potatoes is a more rapid drying of the tubers and the opening of a way for the invasion of secondary infection.

In the field, the disease is favored only by cool, damp, and rainy weather. Besides the potato, the tomato too is attacked by powdery scab. In this case, infection is confined to the root system, which is much more distorted than is the case with the potato. Of the other hosts affected may be mentioned Solanum warscewicii, S. hematoclodum, S. mammosum, S. marginatum, S. ciliatum, and S. commersoni.

The Organism. The plasmodium within the host cells is irregular in shape. It is composed of protoplasm within which are evenly distributed nuclei. Within the host cell the protoplasm of the plasmodium is closely applied to the host nucleus. Infection seems to take place by means of a plasmodium rather than by single amœbæ. The parasite is confined to the phloem of the host. The invaded cells are not killed, but are stimulated to an abnormal cell division. 
Germination of the spore balls may be effected in two ways: (I) the spore walls of the entire spore balls break down, liberating as many amœbæ as there were cells within; (2) the amœbæ may escape through openings in the wall of the spore ball and move about by means of pseudopodia.

Control. Infected soils should never be limed, since the application of lime favors the disease. Rotation of crops is suggested. The land should be given a rest from potatoes, or tomatoes, for at least five years. Since infection of the tubers takes place late, early harvesting and the growing of early maturing varieties is advisable. Since the disease is carried with infected seed tubers, the latter should be disinfected. The use of mercuric chloride or formaldehyde, or both, is recommended. (See also p. 336.) No soil treatment will cure the trouble, but sulphur applied at the rate of nine hundred pounds per acre will reduce the amount of infection.

\section{BLACKLEG}

\section{Caused by Bacillus phytopthorus Appel.}

Blackleg is a dangerous disease which may readily be introduced into new localities with the seed. The trouble has been well described by Morse. ${ }^{x}$

Symptoms. Blackleg does not manifest itself until the plants are about 7 to Io inches high. Diseased plants are unthrifty, undersized, with the branches

${ }^{2}$ Morse, W. J., Maine Agr. Expt. Sta. Bul. 174: 307-328, 1909. 


\section{Family Solanaceæ}

growing upward, forming a compact top. In severe cases, affected plants turn yellowish, topple over, and die. On pulling out a diseased hill, we find that the stem end near the seed potato is black (fig. $59 \mathrm{f}$ ). This blackness may extend even one or two inches on the stem above the ground. The seed pieces in this case soft rot. Occasionally the newly formed tubers become infected in the soil and rapidly soft rot. The disease is carried in the interior of the infected seed tubers, and in this way is distributed from one locality to another. Blackleg is now prevalent in Maine, South Carolina, Virginia, Maryland, Delaware, New Jersey, New York, Ohio, Oregon, and possibly also in Florida, Georgia, New Hampshire, North Carolina, Rhode Island, Vermont, and Wisconsin.

The Organism. Bacillus phytopthorus is a rodshaped organism, motile by means of peritrichiate flagella. It is an aerobe, non-sporiferous, liquefying gelatin slowly and producing no gas. On agar, the colonies are grayish white, round, and smooth.

Control. Careful selection of the seed tubers is essential. Those which show evidence of internal discoloration or rot should be disinfected with formaldehyde, see p. 336.

SOUTHERN Wilt, see TOMato, p. 342.

\section{Common Scab}

Caused by Actinomyces chromogenus Gasp.

Common scab is a discase which is generally skin deep. The kind of injury and the severity of infec- 


\section{8 \\ Diseases of Truck Crops}

tion depends on the variety of tuber and the cultural conditions. Common scab may often be confused with powdery scab; but a careful examination will reveal striking differences.

Symptoms. The disease attacks the tubers only. It begins as small surface spots or stains, which soon spread and increase in depth, penetrating to a depth of a half centimeter. The spots consist of accumulated corky tissue which may be readily removed (fig. $59 \mathrm{~g}$ ). The diseased cells lose their starch and are filled instead with what appears as fat globules. The scab spot is merely the result of the corky cambium cells which are formed to protect the inner starch-bearing parenchyma tissue from the irritation of the parasite. Scab does not impair the germination of the seed, but it reduces the yield as well as prejudicing the keeping qualities of the tubers. It does not in any way impair their edible quality.

The Organism. The scab-causing organism was formerly believed to belong to the class of fungi and was originally named Oospora scabies Thaxter. But two American workers, Lutman and Cunningham, ${ }^{\mathrm{I}}$ found that the scab organism is not a fungus, but belongs to the thread bacteria (fig. $59 \mathrm{~h}, \mathrm{i}$ ). $A$. chromogenus consists of long irregular filaments; the cross walls of the branches are scarcely visible. On agar, under lack of moisture conditions or concentration of medium, the filaments grow out, and become closely segmented into short rods known as gonidia

${ }^{2}$ Lutman, B. F., and Cunningham, G. C., Vermont Agr. Expt. Sta. Bul. 184 : 3-64, 1914. 


\section{Family Solanaceæ}

or spores. The filaments or gonidia are non-motile. It produces no gas, but is capable of producing a brown pigment which is soluble and diffuses through the medium.

Control. The disease is carried about with infected tubers. The latter when fed to cattle will infect the manure. The scab organism can pass the digestive tract of the cows or horses without losing its vitality. Before planting, seed potatoes should be disinfected with corrosive sublimate or formaldehyde. See also p. 336. Fertilizers which tend to make the soil alkaline, such as barnyard manure, lime, wood ashes, or bone meal, all tend to increase scabby potatoes. The use of kainit, muriate of potash, sulphur, or acid phosphate as a fertilizer all tend to decrease scab.

\section{BLACK WART}

Caused by Chrysophylyctis endobioticum (Schilb.) Perc.

Black wart is perhaps one of the most dangerous of the potato diseases. The trouble is now prevalent in Germany, England, Upper Hungary, and in Newfoundland. The disease has not as yet made its appearance in the United States, although it is believed that infected potatoes have been shipped in from Newfoundland.

Symptoms. In early stages of infection, the eyes are first attacked, turning brown and later black. The disease then works down to the tuber, which is but slightly disfigured. In advanced stages, big 


\section{Diseases of Truck Crops}

dark warts, sometimes as large as the tuber itself, appear on its sides or ends (fig. 6I a). The warty growth consists of a scabby gall-like formation, closely resembling the crown gall of the peach. The last stage of the disease is when the fungus has utilized all the food stored in the tuber and has reduced it to a brownish black, soft mass with a very offensive odor. At this stage the fungus consists almost entirely of a mass of spores which, when disturbed, scatter and spread all over the field.

The Organism. Chrysophylyctis endobioticum has been investigated by Johnson ${ }^{\mathbf{x}}$ and others. The vegetative parts of the fungus consist first of a naked mass of protoplasm which attacks and feeds on the protoplasm of the cells of the host. As this bores from cell to cell, it stimulates abnormal growth, which results in the warts or galls already mentioned. During the summer, the plasmodium rounds up, forming a thin smooth wall about itself. Later the contents of this body break up into numerous zoospores, which escape through a hole in the cell wall and attack healthy potato tissue. As the season advances, the fungus ceases to reproduce by means of zoosporangia and zoospores and forms a resting sporangium. This helps to carry the fungus over the winter, and the following spring it germinates by means of zoospores.

Control. So far, there are no methods of control known. It is imperative that we prevent black wart

${ }^{x}$ Johnson, T., The Scientific Proceedings of the Royal Dublin Soc., Vol. 12, 1909. 


\section{Family Solanaceæ}

from getting a foothold in the United States. This can be accomplished only by strict quarantine laws prohibiting the importation of tubers from countries where wart is prevalent.

\section{MELters or LEAK}

Caused by Pythium de Baryanum Hesse; Rhizopus nigricans Ehr.

Melters is a common storage and shipping disease. The trouble is prevalent in the Delta region of San Joaquin River, California. The rot is common during hot weather and begins to work soon after harvesting.

Symptoms. The disease first appears as small discolorations at a cut or bruise made by an implement at harvesting. The rot does not affect unbruised tubers. Later the affected potatoes turn brown, become soft (fig. 6I g), and if pressure is applied a brownish watery liquid exudes, wetting the neighboring tubers.

The Organism. Orton ${ }^{x}$ has shown that leak may be induced by the fungus Rhizopus nigricans. For a fuller description of this fungus, see soft rot of sweet potatoes, p. I56. Hawkins ${ }^{2}$ has further shown that leak may also be caused by the fungus Pythium de Baryanum. For a description of the latter, see also damping off, p. 43 .

${ }^{2}$ Orton, W. A., U. S. Dept. of Agr. Bur. Pl. Ind. Circ. 23 : II, Igog.

${ }^{2}$ Hawkins, L. A., U. S. Dept. Agr. Jour. Agr. Research, 7: 6a7-639, 1916. 


\section{LATE Blight}

Caused by Phytophthora infestans (Mont.) De Bary.

Late blight is a disease which is restricted to some parts of the United States. As it thrives best in States where the midsummers are moist and cool, it is common in the Northern States. Farther south or west, it is unknown or it occurs sporadically, causing little damage.

Symptoms. Late blight attacks both the foliage and the tubers in the field, or the tubers alone in storage, the disease appearing when the plants have passed the flowering stage.

On the leaves the trouble is first manifested as purplish black or brownish black areas on the lower side (fig. $6 \mathrm{I} \mathrm{b).} \mathrm{It} \mathrm{attracts} \mathrm{attention} \mathrm{only} \mathrm{when} \mathrm{the}$ upper leaves are attacked and blackened. At first the infected leaves become watersoaked and pale, then they wilt and blacken. On examining an infected leaf during a dewy morning, a delicate growth of the fungus is perceptible as a fine powdery bloom on the under side.

When the tops are badly blighted, the tubers too will show evidence of disease. In early stages the infection becomes perceptible as brownish to purplish discoloration of the skin with a softening of the inner tissue (fig. 6I c). In dry, well drained soils, the progress of the disease underground is slow, and at harvesting dry rot may be in evidence. Infected tubers when stored in cool, dry cellars may pass the 


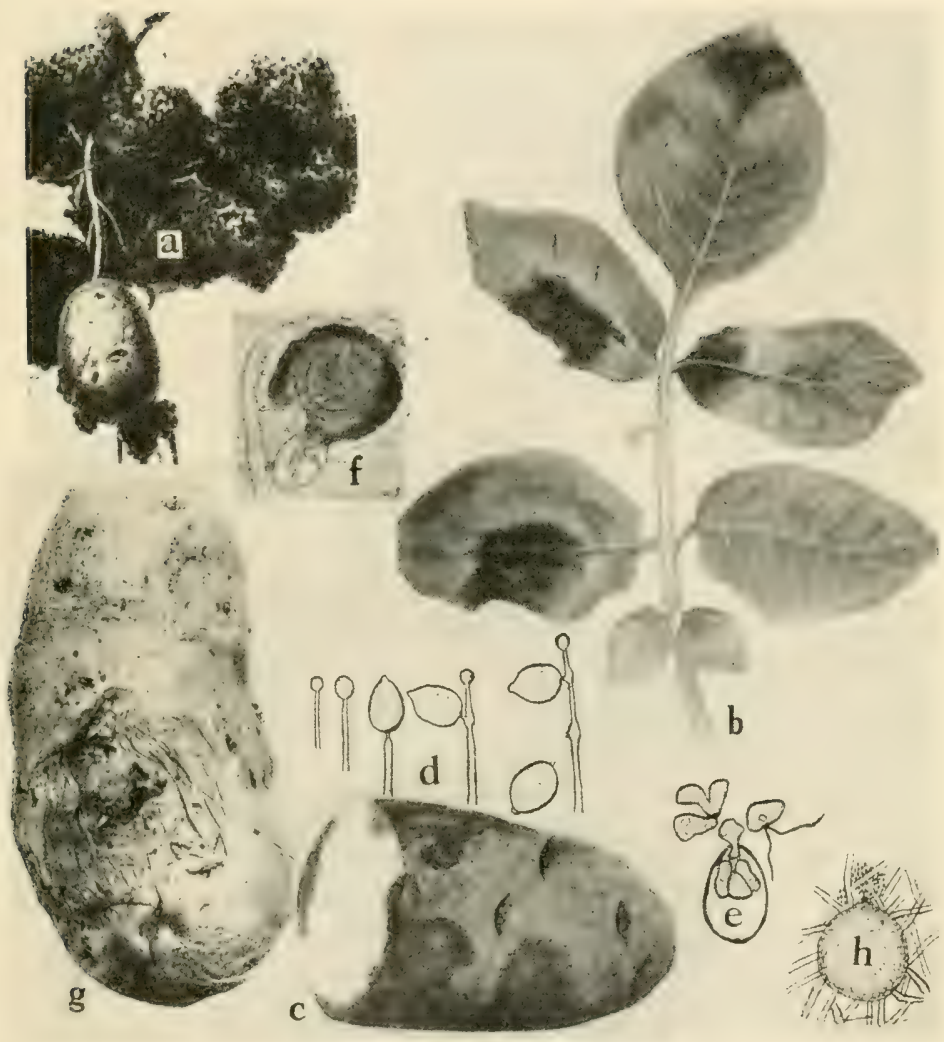

Fig. 6i. Potato Diseases.

a. Black wart (after Güssow), b. late blight on foliage, c. late blight on tuber, $d$. successive stages of the development of the conidia of Phylophihora infestans ( $b$. and $d$. after L. R. Jones), e. germination of conidia of Phytophthora infestans, by means of zoopores (after Ward), $f$. mature oogonium of $P$. infestans (after Clinton). g. melters, surface view, early stage of infection, $h$. pycnidium of Phoma tuberosa (after Melhus and Rosenbaum). 



\section{Family Solanaceæ}

winter unhurt, the rot being checked by the favorable storage conditions.

The Organism. The mycelium of the fungus is hyaline, non-septate. As shown by Melhus ${ }^{\mathbf{x}}$ and others, the mycelium may be carried from year to year within the infected tubers. In fact this is but one way late blight is distributed. Through the stomata of the infected leaf emerge the slender conidiophores (fig. 5I d), bearing the ovoid conidia. According to Melhus, ${ }^{2}$ the conidia of Phytophthora infestans may germinate either directly by a germ tube or by the production of zoospores (fig. 6I e) as in Pythium. The best germination occurs at the optimum temperature, which lies between Io and $13^{\circ} \mathrm{C}$. $\left(50-57^{\circ} \mathrm{F}\right.$.). The conidia may be killed by exposure for 6 to 24 hours to dry atmospheric conditions such as exist in an ordinary room. Frost which kills the top of the plants will also kill the conidia of Pythophthora. Light does not hinder germination and therefore has no inhibiting effect on infection. Phytophthora infestans does not seem to produce sexual spores or oospores within the affected tissue of the leaf or tuber. However, Clinton ${ }^{3}$ succeeded in developing what appeared to be oospores of the fungus in pure culture on oat agar (fig. $6 \mathrm{I} \mathrm{f}$ ). The oogonia appear as swollen terminal heads, cut off

${ }^{x}$ Melhus, I. E., U. S. Dept. of Agr. Jour. Agr. Research, $5: 59-65$, I9I5.

${ }^{2}$ Melhus, I. E., Wisconsin Agr. Expt. Sta. Research Bul. 37 : 1-64, I9I5.

${ }^{3}$ Clinton, G. P., Connecticut Agr. Expt. Sta. Ann. Rept., I9091910:753-774. 
from the main thread by a cross wall. The antheridium resembles that of $P$. phaseoli. Mature oospores have a medium thick, smooth, hyaline wall. It is not known how the oospores germinate. For methods of control, see p. 337 .

\section{Phoma Rot}

Caused by Phoma solani Mel., Rosen., and Sch.

Phoma rot is found only on bruised tubers. It is also found following injuries produced by powdery scab, Spongospora subterranea. The lesions of phoma rot are brownish dark to gray dark sunken pits with irregular and sharply defined margins. The black pycnidia (fig. $6 \mathrm{I} \mathrm{h}$ ) are found scattered over the entire surface of the lesions. The disease may cause considerable damage in storage. The remedy consists in careful handling of the tubers during digging and storing.

\section{ANTHRACNOSE}

Caused by Colletotrichum atramentarium (Berk. and Br.) Taub. ${ }^{x}$

Anthracnose was first described by $\mathrm{O}^{\prime} \mathrm{Gara}^{2}$ as a disease attacking the foot of the plant. The fungus was originally named Colletotrichum solanicolum O'Gara, but was later changed by the writer to $C$. atramentarium. It causes deep lesions

× Taubenhaus, J. J., Mem. N. Y. Bot. Gard., 6 : 549-560, 1916.

${ }^{2}$ O'Gara, P. J., Mycologia, 7 : 38-4I, I915. 


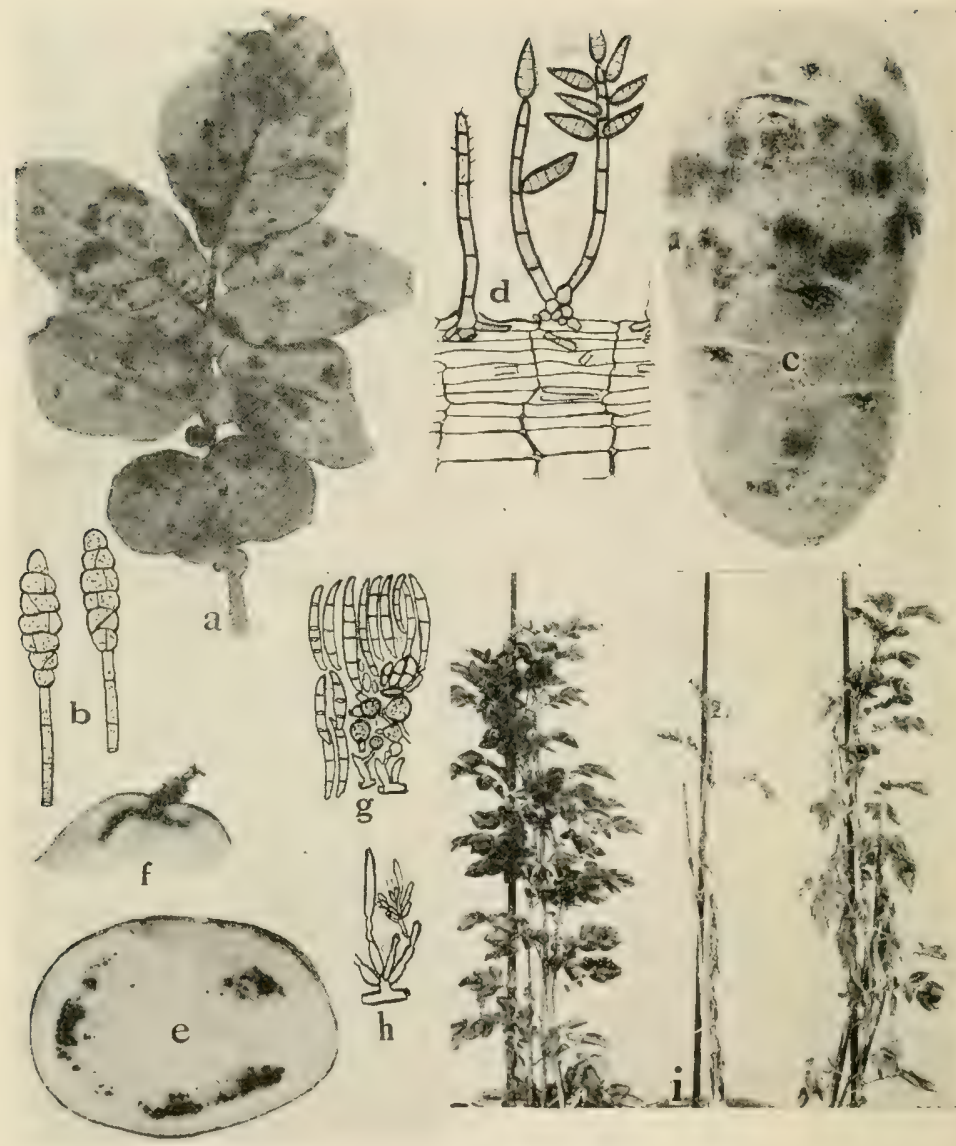

Fig, 62. Potato Diseases.

$a$. Early blight (after L. R. Jones), $b$. spores of the early blight fungus, $c$. silver scurf, $d$. conidiophores and conidia of the silver scurf fungus, $e$. and $f$. Fusarium oxysporum wilt in tubers, $g$. chlamydospores and one to several celled conidia of $F$. oxysporum, $h$. conidiophores of $F$. oxysporum ( $g$. and $h$, after Sherbakoff), $i$. Verticillium wilt (after Orton). 
on the stems, usually attacking plants which are full grown. It is also found as a saprophyte in the soil, or growing on dead potato vines; or frequently associated with silver scurf on the tuber. It was previously thought to be a sclerotial stage of Spondylocladium atrovirens Harz. Colletotrichum atramentarium differs from most Colletotrichums in that it produces an abundance of sclerotia both on the host and in pure culture. It sporulates very poorly but otherwise possesses all the characteristics of the genus Colletotrichum.

\section{EARLY BLIGHT}

Caused by Macrosporium solani E. and M.

Early blight attacks the foliage only. Infection seems to follow injury from insects such as the potato beetle and the flea beetle.

Symptoms. The disease is characterized by circular or irregular brown dry spots made up of a succession of rings (fig. $62 \mathrm{a}$ ). The spots may become so numerous as to involve the entire foliage and cause premature death of the tops.

The Organism. The mycelium is brownish to olive in color. The conidiophores arise through the stomata of the leaf. The conidia are produced singly, the body of the spore has from 4 to 12 transverse septa, with few longitudinal cross walls (fig. 62 b). When germinating, a germ tube may be produced from each cell of the conidia. This penetrates the 
leaf either through the stomata or by piercing through the cell wall of the epidermis. Early blight may be controlled by spraying, see p. 337 .

\section{SILVER SCURF}

Caused by Spondylocladium atrovirens Harz.

Silver scurf is prevalent throughout the East. Fortunately the disease does not cause much direct damage, since it is confined only to the exterior of the epidermis. It is claimed that affected tubers are subject to more rapid shrinking and drying. The spots on the tubers are brown and turn silvery when moistened (fig. $62 \mathrm{c}$ ).

The Organism. The conidiophores are borne either singly or in clusters, erect septate, with numerous sterigmata which bear the spores (fig. $62 \mathrm{~d}$ ). The conidia are thick walled, elongate, many septate, apex narrowed and longer at the bottom.

Control. Seed treatment does not seem to control the disease. Since silvery scurf is directly carried with the seed tubers, selection of clean seed is recommended.

\section{VERTICILLIUM WILT}

\section{Caused byVerticillium albo-atrum McA.}

Verticillium wilt is not a dangerous disease when compared with Fusarium wilt. It does not kill out 


\section{Family Solanaceæ}

entire fields but is generally confined to individual hills irregularly scattered in a field. In distribution, Verticillium wilt has been found only in the more northern States.

Symptoms. The disease as described by Orton ${ }^{\mathrm{I}}$ is characterized by a sudden wilting of the foliage (fig. 62 i) and the premature dying of the hill. In splitting open a diseased stem, the browning of the vessels will be well marked. This will extend to the tips of the stems and into the leaf petioles, a symptom which distinguishes it from Fusarium wilt, since in the latter the browning of the vessels does not extend into the tips of the stalks. Moreover, in Verticillium wilt there is a production of conidia on the stalks long before they are entirely dead. In Fusarium wilt, the conidia appear only after the stem has been killed for some time.

Control. Since the disease is carried internally in the seed tubers, control methods are the same as for Fusarium wilt.

\section{FUSARIUM WILT}

Caused by Fusarium oxysporum (Sch.) Sm. and Sw.

Fusarium wilt is a disease which thrives best in warm climates. In California, Arizona, Ohio, Missouri, and Nebraska the trouble is most prevalent. New England and New York are relatively free from Fusarium wilt. There, however, the Verticillium × Orton, W. A., U. S. Dept. of Agr. Bul. 64 : 16-18, 1914. 
wilt is prevalent. In Michigan, Illinois, Wisconsin, and Minnesota, Fusarium wilt is found in the older potato districts. The trouble is also found in Colorado and Utah where it thrives on irrigated as well as on dry lands, on sandy loams as well as on the heavier clays.

Symptoms. When infected seeds are planted, the result is a poor germination and uneven stand. The disease however does not attract attention until the plant attains a height of a foot or more.

Wilt is characterized by a drooping of the lower leaves, which are first to die. This is followed by a wilting of the upper foliage and by a premature dying of the tops. The leaf roll that is noticed in Fusarium wilt differs from true leaf roll in that in the former the leaves lack the turgidity and soon die as a result of the infection. Wilted plants are at first light green, then yellow, finally drying up and dying. The disease first gains entrance through the tender rootlets in the soil, gradually working up into the main roots, stolons, tubers (fig. $62 \mathrm{e}, \mathrm{f}$ ), and some way into the stem. In splitting open a diseased stem, the interior water vessels are found to be slightly browned. But few Fusarium spores are formed on the dead stems. In the tubers the presence of wilt is indicated by a browning of the vascular rings.

The Organism. The microconidia are pedicellate, sporodochia and pseudopionnotes present, macroconidia 4 to 5 septate, pinkish buff color in mass (fig. $62 \mathrm{~g}, \mathrm{~h}$ ). Bluish black sclerotia are formed on potato plugs. For methods of control see p. 337 . 


\section{Family Solanaceæ}

\section{BlACK Rot or Jelly END Rot}

Caused by Fusarium radicicola Woll.

This disease is seldom found in the field at digging but is usually manifested as a storage trouble. It is common in Idaho, Oregon, Washington, California, Nevada, Mississippi, New York, Virginia, District of Columbia, and certain parts of Pennsylvania.

Symptoms. In the irrigated sections of California, Oregon, and Idaho the trouble is manifested as a soft rot termed "Jelly End Rot." The stem end soft rots, and the affected portion may be easily removed from the remainder of the tuber. The disease progresses inwards until the entire tuber within the skin becomes soft and jellylike in consistency. If not disturbed, the inside tissue will dry, and the skin persist as a loose tunic, or it may shrivel and shrink, giving the appearance of a dry rot.

In the non-irrigated potato districts, the symptoms of the disease are sunken, blackish, leathery areas on any part of the tubers. In Pennsylvania the disease is known as "black rot" or "black head." Microconidia of the fungus are the dominant type of spores. Chlamydospores are common and pseudopionnotes are absent, while sporodochia are usually present.

Control. This disease does not make any progress in storage at or below fifty degrees $F$. The trouble is confined mostly to the Idaho, Rural, and Pearl. So far as possible, these should be avoided and re- 
placed by the more resistant varieties best adapted to the infected localities.

\section{Stem End Rot}

\section{Caused by Fusarium eumartii Carp.}

Although a storage trouble, stem end rot may cause a wilt in the field which may not be easily distinguished from other Fusarium wilts. However, in the laboratory the causative organism may be readily determined by pure culture methods.

Symptoms. The wilt produced on plants in the field resembles other wilts. On the tubers, decay starts at the stem end. The infected part slowly shrivels and becomes filled with a mass of a dried brown pulp, consisting mainly of dead tissue. Infection usually takes place through a wound or even through a lenticel in the tuber. The fungus is characterized by its production of macroconidia which are 4 to 6 septate, pionnotes are present, otherwise the organism resembles $F$. martii.

For control, see p. 337 .

\section{POWDERY DRY ROT}

\section{Caused by Fusarium trichothecioides Woll.}

Powdery dry rot is a storage trouble which is prevalent in the arid and semi-arid sections of the western part of the United States. The disease was 


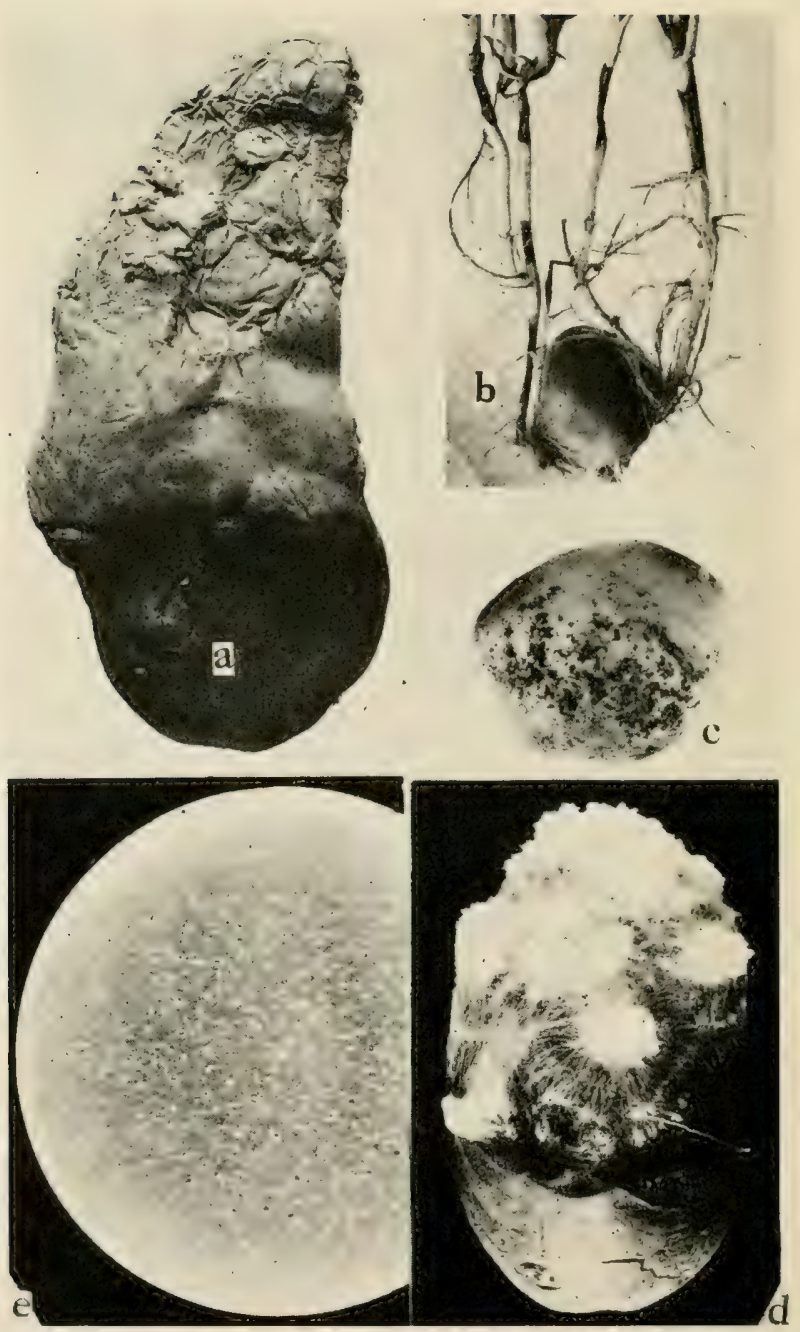

Fig. 63. Potato Diseases.

a. Powdery dry rot, $b$, Rhizoctonia lesion on young potato sprouts (after W. A. Orton), c. Rhizoctonia sclerotia on seed potato tubers, $d$. melters, artificially induced by inoculating with a pure culture of Sclerotium Rolfsii, e. pure culture of S. Rolfsii. 


\section{Family Solanaceæ}

first described by Jamieson and Wollenweber. ${ }^{x}$ The trouble is the same as that described by Wilcox ${ }^{2}$ and the causative organism was previously named Fusarium tuberivorum. In poorly ventilated storage houses, bruised potatoes dry rot (fig. 63 a), the entire content of the tuber turning into a powdery mass. The disease does not attack growing plants in the field nor unbruised tubers.

There are numerous other species of Fusaria which are capable of producing a rot on tubers through a wound. Sherbakoff ${ }^{3}$ mentions twenty-eight of them which may produce a rot on stored potatoes.

\section{ROSETTE OR RUSSET SCAB}

Caused by Corticium vagum B. and $\mathrm{C}$. var. solani Burt.

Rosette, although generally distributed, is more prevalent in the Eastern States. The disease is often very serious, and causes great money losses. The trouble attacks the tuber as well as the foot of the stem.

Symptoms. On the tubers the disease is recognized as superficial dark brown sclerotia varying in size from that of a mustard seed to that of a vetch (fig. $63 \mathrm{c}$ ).

I Jamieson, C. O., and Wollenweber, H. W., Jour. Wash. Acad. Sci., 2 : 146-I52, 1912.

"Wilcox, E. M., et al., Nebraska Agr. Expt. Sta. Research Bul. I : $1-88$, I913.

${ }_{3}^{3}$ Sherbakoff, C. D., New York (Ithaca) Agr. Expt. Sta. Mem., $6: 97-270,1915$. 
In planting infected tubers, the sclerotia germinate and the growing fungus threads attack the young sprouts, causing lesions (fig. $63 \mathrm{~b}$ ). These may be superficial or so deep as almost to girdle the stems. The lesions are usually numerous. Infected plants attempt to overcome the ill effect of the disease by sending out numerous sprouts above the injured parts, giving the appearance of a rosette. Diseased hills often produce aërial tubers. The disease is spread about by the use of the infected seed tubers. The causative fungus, once introduced into a field, will live in the soil on dead organic matter and attack numerous other crops. Rosette is worse on wet, poorly drained soils, and during seasons of heavy rainfall. Recently Rosenbaum ${ }^{\mathrm{I}}$ has found that there are variations in the strains of Rhizoctonia isolated from diseased potatoes. Some of the strains seem to be more virulent pathologically, and differ morphologically from others. For methods of control, see p. 336.

SOUthern Blight (fig. 63 d-e), see PePper p. 305.

\section{RoOT KNOT}

\section{Caused by Heterodera radicicola (Greef) Muller.}

Root knot on the potato may be easily overlooked. Usually there are no knots on the tubers, and the trouble is merely manifested by minute pimples on the surface of the potato, resembling the pimples

${ }^{3}$ Rosenbaum, J., U. S. Dept. of Agr., Jour. Agr. Research, 9 :413419, 1917 . 


\section{Family Solanaceæ}

induced by flea beetle injury. Small knots resembling legume nodules may occasionally be formed on the smaller rootlets of the plant. For a further description of root knot, see Nematode, p. 49.

\section{Control of Potato Storage Rots}

As seen above, numerous fungi are capable of producing a rot on bruised potatoes. The greatest loss from this source occurs when the tubers are held in storage. Most of this loss, however, could be reduced to a minimum if more care were exercised at digging. Few realized the heavy losses from bruises and cuts and rough handling in the field. This could be best appreciated if we were to watch the storers sort out the tubers, to prepare them for the market. A visit to the retail stores where quantities of unsalable potatoes are dumped out will also convince us why the grower must exercise more care.

Potatoes are usually stored in pits, in cellars or dug-outs, and in insulated frame structures. In the larger storage houses, conditions may be better regulated than in pits or cellars. No matter which method of storage we adopt, there are certain fundamental principles to observe.

Temperature. Upon proper temperature usually depends success in storing. Careful investigations by the United States Department of Agriculture has shown that the freezing point of Irish potatoes lies between 26 and 28 degrees $F$. This means that potatoes can stand the low temperatures, which are 
especially necessary for good keeping. A temperature of about thirty-six degrees F. may be considered ideal for the best keeping. This temperature will keep the tubers in the best of condition and will also inhibit the work of decay organisms. It is claimed that when potatoes are stored at low temperatures they take on a sweetish taste when cooked. This may or may not be an objectionable feature. This objection, however, is of little significance, when we consider the fact that stored potatoes become normal in taste after being kept a week at the retailer's store at ordinary room temperature.

Moisture. Little is known as to the amount of moisture necessary during potato storage. The object, however, should be to maintain sufficient moisture in the air to prevent excessive drying of the tubers, and at the same time to keep the moisture content low enough to prevent it from condensing and falling on the potatoes. Appleman ${ }^{x}$ suggests that storage houses be maintained at 33 to 35 degrees $F$., and at a humidity of 85 to 90 per cent.

Ventilation. Pure fresh air seems to be necessary to insure successful storage. This may be secured by top and side ventilators installed in the storage house. In pit or cellar storage, neither the temperature nor the relative humidity can be successfully controlled. Here the trucker is entirely dependent on the chances of natural weather conditions.

Bins. It is bad practice to store in large bins or 2Appleman, C. O., Maryland Agr. Expt. Sta. Bul. 167 : 330, 1912. 


\section{Family Solanaceæ}

piles, for the potatoes in them are almost certain to undergo a heat which will destroy their keeping and germinating power. This is a serious matter in storing seed potatoes. Bins should be small, provided with a false floor, and separated one from the other by a two-inch air space. Direct sunlight should be kept from the storage. Subdued light or electricity will not cause the tubers to turn green and unfit for cooking. Finally, only sound tubers should be stored. The storage house should be carefully cleaned out before the crop is brought in from the field and the interior walls and woodwork thoroughly disinfected by burning flowers of sulphur.

Care in Shipping. In Florida potatoes are shipped in double-headed barrels, as is done for apples. No matter in what receptacles potatoes are shipped, it is imperative to avoid rough handling and to pack securely. This will prevent shaking and bruising of the tubers while in transit. The cars should be cleaned and protected from leakage. During extreme cold weather, the cars should be generously supplied with a layer of straw at the bottom and at the sides.

\section{Control of Potato Diseases in the Field}

It is fortunate that most of the potato troubles in the field may be kept in check. Truckers, therefore, are no longer justified in allowing their potato crops to be carried off by disease.

Seed Selection. Most of the potato diseases are 
carried over with the seed. The importance of clean, carefully selected seed cannot be too strongly emphasized. Selecting seed from resistant and highest yielding hills is preferable to selecting from the bin. In cutting the tuber into pieces for planting, none should be used that show the least blemish or rot on the outside, or decay or discoloration within. By observing this precaution carefully, we shall prevent our seed from carrying scab, rosette, and many of the blights and wilts. Selected clean seed alone will not give the desired result if it is planted on infected soil. Less disease may be expected when clean seed is planted on lands rotated with alfalfa or grain, than when it is planted on virgin land.

Seed Disinfection. The object of disinfecting seed is to destroy disease-producing organisms which may be adhering to the exterior of the seed coat. After the seed pieces are cut, they should be soaked for one and a half hours in a solution made up of four ounces of corrosive sublimate dissolved in thirty gallons of water. It is desirable to disinfect the seed immediately before planting. Doing it a week to ten days before planting leaves the risk of the seed undergoing heat and having its germination injured. For disinfecting large quantities of seed, the dipping process is too tedious, and a preferable method is that of the formaldehyde gas. This method requires care, or else we are apt to injure the seed badly. In this case, it is essential to have 167 bushels of potatoes for each one thousand cubic feet 


\section{Family Solanaceæ}

of space in the disinfecting room. With less quantities of potatoes in this space, the formaldehyde gas will injure the germination and produce a pitting on the tuber. A tight room is used for this purpose, and the seed potatoes are placed in open crates, or in layers in slated bins, or in small piles on the floor. For each one thousand cubic feet of space, three pints of formaldehyde $(40 \%)$ pure and twenty-three ounces of potassium permanganate should be used. The latter is placed in deep wooden or earthen dishes, and the formaldehyde is poured on the salt crystals, the disinfector rushing out locking the door at once. The fumigated house is kept closed for twenty-four hours.

Spraying. The field diseases such as early and late blight, tip burn, and, in fact, all other foliage diseases except leaf roll and curly dwarf may be controlled by spraying. Lime sulphur in any form has failed to give satisfactory results. The spray recommended is 5-5-5o Bordeaux mixture. To each one hundred gallons of Bordeaux, add one pound of Paris green or six pounds of lead arsenate paste. Spraying should begin when the plants are about six inches high, and from 3 to 6 applications should be given, depending on the climatic conditions. To yield the desired result, spraying must be applied in a thorough manner. It is a good form of insurance, as has been demonstrated by many workers. Table 16 by Lutman ${ }^{1}$ clearly shows the profits to be derived from spraying.

${ }^{x}$ Lutman, B. F.,Vermont Agr. Expt. Sta. Bul. 159:216, 296, 191 r. 


\author{
TABLE $\mathrm{I} 6$
}

Gains from the Use of Bordeanx Mixture on Late Potatoes. 20 Years' Experiments.

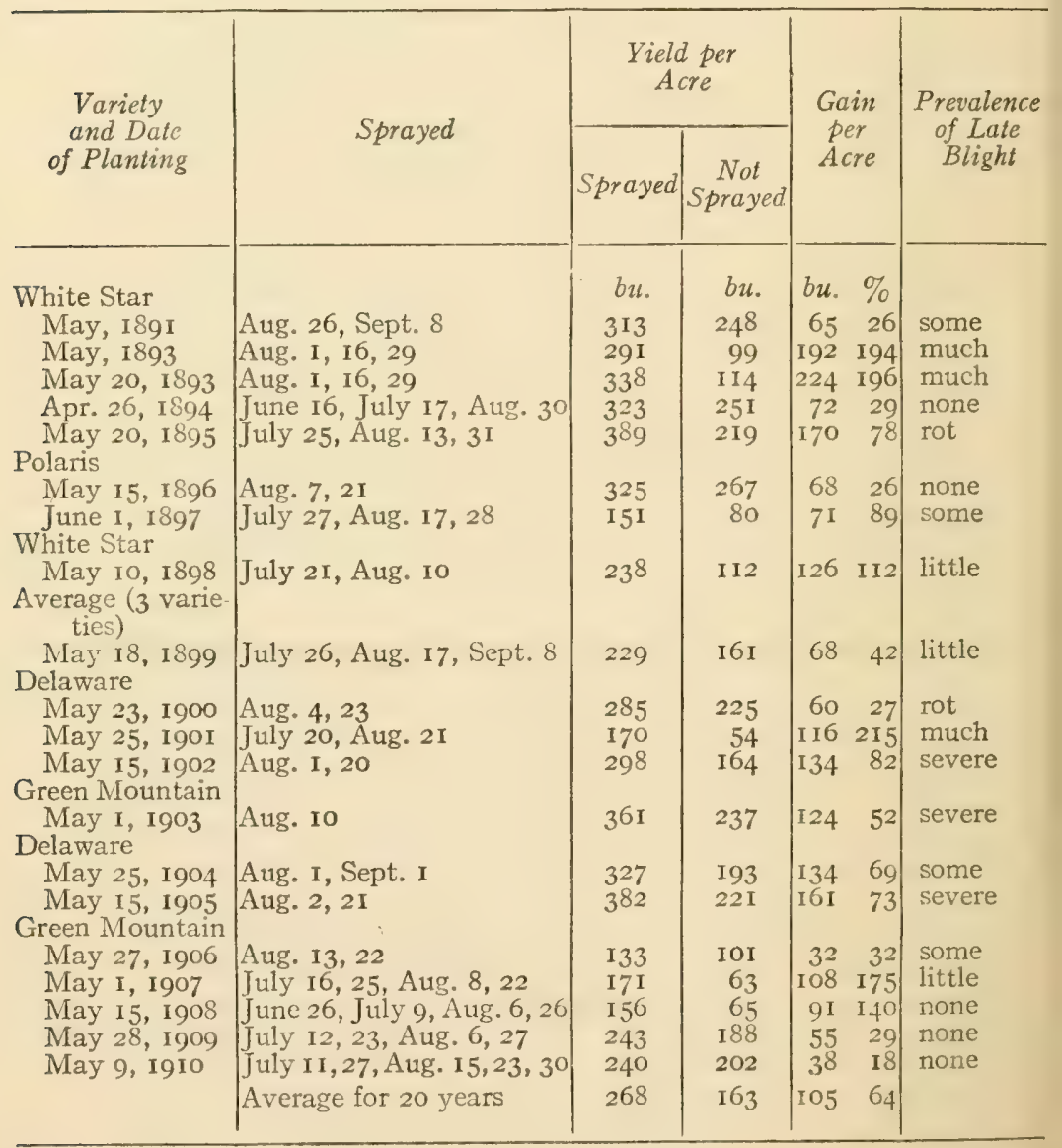




\section{Family Solanaceæ}

DISEASES OF THE TOMATO (Lycopersicum esculentum)

Like potatoes, tomatoes are subject to numerous diseases which the trucker cannot afford to ignore if he is to reap the greatest profits from his crop.

\section{Hollow STEM}

\section{Cause Physiological.}

Hollow stem is a trouble manifested on seedlings in the bed, or after transplanting. The central portion of the head of the plant remains green while the lower leaves turn yellow. In severe cases, affected plants fall over as in damping off, with the absence, however, of signs of rotting. Such plants when examined are found to have hollow stems and seem too weak to stand up.

Cause. There are several causes, all of which when combined may lead up to the hollow stem. I. A highly nitrogenous fertilizer applied to the seed bed to force the seedlings. 2. An abundance of water supply to make the fertilizer quickly available. 3. Sowing seeds of a rapid growing variety. 4. Transplanting without hardening off. 5. Transplanting into a dry soil.

Control. It is evident from what has been said that the fertilizer in the seed bed should be well balanced. Care should be taken to prevent the seedling from becoming leggy, and to see that they are properly hardened before transplanting. The Stone and its related varieties seem to be more resistant to hollow 
stem. On the other hand, the Dwarf Champion seems to be especially susceptible to hollow stem.

\section{BLossom End Rot}

\section{Cause Unknoren.}

Blossom end rot, also known as point end rot, may be found wherever tomatoes are grown. It is a disease of the fruit only. In some seasons fifty per cent. or more of the fruit crop is ruined by it. It seems to be more serious in dry weather and on light soils.

Symptoms. Infection is manifested as a watersoaked spot at the blossom end of the fruit (fig. 64 $\mathrm{b}-\mathrm{c})$. The size of the spot may be that of a pin-head, or it may spread so rapidly as to involve half of the tomato. A few days later, the water-soaked spot becomes black and leathery and ceases to make further progress. Complete rotting of the fruit may be brought about by secondary invasions.

Plants subject to frequent slight wilting produce a greater number of defective fruits. There seems no doubt but that the water supply in the soil is an important factor in limiting or increasing blossom end rot. The factors of drainage and cultivation are therefore important considerations. Although dry soils and drought favor the increase of the disease, yet the condition of health of the plant itself seems more important than the decrease of water supply.

The use of fertilizers, too, seems to influence the trouble. Heavy applications of manure or of potash seem to increase the rot, as do fertilizers in the form of 

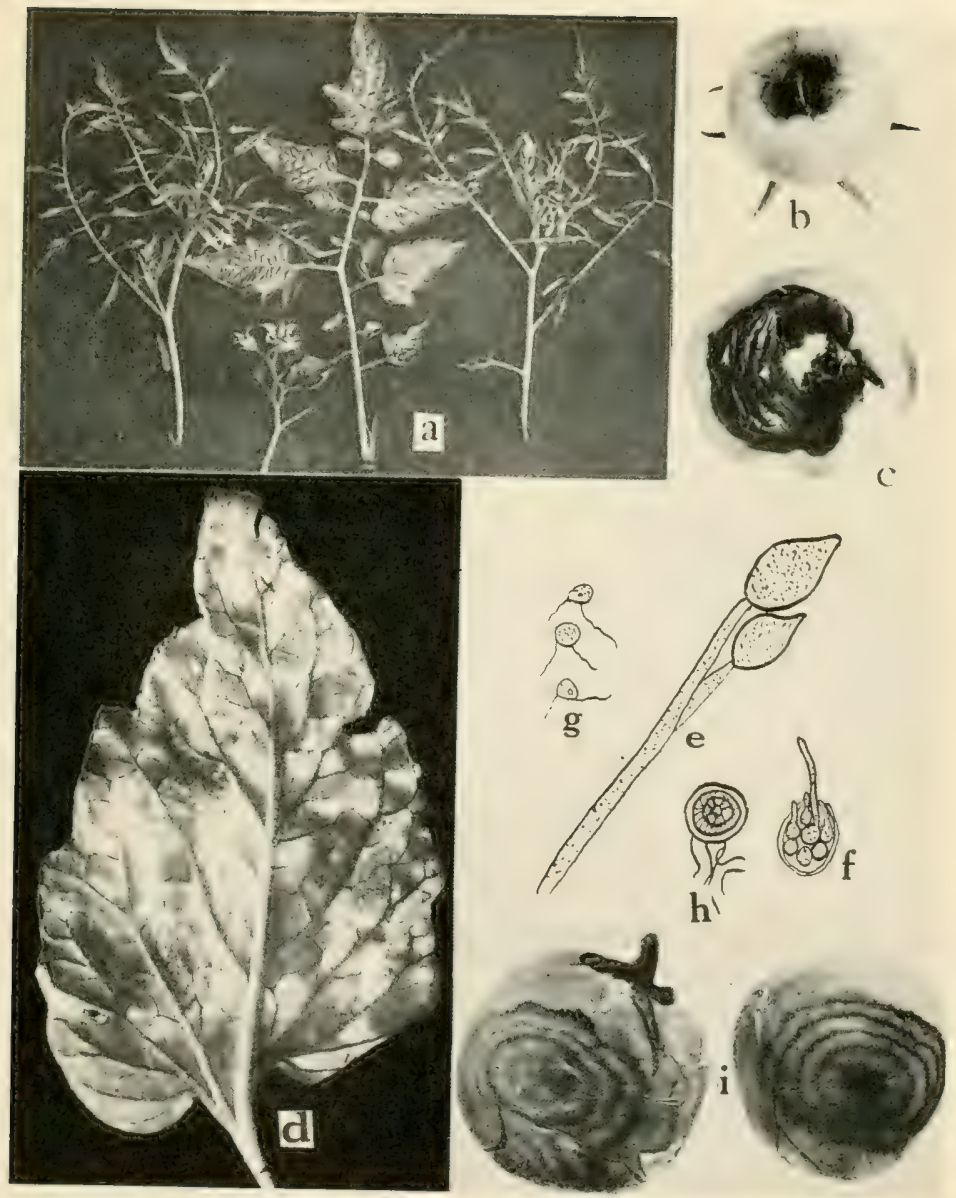

Fig. 64. Tomato Diseases.

a. Various stages of mosaic on foliage, $b$. c. blossom end rot, $d$. downy mildew, Phytophthora infestans, $e$. conidia of buck-eye rot Phytophthora terrestris, fonidia of $P$. terresiris, germinating by means of zoospores, $g$. zoospores; $h$. mature oospores of $P$. terrestris, $i$. buck-eye rot (e. to $i$. after Sherbakoff). 



\section{Family Solanaceæ}

ammonium compounds. This is especially true on sandy loams. On the other hand, nitrate of soda or lime seems to check blossom end rot.

\section{SUNBURN}

Tomato fruits are often burned while they are on the vines by strong sunlight beating on the exposed fruit. This results in a scalding of certain parts (fig. $67 \mathrm{e})$, loss of color, and a local drying which produces white spots with a dry peppery appearance. Such fruit is unfit for the market. Sunburn may also result from other and indirect causes. In dry seasons the tomato cannot supply the necessary supply of moisture to the foliage and fruit. As a result, they become weakened and contain numerous starved areas which dry up when exposed to strong sunlight. The same result may also be brought about by the indirect action of the numerous leaf and roct diseases.

Control. In sections where sunburn is prevalent, it is advisable to plant tomato varieties with dense foliage. The plants should be put out as early as possible so that the vines may attain their maximum before hot weather sets in. The soil should be properly fertilized, and sufficient humus incorporated to hold the moisture during periods of high temperatures. Irrigation should be practiced wherever possible.

\section{Mosaic}

Cause Unknown.

A lengthy discussion on mosaic has already been given on p. 83. Mosaic on tomato is a common field 
trouble, conspicuous on stalks, fruit, and leaves. On the leaves it is manifested as a mottling of yellow areas on the tissue between the veins. The unequal growth of tissue causes the leaves to warp and grow unevenly. In severe cases the normal leaflets are replaced by a filform or fern-like structure (fig. 64 a), with a striking dissected form. The blossom of the diseased plant usually drops off, and the few setting fruits are small and deformed.

\section{SOUTHERN WILT}

Caused by Pseudomonas solanacearum Ew. Sm.

Southern wilt has a wide distribution. As its name indicates, it is generally found in the more southern States. It is generally severe in Texas, Alabama, Georgia, Mississippi, North and South Carolina, Florida, Maryland, Virginia, New York, and Connecticut.

Symptoms. Infected plants usually wilt rapidly without losing their green color. In large leaves, the main axis is bent downward in a drooping way. With the young plants the stems and foliage also droop and shrivel. The vascular system of such plants is browned, indicating the presence of the causative organism within. In cutting across a freshly wilted stem, a dirty white to brownish white slime that is not sticky is seen to ooze out. In soft and rapidly growing plants, the whole pith is often converted into a watery slime. In tomato and eggplants the disease seldom attacks the fruit but is 


\section{Family Solanaceæ}

localized to the vegetative parts. With the Irish potato, the disease works underground where it also penetrates the tubers. These show a yellowing and blackening of the veins, finally giving way to a soft rot. On squeezing, a creamy exudate oozes out from the diseased veins.

Southern wilt attacks not only the tomato, potato, and eggplant, but it also causes a serious disease on the tobacco, peanut, nasturtium, ragweed, impatience, verbena,- - plants which belong to families other than the Solanaceæ.

The Organism. Psendomonas solanacearum is a medium-sized rod, with rounded ends and motile by means of polar flagella. Pseudo-zoöglœæ are common in old cultures. No spores are formed; on agaragar, colonies are white, then dirty white, afterwards becoming brown with age. The organism does not liquefy gelatin and produces no gas.

Control. Crop rotation is the safest method of control. All crops subject to wilt, such as potato and eggplant should be left out from the rotation system.

Damping off, see Pythium, p. 43.

\section{Late Blight}

Caused by Phytophthora infestans (Mont.) De By.

Late blight usually attachs the fall tomato crop. It is especially prevalent during rinily wcather, where it may even be found in the seed bed. The trouble 
may be found wherever Irish potatoes are known to suffer from late blight, since the tomato and potato blight are caused by the same fungus.

Symptoms. Affected plants appear as though killed by frost. The disease first shows itself as small blackened areas on the leaves (fig. 64 d), stems, and fruits. These rapidly increase in size and cause premature death of the affected host. Fruits which may not show signs of disease will develop the trouble in transit if coming from infected fields. For a description of the causative fungus, see late blight of potato, p. 322. Late blight of tomatoes may be controlled by spraying. The best results are obtained by using $5^{-5}-50$ Bordeaux. Spraying should begin with the rainy season. The ripe fruit should be cleaned by wiping off the Bordeaux stains with a dry cloth.

\section{BUCKEYE Rot}

\section{Caused by Phytophthora terrestria Sherb.}

Buckeye rot is a disease which attacks the fruit. The trouble seems to be new and has been recently described by Sherbakoff. ${ }^{\text {I }}$ So far as is known the disease has appeared only in Florida.

Symptoms. The disease, as the name indicates, appears as a pale to dark greenish-brown zonate spots on the fruit (fig. 64 i). The rot is hard and somewhat dry when the fruit is green, but becomes softer as the

${ }^{1}$ Sherbakoff, C. D., Phytopath. 7 : I19-129, 1917. 


\section{Family Solanaceæ}

tomato ripens. It usually begins at a point where the fruit touches the ground, which is most commonly at the blossom end, and might be mistaken for blossom end rot were it not for the characteristic zonations.

The Organisms. The mycelium is at first continuous, then septate. Conidia (fig. $64 \mathrm{e}-\mathrm{g}$ ) germinate by means of swarm spores. Chlamydospores are common, oöspores (fig. 64 h) common on cornmeal agar. Besides tomato fruit, $P$. terrestria causes a foot rot of citrus trees and a stem rot of lupines.

Control. Tomato plants, as far as possible, should be staked. By preventing the fruit from coming into direct contact with the soil, infection will be avoided. Fruit destined for distant markets should not be packed as soon as it is brought in from the field. If possible it should be kept a few days to allow for possible rot to develop so that the affected ones may be culled out and destroyed.

\section{YEAST RoT}

\section{Caused by Nematospora lycopersici Sch.}

Yeast rot, as the name indicates, is induced by a parasitic yeast. This little known trouble has been investigated by Schneider. ${ }^{x}$

Symptoms. The disease is indicated by a slightly depressed reddish-brown spot. The epidermal area of the affected spot becomes indurated and shriveled.

${ }^{1}$ Schneider, A., Phytopath. 6 :395-399, 1916; and in Phytopath. $7: 52-53,1917$. 


\section{Diseases of Truck Crops}

The greatest amount of rotting occurs within the fruit.

The Organism. The parasite is a typical yeast. It produces arthrospores of non-gametic origin, asci of gametic origin (fig. $65 \mathrm{a}-\mathrm{c}$ ). The ascospores are formed in two groups of four each, slender, oneseptate, and each containing a motionless flagellum. Little is known about the control of this disease.

\section{Fruit Rot}

\section{Caused by Phoma destructiva Plowr.}

Fruit rot is found in Cuba, Florida, South Carolina, Kansas, and New York. If not checked, it will no doubt spread rapidly and add to the burdens of losses from other troubles.

Symptoms. On the fruit the disease is characterized by conspicuous dark spots (fig. 65 e) on the side and at the stem end of both green and mature fruit. On the surface of the largest spots numerous dark pycnidia may be seen. Besides attacking the fruit, the disease may also attack the foliage, causing dark spots which resemble those on the fruit (fig. 65 d). Affected leaves shrivel, droop, and sometimes drop off. The disease seems to be unable to attack potatoes or peppers.

The Organism. The mycelium (fig. $65 \mathrm{~h}$ ) forms a dense network of fungal threads within the host tissue. The pycnidia (fig. $65 \mathrm{~g}$ ) are subglobose, carbonaceous, smooth, slightly papillate, and with a distinct central pore. The pycnidia are scattered and 

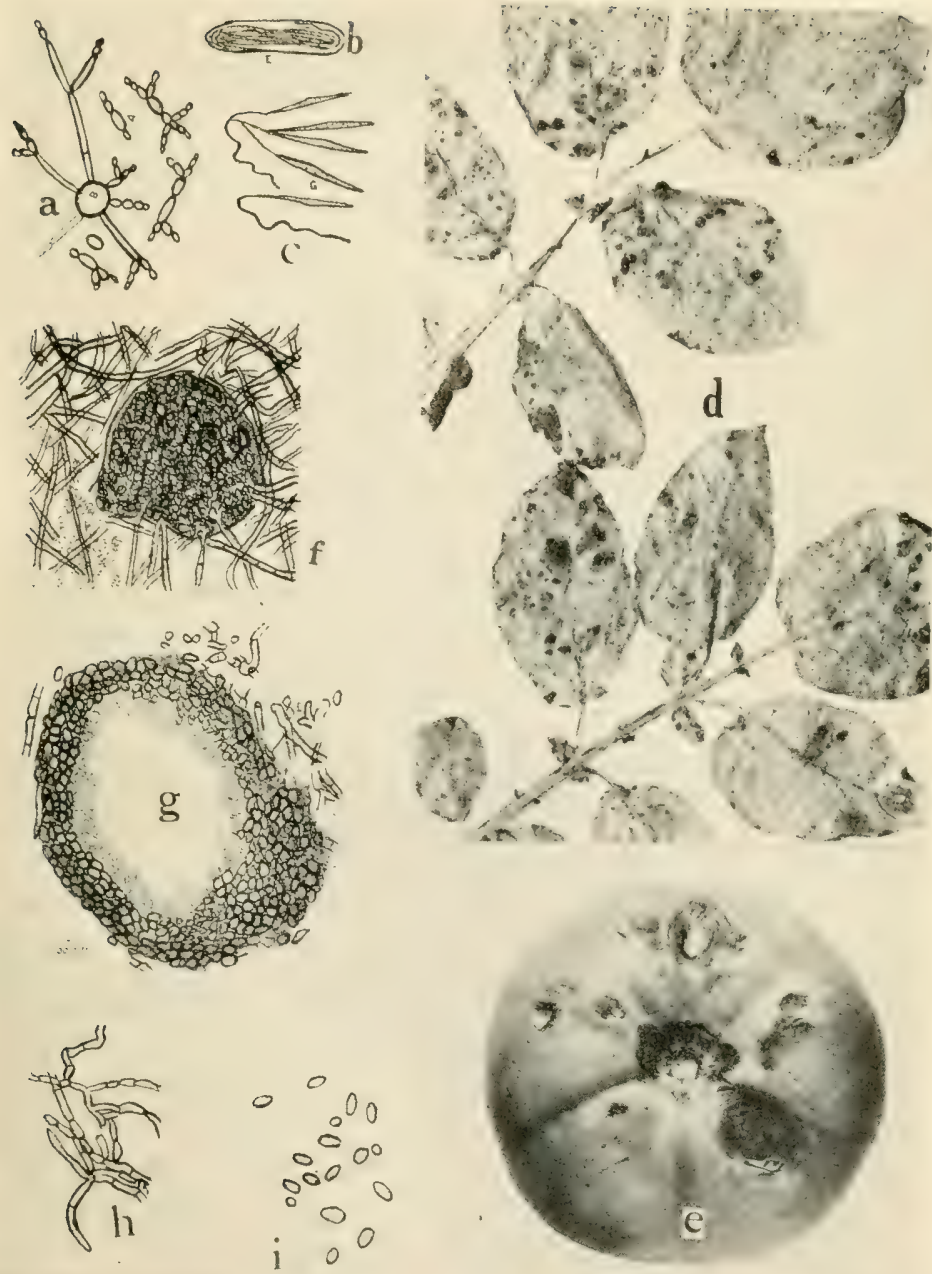

Fig. 65. Tomato Diseases.

$a$. Various forms of vegretistive cells of the yeast rot fungus, $b$. ascus, ascospore rot on fruit, $f$ t fungus ( $a$. to $c$. after Schneider), d. Phoma rot on foliage, $e$. Phoma of the Phoma fungus, $b$ of the Phoma rot organism, $g$. cross-section of a pycnidium 



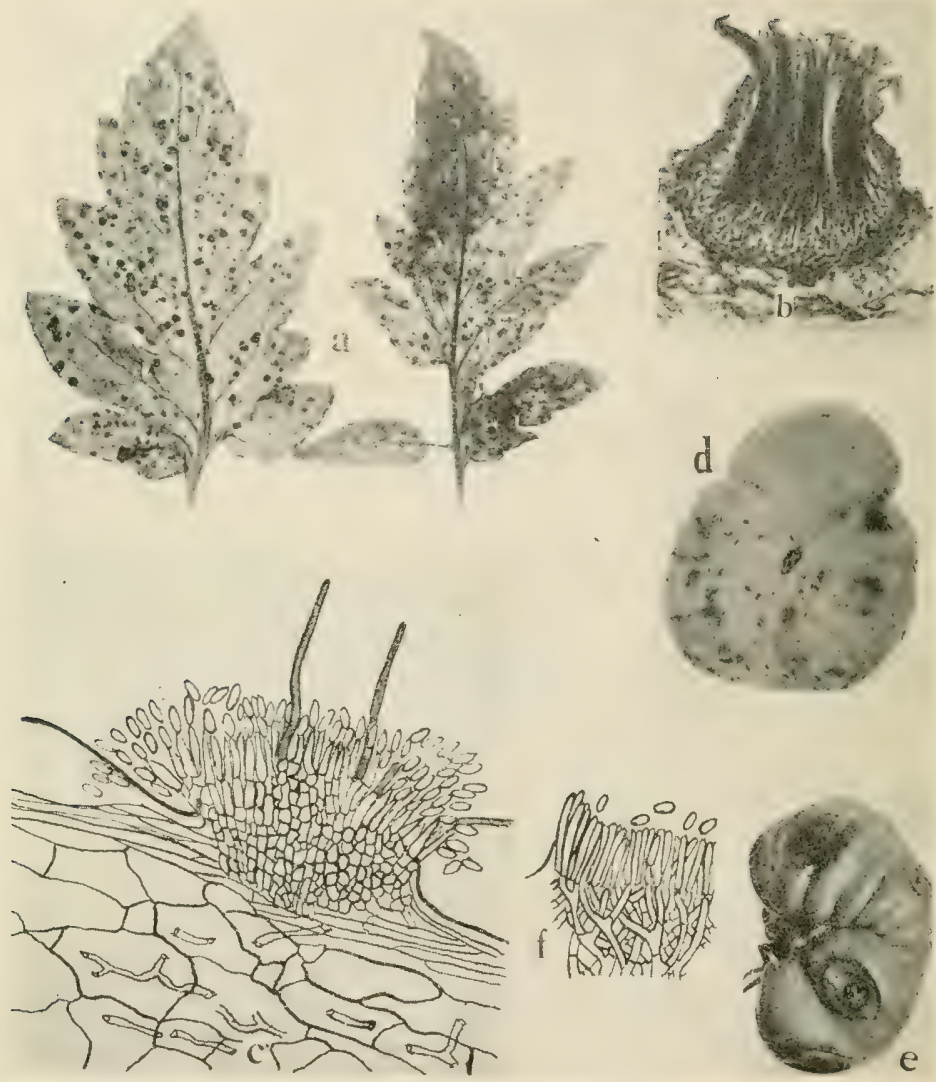

Fig. 66. Tomato Diseases.

$a$. Septoria leaf spot, $b$. section through a pycnidium of Seploria lycopersici (after Levin), $c$. section through acervulus of Colletotrichum phomoides (after Venus Pool), $d$. and $e$. Melanconium rot, $f$. section through an acervulus of the Melanconium fungus ( $d$. to $f$. after Tisdale). 


\section{Family Solanaceæ}

possess a thin wall; the pycnospores (fig. 65 i) are hyalin and one-celled. Jamieson ${ }^{\mathrm{I}}$ failed to find an ascus or winter stage. Should the disease become serious, spraying with Bordeaux is recommended.

\section{LEAF SPOT}

\section{Caused by Septoria lycopersici Speg.}

The disease is generally known as late blight, or blight, both of which names are misleading. Recent investigations by Levin ${ }^{2}$ confirm the belief that leaf spot is widely distributed. It is found in Alabama, California, Connecticut, Delaware, Illinois, Louisiana, Massachusetts, Maryland, Michigan, Missouri, New Jersey, New York, North Carolina, Ohio, Pennsylvania, Virginia, Tennessee, Texas, and Wisconsin.

Symptoms. The first indications of the disease are minute water-soaked spots on the underside of the leaves. With time these increase in size and become circular in outline with a definite margin (fig. 65 a). The spots become hard, dry, dark, and shrunken, and when numerous they coalesce into large blotches, involving the entire leaflets and leaves; the latter soon droop, dry, and cling to the stalk, until broken off by the wind or by any other jar. Within the spots are formed minute black glistening pycnidia and the spores exude as yellowish mucilaginous drops.

On the stems the spots are similar to those on the leaves, although they are not so clearly defined, nor

I Jamieson, C. O., U. S. Dept. Agr. Research, 4 : I-20, 1915.

${ }^{2}$ Levin, E., Michigan Agr. Expt. Sta. Tech. Bul. 25 : 7-5I, 1916. 


\section{8 \\ Diseases of Truck Crops}

do they work in deep to form cankers. Spots may also occur on the calyx and on the fruit. The disease, however, is usually a foliage trouble. Of the more resistant varieties may be mentioned Mikado, King Humbert, Wonder of the Market, and Up to Date. Of the medium resistant varieties may be mentioned Alice Roosevelt, President Garfield, Prelude, Ponderosa, and Magnum Bonum. The Trophy and Ficarazzi are very susceptible varieties.

The Organism. The mycelium of Septoria lycopersici is hyalin, septate. The pycnidia are globose (fig. 66 b); the pycnospores are hyalin, needle-shaped, many-septate, and lose their vitality when exposed to ordinary room temperature for about four days.

Control. The disease often starts on the seedlings in the seed bed. It is important therefore to start with a clean seed bed soil. Seedlings should be sprayed with 4-4-50 Bordeaux before being transplanted. In the field the plant should not be worked in wet weather, or when covered with dew. Spraying with 4-4-5o Bordeaux is recommended, especially in wet weather. Since the carsative fungus is carried over in pycnidia on dead leaves or stems, the burning of all trash becomes necessary.

\section{ANTHRACNOSE}

Caused by Colletotrichum phomoides (Sacc.) Chester.

Anthracnose is a disease to which ripe tomatoes are especially subject. The losses are often considerable both in the field and in transit. 


\section{Family Solanaceæ}

Symptoms. The spots are at first small, but they soon enlarge. They are discolored, sunken, wrinkled, with distinct central zones, closely resembling the anthracnose of apple. In moist weather the spots become coated with a salmon-colored layer which consists of the spores of the fungus.

The Organism. In structure $C$. phomoides is little different from other Colletotrichums. The setæ of the fungus are very numerous, thus giving the acervuli a black appearance. The conidiophores are short, and the conidia, oblong, hyalin, and one-celled (fig. $66 \mathrm{c}$ ).

Control. Anthracnose depends upon wet weather for its activity. Spraying with Bordeaux is recommended.

\section{MELANCONIUM Ror}

Caused by Melanconium Tisdale Taub.

Melanconium rot is a disease which attacks tomato fruit. Tisdale ${ }^{\mathrm{I}}$ was the first to call attention to this trouble which he attributed to a species of Melanconium. The writer has often had occasion to collect this disease on tomatoes in the Bryan (Texas) market. The origin of the fruits could not be exactly ascertained, but they were supposed to come from Florida, while others were home-grown.

Infection experiments by the author affirm the parasitic nature of the organism, which is temporarily named Melanconium Tisdale Taubenhaus.

'Tisdale, W. H., Phytopath. 6 : 390-394, 1916. 
Symptoms. The disease is found both on partly green and on ripe fruit. The spots are brown to black, small, irregular, somewhat sunken, dry, and superficial, with the centers slightly raised (fig. 66 d-e).

The Organism. The mycelium is white, much branched, and closely septate, the septation however being largely influenced by food supply. The conidiophores are straight, short, closely packed together, arising from a basal pseudostroma (fig. 66 f). The conidia are borne singly at the apex of each conidiophore. The conidia are Phoma-like, minute, cylindrical, slightly rounded at both ends, greenish white in color, and germinate by means of a single germ tube produced at either end.

Control. Nothing seems to be known of the control of this trouble. Little is known of its distribution. But since it has been found in Wisconsin by Tisdale, and in Texas by the writer, it seems to be of wider distribution than is generally recognized. Possibly it is usually mistaken for other tomato troubles.

\section{LEAF MOLd}

\section{Caused by Cladosporium fulvum Cke.}

Leaf mold is a tomato trouble which is very troublesome under greenhouse conditions. In some of the Southern States, however, it is found on field tomatoes. The disease is favored by damp, muggy weather.

Symptoms. The mold appears as rusty cinnamon, 



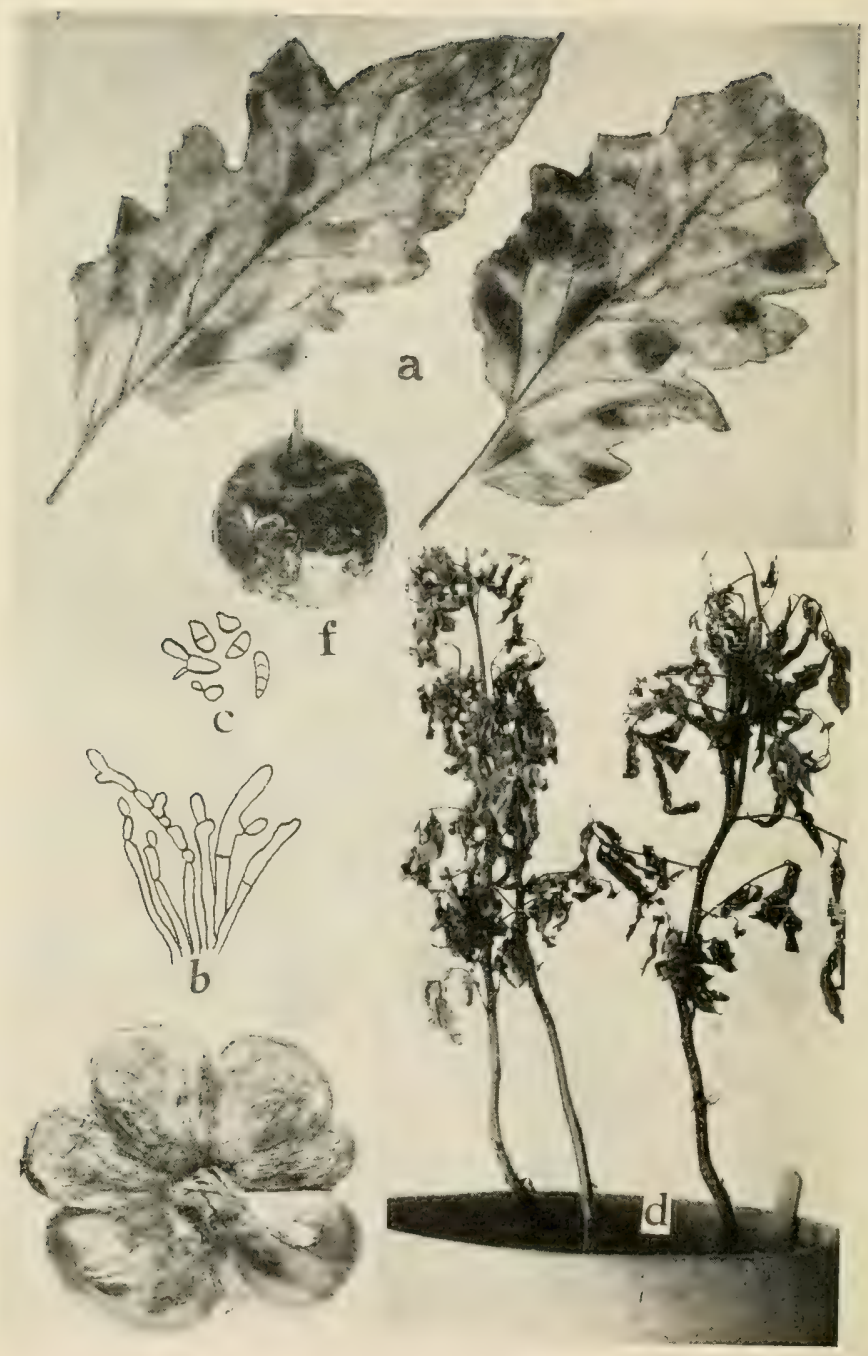

Fig. 67. Tomato Diseases.

$a$. Cladosporium leaf mold, b. conidiophores of cladosporium fulvum, c. conidia of C. fulvum, (b. and $c$. after Southworth), $d$. two plants artificially infected with Sclerotium Rolfsii, e. sunburn, $f$. Macrosporium rot. 


\section{Family Solanaceæ}

irregular, feltlike spots on the underside of the leaf (fig. 67 a), the upper part of which turns brown, then black, and the affected foliage finally curls and dies.

Control. Careful spraying with Bordeaux mixture will help to keep it in check.

\section{Black Rot}

Caused by Macrosporium solani E. and M.

Black rot is a fruit trouble commonly found in dry weather and generally attacking ripe tomatoes. The spots are black, dry, slightly wrinkled, and extending deep into the interior tissue (fig. $67 \mathrm{f}$ ).

The mycelium of the fungus is at first hyalin to brown, then black. The conidiophores and conidia are dark, with three to six transverse and one to two longitudinal septa.

\section{Sleeping Sickness}

Caused by Fusarium lycopersici Sacc.

Sleeping sickness is one of the most serious of tomato troubles. It is prevalent in New Jersey, Delaware, Maryland, Virginia, and in nearly every Southern State.

Symptoms. Infected plants become pale, the leaves wilt and droop and never recover (fig. 68). The droopiness of a diseased plant gives it a sleepy appearance, hence the name of the disease. On splitting open a diseased root or stem, the interior vascular bundles will be found to be brown. 
The Organism. F. lycopersici is a soil fungus which may be introduced with infected manure or seedlings. The fungus greatly resembles $\mathrm{F}$. oxysporum. The conidia are hyalin to yellowish, falcate, acute.

Control. Spraying will not control this malady since the parasite lives internally and cannot be reached by external applications. Long rotations in which the land is given a rest from tomatoes are recommended for at least ten years. The selection of resistant varieties may offer a means of conquering this trouble.

\section{YELLOW BLIGHT}

Caused by Fusarium orthoceras App. and Woll.; Fusarium oxysporum Schl.

This disease is common on tomatoes in the Pacific Northwest. It has been investigated by Humphrey ${ }^{\mathrm{r}}$ and found by him to be caused by the two species of Fusaria above mentioned.

Symptoms. It does not usually manifest itself until late, when the plants are blooming, or even when the fruits are partly formed. At first there is a slight twisting of the entire leaf, accompanied by a purpling of the veins. This is also followed by a rolling inward, and by drooping, but not wilting, of the leaflets and leaves. The foliage then take on glaucous greenish color, the fruit ripen prematurely,

${ }^{5}$ Humphrey, H. B., Washington Agr. Expt. Sta. Bul. 115 : I-22, 1914. 


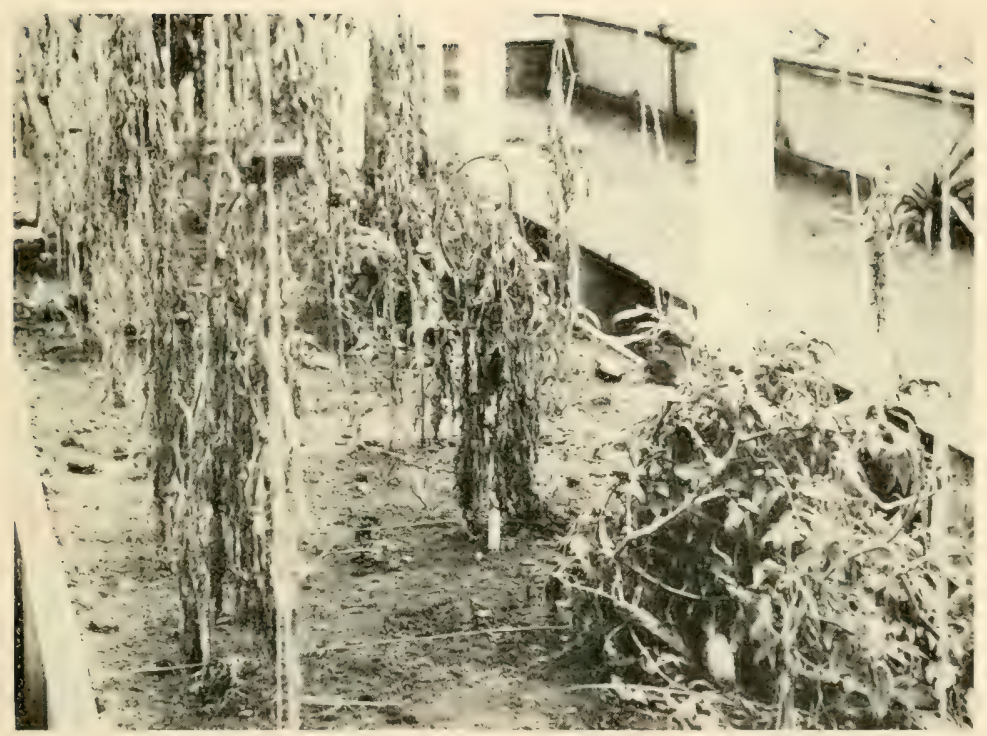

Fig. 68. Slemping Sickness of Tomato. 

but the pulp lacks in flavor and taste. Affected plants cease growing, cxlibit a llin, spindly growth, and cease producing. The disease is confined to the root systen, which is slowly destroyed; it becomes most virulent with the high temperatures. Both Fusarium orthoceras and $F$. oxy'sportm also induce a disease on the potato, see p. 327 .

Control. Both Fusaria produce an abundance of chlamydospores in the soil, thus maling the eradication of the disease vcry difficult. Long rotations seem to have no effect in controlling the trouble. Injuring the rootlets at transplanting secms to increase the amount of diseased plants. Definite methods of control are as yet lacking.

\section{RHIzoctonia Fruit Rot}

Caused by Corlicium vagum $\mathrm{B}$. and $\mathrm{C}$. var. solani Burt.

This form of rot makes its appearance at the place where the fruit touches the ground. The diseased area becomes chocolatc-colored, and the epidermis slightly wrinkled. The rot extends into the interior pulp turning it brown and dry. For further description of the causative fungus, see p. 45 .

Southern Blight (fig. 67 d), see Pepper, p. 305.

Root Knot, see Nematone, p. 49. 


\section{CHAPTER XXII}

\section{FAMILY UMBELLIFERE}

THIs family contains trucking crops which are of considerable economic importance. Of these may be mentioned the carrot, celery, parsley, and parsnip. According to the Thirteenth census of the United States, the area devoted to carrots in the United States in 1909 was 3764 acres, and the total crop was valued at $\$ 473,499$, with New York leading in acreage. The area devoted to celery in I909 was I5,863 acres, and the total crop estimated at $\$ 3,922,848$. Of the leading celery States may be mentioned New York, California, Michigan, Ohio, Massachusetts, and Pennsylvania. The area in parsley in 1909 was 192 acres, and the crop estimated at $\$ 27,18 \mathrm{I}$. This crop is largely grown in Louisiana. The area in parsnip in I909 was 722 acres, and the crop estimated at \$102,674. Parsnip is grown mainly in New York, Massachusetts, Illinois, and Michigan.

\section{DISEASES OF THE CARROT (Daucus carota)}

Soft Rot, see Cabbage, p. I92.

Root Rot, see RHizoctonia, p. 45. 
DISEASES OF TIIE CELERY (A pium graveolens)

Soft Rot, see CAbbage, p. 192.

RusT

Caused by Puccinia bullata (Pers.) Schr.

This rust resembles the rust of asparagus. The disease is unimportant, and is scldom met with in the United States.

\section{LeAF Spot}

Caused by Phyllosicta apii Hals.

Leaf spot is a disease of minor importance. The trouble is characterized by dull brown patches on any part of the leaf. Spraying for late blight will also control leaf spot.

\section{LATE Blight}

Caused by Septoria petroselini Desm. var. apii $\mathrm{Br}$. and Cav.

Late blight is perhaps one of the worst diseases of celery. It may be found wherever celery is grown. In California, the greatest money losses to this crop are attributed to late blight.

Symptoms. The disease first attacks the lower 
leaves of the stalk, producing irregular spots without a definite boundary line. When the spots become numerous the foliage withers and dries up (fig. $69 \mathrm{a}$, b, c, d). The disease attacks the leaves as well as the stallis, rendering the affected plants uscless so far as market is concerned. In storage, plants affected with late blight will keep very poorly or rot altogether.

The Organism. The fungus mycelium is hyalin, septate. The pycnidia (fig. 69 e) are olivaceous, prominent, and abundant in the spots. The pycnidia are filifom, straight or curved, hyalin, and many septate.

Control. According to Rogers, ${ }^{x}$ late blight may be controlicd by spraying with 5-6-50 Bordeaux.

The first two applications should be given the seedlings in the seed bed. In the field the first spraying should be given about six wecks after transplanting and continued once a month until the rainy season is over. With the advent of heavy rains, spraying should be done once every two wcels. Besides spraying, shading also seems to keep the disease in check. In spraying celcry great care should be exercised to use a sprayer which is operated by a pressure of not less than I50 pounds. Where this is overlooked, large drops of the Borcleaux mixture may be deposited on the leaves and stalls, which upon drying may deposit copper salt sufficient to harm the consumer. Sprayed celery should be carefully washed and dried before shipping.

I Rogers, S. S., California Agr. Expt. Stat. Bul. 208 : 83-I I5, I9I r. 

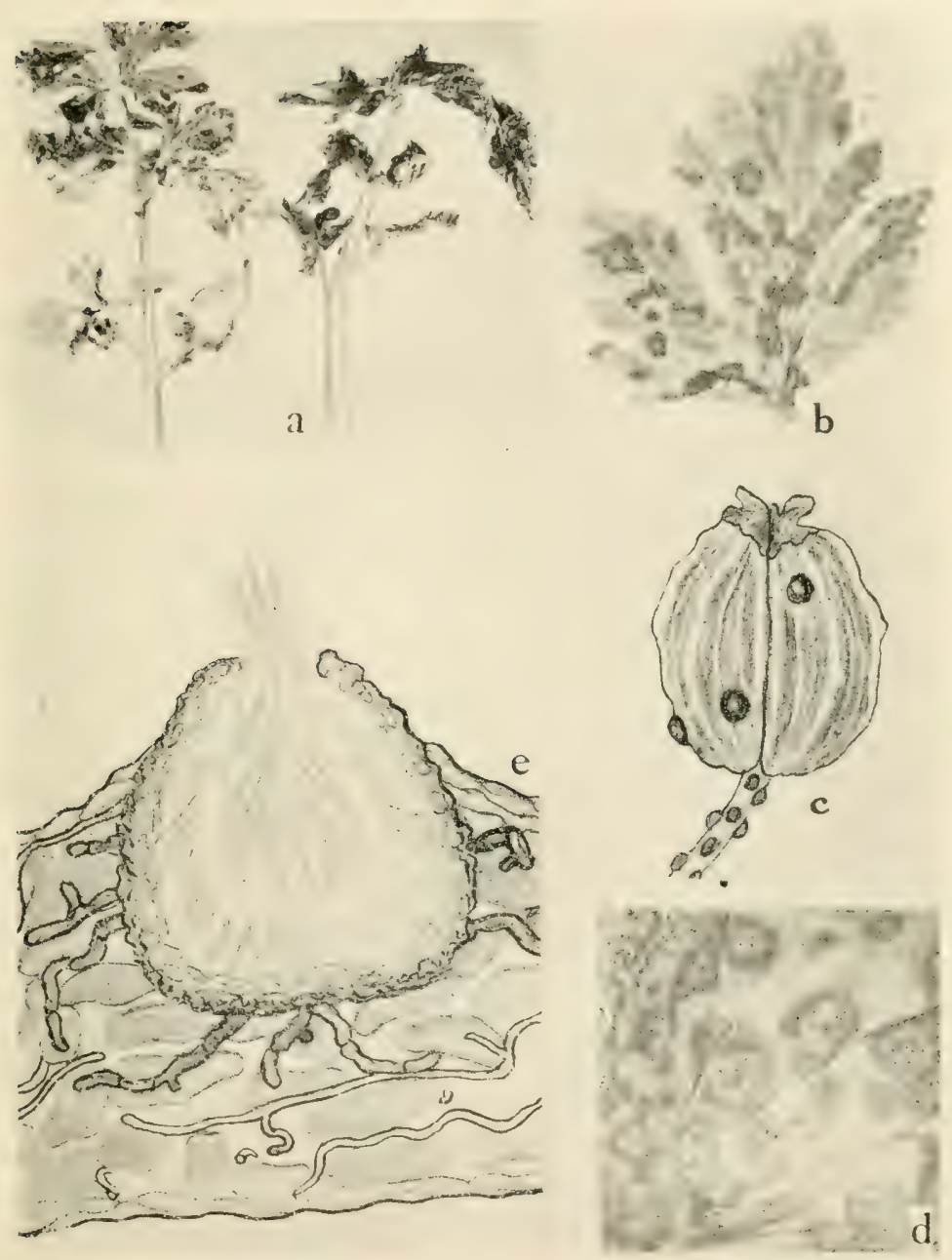

Fig. 69. Celery Diseases.

$a$. Septoria leaf spot on leaf, $b$. Septoria leaf spot on leaflet, $c$. Septoria lesions on celery seed, $d$. Septoria spots showing pycnidial bodies, $e$. cross section showing pyncidium and pycnospores of Seploria petroselini $(a, c$, and $e$ after Coons and Levin). 



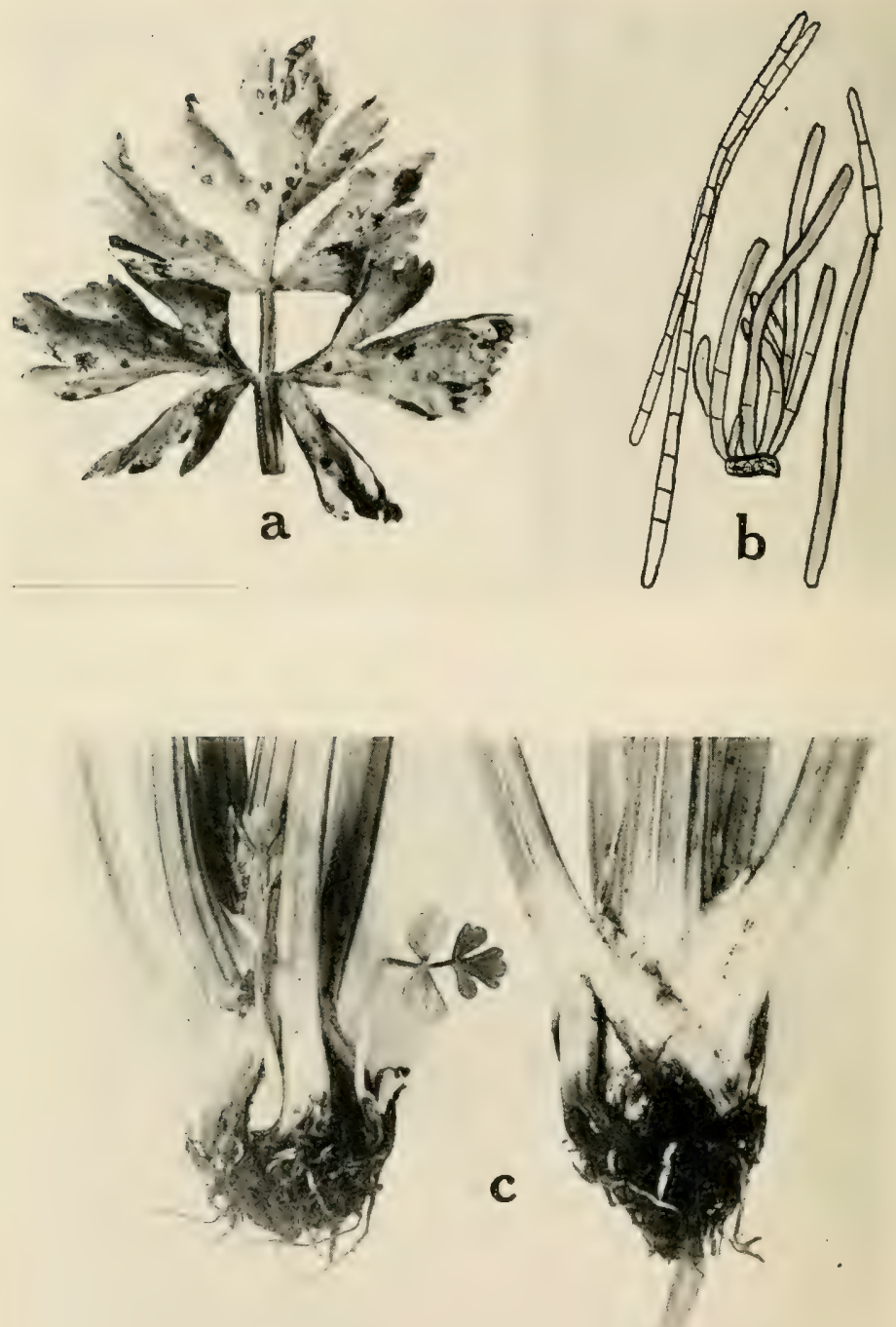

Fig. 70. Celery Diseases.

$a$. Cercospora leaf spot, $b$. conidiophores and conidia of Cercospora apii (afterDuggar and Baily), $c$. Rhizoctonia root rot. 


\section{Family Umbelliferæ}

\section{EARLY BLight}

\section{Caused by Cercospora apii Fr.}

Early blight is as common a disease as the late blight. In some seasons of heavy rains it is very destructive. It appears carly and affected plants have little value for market purposes.

Sympioms. The trouble first appears on the outer leaves as pale blotches visible on both sides of the affected parts. The spots are irregular, angular in outline, limited apparently by the leaf veins, with slichily raised borders (fig. $70 \mathrm{a}-\mathrm{b}$ ). The spots later turn brown to ashy white.

Controi. Early blight may be controlled by spraying with Bordeaux mixture as with late blight. The Boston Market and Gold Heart should be avoiced because of their susceptibility to the disease. The White Plume seems to be resistant.

\section{DISEASES OF PARSLEY (Carum petroselinum)}

Drop, see LETTUCE, p. I43.

Late Bligit, see Celery, p. 355.

DISEASES OF THE PARSNIP (Pastinaca sativa)

Early Blight, see Celery, p. 357.

Root Rot (fig. 70 c), see RHizoctonia, p. 45.

\section{WEEDS}

Of the more important Umbolliferous weeds which truckers have to contend with may be mentioncd 
Wild Carrot (Daucus carsta), wild parsnip (Pastinaca sativa), and poison hemlock (Cornium maculatum). All of these weeds should be eradicated by clean culture. The first two especially help to carry the fungus of early blight, Cercospora apii. 


\section{PART IV}





\section{CHAPTER XXIII}

\section{METHODS OF CONTROL}

Fron the preceding chapters the trucker will be made well aware of the many crop diseases he has to deal with and of the numerous methods at hand to help him to control or keep in check most of the troubles. The methods of control may be classified as follows:

(r) Soil sterilization. This method has been discussed under Chapter IV, page 53.

(2) Seed treatment taken up in Chapter VII.

(3) Spraying.

(4) Crop rotation.

(5) Devclopment of resistant varieties.

\section{Spraying}

While the orchardist has learned the necessity of spraying, it is doubtful whether truckers have sufficiently realized its value. Spraying has two aims: to kill the insect and animal pests, and to control fungous diseases. The substances which are uscd for the one purpose are without effect on the other. 


\section{INSECTICIDES}

All animal and insect pests are best controlled by the use of poisonous mixtures applied in the form of liquid sprays or of powders. Insecticides may be classified as internal or stomach poisons, and external or contact poisons.

(a) Stomach Poisons. Paris green is one of the oldest of stomach poisons. When chemically pure, it is composed of copper oxide, acetic acid, and arsenious acid. It destroys cutworms, caterpillars, beetles, grubs, slugs, etc. It should be applied preferably as a liquid, using one pound of the poison and two pounds of lime to two hundred gallons of water. It tends to sink to the bottom of this mixture, unless constantly stirred while being applied. This chemical is often adulterated with white arsenic, causing it to scorch the treated plants badly. Therefore for truck crops the use of arsenate of lead is to be preferred, since it is less liable to scorch the foliage, and it adheres better. Its chemical composition consists of acetate of lead and arsenate of soda. It is applied to the best advantage as a liquid, using about three pounds of powdered arsenate or five pounds of paste arsenate to one hundred gallons of water.

Arsenite of zinc may also be used. It is a very finely divided fluffy white powder which distributes and adheres well to the foliage. It is intermediate between Paris green and lead arsenate in strength, and it costs less than either. 


\section{Methods of Control}

It is essential when arsenicals are used to see that they are correctly labeled, and kept under lock and key, as they are poisonous to man and animals.

Hellebore or white hellebore is somewhat less dangerous than the arscnicals. However, it loses its insecticidal value by being exposed to the air. It is a specific against slugs.

(b) Contact Poisons. All the tobacco or nicotine products sold principally as extracts or powders belong to this class. A common brand much used is the preparation known as "Black leaf 40," diluted I part to 700 or 800 of water. An addition of ivory soap at the rate of two bars to each 100 gallons of the solution increases its effectiveness by making it spread out better. Aphine, sulpho tobacco, and a number of other products found on the market are usually valuable as contact poisons if properly tested out and guaranteed by the dealers. Ordinary laundry soap, one pound to seven gallons of water, is very effective against all softbodied sucking insects.

\section{Fungicides}

These are poisons used to control fungous diseases. As previously stated, some parasitic fungi live on the surface of the leaves and stems and are therefore easily controlled. An example of this is the powdery mildew. Other fungi, and these are in the larger majority, are those which live parasitically within the tissue of the host, and therefore cannot be reached 
by any spray. Fungicides are helpful only in preventing entrance of the parasite in the host. They are as ineffective in controlling insect pests, as are insecticides in controlling fungous diseases.

(a) Bordeaux Mixtures. This is the standard fungicide. The strength used for tender plants is three pounds of copper sulphate-also known as blue stone,-six pounds of lime, and fifty gallons of water. The easiest way to prepare it is to dissolve the blue stone thoroughly in twenty-five gallons of water. The best quality of unslaked lime should be used and slaked in a little hot water, care being taken, however, not to flood it while slaking, nor to let it become too dry. When the slaking is completed, enough water is added to male twenty-five gallons. The limewater and the blue stone solution are then mixed, pouring first one part of lime water, then another part of the blue stone; the mixture is then strained and used at once. With crops with delicate foliage, such as watermelon, weak Bordeaux must be used to prevent burning of foliage (see page 243).

For truck crops with less delicate foliage, the standard Bordeaux mixture is 4-4-50-that is, four pounds copper sulphate, four pounds unslaked lime, and fifty gallons of water.

Stock Solutions. In spraying large areas, it is not always practical to weigh out and prepare the ingredients at short notice. The trucker will therefore find it adrantageous to prepare stock solutions so that large quantities of both dissolved copper sul- 


\section{Methods of Control}

phate and of lime may be ready for instant use. A stock solution of lulue stone may be prepared as follows: Forty gallons of water are put into a fifty-galion barrcl; forty pounds of blue stone are ploced in a basket and hung up so that the basket is half covercd by the water in the barrel. As the blue stone is cissolved, each gallon of the water contains one pound of the chemical. In another barrel may be slatied forty pounds of fresh lime. Each gallon of that will contain one pound of lime. By keeping the slaked lime in the barrel covered with water and preventing it from evaporating, and also keeping the barrel with the blue stone solution covered to prevent evaporation, we shall have stock solutions ready for instant use. To make a 4-4-50 Bordeaux from stock solutions, for instance, it is necessary to take four gallons from the stock solution barrel with blue stone, and add this to twenty-one gallons of water. Four gallons are also taken from the stock solution barrel of slaked lime and added to twenty-one gallons oi water. The two solutions of twenty-five gallons anch are now added together, thus making a $4-4-50$ Bordeaux. In this way it is easy to prepare any formula from the stock solutions. To determine if the Bordeaux contains sufficient lime, the following test may be carried out. A few drops of potassium ferrocyanide are added to the Bordeaux mixturc. If sufficiont lime is present, no change will take place, but if the mixture is deficient in lime, a dark reddish brown color will appear where the drop strikes the liquid. This testing fluid is easily prepared by dis- 
solving one ounce of potassium ferrocyanide in about eight ounces of water. This chemical costs but a few cents in any drug store and will last a long time if kept in a tightly sealed bottle.

\section{Points to BE Remembered}

In preparing Bordeaux the following points should be kept in mind:

(I) Copper sulphate solutions must be kept only in vessels of wood, fiber, brass, bronze, or copper. They must not be kept in iron or tin vessels, as they will corrode them.

(2) It is necessary to use fresh stone lime, as airslaked lime is useless.

(3) Bordeaux mixture can be used only when freshly mixed. If allowed to stand twelve hours after making, it loses all fungicidal value.

(4) Bordeaux mixture or lime should never be strained through burlap. The lint of the burlap is likely to work up into the nozzles and clog them.

(5) Undiluted solutions of copper sulphate or lime should never be mixed together.

(6) Bordeaux mixture should not be prepared with hot water.

(b) Ammoniacal Copper Carbonate. The objection to the use of Bordeaux is that it stains the leaves and foliage.

To avoid staining, colorless ammoniacal copper carbonate may take the place of Bordeaux. It is prepared as follows: 
Copper carbonate...................5 ounces Ammonia (26 Baumé)................. 3 pints Water........................ 50 gallons

The best results are obtained when the copper carbonate is first made into a paste with a little water. It is then dissolved by adding the ammonia, which is diluted with four quarts of water. If three pints of ammonia fail to dissolve all the copper carbonate, more may be used. Ammoniacal copper carbonate is only effective when used fresh. It loses its fungicidal value by standing, as the ammonia evaporates quickly.

(c) Sulphur. Flowers of sulphur are often used to control powdery mildew or asparagus rust. It may be applied either by hand or with a duster. There are a number of other fungicides on the market which are not mentioned here. They should be thoroughly tested before they are used. Considerable discretion should be exercised before using a new fungicide which claims to be a "Cure all."

\section{Combination Sprays}

In the foregoing chapters on diseases, it was seen that truck crops are subject to the attacks of more than one malady. Moreover, truck crops are also subject to the attacks of insect pests. It is therefore advisable to control both insect pests and fungous diseases at the same time. Spraying, if properly 
done, is effective in controlling or in keeping in check all the pests which attack trucle crops. In combining a fungicide with an insecticide, we may accomplish two aims in one operation. The various spray mixtures which may or may not be combined are indicated by Cooley and Swingle ${ }^{\mathrm{I}}$ as follows:

\section{Tobacco Bordeaux extracts mixture}

Paris green

Arsenate of lead

Arsenite of zinc (ortho)

Arsenite of lime

$\begin{array}{ll}\text { yes } & \text { yes } \\ \text { yes } & \text { yes } \\ \text { yes } & \text { no } \\ \text { yes } & \text { yes }\end{array}$

Each of these preparations is mixed and applied just as if it were used alone. A combination of the ammoniacal copper carbonate with an arsenate would be unsafe, since the ammonia renders the arsenic more soluble, and hence may result in the burning of the foliage. However, it may be safely mixed with the tobacco products.

Recent investigations by Professor Safro, Entomologist to the Kentucky Tobacco Products Co., indicate that "Black leaf 40 " may be used in combination with such spray chemicals as lime-sulphur, arsenate of lead, arsenite of zinc, and iron sulphate, for controlling sucking and chewing insects and fungous diseases, the soap in this case being omitted. Professor Safro's work further claims that "Black leaf 40 " may

${ }^{2}$ Cooley, B. A , and Sringle, D. B., Montana Agr. Expt. Sta. Circ. 17: I19-I5I, I912. 


\section{Methods of Control}

be safely combincd with Bordeaux, and the desired results obtained. He writes as follows: "For purposes of spraying, add to every one hundred gallons of Bordeaux three fourths of a pint of 'Black leaf 40.' As far as safety to the foliage is concerned, much greater strengths of nicotine may be added to the Bordeaux, but no additional effectiveness will be given to the mixture as an insecticide. Any nicotine solution which contains four hundredths of one per cent. nicotine will be effective in controlling plant lice, provided, however, the work is thoroughly done."

\section{Proportions of Combined Sprays}

\section{Bordeaux and Paris Green}

Paris Green........ T/2 pound

Bordeaux mixture....50 gallons

Bordeaux and Arsenite of Soda

Arsenite of Soda......... I quart

Bordeaur mixturc....5 5 gallons

Bordeaux mixture must never be combined with herosene emulsion, carbolic acid emulsion, and miscible oils.

(d) Potassium Sulphide. Like sulphur this is a valuable fungicide for the control of the powdery mildew. The following strength is recommended:

Potassium Sulphide......4 oz.

Water............. Io gallons 
Potassium sulphide is effective only if used immediately it is prepared. It loses its value by being exposed for any length of time.

\section{STICKERS}

It is well known that with some plants, such as cabbage, spray mixtures cannot be made to stick. The use of a sticker added to the spray mixture will largely overcome this difficulty. A sticker may be prepared as follows:

$$
\begin{aligned}
& \text { Resin........... 2 pounds } \\
& \text { Sal Soda (crystals)... I pound } \\
& \text { Water.......... I gallon }
\end{aligned}
$$

The resin and the sal soda should be added to one gallon of water and boiled in an iron kettle for one and a half hours until clear. For plants which are hard to wet, such as cabbage, or onions, the amount of the sticker given above should be used for each fifty gallons of Bordeaux or ammoniacal copper carbonate. For other plants, this amount is added to each one hundred gallons of the spray mixture.

\section{Principles Involved in Spraying}

It should be remembered that to destroy chewing insects, such as caterpillars, etc., the stomach poison must be evenly distributed all over the plant. This thorough spraying should be done as soon as the presence of the pest is suspected. Intelligent and observant growers will remember the time of ap- 
pearance of the pest every year, although this date depends somewhat on the climate of each season. In destroying the green aphids, the contact poison should be distributed as evenly as possible on the insect itself. It is, therefore, best to spray for aphids when they are actually found working on the plants. To check chewing insects and fungous pests, however, the applications are made before the parasites appear. Before spraying it is necessary to have well in mind which organism is to be destroyed, and the proper ingredients to be used. To keep fungous pests in check it is necessary to have the plant covered with the fungicide all the time infection is feared or suspected. This spraying is preventive, protecting the plant from becoming infected. When the parasite has penetrated the host, spraying is of little value in saving the infected plant, although it will protect others which are as yet healthy. It is essential that the trucker be always ready to spray. Somctimes retardation for even a day may prevent the attainment of positive results. The timely destruction of one insect, or of one spore, means the destruction of countless generations of these pests.

Thoroughness is as important in spraying as $1 \mathrm{t}$ is in everything else in life. Especially is this true for the control of fungous diseases.

\section{SPRAYING MACHINES}

Success in spraying often depends on the sprayer, and especially on the nozzle. In small scale garden- 


\section{2 \\ Diseases of Truck Crops}

ing, an ordinary knapsack or barrel sprayer (fig. 7I a) will answer the purpose. For trucking on large areas the use of power sprayers (fig. 7 I b) becomes necessary. It is difficult to recommend the use of any one type when there are so many models on the market. After consulting various catalogues and examining types of spray machines at the county fairs and other exhibits, the grower will be in a position to determine the kind of apparatus best adapted for his conditions. A good power sprayer should be capable of maintaining a pressure of at least one hundred pounds while the nozzles are open. The sprayer should also have a convenient attachment for spraying four rows or more, and should also possess a device by which each row can be sprayed with either single or double nozzles. Moreover, all the working parts must be easily accessible, simple, and solidly built.

\section{Care of the Spraying Machine}

After each spraying the outfit should be emptied and carefully cleansed with water. Failure to do this will result in the corroding of the tank, rods, and nozzles.

\section{Crop Rotation}

Many of the soil diseases, such as root knot, Fusarium wilts, etc., may be economically controlled by crop rotation. If a certain disease gains a foothold in the soil, it is likely to become progressively serious, 

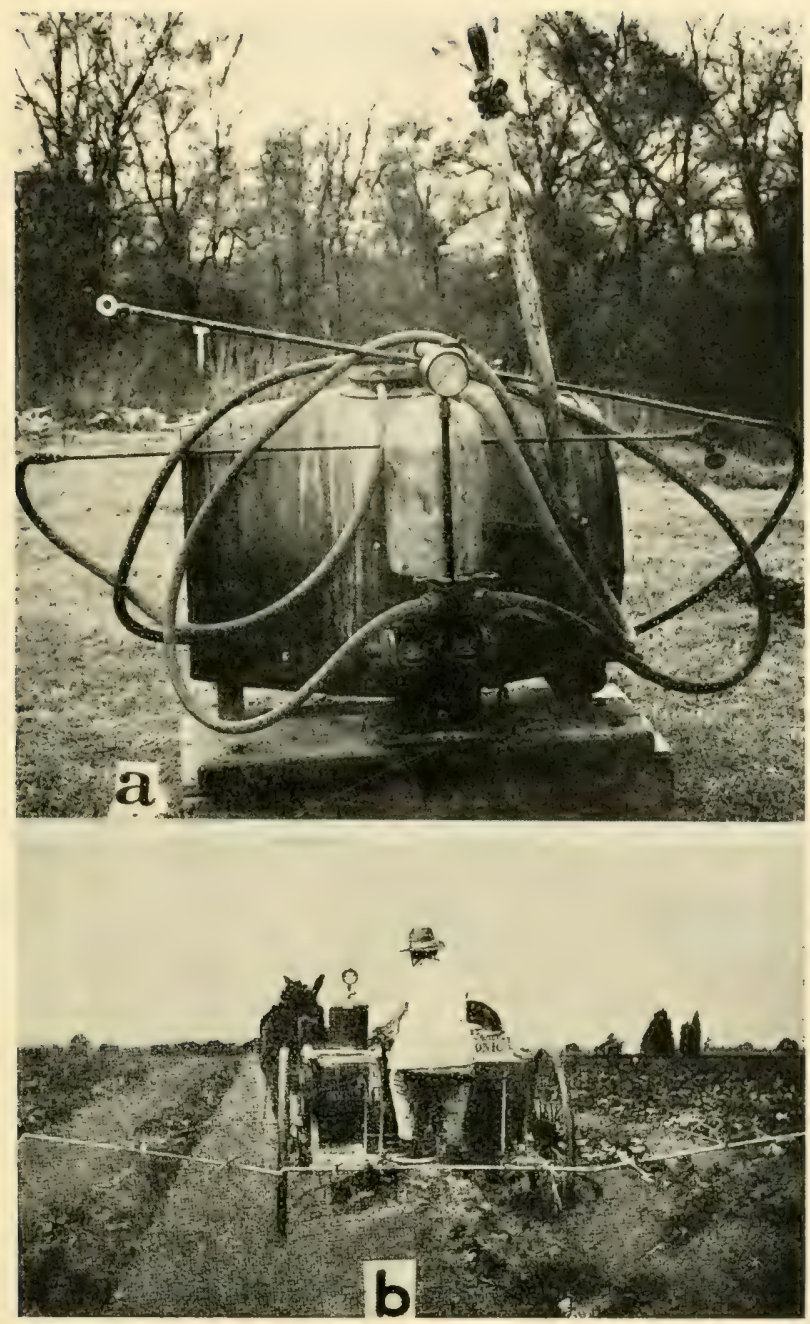

FIG. 71. SPRAY MAChinery.

$a$. A hand power pump, $b$. a power machine, rear view, showing arrangement for spraying three rows of cucumbers (after W. A. Orton), 



\section{Methods of Control}

as the particular crop which the disease attacks is grown for a number of years on the same field, the soil becoming thoroughly permeated by the mycelium and spores of the parasitic organism. If the infected land is planted with crops not subject to the disease, the parasitic organism will sooner or later die for want of a suitable host to live upon. For this reason crop rotation plays an important part in the control of numerous truck crops. To meet with success in rotation, the trucker must know what crops are subject to the disease to be controlled, so as to avoid them temporarily in the sick land. Weeds, too, are often subject to the same diseases as the cultivated crops. Crop rotation often fails if we overlook the importance of clean culture.

\section{Varieties Resistant to Disease}

It is a well-known fact that not all varieties of plants are alike subject to the same disease. In going over a diseased field, we find that while a large percentage of the plants may be dying, some few individuals will stand up and thrive in spite of the disease. If these individual plants are perpetuated in the same sick field, we may succeed in developing a strain or variety of plant which will produce one hundred per cent. healthy individuals in the same sick soil. On this principle are based the selection and development of resistant varieties. Much has already been accomplished in this direction and still more is to be expected in the future. 


\section{How to Develop a Resistant Variety}

This may be accomplished by selecting, from the sickest piece of land on which the crop is growing, the healthiest individuals, and taking the seed from them. The following year the selected seeds are again planted on the same infected land. The best individual plants from this sowing are selected and their seeds saved. By continuing this method of selection for a number of years it may be possible to develop a strain which will yield one hundred per cent. of healthy plants in a sick soil. To maintain the purity of the selected strain as well as its resistance, it is necessary to reserve a plot of the sick soil, upon which the selected strain is grown for seed purposes. Care must be taken toward carrying any of the sick soil of this plot to other parts of the field.

Drawbacks. With some crops and with certain diseases it seems hopeless to try to develop a resistant strain. If a variety is resistant to one disease it may be susceptible to several others, which are perhaps more serious. The resistance may often be local, in which case it becomes necessary to develop resistant types for each local condition. Resistant varieties often may not embody the requirements of the market. Nevertheless, the development of resistant strains should be tried wherever it gives any promise of success. 


\section{CHAPTER XXIV}

CONTROL OF INSECT PESTS BY NATURAL FACTORS

IN this discussion we shall consider very briefly the natural factors which help in the control of parasitic insects.

(a) Beneficial Predacious Insects. It is fortunate that nature always provides its own remedies. If insect pests were not kept in check by natural enemies the trucker who does not spray would be faced by tremendous odds in attempting to raise crops. The natural and beneficial enemies may be grouped, first, into parasites which develop within the body of the host, and second, predacious or those which feed externally.

I. Of the first group may be mentioned a small wasp-like insect, Lysiphlebus testaceipes. This is no doubt an important parasite, which greatly helps to keep the green Aphis in check. Its life history was originally worked out by Webster, ${ }^{\mathrm{I}}$ and may be briefly summarized as follows:

A mature female thrusts her ovipositor into the upper side of the Aphis and deposits a single egg

× U. S. Dept. of Agr. Bur. of Entomology Bul., I I0, I9I2. 
within its body (fig. $72 \mathrm{c}-\mathrm{d}$ ). The egg of Lysiphlebus hatches and soon begins to feed on the vital parts of the Aphis. The latter gradually ceases activity and finally dies and becomes mummified. When the larva of Lysiphlebus reaches maturity and pupates, it emerges through a circular lid cut on the back of the dead Aphis. Lysiphlebus is not active at temperatures below 56 degrees $\mathrm{F}$.

2. Of the parasites which feed externally on Aphids may be mentioned the lady-bird beetle, of which there are several species. These actually devour great numbers of plant lice. Lady beetles need no description, as they are well known to all truckers. There are, of course, other important beneficial insects such as the Syrphid and the lacewinged flies. For a further description of these the reader should consult Webster's original publication already cited.

(b) Beneficial Fungus Parasites. There are numerous species of fungi which from an economic consideration are very important. These live parasitically on numerous insect pests and undoubtedly greatly help in keeping them in check. Of these may be mentioned species of Empusa, and of Acrostalagmus, which live on Aphids or plant lice. Fungi which belong to species of Aschersonia are parasitic on the white fly. The fungus Botrytis rileyi is parasitic on numerous caterpillars. The fungus Cordyceps (fig. $72 \mathrm{a}-\mathrm{b})$ contains some important species which are parasitic on the Harlequin bugs and other insect pests. The green muscardine fungus Metarrhizium 


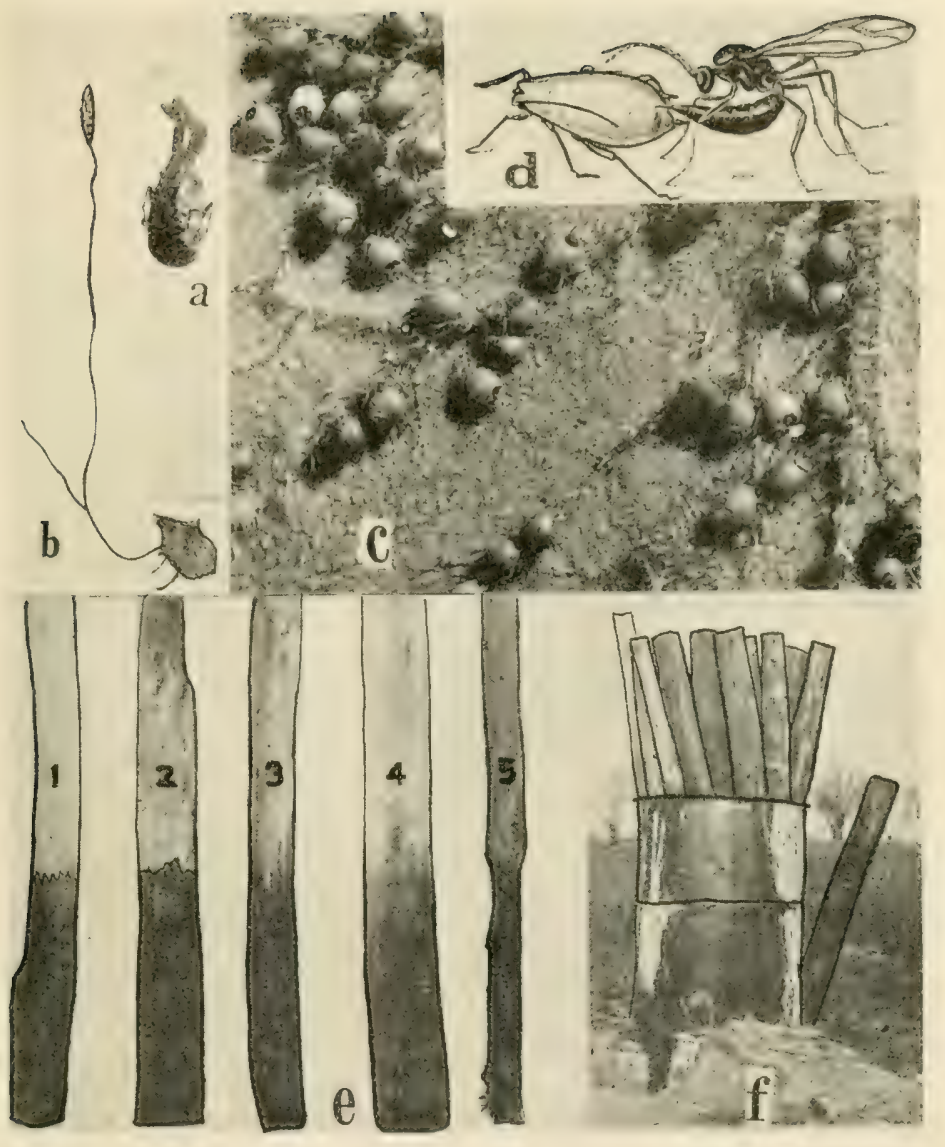

Fig. 72. Parasitized Insects. Treatment of Fence Posts.

$a$. Cabbage bug parasitized by Cordyceps nutans, $b$. cabbage bug parasitized by Cordyceps sobolifera ( $a$. and $b$. after Lloyd), $c$. watermelon aphids parasitized by Lysiphlebus testaceipes, showing circular holes on the backs of the aphids through which parasite emerged, $d$. a female of $L$. teslaceipes in the act of laying her eggs in the back of a green aphis (after Webster), e. Creosoted post af ter a period of service, $I$. a willow post treated 4 hours in hot creosote and Io hours in cold; set June $I_{3}$. 1905, examined November I, I9I 4 , and showing practically no deterioration aftcr $91 / 2$ years' service. 2. A split soft maple post treated 4 hours in hot creosote and Io hours in cold; set in 1905 and examined November 15, I9I4. The post was set below the creosote line and some decay has entered beneath the creosote shell. 3. A 5 -inch split cottonwood post given a creosote bath treatment, set in 1905 and examined in 19I4. The post shows practically no decomposition in either top or bottom. 4. An 8-inch ash post split in half, given butt creosote treatment of 6 hours in hot and 12 hours in cold, set 1905 and examined in November, I9I. The creosoted bottom is sound, penetration on the heart wood surface was less than in the sap wood. The heart wood portion of this post will undoubtedly give away first. The untreated top is in excellent condition. 5. A $4 \frac{1}{2}$-inch untreated white cedar post after standing $91 / 2$ years. $f$. A small treating tank in operation, ( $e$. and $f$. after McDonald). 



\section{Natural Factors Controlling Pests 377}

anisoplice is parasitic on numerous grubs and beetles. Most of these fungi, however, are only active during warm moist weather and cannot always be depended upon with certainty. 


\section{CHAPTER XXV}

\section{TREATMENT OF FENCE POSTS}

Whether trucking on a large or small scale, fence posts are always used to protect the crops from pasturing animals or undesirable marauders. In buying fence posts, the aim should be to secure those which naturally last longest. Posts of willow, cottonwood, or soft maple will last far less than those of red cedar, osage orange, or the mulberry. Posts made largely of sapwood will rot much faster than those made of heartwood. All posts, before being used, should be rid of all their bark. The latter usually harbors insect and fungi which when active hasten destruction or decay. In order to preserve the life of fence posts longest, they should be treated with some good standard preservative. Creosote is the most important preservative for fence posts (fig. $72 \mathrm{e}$, I to 5). On a moderate scale, tanks (fig. $72 \mathrm{f}$ ) four feet high, three feet in diameter, and capable of holding thirty-five $4^{\mathrm{T}} / 2^{\text {-inch }}$ posts should be used. The tank is raised about one foot above the ground to provide room for the fire box. The creosote is poured in the tank and the posts are allowed to remain in the hot preservative for a period of from two to six hours. The posts may then be allowed to 


\section{Treatment of Fence Posts}

remain in the tank until the preservative cools off, or it is immediately transferred to another tank which contains cold creosote. This cooling off is necessary, as it causes a contraction of the remaining air and moisture in the wood structure. This causes additional preservative to be drawn into the wood.

Fence posts may be treated at any time of the year. The time of the year posts are cut affects only the seasoning, but not its durability. Posts cut in the winter are more difficult to peel. Contrary to general belief, winter cut posts contain more moisture and hence require longer seasoning. All posts to be treated must have all the bark removed. If the posts are cut in the spring, the peeling of the bark is very easy. Beveling the tops of treated posts is also recommended. This is especially necessary when the posts are treated at the butt end which is stuck in the ground. 



\section{GLOSSARY}

\section{A}

ACERvulr. Small groups of mycelial tufts upon which fungus spores are formed.

FECIDIOSPORES. Spores of the rust family formed in an æcidium.

ECIDIUM (æcium). A cup-shaped body in which are formed the spring spores of certain rust fungi.

AEROBE. Organism requiring air, more especially oxygen. AMMONIFICATION. The formation of ammonia at the expense of other forms of nitrogen compounds, by the action of microörganisms upon organic substances.

AMuonifiens. Microōrganisms capable of transforming nitrogen compounds into ammonia.

AMcBoId. Like an amœba, the creeping movement of which is rnade possible by appendage-like bodies. ANTHERIDIUM. The male sexual organ in fungi.

APICAL. Terminal formation at the point of any structure.

ARTHROSPORES. Whole vegetative cells of either bacteria or fungi, which by a thickening of their walls become resting spores.

Ascospores. Spores formed in an ascus.

Ascus. A sac-like structure in which the winter spores of certain fungi are formed. 
BASIDIOSPORES. Spores formed on basidia.

BASIDIUM. A straight stick like spore bearing fungal thread.

\section{C}

CANKER. Definite dead area in the bark of stems or roots of plants.

CAPItate. Possessing a head.

CARBONACEOUS. Dark to black colored.

CHLAMYDOSPORES. Resting spores with very thick walls, formed within mycelial cells.

CHLOROPHYLL. Green coloring matter in leaves of the higher plants.

CHROMOGENIC. Producing color.

CILIATE. Fringed with hairs.

COLUmella. Sterile axle of a pillar-like structure within a sporangium.

CONIDIA. Spores formed asexually.

CONIDIOPHORE. A spore-bearing fungal stalk.

CONSTRICTED. Drawn together or contracted.

CORTEX. Outer bark.

CUTICLE. The outermost skin of plants.

CYST. Sac or cavity.

D

DELiquesCent. Dissolving or melting.

DIFFUSE. Loosely spread.

DILATED. Enlarged.

E

ENDOSPORE. Spore formed within another cell. ENTOMOGENOUS. Living on insects. 


\section{Glossary}

ENZYMe. An organic chemical product capable of bringing about chemical changes, but without itself undergoing any change, or entering into the final product.

EXOSPORE. Outer covering of a spore.

F

FALCATE. Sickle shaped.

FLAGELLA. Whip-like appendage of protoplasm of bacteria and swarm spores.

FUnGUS. A plant of very low order. Its mycelium corresponds to roots and reproduces by means of spores.

\section{G}

GLAUCUS. Sea green.

GONIDIA. Algæ-like cells.

gutTulate. Drop-like.

HAUSTORIA. Special organs of a fungus used for attachment or for obtaining food.

HOST. Any plant which nourishes a parasite.

HYALINE. Translucent or colorless.

HyPERTROPHIED. Part of diseased plant abnormally enlarged.

HYPHÆ. Thread-like vegetative part of a fungus.

INDURATED. Hardened.

INFECT. To cause disease.

INTERCELLULAR. Growing between the host cells.

INTRACELLULAR. Growing inside the host cells. 
LENTICEL. A special loose corky structure in plants intended for the exchange of gases of the air and the interior of the plant.

LESIONS. A definite diseased area.

\section{M}

MACROCONIDIA: Large conidia.

MICROCONIDIA. Very small conidia.

MIDDLE LAMELLA. The connecting or cementing membrane between any two cells of a plant.

MYCELIUM. Vegetative threads or hyphæ of a fungus.

Mycology. The study of fungi.

\section{$\mathrm{O}$}

omnivorous. Attacking a large variety of plants.

oogonium. Female sexual organ of fungi, containing one or more oospheres.

OOSPHERE. Naked mass of protoplasm developing into oospores after fertilization.

OOSPORE. Fertilized oosphere.

\section{$\mathrm{P}$}

PAPILlATE. Having wing-like structures.

PARAPHYSES. Sterile filaments found in some fruiting forms of fungi.

PARASITE. An organism living at the expense of another (the host).

PATHOGENE. A disease-producing organism.

PEDICILlATE. Borne on a stalk. 
PERITHECIUM. A flask-shaped or globose sexual fruiting body containing asci.

PERITRICHIATE. Flagella all over the surface.

PIONNOTES. An effuse conidial stage containing a maximum of conidia and a minimum of aerial mycelium.

PLASMODIUM. A mass of naked protoplasm with numerous nuclei and capable of amoboid motion.

POLAR FLAGELla. Flagella borne at the polar ends of an organism.

PROTOPLASM. The living substance of any plant cell. PSEUDOPIONNOTES. False pionnotes.

PSEUDOSTROMA. False stroma.

PUSTULE. A blister or pimple.

PYCNIDIA. Sac-shaped fruiting bodies of a fungus in which the pycnospores or summer spores are formed. PYCNOSPOREs. Summer spores of certain fungi which are formed in pycnidia.

\section{S}

SCLEROTIA. Compact masses of mycelium in a ciormant state. These help to carry the fungus over unfavorable weather conditions.

SEPTUM. Any partition between two cells in the same fungus filament.

SETE. Bristle-shaped bodies.

SOIL FLORA. Bacterial or fungus growth in a soil.

SORUS. Heap of spores.

SPORANGIOPHORE. Stalk-bearing sporangium.

SPORANGIOSPORES. Spores formed in a sporangium.

SPORANGIUM. Free non-sexual bearing spore sac.

SPORES. Seed of bacteria or fungi.

stomata. Minute openings in the stems, leaves, or fruits of plants which serve as a medium of exchange of gases. 
STROMa. A spore-bearing cushion composed of mycelium and sometimes of host tissue.

SWARM SPORES. Spores possessed with the power of motility.

TELEUTOSPORES (TELIOSFORES). Resting or winter spores of certain rust fungi.

U

UREDOSPORES. Summer spores of certain rust fungi.

V

VESICULAR. Composed of vessels. vISCID. Sticky.

Z

ZOOGLEe. Colony embedded in a gelatinous bed. zOosporangIA. Sporangia which produce zoospores. ZOOSPORE. A motile spore. 


\section{INDEX}

A

Abbot, J. B., 30.

Acid sick soils, 25 et seq . Acrostalagmus panax, 113. Actinomyces, 6.

- chromogenus, 317 .

- - attacking beets, I20.

_ttacking radish, 209.

Alkali sick soils, 34 et seq.

Allard, H. A., 84.

Allium cepa, 285 . schoenoporasum, 284.

Alphano Humus Co., 20.

Alternaria brassica, 196.

- - var. nigrescens, 2,23.

- - panax, II4.

Ammoniacal copper carbonate, 366.

Ammonification, I4.

Antheridium, II.

Aphis gossypii, 233.

Apium graveolens, 355 .

Arthur, J. C., II7, I38.

Artichole, Globe, diseases of, I39 et seq. Leaf spot, 139.

_- Jerusalem, diseases of, I37 et seq.

___ Downy mildew, 138.
Leaf blotch, 138 et seq.

- Rust, I38.

Ascochyta armoracia, 205.

- - hortorum, 302.

- - pisi, 277.

Asparagus (officinalis), 280.

diseases, 279 et seq.

Leopard spot, 280.

Rust, 280.
Asparagus, resistant to rust, 283.

- rust, natural enemies, 283.

Atkinson, G., 43 .

Available nitrogen, elaboration of, I3.

B

Bacillus, 4.

Bacillus carotovorus, 192.

- — attacking onions, 285. attacking salsify, I46. firorescens liquefaciens, I4.

_-_ putridus, 14.

- - lathyri, 26I.

-.. on cowpea, 270.

- - pliytoptizorzes, 316. -melonis, $22 \mathrm{r}$.

- mesentericus vulgatus, $14,23$.

- mycoides, 14, 23.

- pestifer, 23.

- proteus vulgaris, I4.

- ramosus, 23.

- subtilis, 23.

—- tracheiphillus, attaching cucumber, 229.

Bacteria, distribution in soil, 6 .

- forms, 4 .

- influence of depth of cultivation, 8.

- number influenced by manure, 9. relationship to function of soil, 5 .

Bacterizin teutlium, II 8 .

Balm diseases, 256. Leaf spot, $25^{6}$. Rust, 256.

Barus, M. F., 265. 
Bean diseases, 260 et seq.

Anthracnose, 263.

Blight, 260.

Damping off, $26 \mathrm{r}$.

Downy mildew, 26r.

Powdery mildew, 262.

Rust, 262.

Sclerotinia rot, 263.

Stem anthracnose, 263.

Streak, 26 I.

Beattie, W. R., 293.

Beet diseases, II 7 et seq.

Crown gall, I I8, I I9.

Damping off and root rot, $122,123$.

Downy mildew, 123.

Drop, 124.

Leaf spot, 126, 127.

Leaf spot and heart rot, I25, 126.

Root knot, I29, I30.

Root rot, 128.

Root tumor, I2I, I22.

Scab, I20-I2I.

Soft rot, I 8 .

Tuberculosis, I2O.

Water core spots, II 7 .

White rust, 123 .

Beneficial fungi, 376 .

Bessey, E. A., 5I.

Beta vulgaris, 117.

"Black leaf 40," 368.

Blinn, P. K., 224.

Blossom drop, 82, 83 .

Bordeaux mixture, 364 .

Branch, G. V., 226.

Brassica Japonica, 208.

oleracea, $\mathbf{1} 86$.

- var. acephala, 207.

var. botrytis, 202.

rapa, 2 I 4.

Bremia lachuce, I4I.

Brown, N. A., 140.

\section{C}

Cabbage diseases, I 86 et seq.

Black leg or foot rot, 195.

Black mold, 196.

Black rot, I9o.
Club root, $\mathbf{1} 86$.

Damping off, 193 .

Downy mildew, I94.

Drop, I94.

Leaf spot, I96.

Root knot, 199.

Soft rot, 192.

White rust, 193.

Wilt or yellows, 197.

storage decays, 199 et seq.

Cantaloupe, 225.

- blight resistant, 225.

care in shipping, 225 et seq.

diseases, 219 et seq.

Anthracnose, 223.

Bacterial wilt, 2 I9.

Cercospora leaf spot, 224.

Cladosporium mold, 224.

Downy mildew, 22 I.

Leaf blight, 223.

Mycosphærella wilt, 222.

Phyllosticta leaf spot, 224.

Powdery mildew, 222.

Root knot, 225.

Soft rot, 221.

Southern blight, 225.

spraying, 232.

Capnodium, 238.

Carbon, transformation of, 13 .

Carrot diseases, 354 .

Root rot, 354 .

Soft rot, 354 .

Carum petroselinum, 357 .

Catnip diseases, 257.

Leaf spot, 257.

Stem rot, 257.

Cauliflower diseases, 202 et seq.

Bacterial leaf spot, 202.

Ring spot, 204 .

Causes of diseases in crops, $7 \mathbf{I}$ et seq.

Celery diseases, 355 et seq.

Early blight, 357.

Late blight, 355 .

Leaf spot, 355 .

Rust, 355.

Soft rot, 355 .

Cercospora apii, 357,358 .

- amoracia, 207.

canescens, 269. 
Cercospora capsisi, 304.

- citrullina, 243.

- cruenta, 27 I.

-Cucurbita, 224.

dolichi, 27 I.

hibisci, 295.

Chive diseases, 284.

Choanophora cucurbitarum, 235.

Chrysophylyctis endobioticum, 3 I9.

Citron diseases, 234.

Citrullus vulgaris, 234 et seq.

Cladosporium fulvum, 350 .

- macrocarpum, I34.

- sp., 284.

Clinton, G. P., 122, I24, I47, $215,284,323$.

Coccus, 4 .

Cochleaia armoracia, 204.

Colletotrichum atramentarium, 325,326

- caulicolum, 266.

- Higginsianum, 2I4.

- nigrum, 303.

- phomoides, 348 .

Combination sprays, 367 .

Conidia, I2.

Conn, J. H., 6.

Contact poisons, 363 .

Convulvulus batatas, I5I.

Cooley, B. A., 368.

Corticium vegum, 128.

Cowpea diseases, 270 et seq.

Angular leaf spot, $27 \mathrm{I}$.

Powdery mildew, 27 I.

Rust, 271.

Streak, 270.

Wilt or Yellows, 270.

Crop rotation, 272.

Cucumber diseases, $228 \mathrm{et} \mathrm{seq.}$

Angular leaf spot, 229.

Anthracnose, 232.

Bacterial wilt, 229.

Damping off, 230.

Downy mildew, 230.

Mosaic, 228.

Powdery mildew, 230.

Root knot, 232.

- spraying, 232.

Cucumis sativus, 228.
Cucumis melo, 210.

Cucurbita maxima, 234.

- moschata, 234.

pepo, 234.

Cutworins, 52 .

Cystopus candidus, attacking radish, $21 \mathrm{I}$.

- - on horseradish, 205. ipomar-pandurana, 155. portulacea, 299.

Cystospora batatas, 152.

D

Damping off, 42 et seq.

Darluca flum, 284.

Daucus carota, 354.

Denitrification, 24.

Denitrified soils, 23.

Diabrotica vittata, 220.

Diaporthe battis, I57, I59.

Didlake, M., 20.

Didymella cataria, 257 .

Diplodia herbarum, 258.

- herbicola, 257.

tubericola, $\mathbf{1 6 5}$.

-_., attacking watermel-

on, 239.

Diseases of a mechanical nature, $72 \mathrm{et} \mathrm{seq.}$

-

et seq.

due to bacteria or fungi,

86 et seq.

Dodder, 90, 91.

Doryland Ch., 8.

Drought injury, 78 .

Duggar, B. M., I 28, 298.

Durst, C. E., 233.

\section{E}

Edgerton, C. A., 264.

Edson, H. A., 209.

Eggplant diseases, 300 et seq.

Anthracnose, 302.

Damping off, $30 \mathrm{I}$.

Fruit rot, 301 .

Root knot, 303.

Southern blight, 303 . 
Eggplant diseases-Continued Southern wilt, $30 \mathrm{I}$.

Stem anthracnose, 303.

Elliott, J. A., I54.

Enlows, E. MI., 229.

Entyloma Ellisii, I33.

Erysiphe cichoracearum, 232.

—_ galeopsidis, 258.

- polygoni, 216.

- - on bean, 262.

- - on cantaloupe, 222.

\section{F}

Family Agaricaceæ, I03 et seq.

- Araliaceæ, 108 et seq.

-Chenopodiacex, I 16 et seq.

- Compositæ, I37 et seq.

- Convolvulacex, 15 I et seq.

- Cruciferæ, $185 \mathrm{et}$ seq.

- Cucurbitacer, 218 et seq

- Gramineæ, 250 et seq.

- Labiatæ, 255.

—_Liliacex, 279 et seq.

- Malvaceæ, 295 et seq.

- Portulacaceæ, 299.

- Solanaceæ, 300 et seq.

- Umbelliferæ, 254 et seq.

Fence post treatment, 378 .

Fertility of soil, I6, 17

Fisher, O. S., 3 I.

Fleet, W. V., 255.

Formaldehyde, treatment of soil, 53,54 .

Freiberg, G. W., 84 .

Frost injury, 74, 75 .

- prediction, 76,77 .

protection, 77,78 .

Fuligo violacea, 152.

Fungicides, 363 .

Fungi, structure and life history, Io.

Fusarium batatatis, 47, I57, 170 .

- citrulli, 244.

- conglutinans, 197.

- cucurbite, 237.

- eumartii, 330.

- hyperoxysporum, 47 et seq.

- lycopersici, 35 I.

- niveum, 244 .
Fusarium orthoceras, 352.

- oxysporum, 327,352 .

Poolensis, 244.

redicicola, 329 .

trichothecioides, $33^{\circ}$.

tuberivorum, $33 \mathrm{I}$.

\section{G}

Garden pea, 275.

diseases, 273 et seq.

Pod spot, 276 .

Root knot, 278.

Root rot, 278 .

Septoria leaf spot, 278 .

Stem blight, 273.

Thielavia root rot, 275 .

Garman, H., 20.

Gilbert, W. W., 74 .

Gilman, J. C., I98.

Ginseng, IIO, III, II3.

diseases, 108 et seq.

Acrostalagmus wilt, II3, II 4

Alternaria blight, I I4.

Black rot, I I Io, I I I.

Bordeaux injury, II5.

Damping off, Io8.

Downy mildew, 108, 109.

Fiber rot, II I, II2.

Leaf anthracnose, II 3 .

Papery leaf spot, II5.

Root knot, II5.

Stem anthracnose, II 2 .

White rot, IIo.

Gleosporium melongence, 302 .

Glomerella piperata, 303.

Grossenbacher, J. G., 222.

\section{$\mathrm{H}$}

Hail storm, 73, 74 .

Halstead, B. D., 125 .

Harding, H. A., I9I.

Harris, F. S., 35 .

Harter, L. L., 199, 301.

Hawkins, $32 \mathrm{I}$.

Headen, W. P., I6, 24.

Heald, F. D., 139, 266.

Healthy host and its requirements, 63 et seq. 
Healthy soil flora, nature and function, 12.

Helianthus annuนs, 148.

- tuberosus, 137 .

Heterodera radicicola, 48, 52, 332 . _- attacking cabbage, 199.

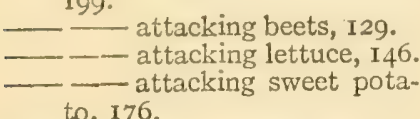

Heterosporium variabile, I34.

Hibiscus esculentus, 295.

Hicks, G. A., 96.

Higgins, B. B., 2 I4.

Hopkins, G. G., 3 I.

Horehound diseases, $25^{8}$.

Leaf spot, 258.

Powdery mildew, 258.

Horseradish diseases, 204 et seq. Leaf spot, 207.

Macrosporium black mold, 206.

Root rot, 205.

Shot hole, 206.

White mold, 206.

Humbert, J. G., 55 .

Humphrey, J. E., 232.

\section{I}

Insecticides, 362 .

Iron, changes of, I5.

Irrigation, methods of, 67 et seq.

Isariopsis griseola, 269.

Istvanff, G. De, I43.

\section{J}

Jamieson, C. O., 33 I.

Johnson, J., 57, 276.

T., 320,347 .

Jones, L. R., 74 .

\section{K}

Kale diseases, 207, 208.

Koch, Robert, 4.
L

Lactuca sativa, I40.

Lady beetles, 376 .

Leeuwenhoek, Anton van, 4.

Lettuce diseases, $140 \mathrm{et} \mathrm{seq.}$

Bacterial blight, I40.

Cercospora leaf spot, $\mathbf{1 4 5}$.

Downy mildew, I4I.

Gray mold, 142.

Leaf spot, I44.

Lettuce drop, 143.

Root knot, 146.

Rosette, 146.

Shot hole, I45.

Levine, E., 347.

Lightning injury, 74, 75 .

Lima bean diseases, 267 et seq.

Blight, 267.

Downy mildew, 267.

Leaf blotch, 269.

Leaf spot, 269.

Pod blight, 268.

Powdery mildew, 268.

Root rot, 269.

Rust, 268.

Texas root rot, 269.

Lutman, B. F., 318.

Lycopersicum esculentum, 339.

Lysiphlebus testaceipes, 375.

\section{M}

McClintock, J. A., 263.

McCulloch, L., 202.

McKay, M. B., 127.

Macrosporium herculeum, 206,

217.

— parasiticum, 290.

porri, 290.

solani, 325.

sp., 304 .

Malnutrition, 80 et seq.

Manns, T. F., 99, 195.

Marrubium vulgare, 258.

Marsonia perforans, I45.

Meier, F. C., 239.

Melanconium Tisdale, 349.

Melhus, T. E., 212, 323.

Meliotus alba, 20. 
Meliolus denticulata, 20.

- lupulina, 20.

Melissa officinalis, 256.

Mentha virides, 258.

Merrill, L. A., 65 .

Methods of control, 36 I.

Mint diseases, 258.

Monilochctes infuscans, I68.

More, C. T., 226.

Morse, W. J., 316.

Mosaic, 83 et seq.

Muck or peat soils, 34 et seq.

Mushroom diseases, 103 et seq.

Bacterial spot, I03, I04.

The Mycogone disease, 103 et seq.

Mustard diseases, 208.

Mycogone perniciosa, 104, 105.

Mycosphcerella brassicola, 204.

- citrulina, 22.

\section{$\mathrm{N}$}

Nematospora lycopersici, 345 .

Nepeta cataria, 257.

Niter-sick soils, 24 .

Nitrification, I4.

Nitrobacter, I4.

Nitrogen fixation from air, Is.

- maintaining supply, $\mathbf{I} 7$.

Nitrosococcus, I4.

Nitrosomonas, I4.

\section{O}

O'Gara, P. J., 324.

Okra diseases, 295 et seq.

Leaf spot, 295.

Root knot, 298.

Root rot, 297.

Texas root rot, 297.

Wilt, 296.

Oipidium brassica, 193.

Onion diseases, 285 et seq.

Anthracnose, 289.

Black mold, 290.

Black neck, 290.

Blight, 286.

Bulb rot, 290.

Damping off, 286.
Downy mildew, 286.

Pink root, 29I.

Rust, 289 .

Sclerotium rot or black neck, 290.

Smut, 288.

Soft rot, 285 .

- - storage, 292 et seq.

Oogonia, 43.

Oogonium, II , 43.

Orton, W. A., 232, 273, 327.

Ozonium omnivorium attacking okra, 297.

to, $\mathbf{1 7 5}$.

\section{$\mathrm{P}$}

Pammel, L. H., 46, I23.

Parasitic fungi, ro.

- soil Fusaria, 46, 47 .

Parsley diseases, 357 .

Drop, 357.

Late blight, 357 .

Parsnip diseases, 357.

Early blight, 357 .

Root rot, 357 .

Pastinaca sativa, 357.

Penicillium expansum, Ir.

Pepper diseases, 303 et seq.

Anthracnose, 303.

Black anthracnose, 303.

Fruit rot, 304.

Leaf spot, 304 .

Southern blight, 305 .

Peppermint diseases, 258.

Perithecium, I2.

Peronospora effusa, I31, 132. parasitica attacking cab-

bage, I94.

- schachtii, 123. schleideni, 286.

Pestalozzia funerea attacking ginseng, 113.

Phaseolus vulgaris, 260.

Phoma betce, 125 . destructiva, 346. napobrassice, $2 \mathbf{1} 5$.

oleracea, I95. solani, 324 . 


\section{Index}

Phoma subcircincta, 268.

Phomosis vexans, 301 .

Phosphates, changes of, 15 .

Phyllosticta apii, 355 .

- balatas, 164.

- chenopodii, 133, 134. cucurbitacearum, 224.

Physiological diseases, 80 et seq.

Phythium de Baryanum, 42, 44, 193.

- attacking beet, 122 .

Phytophthora cactorum, 108.

- infestans, late blight of

Irish potato, 322.

- late blight of tomato,

343.

\section{- phaseoli, 267. \\ terrestria, 344.}

Pisum sativum, 273.

Plasmopora Halstedii, I38, 148.

Plenodomus destruens, $\mathbf{1 5 9 .}$

Points to remember, 366 .

Pool Venus, 127.

Poor seed, 92, 97.

Potassium, changes of, I5.

- sulphide of, 369 .

Potato diseases, 306 et seq.

Anthracnose, 324 .

Arsenical injury, 3I3.

Black heart, 3 II.

Black leg, 3 I6.

Black rot or jelly end rot, 329.

Black wart, 3 I9.

Common scab, 317.

Curly dwarf, 309 .

Early blight, 322.

Fusarium wilt, 327 .

Hollow heart, 312.

Internal brown spotting, 3 IO.

Late blight, 322.

Leaf roll, 308.

Melters or leak, 32 I.

Mosaic, 3 I 2.

Net necrosis, 3 I I.

Phoma rot, 324.

Powdery dry rot, 330 .

Powdery scab, 3 I 4.

Pox or pit, 313 .
Root knot, 332.

Rosette, 331 .

Silver scurf, 326.

Southern blight, 332 .

Southern wilt, 3 I7.

Spindling sprout, 3 Io.

Stem end rot, 329.

Tip burn, 312.

diseases, field control, 335.

storage rots control, 333 .

Predacious insects, beneficial, 375.

Pseudomonas beticola, I20.

—_campestris, 190, I9I, 205.

—- - attacking radish, 208.

-- attacking turnip, 2 I4.

- fluorescens, $\mathrm{IO}_{3}$, 104.

lachrymans, 229.

- maculicola, 202, 203.

pisi, 273.

radicicola, 18 et seq.

solanacearum, attacking to-

mato, 342.

- Stewarti, 25 I.

- tumefaciens, attacking beets, II 8.

viridilividum, $\mathbf{1} 40$.

Pseudoperonospora cubensis, 230.

Puccinia alli, 289.

- asparagi, 280.

- bullata, 355 .

- helianthi, 149 . attacking Jerusalem

artichoke, 138.

- tragopogoni, $\mathbf{1} 48$.

Purslane diseases, 299.

Pycnidium, 12.

\section{R}

Radish diseases, 208 et seq.

Black rot, 208.

Club root, 208.

Damping off, 209.

Downy mildew, 2 I I.

Root knot, 214.

Root rot, $2 \mathrm{I}_{4}$.

Scab, 209.

White rust, $2 \mathrm{I}$ I.

Rainstorms, 73 . 
Ramularia armaracia, 206.

- cynarce, I38.

Rand, F. V., 229.

Rankin, W. H., I Io.

Raphanus sativus, 208.

Readhimer, J. E., 3I.

Reid, H. L., I34, I38.

Resin, 370.

Resistant varieties, 373 .

Rheosporangium aphanidermatum, 209.

Rhizoctonia solani, 44 .

Rhizopus nigricans, 156, I58.

- attacking squash, 236.

Roasting or pan firing, 56 .

Rogers, S. S., 356.

Root knot, 48 et seq.

Root rot, caused by Rhisoctonia solani, 45,46 .

Rosenbaum, J., I09, I10, 3 I4.

S

Sackett, W. G., 24.

Salsify diseases, 146 et seq.

Rust, 148.

Soft rot, I46.

Southern blight, 148.

White rust, 147 .

Sal soda, 370.

Sanitary environment, 69,70 .

Sarcina lutea, 14 .

Schneider, A., 345.

Schrenk, H. von, 203.

Scleratinia libertiana, 45 .

——attacking bean, 263.

- - attacking beet, 124.

194.

- - attacking ginseng, I IO.

- panacis, Iro.

Sclerotium bataticola, I57, I73,

I74.

- cepivorum, 290.
Rolfsii, 44 .
$225 . \quad$ attacking cantaloupes,
305.
Sclerotium Rolfsii, attacking sweet potatoes, I74. - attacking watermelon, 247.

Seed, age of, 92.

- cultural conditions, 92, 93 . fertilizer effect, 95, 97. storage conditions, 94 . testing, 95 .

treatment against insects, 97.

treatment with formaldehyde, 99.

weight and color, 93, 94 .

Selby, A. D., 55, 291.

Septoria bataticola, 165.

- consimilis, I44.

- lactuce, I44.

-lycopersici, 347 .

- melissce, 256.

- nepete, 257. - pisi, 278.

Shamel, A. D., 54 .

Sherbakoff, C. D., 33 I, 344.

Sick soil, treatment, 53 .

Sirrine, F. A., 282.

Smith, E. F., I19, I90, 25 I.

- E. W., 230.

R. E., 28I.

Smoke injury, 78 et seq.

Soft rot, 236.

Soil flora, action on mineral sub. stances, I4.

Solonum tuberosum, 306.

Spearmint diseases, 258.

Spharella pinodes, 276 .

Spharonema fimbriatum, 160 , 173.

Spinach diseases, I30 et seq. Anthracnose, $\mathbf{1}_{32}$.

Black mold, 134 .

Downy mildew, I3I, I32.

Leaf spot, I34, I36.

Malnutrition, I30, 13 I.

Phyllostictaleaf blight, I33, I34.

White smut, I33.

Spinacia oleracea, $\mathrm{I} 30$.

Spondylocladium atrovirens, 324 , 326. 
Spraying, $36 \pi$.

— machines, 370. principles involved, 370 .

Squash diseases, 234 et seq.

Anthracnose, 237.

Bacterial wilt, 23.

Fruit rot, 235 .

Leaf spot, 237.

Powdery mildew, 237.

Root knot, 238.

Root rot, 238.

Soft rot, 236.

Wilt or yellows, 237.

Steaming sick soil, 54 .

Stevenson, J. A., I46.

Stewart, F. C., 128, 285.

- F. G., 25 I.

Stickers, 370.

Stock solutions, 364 .

Stomach poisons, 362 .

Stone, G. E., 93.

- R. E., 277.

Subirrigation, 67,68 .

Sulphur, 367 .

Sunfower diseases, I48.

Downy mildew, I48.

Rust, I49.

Surface or spray irrigation, 63, 67.

Street potato diseases, I $51 \mathrm{ct}$ seq.

Black rot, 160.

Charcoal rot, 173.

Cottony rot, 174 .

Dry rot, 159.

Foot rot, I59.

Java black rot, I65.

Phyllosticta leaf blight, I64.

Ring rot, I58.

Root knot, 176 .

Septoria leaf spot, I65.

Slime mold, I 52.

Soft rot, 156 .

Soil rot, 152 .

Soil stain or scurf, I63.

Texas root rot, $x 75$.

Trichoderma rot, 167 .

Vine wilt or yellows, 170 .

White rust, I55.

I 76 et seq.

\section{$T$}

Taubenhaus, J. J., I60 et seq.

Temple, J. C., 9.

Thick sowing, effect on damping off, 57 .

Thielavia basicola attacking garden pea, 275 .

_- - attacking ginseng, $\mathrm{I}$ I I .

205.

Tinsley, J. D., 37.

Tolaas, A. S., I03.

Tomato diseases, 339 et seq.

Anthracnose, 348 .

Blossom end rot, 340.

Buckeye rot, 344 .

Damping off, 343 .

Fruit rot, 346.

Hollow stem, 339 .

Late blight, 343 .

Leaf spot, 347 .

Melanconium rot, 349 .

Mosaic, $34 \mathrm{I}$.

Rhizoctonia fruit rot, 353 .

Southern wilt, 342.

Sunburn, 34I.

Yeast rot, 345 .

Yellow blight, 352.

Tragopogon porrifolius, 146.

Trichoderma köningi, I67.

lignoruin, 167.

Tubercularic persicina, 284 .

Turnip diseases, $2 \mathrm{I}_{4}$ el seq.

Anthracnose, 214.

Black rot, 2 I 4.

Club root, 214.

Macrosporiumleaf spot, 217 .

Phoma rot, 2 I 5.

Powdery mildew, 216.

\section{U}

Uredinales, Io.

Urocystis cepulce, 288.

Uromyces appendiculatus, 262.

Urophlyctis leproides, $12 \mathrm{I}$. 


\section{V}

Veihmeyer, F. J., 105.

Vermicularia circinans, 289. dematium, II2.

Verticillium albo-atrum, 326.

\section{W}

Ward, M., 43.

Water, need of plants, 64,67 .

Watermelon diseases, 238 et seq.

Anthracnose, 240.

Bacterial wilt, 238.

Blossom end rot, 247.

Cercospora leaf spot, 243.

Downy mildew, 238.

Fruit rot, 247.
Honey dew or sooty mold, 238.

Malnutrition, 238.

Mycosphærella wilt, 239.

Powdery mildew, 238.

Root knot, 246.

Stem end rot, 239.

Vine wilt or yellows, 244.

Whetzel, H. H., I IO, 287.

White grubs, 52 .

Whitney, M., 64 .

Widtsoe, J. A., 65.

Wind storms, 72,73 .

Wire worms, 52.

Wolf, F. A., 139, 235.

Wollenweber, H. W., 33r.

Z

Zea mays, 250. 






LIBRARY OF CONGRESS

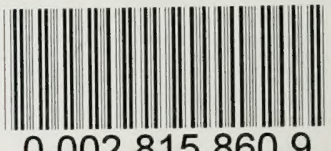

00028158609 